\title{
Economics and accounting teachers' beliefs about school-based assessment, the summative and formative tension: A mixed method study.
}

By

\begin{abstract}
Anne Yates
A thesis

submitted to Victoria University of Wellington in fulfilment of the requirements for the degree of Doctor of Philosophy
\end{abstract}

VICTORIA UNIVERSITY OF WELLINGTON 



\begin{abstract}
The National Certificate of Educational Achievement (NCEA) is New Zealand's main national qualification for senior secondary school students. A key feature of NCEA is that it allows for more than half of students' final NCEA grades to be assessed by teachers during the school year through school-based assessment, known as internal assessment. This key role of teachers in awarding qualifications is likely to have an impact on their conceptions of assessment, conceptions of assessment that are not necessarily fixed. In turn, conceptions can influence teaching practice and are likely to have an impact on how teachers implement internal assessment.
\end{abstract}

This thesis uses an explanatory sequential, mixed methods design to investigate a group of economics and accounting teachers' conceptions of assessment, their practices in relation to NCEA internally-assessed standards, and the influences on those practices. G.T.L. Brown's (2006) Teachers' Conception of Assessment Abridged (TCoAIIIA) Inventory was used to investigate the participants' conceptions of assessment, and interviews were conducted to probe their internal assessment practices and reasons for those practices.

The quantitative data were analysed using confirmatory factor analysis which showed an inadmissible fit to G.T.L. Brown's (2006) model. A subsequent exploratory factor analysis revealed partly similar and partly different dimensions in the data, compared with those previously reported in other studies using the TCoAIIIA. Qualitative data were thematically analysed and when the qualitative and quantitative data were considered together, greater similarities with G.T.L. Brown's model emerged. Participants revealed four overarching conceptions of assessment: assessment is for learning; assessment is for qualifications; assessment is for accountability; and assessment is detrimental. This finding has reinforced the view that teachers' conceptions of assessment are ecologically rational in that a distinct conception that probably relates to the role participants play in assessing for NCEA emerged. 
Despite this role, participants also adhered to the conception that a primary function of assessment is to improve students' learning; furthermore, they did not support the use of assessment results as a measure of school quality. An implication of this finding is a belief that promoting a school-accountability use of assessment results is likely to be counter-productive to students' learning.

The qualitative findings revealed a complex set of beliefs and practices towards implementing the internally-assessed component of NCEA, and that beliefs were only one influence on teachers' internal assessment practices. Teachers had to balance their beliefs with the systemic realities of NCEA and their school's policy requirements, and articulated a tension between the improvement and accountability conceptions of assessment. Moderation processes, procedures and policy encouraged teachers into a cycle of safe rather than innovative internal assessment practice, which means that the original vision for NCEA internal assessment is yet to be realised. There are implications of this finding for professional development, leadership of assessment, and initial teacher education.

One such implication is a requirement for professional development that would provide teachers with successful, innovative internal assessment practices, rather than the present approach which focusses on the reliability of marking. Schools' management needs to take a greater role in leading and encouraging pedagogically sound internal assessment, rather than focussing primarily on agreement rates with NZQA moderators. Initial teacher educators could also introduce student teachers to effective internal assessment practices and to encourage such practices. In addition, attempts to change teachers' assessment practices need to consider existing conceptions of assessment because beliefs have an impact on practices and may need to be challenged. While there is debate about whether beliefs change practice or vice versa, one cannot be changed without considering the other. 


\section{Acknowledgements}

Research cannot take place without willing participants, so my first acknowledgement must go to the 135 teachers of economics and accounting who completed the online surveys and to the 21 who agreed to be interviewed. They willingly gave time from their busy working lives to contribute to this study. It was their journey in implementing the internally-assessed component of NCEA that inspired this research. I would like to acknowledge all teachers in their endeavours to educate our tamariki.

Supervisors are also essential to the successful completion of a doctoral dissertation and their expert guidance and care mean I have finally reached this point. I owe gratitude to Dr Michael Johnston who guided me in the quantitative realm, and for his careful critique of all aspects of this work. I am most grateful to Emerita Professor Luanna Meyer for continuing to support me, and my work, into her retirement from Victoria University, and am very proud to be her final doctoral student.

My colleagues in the Faculty of Education have been a tower of strength, empathising with the enormity of completing a $\mathrm{PhD}$ later in one's career. They have offered support through academic discussions and encouragement, and also by their willingness to be an ear for the trials and tribulations that inevitably emerge on the journey. The Faculty of Education has been generous with support of time, research grants, study leave, workshops and access to expertise. I am also grateful for Susan Kaiser's expert help in preparing the final manuscript and thank you to my esteemed examiners, I greatly value your perspectives and critical feedback.

My parents, Alice, and the late George, highly valued education and encouraged me to aim high. My Scottish heritage is reflected in the pseudonyms I chose for the participants, and I believe it is a strong driver in my quest for education. I want to thank my husband, Eric, for his support over the course of this work, for offering helpful editorial suggestions, and for keeping the home fires burning. To my daughter Kenzie, her partner Daniel, my grandsons Jake and Liam, and my sister Judi - thank-you for your love and support throughout this endeavour. I would also like to acknowledge my daughter, the late Heather, whose untimely death created gaps in my motivation, but ultimately spurred me to complete. Jake and Liam - this is for you - aim high and reach the stars in all your endeavours. 


\section{Table of Contents}

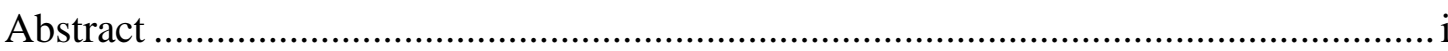

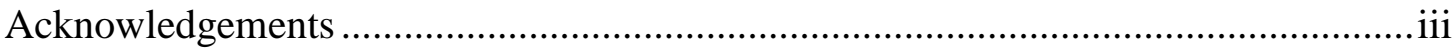

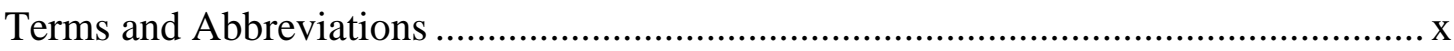

CHAPTER 1 Introduction and background to the study ...................................... 1

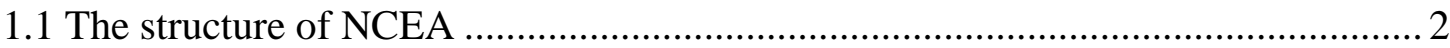

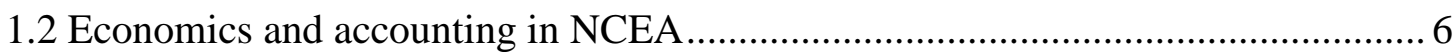

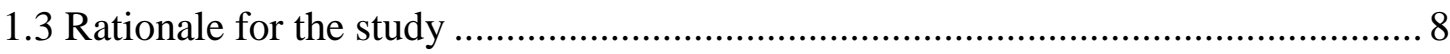

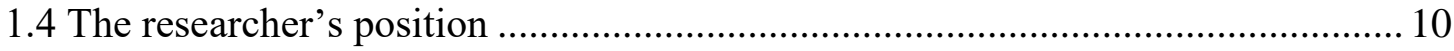

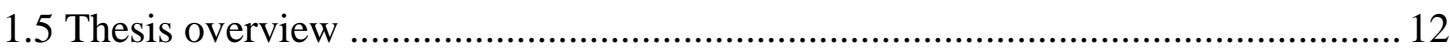

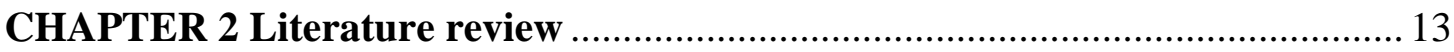

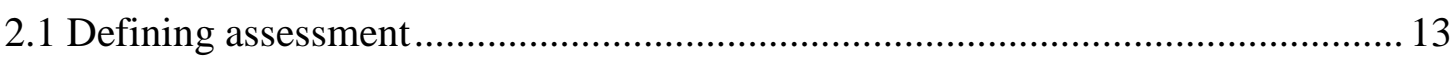

2.2 School-based (internal) assessment................................................................. 15

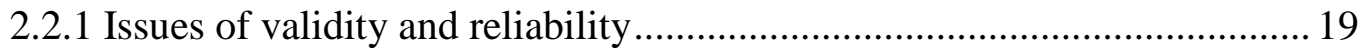

2.2.2 Validation and moderation ................................................................ 22

2.2.3 Impact of internal assessment on teachers ........................................... 24

2.2.4 Impact of internal assessment on students ......................................... 27

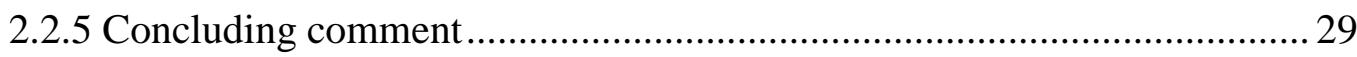

2.3 Assessment policy as a tool to improve teaching and learning ............................2 29

2.3.1 Assessment reform in New Zealand ........................................................ 29

2.3.2 The impact of assessment reform .......................................................... 32

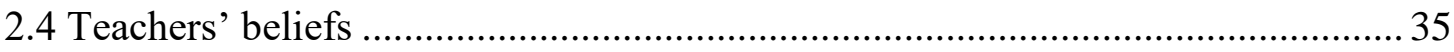

2.4.1 Measuring teachers' conceptions of assessment........................................ 37

2.4.2 Differences in teachers' conceptions of assessment ................................. 39

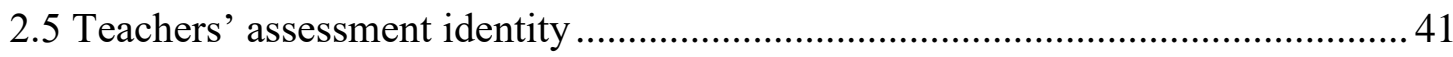

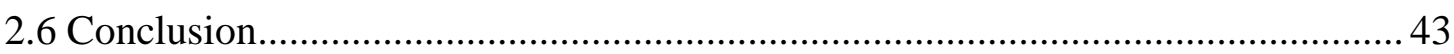

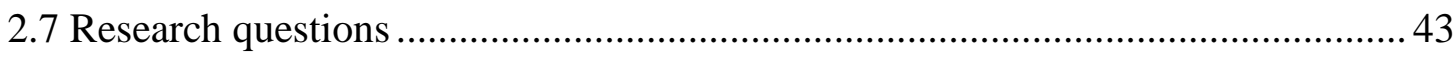

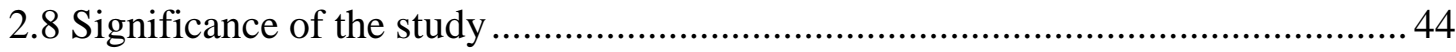

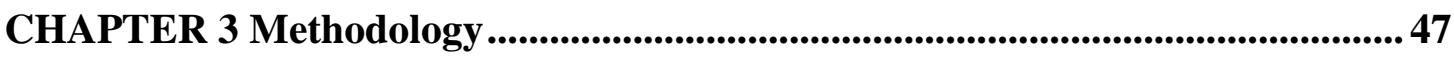

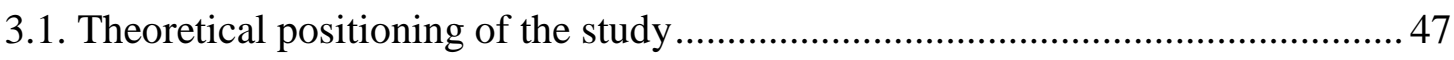

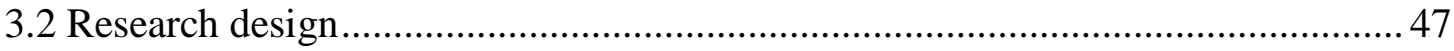

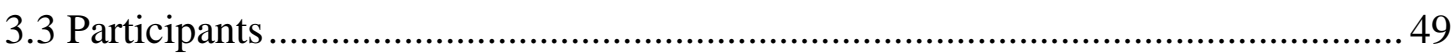

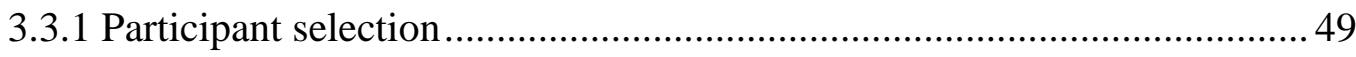

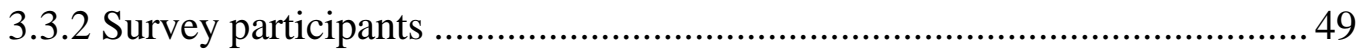




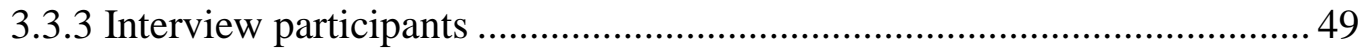

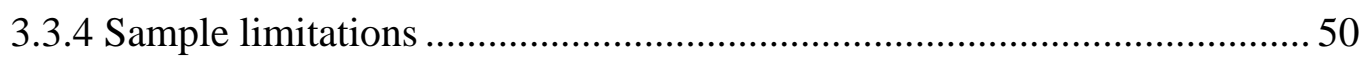

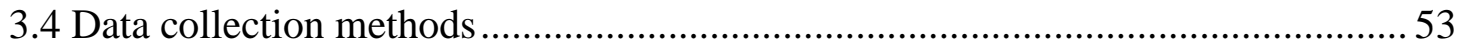

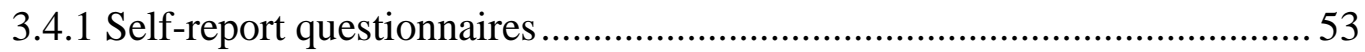

3.4.2 Survey administration and quantitative data collection........................... 54

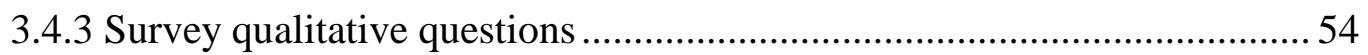

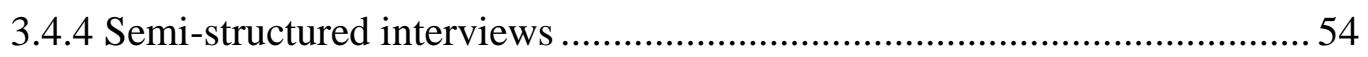

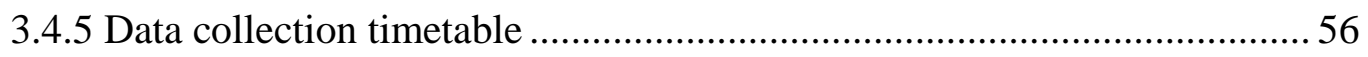

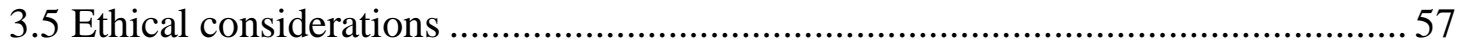

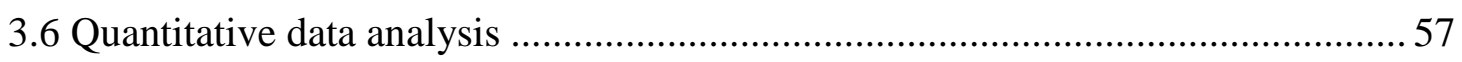

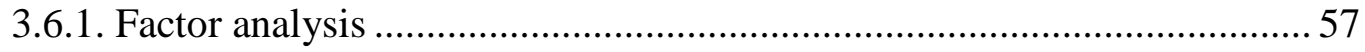

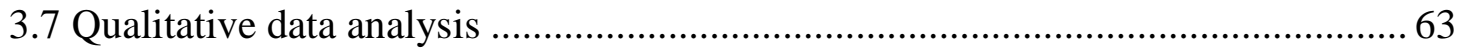

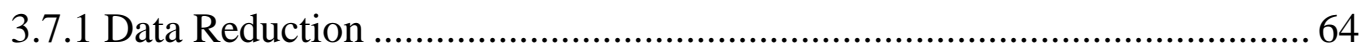

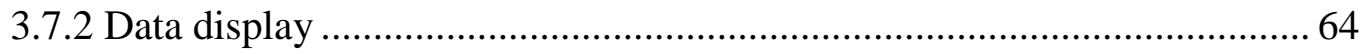

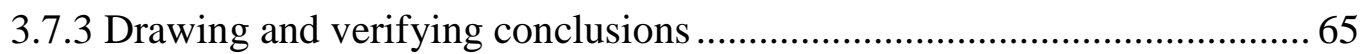

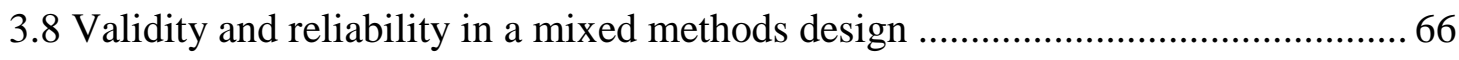

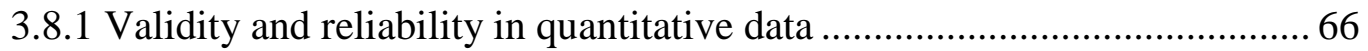

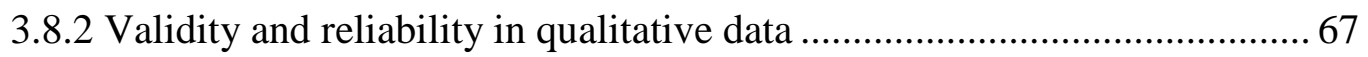

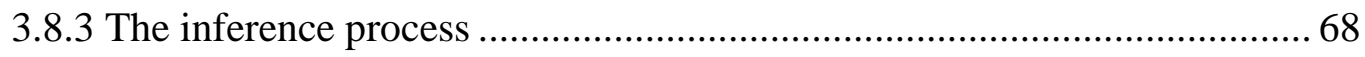

CHAPTER 4 Quantitative findings ....................................................................... 71

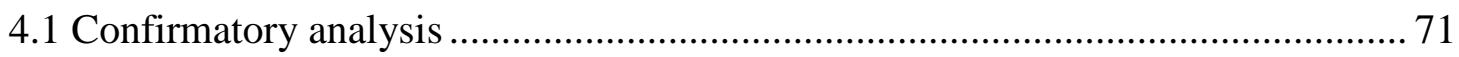

4.1.1 Strength of the present data loadings to factors ..................................... 73

4.2 Acceptability of G.T.L. Brown's (2006) model.................................................. 76

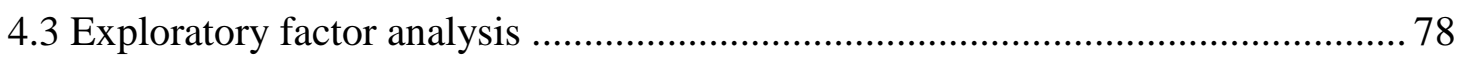

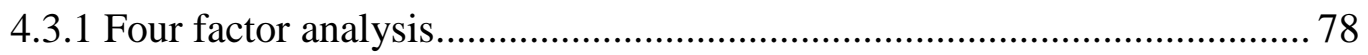

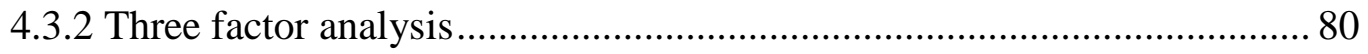

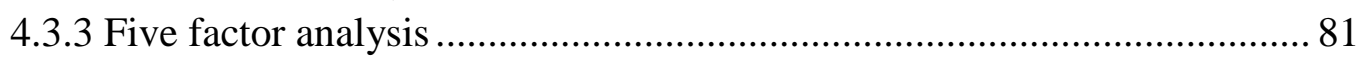

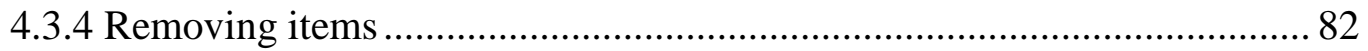

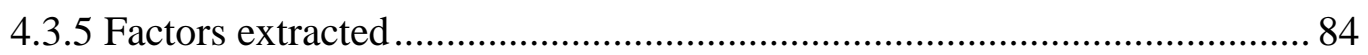

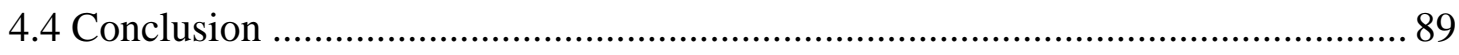

CHAPTER 5 Qualitative findings ..........................................................................95

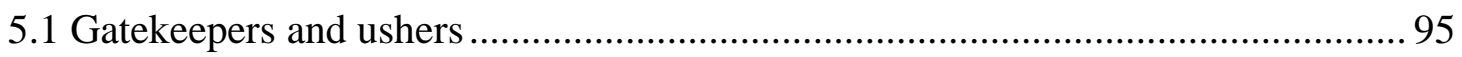

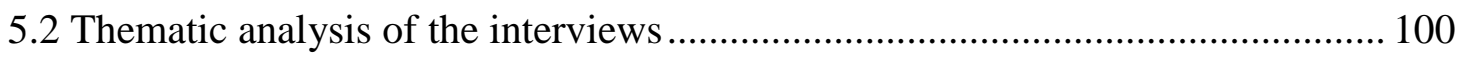

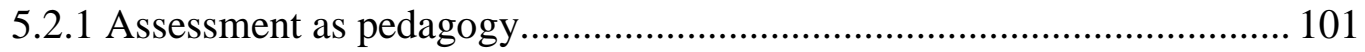

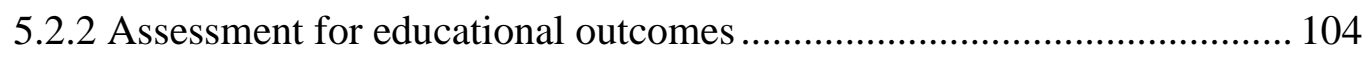

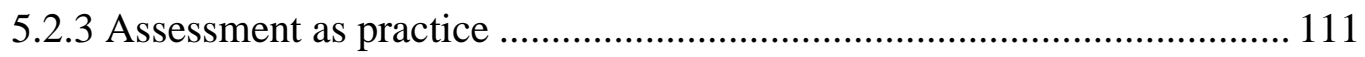

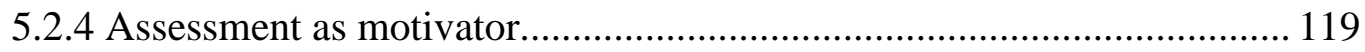




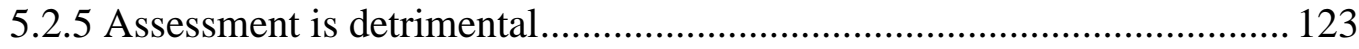

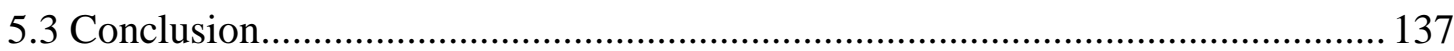

CHAPTER 6 Discussion of the strands.................................................................... 139

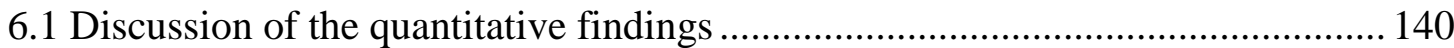

6.1.1 Confirmatory factor analysis ........................................................... 140

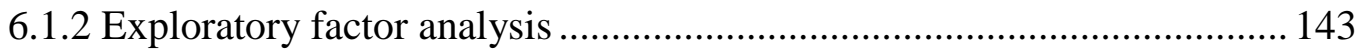

6.1.3 Participants' conceptions of assessment ............................................... 148

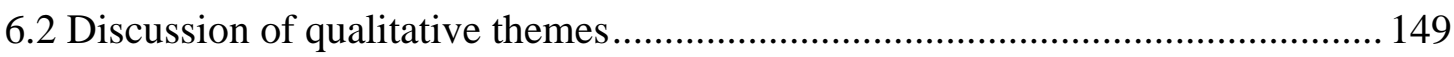

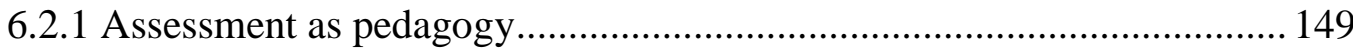

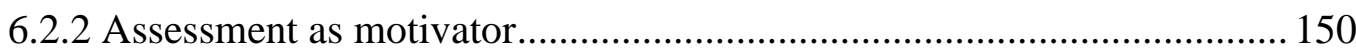

6.2.3 Assessment for educational outcomes ................................................ 152

6.2.4 Assessment as practice and is detrimental ........................................... 154

6.2.5 Internal assessment practices ............................................................. 162

CHAPTER 7 Discussion - Converging the data strands......................................... 165

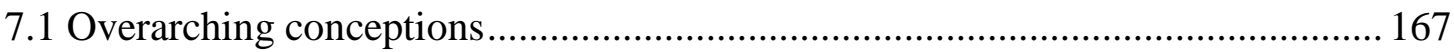

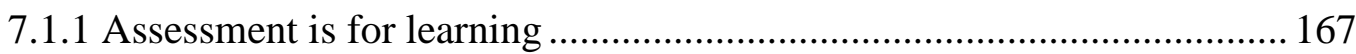

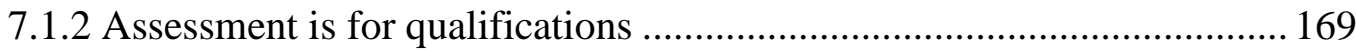

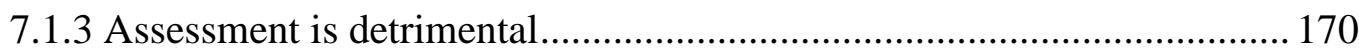

7.1.4 Assessment is for accountability .................................................... 171

7.2 Influences on teachers' internal assessment practice ........................................ 173

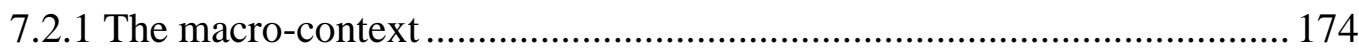

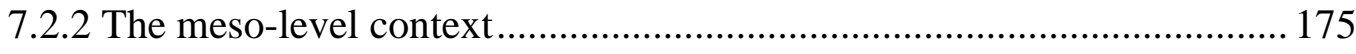

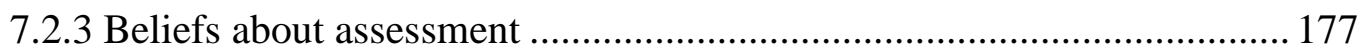

7.3 Enacting and embedding assessment reform ................................................. 178

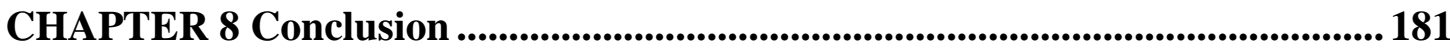

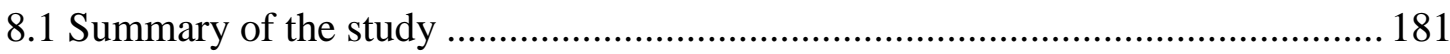

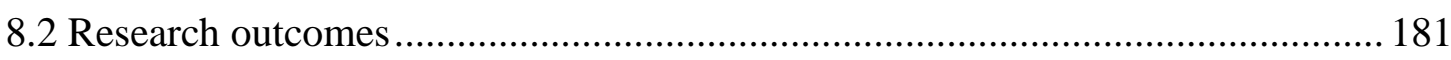

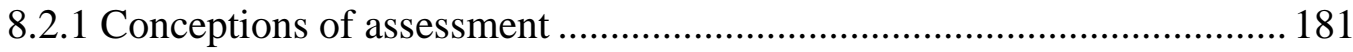

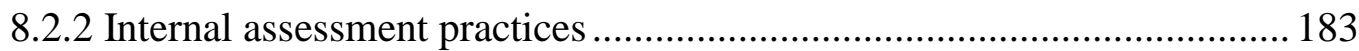

8.2.3 The impact of accountabilty on internal assessment practices ............... 184

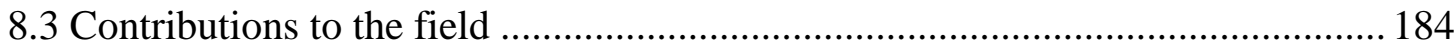

8.3.1 Conceptions of assessment are ecologically rational............................ 184

8.3.2 Contradictory conceptions are rational ................................................. 185

8.3.3 Vision for NCEA yet to be realised .................................................... 186

8.3.4 The meso-level is a dominant impact .................................................... 186

8.3.5 Teachers are responsible in their role as assessors ................................ 187

8.3.6 Teachers are vulnerable in their role as assessors................................... 187 


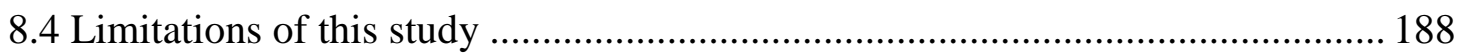

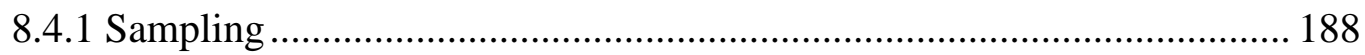

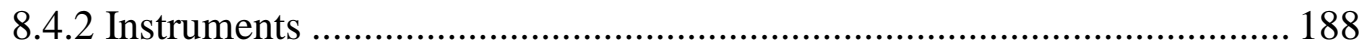

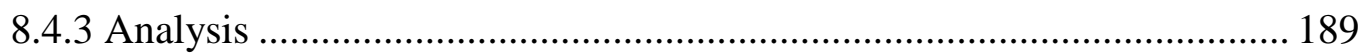

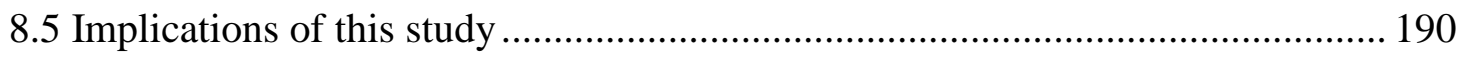

8.5.1 Changes to internal assessment practice are needed.............................. 190

8.5.2 Professional development is needed ..................................................... 191

8.5.3 Leadership of internal assessment ......................................................... 193

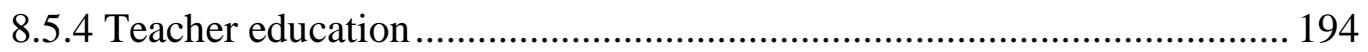

8.5.5 Assessment policy should work for teachers and students ..................... 195

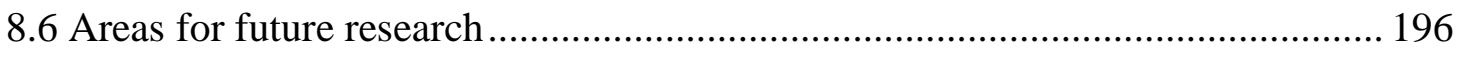

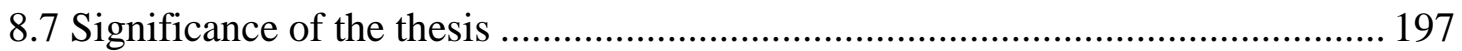

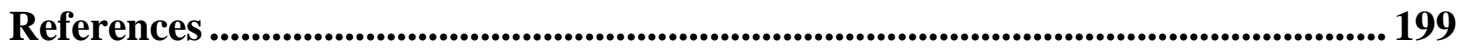

\section{Appendices}

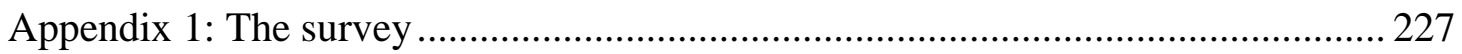

Appendix 2: The generic interview schedule ......................................................... 236

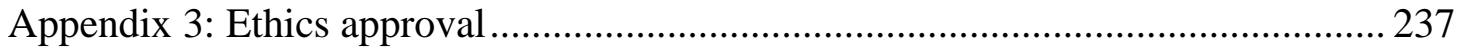

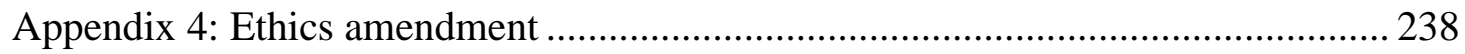

Appendix 5: Factor matrix for 4 factor solution ................................................... 239

Appendix 6: The anti-image correlation matrix for a four factor solution ................ 240 


\section{List of Tables}

Table 1.1 Requirements to gain NCEA at each level ........................................... 3

Table 1.2 Total number of standards and credits available at each level for

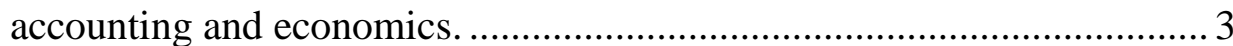

Table 1.3 Economics matrix for NCEA (Ministry of Education, n.d.a) ................... 7

Table 1.4 Accounting matrix for NCEA (Ministry of Education, n.d.b) ................... 8

Table 3.1 Demographic characteristics of interviewees .....................................50

Table 3.2 Percentages of participants in demographic categories compared

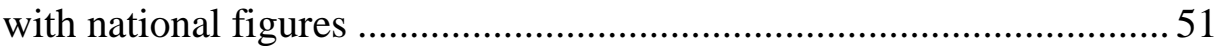

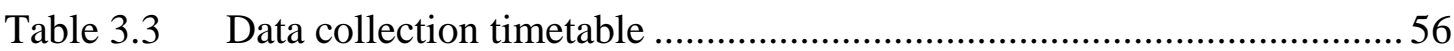

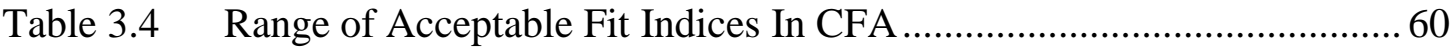

Table 4.1 Fit Indices for 135 Secondary Teachers of Accounting

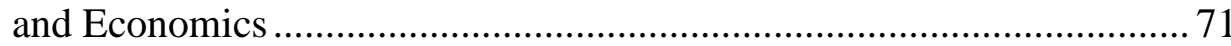

Table 4.2 Items relating to first order factors which contribute to second order factor of "Asessment improves education"............................................. 73

Table 4.3 Items relating to first order factor of "Assessment Makes Schools

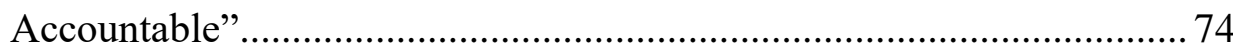

Table 4.4 Items relating to first order factor of "Assessment Makes Students

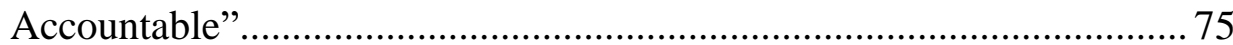

Table 4.5 Items relating to first order factors which contribute to second order factor of "Assessment is Irrelevant"

Table 4.6 Conceptions of assessment inter-correlations: New Zealand primary and secondary teachers (G.T.L. Brown, 2011a) compared with economics and accounting teachers

Table 4.7 Pattern matrix extracted using Maximum Likelihood Estimation with an Oblique rotation (Promax) with a four-factor solution 79

Table 4.8 Pattern matrix extracted using Maximum Likelihood Estimation with an Oblique rotation (Promax) with a three-factor solution..... 81

Table 4.9 Pattern matrix extracted using Maximum Likelihood Estimation with an Oblique rotation (Promax) with a four-factor solution and items 2, 11, $18 \& 26$ removed

Table 4.10 Conceptions of assessment inter-correlations: economics accounting teachers

Table 4.11 Comparison of items and factors of G.T.L. Brown's (2006) model with factors and items for economics and accounting teachers.

Table 5.1 Typology of teachers' beliefs and actions towards NCEA internal

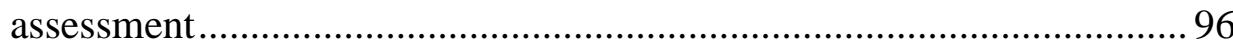

Table 5.2 Themes and their general description ................................................ 101

Table 7.1 Convergence and complements among quantitative factors and qualitative themes 166 


\section{List of Figures}

Figure 3.1. Overview of themes derived from qualitative data

Figure 3.2. Example from matrix of themes and some codes contributing to that theme....

Figure 3.3. Typology of teachers' beliefs and actions towards NCEA internal assessment......

Figure 3.4. Convergence and complements among quantitative factors and qualitative themes

Figure 4.1. Measurement model of 135 economics and accounting teachers' conceptions of assessment

Figure 4.2. Distribution of responses from items contributing to factor - assessment describes learning.

Figure 4.3. Distribution of responses from items contributing to factor - assessment has weaknesses

Figure 4.4. Distribution of responses from items contributing to factor - assessment improves learning and teaching.

Figure 4.5. Distribution of responses from items contributing to factor - assessment for school accountability. 88

Figure 5.1. Overview of themes derived from the qualitative data 100 


\section{Terms and Abbreviations}

Māori Indigenous New Zealander.

NCEA National Certificate of Educational Achievement: New Zealand's secondary school qualification.

NZC New Zealand Curriculum

NZCETA New Zealand Commerce and Economics Teachers' Association.

NZQA New Zealand Qualifications Authority, the government organisation that administers NCEA.

OECD Organisation for Economic Cooperation and Development.

Pākehā Māori language word for New Zealanders who are of European descent. A term that is commonly used to describe this demographic grouping in New Zealand.

PPTA New Zealand Post Primary Teachers' Association (union that represents New Zealand secondary school teachers).

TKI A Ministry of Education bilingual web-based community that provides educational material for teachers, including exemplars for NCEA internal assessment. 


\section{CHAPTER 1}

\section{Introduction and background to the study}

The National Certificate of Educational Achievement (NCEA) is New Zealand's main national qualification for senior secondary school students. NCEA is a standardsbased assessment system which was introduced progressively between 2002 and 2004 . It replaced the former norm-referenced qualification system of School Certificate, University Entrance and Bursary (New Zealand Qualifications Authority; NZQA, n.d.a), and was introduced because the previous system was perceived to be inadequate for assessing the education that young people require in a changing world (Barker, 1995). NCEA specifically sought to provide more opportunities for young people to succeed and achieve qualifications, as well as promote a culture of life-long learning (NZQA \& Organisation for Economic Co-operation; OECD, 2004). This disruption to "entrenched practices and hierarchies" (Hipkins, Johnston, \& Sheehan, 2016, p. 4) was not without controversy, and implementation of a standards-based system for school qualifications, such as NCEA, has not been common internationally (Shulruf, Hattie, \& Tumen, 2010). A key feature of NCEA is that it allows for more than 50\% of students' final grades to be assessed by teachers during the school year through school-based assessment, known in New Zealand as internal assessment.

Teachers working with NCEA are of interest to study because although they arguably work in a qualifications-oriented education culture, they also have, by international standards, a comparatively substantial role in decisions regarding the format and content of assessment for qualifications. Despite this responsibility, little is known about teachers' practices in relation to internal assessment and what might be the influences on those practices. There has been some research conducted on the practices of teachers in relation to specific internally-assessed standards within NCEA, for example, science investigations (Hume \& Coll, 2009; Moeed, 2010) and foreign language spoken proficiencies (East, 2016), but none with teachers of accounting and economics. These disciplines are of interest, and were chosen as a lens for investigating conceptions of assessment and internal assessment practices, because 
they are taught predominantly in the senior secondary school. The main - and often the sole - assessment focus for teachers of these subjects is on national qualifications.

\subsection{The structure of NCEA}

NCEA is considered to be one of the most complex school qualification systems in the world (Hipkins et al., 2016) and schools and teachers have considerable flexibility in how they choose to implement it. This section provides a brief introduction to the structure of NCEA and how students achieve NCEA qualifications.

NCEA is predicated on elements of assessment called standards that specify outcomes and criteria that students must meet to gain credits towards qualifications (Hipkins et al., 2016). Students usually work towards the three levels of NCEA in their last three years of schooling with Level 1 generally being attempted in Year 11, Level 2 in Year 12, and Level 3 in Year 13 (NZQA, n.d.b).

There are two types of standards that can contribute credits towards NCEA: achievement standards and unit standards. Achievement standards assess learning goals from the New Zealand Curriculum (NZC), whereas unit standards are more often linked to vocational training and are predominantly, but not exclusively, used by polytechnics and industry training organisations (NZQA, n.d.c). A further difference between achievement and unit standards is that most unit standards ${ }^{1}$ operate on a pass/fail basis (rather than awarding a range of grades), whereas achievement standards specify criteria for three levels of achievement - Achieved, Merit, Excellence - and also have a Not Achieved/fail grade. All unit standards are internally assessed (i.e., assessed by teachers during the year), whereas some achievement standards are internally assessed and others externally assessed, generally by an endof-year examination. Each subject is limited to three externally-assessed achievement standards at each of the three levels of NCEA.

\footnotetext{
${ }^{1}$ A limited number of unit standards do have the different grade levels available.
} 
The assessment of a school subject for NCEA comprises a number of standards, with each assessing an area of content or skill from the subject domain. Students accumulate credits from standards towards NCEA qualifications at one of its three levels. Standards carry varying numbers of credits with those in accounting and economics ranging from three to six credits. In addition, to gain any level of NCEA students must also meet a minimum level of literacy and numeracy, which can be gained from either prescribed achievement standards or specific unit standards (NZQA, 2011). The requirements to gain NCEA at each level are outlined in Table 1.1.

Table 1.1

Requirements to gain NCEA at each level

\begin{tabular}{ll}
\hline NCEA level & Requirements \\
\hline Level 1 & 80 credits fromeither level 1,2 or 3 , i ncludi ng literacy and nu meracy. \\
Level 2 & $\begin{array}{l}60 \text { credits at level } 2 \text { or above, plus } 20 \text { credits from any level. Level } 1 \\
\text { literacy and nu mer acy require ment. }\end{array}$ \\
Level 3 & $\begin{array}{l}60 \text { credits at level } 3 \text { or above, plus } 20 \text { credits fromlevel } 2 \text { or above. Level } \\
1 \text { literacy and nu mer acy require ment. }\end{array}$ \\
\hline
\end{tabular}

The number of credits available in each subject domain, and at each NCEA level, varies. Table 1.2 shows that in economics and accounting the numbers of available credits range from 24 to 30 .

Table 1.2

Total number of standards and credits available at each level for accounting and economics.

\begin{tabular}{llll}
\hline & Level 1 & Level 2 & Level 3 \\
\hline Accounting & 27 & 26 & 26 \\
& 15 i nt ernal/12 ext ernal & 14 i nt ernal/12 ext ernal & 13 i nt er nal/13 ext ernal \\
Econo mics & 24 & 30 & 24 \\
& 12 internal/12 ext ernal & 18 i nt ernal/12 ext ernal & 10 int ernal/14 ext ernal \\
\hline
\end{tabular}


If a student studies five subjects at Level 1, then an average of 16 credits per subject is needed to achieve NCEA at that level, and if they have six subjects (which is common at Year 11), then an average of only 14 credits per subject is required. So for levels 2 and 3, if a student has credits from the previous level then they only require an additional 60 credits, an average of 12 credits per subject. As students do not need all available credits in each subject to gain NCEA, teachers are able to alter their assessment programmes (and possibly their curriculum) to offer fewer than the total number of available standards. Students themselves can also choose which standards to attempt, and choices can be made as to the number of externally-assessed versus internally-assessed standards that will be attempted.

This flexibility and choice can make the system responsive to students' needs, and they can be assessed on a large variety of tasks and activities (Education Review Office, 2007; Hipkins et al., 2016). Schools can use the standards to assess courses based on traditional subject areas and assess them using combinations of internallyand externally-assessed achievement standards, as well as unit standards (if appropriate). Alternatively, standards from different subjects can be grouped to assess cross-disciplinary courses. For example, NZQA (n.d.d) cites Alfriston College designing a course called 'People, Places and Events', which is assessed using a combination of Level 1 History, Geography and Social Studies achievement standards. A further flexibility is that standards from different year levels can be attempted within the same course.

On the other hand, there can be drawbacks to the modular approach to assessment because course design can be fragmented and become aggregations of topics and standards rather than being based on a coherent curriculum (Hipkins et al., 2016). There is also a possibility that teachers (and students) only value material that will be assessed and that teachers will only teach that content (Pedulla et al., 2003; Stobart, 2008). To date, there is little research about what teachers are doing with respect to their use of the flexibility that NCEA affords, particularly in relation to teachers of economics and accounting. 
NCEA certificates and courses can be endorsed with Excellence or Merit to recognise higher levels of aggregate achievement. To gain an Excellence endorsement for an NCEA certificate a student must gain 50 credits or more at Excellence in the level of the certificate or higher. Excellence for a course (subject) is gained by achieving 14 or more credits at Merit or Excellence, with at least three of these credits from externally-assessed standards, and three credits from internally-assessed standards (NZQA, n.d.e). A layer of complexity is that teachers may also need to ensure that students are able to gain university entrance at Level 3. The requirements for university entrance are:

- NCEA Level 3.

- Three subjects at Level 3, made up of 14 credits each, in three approved subjects (of which economics and accounting are both included).

- Literacy - 10 credits at Level 2 or above.

- Numeracy -10 credits at Level 1 or above.

A further adjunct to NCEA is New Zealand Scholarship, which is an award made to the top achievers in secondary schools. Scholarship is examined largely by external examinations which are separate to NCEA examinations and are undertaken by relatively few students (Hipkins et al., 2016). Standing completely separately from New Zealand qualifications, but offered in some New Zealand schools in addition to NCEA, are the International Baccalaureate and the Cambridge International Examinations. These are further considerations for teachers to factor into their programmes. NCEA could be described as one of the most flexible, but complex assessment systems in the world and these additional qualifications further complicate assessment in the senior secondary school. This thesis focuses on NCEA, but teachers in New Zealand schools are potentially dealing with a more complex combination of qualifications and assessment demands.

According to NZQA (2017a) NCEA devolves much greater responsibility for course design and assessment to schools and teachers than the previous system did, because internal assessment accounts for approximately $70 \%$ of the students' results annually. The ability to choose which assessment standards will be used for a course, in addition to the internally-assessed component, gives schools opportunities to develop specific 
programmes, to assess students in authentic ways, and provides students with opportunities to show what they can achieve in familiar surroundings and with ample time (Education Review Office, 2007; NZQA, n.d.f). However, teachers have to balance this flexibility with ensuring that students can meet the requirements for each NCEA level as well as course and certificate endorsements, and university entrance.

\subsection{Economics and accounting in NCEA}

Economics and accounting are long-standing subjects in New Zealand secondary schools; both were taught prior to NCEA and were examined under the former School Certificate, Sixth Form Certificate, and Bursary system. Both subjects were included in the NZC Framework (1993) but only economics was supported by a Ministry of Education curriculum document; it was up to the New Zealand Commerce and Economics Teachers' Association (NZCETA) to develop such a document for accounting (NZCETA, 2006). The NZC (Ministry of Education, 2007) omitted accounting, much to the dismay of accounting teachers who argued strongly for it to be included in the Social Science learning area (NZCETA). Despite this omission, achievement standards and unit standards have continually been provided, and supported, for both subjects since the inception of NCEA.

The popularity of economics and accounting has been waning for some time, with the numbers of students studying economics at all levels falling from 35,000 in 2003 to 24,000 in 2015 and those in accounting falling from 21,000 in 2003 to 15,000 in 2015 (Education Counts, n.d.). A new subject, Business Studies, which has been developed since the advent of NCEA, may have gained some of these students with 21,000 enrolled for 2015 (Education Counts). These issues are relevant because it is generally economics and accounting teachers who teach Business Studies, and some teachers add Business Studies achievement standards to their accounting and economics programmes.

The structure of NCEA economics and accounting is summarised in Tables 1.3 and 1.4. The numbers of credits available at each year level exceed those needed to gain a course in NCEA, so teachers and students make choices regarding which standards 
to include in assessment programmes. In addition, the numbers of credits available for each course, at each level, from internal assessment range from 10 to 15, which also allows for a degree of choice, and provides scope for teachers to create programmes to meet students' needs and interests.

Table 1.3

Economics matrix for NCEA (Ministry of Education, n.d.a)

\begin{tabular}{|c|c|c|}
\hline Level 1 & Level 2 & Level 3 \\
\hline $\begin{array}{l}\text { AS90983 } 4 \text { credits. External } \\
\text { De monstrate understandi ng } \\
\text { of consumer choices, usi ng } \\
\text { scarcity and/or de mand. }\end{array}$ & $\begin{array}{l}\text { AS91222 } 4 \text { credits. Ext ernal } \\
\text { Analyse inflation usi ng } \\
\text { economic concepts and } \\
\text { models. }\end{array}$ & $\begin{array}{l}\text { AS91399 } 4 \text { credits. External } \\
\text { De monstrate understandi ng } \\
\text { of the effici ency of market } \\
\text { equi li bri um }\end{array}$ \\
\hline $\begin{array}{l}\text { AS } 909845 \text { credits. Int ernal } \\
\text { De monstrate understanding } \\
\text { of decisions a producer } \\
\text { makes about production. }\end{array}$ & $\begin{array}{l}\text { AS91223 } 4 \text { credits. Ext ernal } \\
\text { Analyse international trade } \\
\text { using econo mic concepts } \\
\text { and models. }\end{array}$ & $\begin{array}{l}\text { AS91400 } 4 \text { credits. External } \\
\text { De monstrate understandi ng } \\
\text { of the effici ency of different } \\
\text { market struct ures usi ng } \\
\text { margi nal analysis. }\end{array}$ \\
\hline $\begin{array}{l}\text { AS90985 } 3 \text { credits. External } \\
\text { De monstrate understanding } \\
\text { of producer choi ces using } \\
\text { supply. }\end{array}$ & $\begin{array}{l}\text { AS91224 } 4 \text { credits. Ext ernal } \\
\text { Analyse econo mi c grouth } \\
\text { using econo mic concepts } \\
\text { and models. }\end{array}$ & $\begin{array}{l}\text { AS91401 } 5 \text { credits. Int ernal } \\
\text { De monstrate understandi ng } \\
\text { of nicro-econo mi c } \\
\text { concepts. }\end{array}$ \\
\hline $\begin{array}{l}\text { AS90986 } 5 \text { credits. Ext ernal } \\
\text { De monstrate understandi ng } \\
\text { of how consu mer, producer } \\
\text { and/or govern ment choi ces } \\
\text { affect society, using market } \\
\text { equi li bri um }\end{array}$ & $\begin{array}{l}\text { AS91225 } 4 \text { credits. Internal } \\
\text { Analyse une mployment } \\
\text { using econo mi c concepts } \\
\text { and models. }\end{array}$ & $\begin{array}{l}\text { AS91402 } 5 \text { credits. Int ernal } \\
\text { De monstrate understandi ng } \\
\text { of government inter venti ons } \\
\text { to correct market fai lures. }\end{array}$ \\
\hline $\begin{array}{l}\text { AS } 909874 \text { credits. Int ernal } \\
\text { De monstrate understanding } \\
\text { of a government choi ce } \\
\text { where affected groups have } \\
\text { different vie upoi nts. }\end{array}$ & $\begin{array}{l}\text { AS91226 } 4 \text { credits. Int ernal } \\
\text { Analyse statistical data } \\
\text { relating to to no } \\
\text { conte mporary econo mi c } \\
\text { issues. }\end{array}$ & $\begin{array}{l}\text { AS91403 } 6 \text { credits. Ext er nal } \\
\text { De monstrate understandi ng } \\
\text { of macro-econo mi c } \\
\text { influences on the New } \\
\text { Zealand econo my. }\end{array}$ \\
\hline \multirow[t]{2}{*}{$\begin{array}{l}\text { AS } 909883 \text { credits Internal } \\
\text { De monstrate understanding } \\
\text { of the interdependence of } \\
\text { sect ors of the New Zealand } \\
\text { econo my. }\end{array}$} & $\begin{array}{l}\text { AS91227 } 6 \text { credits. Internal } \\
\text { Analyse how government } \\
\text { policies and conte mporary } \\
\text { econo mic issues int eract. }\end{array}$ & \\
\hline & $\begin{array}{l}\text { AS91228 } 4 \text { credits Int ernal } \\
\text { Analyse a conte mporary } \\
\text { economic issue of special } \\
\text { interest using econo mic } \\
\text { concepts and models. }\end{array}$ & \\
\hline
\end{tabular}


Table 1.4

Accounting matrix for NCEA (Ministry of Education, n.d.b)

\begin{tabular}{|c|c|c|}
\hline Level 1 & Level 2 & Level 3 \\
\hline $\begin{array}{l}\text { AS90976 } 3 \text { credits. Ext ernal } \\
\text { De monstrate understandi ng } \\
\text { of accounting concepts for } \\
\text { s mall entities. }\end{array}$ & $\begin{array}{l}\text { AS9117 } 4 \text { credits. Ext ernal } \\
\text { De monstrate understanding } \\
\text { of accounting concepts for } \\
\text { an entity that operates } \\
\text { accounting subsyste ns. }\end{array}$ & $\begin{array}{l}\text { AS91404 } 4 \text { credits. External } \\
\text { De monstrate underst andi ng } \\
\text { of accounting concepts for a } \\
\text { New Zealand reporting } \\
\text { entity. }\end{array}$ \\
\hline 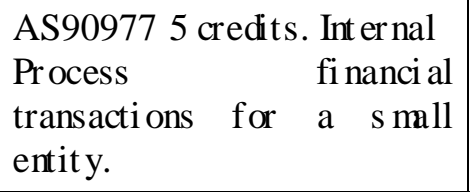 & $\begin{array}{l}\text { AS91175 } 4 \text { credits. Int ernal } \\
\text { De monstrate underst anding } \\
\text { of accounting processing } \\
\text { usi ng accounting soft ware. }\end{array}$ & $\begin{array}{l}\text { AS91405 } 4 \text { credits. Int ernal } \\
\text { De monstrate underst andi ng } \\
\text { of accounting for } \\
\text { part nerships. }\end{array}$ \\
\hline $\begin{array}{l}\text { AS9097 } 5 \text { credits. Ext ernal } \\
\text { Prepare fi nancial state ments } \\
\text { for sole propriet ors. }\end{array}$ & $\begin{array}{l}\text { AS91176 } 5 \text { credits. External } \\
\text { Prepare fi nancial } \\
\text { inf or mati on for an entity that } \\
\text { operat es accounting } \\
\text { subsyste ms. }\end{array}$ & $\begin{array}{l}\text { AS91406 } 5 \text { credits. Ext ernal } \\
\text { De monstrate underst andi ng } \\
\text { of company fi nancial } \\
\text { state ment preparation. }\end{array}$ \\
\hline $\begin{array}{l}\text { AS90979 } 4 \text { credits. Internal } \\
\text { Prepare fi nanci al } \\
\text { infor mation for a } \\
\text { community or ganisation's } \\
\text { annual general meeting. }\end{array}$ & $\begin{array}{l}\text { AS91177 } 4 \text { credits. External } \\
\text { Int er pret accounting } \\
\text { inf or mati on for entities that } \\
\text { operate } \\
\text { subsyste ms. }\end{array}$ & $\begin{array}{l}\text { AS91407 } 5 \text { credits. Internal } \\
\text { Prepare a report for an } \\
\text { ext ernal user that interprets } \\
\text { the annual report of a New } \\
\text { Zealand reporti ng entity. }\end{array}$ \\
\hline $\begin{array}{l}\text { AS90980 } 4 \text { credits. Ext ernal } \\
\text { Int er pret } \\
\text { inf or mation } \\
\text { propriet ors. }\end{array}$ & $\begin{array}{l}\text { AS91481 } 4 \text { credits. Int ernal } \\
\text { De monstrate underst anding } \\
\text { of a conte mporary } \\
\text { accounting issue for } \\
\text { decision-making. }\end{array}$ & $\begin{array}{l}\text { AS91408 } 4 \text { credits. Ext ernal } \\
\text { De monstrate underst andi ng } \\
\text { of manage ment accounti ng } \\
\text { to inf or m deci si on- maki ng. }\end{array}$ \\
\hline $\begin{array}{l}\text { AS90981 } 3 \text { credits. Internal } \\
\text { Make a fi nancial decisi on } \\
\text { for an indi vi dual or group. }\end{array}$ & $\begin{array}{l}\text { AS91179 } 3 \text { credits. Int ernal } \\
\text { De monstrate underst andi ng } \\
\text { of an accounts recei vable } \\
\text { subs yste mf or an entity. }\end{array}$ & $\begin{array}{l}\text { AS91409 credits. Int ernal } \\
\text { De monstrate underst andi ng } \\
\text { of a job cost subsyste m for } \\
\text { an entity. }\end{array}$ \\
\hline $\begin{array}{l}\text { AS90981 } 3 \text { credits. Internal } \\
\text { Make a fi nancial decisi on } \\
\text { for an indi vi dual or group. }\end{array}$ & $\begin{array}{l}\text { AS91386 } 3 \text { credits. Int ernal } \\
\text { De monstrate understanding } \\
\text { of an invent ory subsystem } \\
\text { for an entity. }\end{array}$ & \\
\hline
\end{tabular}

\subsection{Rationale for the study}

The internally-assessed achievement standards potentially provide scope for teachers to make decisions about the content to be assessed and the conditions under which the assessment will take place. There is also scope at each level to vary the curriculum (by varying the standards to be assessed) for individual students or groups of students. In their study on teachers' assessment practices for Level 3 NCEA, Stewart, Gray, and Pilcher (2007) found that teachers varied the numbers of standards they offered, and 
allowed students to choose the standards on which they would be assessed. They also found that some teachers were designing their own assessment activities and/or modifying Te Kete Ipurangi (TKI) ${ }^{2}$ tasks for the internally-assessed standards. However, other research tends to suggest that such innovative practices are not particularly widespread. Moeed (2010) reported that Year 11 science teachers tended to use the same TKI internal assessment resource for science achievement standard 90186 (Carry out a practical science investigation, with direction), and had done so for the previous eight years. Hipkins (2010) found that only 3\% of teachers in her survey agreed that they involved students in co-creating NCEA plans, while 64\% said that this never or almost never occurred. Hipkins also found that most principals and teachers agreed or strongly agreed that a range of assessment methods can be valid for NCEA, but her findings prompted her to ask if "teachers simply agree in principle, or are they actively extending the scope of assignments in practice" (p. 28). This question could equally well have applied to Wylie and Bonne's (2016) finding that nearly $70 \%$ of teachers in their survey agreed that NCEA allows them to design courses to meet students' learning needs, but without any evidence that this actually occurs. Edwards (2013) suggests not, claiming that many teachers do not develop their own assessment tasks; instead, they use TKI exemplars or commercial materials. Alison (2005) made similar assertions; however, there is still much to find out about how teachers are assessing the internally-assessed achievement standards and the motivation behind their choices. Are they giving students one-off, time-limited test-type activities, or, as suggested by NZQA and Education Review Office, providing students with ample time to show what they can do? Are they being creative and innovative in their design of assessment activities and the place of those activities within their course? It is an aim of this research to contribute answers towards these questions, in particular for teachers of economics and accounting.

Research into teachers' beliefs (Borko \& Putman, 1996; Fives \& Buehl, 2016) suggests that beliefs are a major influence on what teachers do in the classroom and subsequently their assessment practice. G.T.L. Brown (2008) refers to beliefs about assessment as conceptions and, because of teachers' extensive experience of assessment, they have

\footnotetext{
${ }^{2}$ TKI is a Ministry of Education bilingual web community that provides educational material for teachers, including exemplars for NCEA internal assessment.
} 
developed conceptions of assessment and there is evidence that teachers' conceptions of assessment will mediate how they implement it (Bonner, 2016; Richardson \& Placier, 2001; Thompson, 1992). It might, therefore, be predicted that teachers' conceptions of assessment will have an impact on how they implement the internally-assessed achievement standards. Additionally, conceptions of assessment are not fixed and can be influenced by external factors (e.g., G.T.L. Brown, 2008; Brown, Hui, Yu, \& Kennedy, 2011; Brown, Kennedy, Fok, Chan, \& Yu, 2009; Harris \& Brown, 2009), so assessing for NCEA may have an impact on those conceptions. However, there is little existing evidence regarding the impact of NCEA on teachers' conceptions of assessment and little on how their conceptions influence their implementation of the internal assessment component of NCEA.

\subsection{The researcher's position}

I am a former teacher of accounting and economics, now working in initial teacher education. My current position includes teaching prospective economics and accounting teachers, which made me aware of the lack of research on this particular group of teachers. As a former secondary school teacher of economics and accounting for 25 years, I have always had a strong interest in assessment for qualifications. For most of those 25 years, the secondary school sector underwent assessment reform that generally saw a move towards senior secondary school qualifications including internally assessed components. In the 1980s, Sixth Form Certificate was introduced as a Year 12 qualification that was entirely internally assessed. These assessments were statistically moderated to a pre-determined national distribution (NZQA, n.d.g). This period also saw the introduction of internal assessment components for two-thirds of School Certificate and Bursary subjects, including economics, but not accounting.

The 1990s saw the introduction of fully internally-assessed unit standards for all subjects; School Certificate, Sixth Form Certificate, and Bursary were continued alongside the new assessment system. The school in which I taught at the time fully adopted the new unit standard regime. There were three strong drivers for this adoption: the capacity for unit standard assessment to be integrated with learning; the ability for students to receive immediate feedback on reaching the standards; and for students to 
achieve credits towards a qualification progressively throughout the year rather than relying totally on an end-of-year examination. My involvement extended beyond school; I was appointed to NZQA expert panels to write and rewrite unit standards. I also served as a moderator for unit standards and, subsequently, internally-assessed achievement standards for NCEA.

In 2000, it was announced that NCEA would be introduced in 2002 and that all assessment for qualifications would use internally- or externally-assessed achievement standards or unit standards. At this point NZQA called for educators to conduct and facilitate workshops for the implementation of the new system. Based on my previous experience with standards-based assessment, I was appointed as a facilitator to deliver professional development for economics teachers, particularly with regard to internally-assessed achievement standards.

Upon appointment to a College of Education teaching position, I continued my interest in NCEA internal assessment through participation in two research projects evaluating NCEA professional development (Starkey, et al., 2006; Taylor, Kinsella, Yates, McKenzie, \& Meyer, 2007). My contact with teachers through NCEA professional development, research, and visiting student teachers on their teaching placements resulted in exposure to widely varying opinions on NCEA. I was surprised at the negativity (sometimes vehement) expressed towards NCEA, which was not solely a personal impression; Alison (2005) reported that about two-thirds of teachers were either opposed to or ambivalent about NCEA. Teachers' support for NCEA has improved over the years, and Wylie and Bonne (2016) reported that in 2015 nearly 70\% of teachers they surveyed either agreed or strongly agreed that they support NCEA. Even so, this leaves $30 \%$ not supporting NCEA. My own view had been (and still is) supportive of NCEA and its goal of improving student achievement in the senior secondary school by allowing for the assessment of a broader range of skills and knowledge. 
As a researcher, I am declaring my longstanding interests favouring internal assessment and am aware of the potential for my own perspectives to bias my interpretation of the data. However, as a researcher I am committed to a primary and overarching responsibility to collect valid and reliable data, to carry out accurate analyses of the data, and interpret findings consistent with the evidence.

\subsection{Thesis overview}

In this opening chapter, I outlined the rationale for the study and explained the structure of NCEA, in particular the structure of accounting and economics within NCEA. Chapter 2 provides a review of the literature relevant to the purposes of assessment and how teachers use assessment, literature on the impact of assessment policy on teachers' beliefs and practices, and of the literature examining teachers' conceptions of assessment and teachers' assessment identity. Chapter 3 outlines the research design and the rationale for using mixed methods. It also addresses how the data were analysed and the inference process chosen to converge the two strands of the data. Chapter 4 presents the findings from the quantitative data and chapter 5 the findings from the qualitative interviews. Chapter 6 discusses the quantitative and qualitative findings contiguously in order to answer the first two research questions and chapter 7 considers how both strands of data connect and converge. Chapter 8 concludes the thesis by outlining the key contributions of this thesis, the limitations and implications. 


\section{CHAPTER 2}

\section{Literature Review}

\subsection{Defining assessment}

Assessment is fundamental to education because it provides a means of finding out what students have learned (Wiliam, 2008). Gipps (1994), Harlen (1994) and Wiliam (1994) have emphasised that assessment is a way of gathering evidence that can be used for decision-making to inform future learning, whereas Taras (2010) asserted that educational assessment essentially entails a judgement and that the outcome of the judgement can be represented by a grade, by marks, or by feedback. Assessment has been conceptualised as a process contributing to improving learning (the formative use of assessment) and in contrast, as a strategy to measure what has been learned (the summative use of assessment).

In their seminal literature review on assessment and classroom learning, Black and Wiliam (1998) described the formative function of assessment as assessment that takes place during the learning process to inform students, and their teachers, of what will be required for students to take their next learning steps. To enable this, Scriven (1966) emphasised the need to look beyond grades and percentages as indicators of learning and encouraged teachers to analyse students' work to ascertain where any lack of understanding has occurred; that is, understanding the nature of students' mistakes and omissions is important if assessment is to improve learning. Sadler (1989) agreed that the focus of the formative use of assessment is to recognise the gap between what students currently know and what they need to know, and that feedback is a key element in this regard. Agreeing with this position, and moving towards a more precise meaning of the formative function, Black, Harrison, Lee, Marshall, and Wiliam (2002) further refined the description by adding that formative assessment requires that the evidence gathered during an assessment process to be used to adapt teaching to meet learning needs. In addition, Harlen (2006) considered that students should be active participants in the formative process; not only should the teacher act 
on the feedback, but students should also decide on possible actions based on the feedback. Taras (2010) added a stricter proviso that assessment can only be considered formative "when feedback has been used to improve the work" (p. 3021). Taken together, the formative function of assessment includes making judgements on students' learning in order to ascertain the gap between actual learning and desired learning, using that information to decide a course of action, which may include the teacher changing their pedagogy and should include the student in the process. Ultimately, the formative use of assessment should lead to improved learning.

The summative function of assessment, on the other hand, is to estimate what students know and can do at any point in time. It is usually described by a grade and is often geared towards certification (Sadler, 1989). The summative purpose of assessment is an integral part of the secondary school system and can have positive outcomes for students in the form of qualifications attainment (Madaus \& Russell, 2011). It also provides a record of students' achievements for themselves, their parents, future employers, and higher education institutions (Harlen, 2006).

There has been debate on the usefulness of the summative function of assessment to the learning process with Black and Wiliam (1998) claiming that the summative function of assessment was not particularly useful to future learning. Sadler (1989) agreed that summative assessment does not normally improve learning, but it often influences decisions and "may have profound educational and personal consequences for the student" (p. 120). In what appears to be a modification of Black and Wiliam's (1998) earlier position, Black, Harrison, Hodgen, Marshall, and Serret (2011) used empirical evidence from a qualitative longitudinal study with 18 teachers to describe how working towards the summative process can help students' learning. They concluded that, if students are actively involved then they are able to see how summative functions of assessment, for example tests and examinations, might help their learning. Further to this argument, and building on an earlier stance, Black, Harrison, Lee, Marshall, \& Wiliam (2003) considered that the summative function of assessment could and should be a "positive part of the learning process" (p. 56). 
Despite the distinction between these two functions being seemingly clear, and the terms formative and summative designed to clarify the purposes of assessment, Newton (2007) has argued they have in fact caused confusion. Confusion about the functions and purposes of assessment has possibly arisen because educationalists attributed intrinsic properties of the assessment process to the terms formative and summative. These terms refer to the purposes of the assessment rather than to the timing or the nature of the tasks. Black and Wiliam (1998) argued that the two purposes were at opposite ends of a spectrum, that they are "two isolated and completely different functions" (p. 35). Taras (2010) agreed that the terms formative and summative have led to confusion between the process and purpose of assessment and argues that assessment is a "single process with more than one function" (p. 3018). She added that the distinction between the formative and summative functions of assessment is that for a formative process to occur, the feedback should lead to improved learning, so any assessment without feedback and improved learning is summative. Furthermore, she argued that formal work used for qualifications, along with students' work produced in less formal situations, can perform a formative function as long as learning is improved. Despite the confusion caused by the terminology, Harlen (2006) has suggested that the dual functions of assessment are reason enough to maintain the distinction.

\subsection{School-based (internal) assessment}

Assessment can be put to more than one purpose: it can be used for a formative purpose, a summative purpose, or for both purposes. There is also a possibility that it may have no purpose at all. Rather than considering the summative and formative functions of assessment as being polarised, Harlen (2006) has suggested that there should be more focus on how potential synergies between the two functions could be developed. While there is some concern that if teachers have to provide summative information about students, this can undermine formative assessment purposes (Nusche, Laveault, MacBeath, \& Santiago, 2012), internal assessment for NCEA lends itself well to being used for both purposes and possible synergies could be realised. 
Internally-assessed standards for NCEA are those that are assessed by teachers during the year and are sometimes used to assess skills and knowledge that cannot be tested in end-of-year of examinations (NZQA, n.d.f). Internal assessment involves teachers in all stages of the assessment cycle; they plan the assessment programme, design or choose assessment tasks, and make judgements about the final grade. In addition, internal assessment allows students to have more than one attempt to achieve standards, meaning that earlier attempts can provide formative information to support later attempts.

Internal assessment lends itself to both formative and summative functions because it provides opportunities for feedback and learning to occur, while at the same time allowing teachers to make summative judgements on what students know and can do at any point in time. Rawlins (2008) argued that NCEA internally-assessed standards have the potential "to satisfy both the summative and formative purposes of assessment" (p. 115) because they meet Sadler's (1989) three characteristics needed for assessment to be considered formative. They have criteria that can be shared with students so that they know what they are aiming for, feedback can be provided as students work towards achieving the criteria, and they can use the teachers' feedback and self-assessment to recognise their next learning steps. Of course, to realise a formative purpose, students must engage with the feedback and improve their learning. As noted above, NCEA internally-assessed standards explicitly provide this opportunity by allowing students further opportunities to reach the standard.

The Ministry of Education (2011) concurs with Rawlins' (2008) view and stated that even though NCEA standards constitute high-stakes assessment, this should not preclude them from being used to support learning. The Ministry of Education stated that the design of internal assessment for NCEA "provides the potential for assessment to be used formatively and to be an integral part of teaching practice" (p. 14). NCEA internally-assessed standards allow synergies between the formative and summative functions of assessment to be developed with Black et al. (2011) arguing that teachers' internal assessments can promote formative practices because teachers are in control of the assessment process. Furthermore, their empirical data suggested that students often become more involved, and actively engaged, in a summative process when it is managed by teachers. 
Internal assessment allows for a much greater range of tasks to be used than externallyassessed examinations; course work can include a range of assessment activities including projects, research, essays, presentations, portfolios and group work and "course work lends itself to formative assessment practice, as teachers provide feedback and appropriate guidance to students" (Ministry of Education, 2011, p. 69). From a sociocultural perspective, the flexibility (in terms of tasks, the timing of assessment, and resit opportunities) afforded by internal assessment is beneficial because, under this view, assessment activities should be used to engage students in learning and "to increase their participation and sense of belonging" (Klenowski \& Wyatt-Smith, 2014, p. 33). Klenowski and Wyatt-Smith proposed that inclusive assessment practices can involve teachers adapting assessment tasks to meet the diverse needs of students more effectively and this can be achieved through internal assessment.

Nonetheless, tensions can arise from attempts to use assessment for both formative and summative purposes. In particular, fairness and authenticity are important considerations in assessment for qualifications, but measures taken to assure authenticity can limit the extent to which assessment can be effective in a formative sense. A time-limited test is a case in point; the time limit and the uniformity of the task deliver a high probability of equal assessment conditions and minimise opportunities for cheating, but also place constraints on the format of the assessment task itself and so may limit its formative value. Harlen (2006) agreed that there are limitations to using data gathered primarily for one purpose in another way, noting that data gathered for summative purposes may lack the detail required to address specific learning needs. Similarly, evidence gathered for formative purposes may be inconsistent because it relates to the specific learning goals of individual students and is bound by the context of their learning. Harlen proposed that both functions of assessment can be served from the same evidence as long as a distinction "is made between the evidence and the interpretation of the evidence" (p. 109). Carless (2011) agreed that school-based assessment has the potential to combine the formative and summative functions of assessment. 
For the formative use, assessment data will inform what further learning needs to be done, while at the same time the data can fulfil a summative purpose by describing the level that a student has reached at that point in time. For NCEA internal assessment teachers could ascertain from students' classwork whether they have met criteria, for example, the criteria required to achieve the standard at the Achieved level. They could provide feedback to improve the work to an Excellence or Merit level and at some point in time decide which achievement level the student has reached.

Maxwell (2004) offered possible synergies that can be obtained between the two functions of assessment and suggested that portfolios of evidence gathered over time can serve both formative and summative functions. Countering the argument that assessment should be the same for all students in order for it to be fair in summative terms, Maxwell contended that evidence towards an assessment does not have to be identical to be comparable. He argued that the contents of student portfolios (for example) could differ, but still be judged against common standards. In addition, portfolios or other types of assessment gathered over a period of time can involve feedback to students and therefore perform a formative, as well as a summative, function.

Maxwell (2004) and Harlen (2006) provided theoretical possibilities for the formative and summative functions of assessment to be implemented within internal assessment; however, empirical studies have found that teachers vary in their implementation of internal assessment in practice. Yung's (2012) qualitative case study of 10 Hong Kong science teachers reported different approaches by teachers to practical science assessment. Some teachers conducted these separately from classroom practice, in test-like conditions, which generates few opportunities to provide formative feedback, whereas others made assessment judgements in the course of the students' learning, while at the same time giving them formative feedback. While Yung's conclusions were drawn from a relatively small group of teachers, survey research from larger groups have reported similar findings. Reporting on survey data from 152 language teachers in New Zealand, East (2016) also found that teachers' reactions to internal assessment varied; some conducted internal assessment in the course of learning programmes and provided feedback as students worked on assessments, whereas others conceived of the internal assessment as a one-off assessment event, such as a 
test, with little feedback provided. Also, in New Zealand, Moeed (2010) reported on a survey of 189 science teachers who described varying practices. Some carried out practical science assessments in test-like conditions, with $78 \%$ stating that they carried out formative preparation as a trial run or 'mock exam' of the actual internal assessment. In their in-depth qualitative study of 11 New Zealand secondary school teachers Irving, Harris, and Peterson (2011) reported that teachers were reluctant to use internal assessment results for a formative purpose when there was also a summative requirement. Despite expressing a preference for using internal assessment in a formative way, they noted tensions between this pedagogical aim and requirements to report results for summative purposes. A reason given for this dilemma was that teachers in the study were not clear about which practices could be considered formative and they based the distinction between summative and formative functions on whether or not a grade was given.

Internal assessment affords the possibility of gaining synergies between the formative and summative functions of assessment and authors such as Maxwell (2004), Harlen (2006) and Rawlins (2008) have made suggestions as to how this could occur. However, achieving such synergies with NCEA internal assessment has proven difficult to achieve in practice (East, 2016; Irving et al., 2011; Mooed, 2010).

\subsubsection{Issues of validity and reliability}

If teachers' judgements are used to award students national qualifications, their assessment tasks must be valid and their marking reliable to ensure fairness for all students. According to the American Educational Research Association, American Psychological Association and the National Council on Measurement in Education (2014), validity is "the degree to which evidence and theory support the interpretation of test scores for proposed uses of tests" (p. 11) which is reminiscent of Messick's (1975) definition that validity requires that assessment must measure what it is intended to measure and that it supports the inferences that are drawn from the assessment. 
Validity has been differentiated into types which include (among others): content validity; predictive validity; and construct validity. Content validity is the extent to which an assessment measures against curriculum coverage; predictive validity is the extent to which an assessment can be used to predict some future outcome; and construct validity refers to the measurement of an underlying psychological quality (American Psychological Association, American Educational Research Association, \& National Council on Measurement in Education, 1954; Newton \& Shaw, 2014). Not all academics have agreed with these fragmented definitions and Messick (1989) rationalised that construct validity incorporated the ideas of content and predictive validity, but added that valid assessment should also take into account the ethical consequences of assessment. Newton and Shaw provided a comprehensive history of the concept of validity in educational assessment, but argued that the term is still "heavily contested" (p. 1). In proposing a twenty-first century framework for validity, Newton and Shaw, suggested that for assessment to be valid it must be both technically possible and socially acceptable, and that this may involve "trading costs against benefits" (p. 187). Therefore, the argument is not so much about whether one type of assessment is more valid than another, but rather whether an assessment policy as a whole is acceptable, which Newton and Shaw acknowledge may differ "from one stakeholder to the next" (p. 188). What is acceptable in one assessment jurisdiction may not be acceptable for another and in New Zealand, this would be acceptability of the structure of the NCEA qualification that includes internal, teacher-assessed standards as well as externally-examined standards.

Achieving validity can be complex and questions have been raised about teachers' ability to construct valid tasks for internal assessment. Davison and Leung (2009) claimed that there is no guarantee that teacher-made assessment tasks assess what is intended, and Johnson (2011), while acknowledging that there is little research on teacher-conducted internal assessment, argued that "different teachers might operationalise their assessment of a subject domain differently" (p. 3). In her systematic literature review, which concerned the validity of teachers' assessment for summative purposes, Harlen (2004) defended teacher-conducted assessments, arguing that because teachers build a picture of student learning over a range of objectives, they are able to provide a fuller account of student achievement than can be obtained through tests. 
Reliability refers to the degree to which an assessment process produces consistent and stable results over markers, time and tasks (Brookhart, 2003; Harlen, 2007) and marker reliability has been raised as a concern for internal assessment. Johnson (2013) argued that there is little empirical evidence for the reliability of teacher judgements, calling for more research to be done in this area. She provided some examples from Australia and Scotland to exemplify the issue. In Australia, the Queensland Studies Authority reported $87 \%$ marker agreement and only serious disagreement in $4 \%$ of cases, suggesting a good level of reliability. However, the Scottish example revealed lower agreement levels of $45 \%$ for numeracy, around $40 \%$ agreement for reading, and between $10 \%$ and $35 \%$ for science, figures that question the reliability of the marking of the teachers concerned. Hay and McDonald (2008) in their study of Australian physical education teachers reported that, although teachers were provided with criteria and standards, they would make judgements about students' levels of achievement without reference to these. The teachers believed they had internalised the criteria, but Hay and McDonald reported that the judgements were intuitive and reliant on the teachers' memories of students' past performances.

Evidence from New Zealand suggests that marker reliability can improve over time. NZQA (2016) reported that agreement rates between teachers and moderators for grade level in NCEA had improved from $79.6 \%$ in 2012 to $84.6 \%$ in 2015. Arguments around agreement rates need to consider the scale of measurement; it would be more difficult to get agreement if the mark range is $0-100$ than if the range is A-E, or in the case of NCEA achievement standards which afford only four possible grades. Evidence from longitudinal studies has supported the notion that reliability of teacher judgements can improve and become more consistent with professional development. In their two-and-a-half year qualitative collaboration with 18 teachers, Black et al. (2011) reported that despite initial variability in teacher judgements, with ongoing professional development the consistency of judgements improved over time. Similarly, Adie, Klenowski, and Wyatt-Smith (2012), also reporting on a longitudinal study, which investigated how teachers came to shared judgements about student work, concluded that the reliability and consistency of teachers' judgements did increase over time. 


\subsubsection{Validation and moderation}

Systems can be put in place to ameliorate deficits in the validity of assessment tasks and reliability of teachers' marking. Johnson (2011) described 'controlled assessment' for the General Certificate of Secondary Education in the United Kingdom, whereby the Qualifications and Curriculum Development Agency provided a range of tasks that teachers had to select from, rather than allowing them to create their own. The agency provided marking schemes, and prescribed levels of supervision under which the assessment had to take place. The system operating in New Zealand for assessment material is more akin to support than control; NZQA provides exemplar materials for NCEA for teachers to adapt and use if they choose. Control is asserted over teachers' marking because the validity of a proportion of tasks set by teachers is checked by moderators (NZQA, n.d.h). While these measures may alleviate validity concerns, they are in tension with some possible purposes of internal assessment. For example, Klenowski and Wyatt-Smith (2014) and Maxwell (2004) suggested that internal assessment allows for assessments to be personalised to meet the needs of a diverse range of students, which is not possible if all students are expected to complete identical assessments. Davison and Leung (2009), in their article promoting a theory for internal assessment, attempted to explain the validity dilemma by arguing that a fundamental paradox of internal assessment is that its strengths can also be considered weaknesses. They claim that the validity of internal assessment is derived from teachers knowing students' work and not from similarity of tasks.

Moderation is a practice that involves supporting the reliability of teachers' judgements. Linn (1993) describes two key ways of carrying this out: statistical moderation and social moderation. Statistical moderation involves students' marks in one type of assessment being checked, and sometimes altered, on the basis of a statistical comparison with another assessment (Linn); for example, internal assessments may be moderated against an external examination (Hipkins et al., 2016). Social moderation involves groups of teachers sharing their understandings of standards, and students' work towards the standard, in order to develop common judgements (Adie et al., 2012; Hipkins et al., 2016; Linn, 1993). According to Linn, social moderation also includes teachers' judgements being rated independently by teachers external to the school or other independent experts. This latter description of 
moderation is referred to as external check moderation in NCEA and the external expert is known as a moderator (NZQA, n.d.h).

Nevertheless, such strategies to achieve greater reliability have been criticised. Statistical moderation addresses anomalies in marking, but Johnson (2013) questions the value of carrying out internal assessment if statistical moderation is then applied. She also points out that a weakness of check moderation is that the moderation takes place after the assessment and "any injustices seen to be done to individual students by their teachers' assessments remain unidentified, or, if identified, unaddressed" (p. 99). A further weakness is that moderators become custodians of standards and, according to Johnson, the validity and reliability of their judgements are open to question. A major weakness of social moderation is that consistency among teachers cannot be addressed if there is no external system to moderate across the groups (Hipkins et al., 2016). A further weakness reported by Adie et al. (2012) was that changing teachers' judgements through social moderation is a complex process, influenced by many factors, but as argued by Linn (1993), "staff development is a critical component" (p. 99). Arguing against the possibility of total reliability, Davison and Leung (2009) suggested that internal assessment does not require teachers to give identical marks; some variation within a range should be acceptable.

Assessment jurisdictions that include some form of internal assessment must consider the reliability of teachers' marking and the validity of their assessments to ensure fairness for all students. However, concern about these is not, in itself, a reason for not including internal assessment in national qualifications. Systems such as moderation can be put in place to ameliorate potential deficits in this regard. The validity of teachers' internal assessment tasks and judgements is derived from teachers knowing their students' work and not from the similarity of assessment tasks. As Newton and Shaw (2014) have argued, for assessment to be ethical and socially acceptable, the benefits of one type of assessment often have to be traded against those of another. 


\subsubsection{Impact of internal assessment on teachers}

Internal assessment can support positive changes in teachers' practice, such as: promoting the provision of formative feedback during the assessment process (Harlen, 2004); heightening their awareness of their teaching effectiveness (Meyer, McClure, Walkey, McKenzie, \& Weir, 2007); and, enabling them to use a wider range of assessment tools with the autonomy to design programmes to meet the needs of their students (New Zealand Post Primary Teachers' Association; PPTA, 2015). Further benefits for teachers of using internal assessment are having their professionalism acknowledged, empowering them by recognising their extensive knowledge of their students as learners and developing high levels of assessment skill (Johnson, 2013). Evidence from New Zealand has shown that teachers do believe that they are professionally supported in their internal assessment practice. In a national survey of secondary teachers, Hipkins (2013) reported that $75 \%$ of teachers attending Best Practice Workshops (professional development offered by NZQA for internal assessment) said these had increased their confidence in making assessment decisions. Hipkins also reported that teachers thought moderation procedures provided them with useful feedback to improve their assessment skills. In her research on internal assessment systems in the United Kingdom, Queensland and California, Harlen (2007) similarly claimed that feedback from moderation can provide valuable professional development and improve teachers' assessment practices.

In contrast, Taylor et al. (2007) reported that teachers interpreted feedback on their marking and assessments as questioning their professionalism, a sentiment echoed by the PPTA (2016). The PPTA, in their investigation into teacher workload issues, which consisted of a survey of 1,300 secondary teachers and focus group interviews, reported that teachers thought that their ability to assess accurately was questioned by the current levels of moderation required by NZQA, levels that participants in the PPTA research considered excessive. However, NZQA (2017a) claimed that moderation requirements are relatively low and operate as a high-trust model because only approximately $4 \%$ of results reported are required for moderation. While it is in the interests of teacher unions to make claims in favour of teachers, independent studies have similarly reported that teachers can find moderation processes critical, inconsistent, and unhelpful professionally (Brooks, 2010; East, 2016; Mizutani, 2009; 
Wylie \& Bonne, 2016). Contrasting opinions on teachers' perceptions of their professionalism could be a result of differing levels of competency with regards to internal assessment. Those showing higher levels of competency have their skills endorsed by external procedures, while those less competent or confident in internal assessment may think their professionalism is more exposed and therefore report more negative feelings. Nonetheless, the most important question is perhaps whether or not the reliability of teachers' marking improves as a result of the process.

Teachers in a number of jurisdictions have raised concerns about the workload associated with carrying out internal assessment. In their review of practices of internal assessment in Australia, Scotland and Wales, Stanley, MacCann, Gardner, Reynold, and Wild (2009) identified teacher workload as an issue, and called for internal assessment systems to be manageable for teachers and not to require overassessment or excessive record keeping. Workload issues have also been reported in Hong Kong, New Zealand, and Malaysia. For example, in Hong Kong, Yip and Cheung (2005), reporting on a quantitative study of 351 teachers, noted that teachers were very concerned about the high workload associated with internal assessment with many regarding it as additional work imposed by examination authorities. Yan's (2014) quantitative study with 280 participants similarly reported that teachers considered carrying out internal assessment to be a burden and workload concerns contributed to teachers' negative attitudes towards internal assessment. In a qualitative study, Qian (2014) added that the heavy workload of internal assessment may result in teachers not producing quality work and that excessive workload can have negative effects on teachers' well-being.

In New Zealand, teachers and senior leaders in schools have criticised the increased workload created by internal assessment and moderation requirements (East, 2016; Mizutani, 2009; PPTA, 2016; Wylie \& Bonne, 2016). Wylie and Bonne, in the triennial survey of secondary teachers run by the New Zealand Council for Educational Research, reported that the impact of internal assessment on teacher workloads "has been an issue since its inception" (p. 26). Only 32\% of teacher participants in their survey agreed that the workload was manageable, with over $40 \%$ disagreeing. An even greater proportion of principals (84\%) agreed that teachers struggled with the workload created by internal assessment. 
Studies that include interviews as well as surveys allow participants to expand on the sources of workload pressure. According to the PPTA (2016), internal assessment was the "most referenced source of workload pressure" (p. 68) with moderation requirements being cited as a source of considerable workload. East (2016) reported that language teachers participating in his study found it time-consuming and complicated to carry out internal assessment because multiple assessment opportunities were being offered for students to meet spoken language proficiency standards. Further sources of workload that have been reported are a lack of resources and support for developing new assessment materials, inconsistent moderator feedback, and an increase in administration associated with moderation and record keeping for internal assessment (Mizutani, 2009).

In their major review of the Queensland system of senior assessment, which received 2,200 survey responses, Matters and Masters (2014) referenced workload issues associated with internal assessment and argued that one advantage of introducing some external assessment back into the Queensland system would be a reduction in teachers' workload. Mills and McGregor (2016), in their analysis of the Queensland education system, agreed that a challenging aspect of internal assessment is the "great increase in teacher workload" (p. 114).

Three studies from Malaysia have also reported workload issues related to implementing internal assessment. Majid (2011), in a quantitative study investigating teachers' concerns with assessment innovation, reported that teachers felt that they did not have enough time to implement internal assessment and that too much time was spent on administrative tasks associated with it. Furthermore, time pressure led to negative feelings about internal assessment. Although Majid reported on a relatively small $(n=40)$ group of teachers, her findings are supported by a larger study that surveyed 322 teachers and also concluded that the heavy workload associated with internal assessment leads to negative attitudes towards it (Jaba, 2013). Raman and Yamat (2014), in their qualitative study similarly identified workload concerns, with participants revealing that the sources of extra workload were the marking, filing, documentation and paper work associated with internal assessment. 
A consideration with regard to workload concerns is that, if teachers saw the formative value in internal assessment they may have a different view. If they considered internal assessment a valuable part of the learning process that at the same time awards credits towards national qualifications rather than an administrative imposition, their attitudes towards the workload could be different.

\subsubsection{Impact of internal assessment on students}

Harlen (2004) reported on an in-depth literature review on the impact of using internal assessment for summative purposes. At the time, only six studies were exclusively concerned with the use of internal assessment for senior secondary school qualifications. From this limited database, Harlen concluded that internal assessment had a positive effect on students: students often find internal assessments motivating; they value managing their own learning; and that they appreciate becoming more independent in terms of assessment. Empirical studies since then have reiterated such positive outcomes of internal assessment for students. Sheehan (2013), in his mixed methods study of New Zealand history students, concluded that through internal assessment students were developing understandings of how history works as a discipline and were learning how to think historically. He claimed that the internallyassessed course work was making a major contribution to these students "learning to participate in society as critical citizens who can think independently and adjudicate between competing claims of historical authenticity" (p. 11). Furthermore, he reported that students in his study were motivated to engage with internally-assessed course work, that they valued the autonomy of investigating issues of personal interest, and that they were prepared to commit to the substantial workload required. Also using mixed methods to report on the internal assessment component of NCEA, Mizutani (2009) identified several benefits for students. These included: more authentic assessment, for example, conversations in a target language as opposed to written translations; students being more aware of expectations through specific assessment criteria; ongoing formative feedback; and students taking more control of their own learning and feeling motivated to try to achieve higher grades. 
Also, taking a mixed methods approach in their study of the impact of NCEA on student motivation, Meyer et al. (2007) reported positive perceptions of the internallyassessed component of NCEA. They found that internal assessment provides achievement opportunities for students who may be unsuccessful in examinations as well as increasing the choice of topics to study. It allows assessment workload to be spread over an entire year, and can afford opportunities to resubmit or repeat assessments. Student participants in Mizutani's (2009) study also reported that they appreciated having assessments spread out over a year because that gave them opportunities for feedback, which assisted their learning by giving them clear goals to work towards.

Some concern has been expressed about student workload with regard to internal assessment, for example, by Wylie and Bonne (2016). However, this concern has often emanated from parents and teachers rather than the students themselves. For example, Mizutani (2009), who surveyed and interviewed students, reported that while teachers thought ongoing assessment throughout the year was a burden to students, the students themselves did not agree. Students reported that they found the system motivating and manageable.

The international literature on student voice in internal assessment is rather sparse. Two studies from Hong Kong have reported varying student attitudes towards internal assessment. Gao's (2009) small-scale quantitative study showed that students within one school had contrasting views, with some thinking the internal assessment process was highly beneficial, while others thought the feedback from teachers was inadequate. Tong and Adamson (2015) followed up Gao with a larger mixed methods study of 423 survey respondents and interviews with 45 students that reported mixed responses: over $70 \%$ of respondents did not agree that internal assessment led to a less stressful assessment experience, but some participants did think that the feedback was supportive of learning. Overall, they concluded that students did not appreciate internal assessment and that they were dissatisfied with the feedback they received from teachers, considering it insubstantial and imprecise. 
In these examples, it seems the utility of internal assessment to students is mediated by its implementation by teachers. Mizutani (2009) reported that students in her study found that teachers' feedback assisted their learning, and that they were generally positive about internal assessment. On the other hand, students in the studies of Gao (2009) and Tong and Adamson (2015) were disappointed with teacher feedback and were subsequently not supportive of internal assessment.

\subsubsection{Concluding comment}

Using internal assessment for external qualifications has the potential to benefit students and teachers alike. Students can be assessed on a greater range of skills that cannot feasibly be tested under examination conditions and assessment can be carried out in less stressful conditions; thus it is likely to give students more opportunities to demonstrate their full potential. Issues of validity and reliability of teacher assessment have to be considered and systems put in place to ensure fairness. In an environment with internal assessment for external qualifications, teachers must balance the multiple purposes of assessment and the workload associated with carrying out a substantial level of summative assessment. We need to know how they react to this challenge to ensure that change is implemented as intended.

\subsection{Assessment policy as a tool to improve teaching and learning}

\subsubsection{Assessment reform in New Zealand}

Assessment is not an isolated educational phenomenon; it is essentially a social tool used to judge performance (for formative and summative purposes) and often regulates access to further opportunity. Barker (1995) argued that education and assessment policy were increasingly being used to promote social, political and economic agendas. As a result of New Zealand's weakening economy in the 1970s and 1980s there were calls for changes in the education and qualifications systems as these were now perceived to be inadequate in educating and assessing people to work in a changing economy. Numerous reports (e.g., Education in Change, PPTA, 1969; Towards partnership: The report of the Committee on Secondary Education, 1976; Learning and achieving: Second report of the commission of inquiry into curriculum, assessment and qualifications in forms 5 to 7, 1986; Assessment for better learning, 1989, Assessment: Policy to practice, 1994) advocated such change, arguing that the 
existing normative assessment model, which ensured compulsory failure of approximately $50 \%$ of students, could not support a nation of successful achievers (Barker, 1995).

Very little change took place until 1990 when NZQA was established under the 1990 Education Amendment Act, with the main purpose of reforming qualifications, including those assessed for secondary school students. The New Zealand Qualifications Framework (NQF) was introduced in 1991 (NZQA, 1991). Its features included standards-based assessment that would be assessed by unit standards. NZQA introduced unit standards progressively from 1992 with an intention to completely replace the norm-referenced examination-based system with internally-assessed unit standards by 1996 (NZQA, 1992). The school assessment system was to move simultaneously to a standards-based regime that would be fully internally assessed.

The move to standards-based assessment was criticised by a number of education academics. Elley (1995) claimed that the use of standards-based assessment for highstakes assessment is suspect and argued that setting specific standards for some skills such as writing fluently or critically examining texts was not possible. He further argued that the standards proposed by NZQA were not precise enough and terms used to describe criteria within standards 'like 'some', 'an inclusive range' and a 'reasonable amount' are inexplicit and unhelpful" (p. 83). These views were echoed by Crombie (1995) who asserted similarly that standards could not be used to assess higher-level skills in languages. She believed that only low-level skills could be assessed using criteria-based standards. While not criticising standards-based assessment per se, Hall (1998) raised serious issues with the structure of the unit standard system that modularised the assessment for each subject into small components. He was also wary of the proposal for total reliance on internally-assessed standards and supported a system that used both internal and external assessment. Hall claimed that clearly defining performance standards was difficult and the application of standards "inevitably involves some element of norm-referenced assessment" (p. 38), because the proportions of students in large cohorts gaining various grades is not expected to vary statistically from year to year (Hipkins et al., 2016). He argued that rather than dismissing either norm-referenced or standards-based assessment due to their weaknesses, the strengths of each approach should be used in tandem. 
In the meantime, NZQA continued to offer two systems: the NQF with its unit standards and the traditional norm-referenced examinations of School Certificate and University Bursary. Schools and individual students were able to choose between these systems, or in some cases, operate in both. Research (e.g., Ministry of Education, 1996) with schools using unit standards found that teachers were generally positive about the potential of the NQF and unit standards to deliver a fairer qualification structure for their students. Some positive aspects they noted were that the system was flexible, that reassessment was possible, and that it allowed more students to gain qualifications.

In 1997, the Ministry of Education released a draft policy document: A Future Qualifications Policy for New Zealand: A Plan for the National Qualifications Framework. The paper acknowledged the debate surrounding the NQF and proposed a way forward to develop a cohesive qualifications system. The draft policy proposed to retain unit standards as many providers had "enthusiastically embraced the unit standards-based NQF" (p. 15), but to incorporate the existing school examinations into the NQF as their supporters "believe they identify excellence in student performance better" (p. 26). Achievement 2001, the policy for school qualifications, was announced in November 1998 with the main points of the policy being:

- All students would study towards NCEA.

- In conventional curriculum subjects, credits would be gained from a mix of internal and external assessment that would be against achievement standards.

- Achievement standards would recognise merit and excellence.

- Unit standards would remain. (Baker, 2001)

At the time of its launch, NZQA claimed that NCEA would "provide a more comprehensive record of what students achieve while they are at school. It would also give students a better launching pad for ongoing learning and their future careers than the previous system" (NZQA, n.d.a, p. 3). The progressive introduction of the NCEA between 2002 and 2004 moved secondary school assessment from a norm-referenced paradigm to a standards-based one, with an additional intention of recognising, and giving credit for, a wider range of knowledge and skills than the previous school 
qualification system (NZQA, n.d.a). According to Meyer et al. (2007), NCEA was intended to achieve particular educational and social outcomes such as higher proportions of students staying in school in Years 12 and 13, and higher qualifications attainment. However, resistance to NCEA remained and led to some secondary schools adopting foreign qualifications such as the Cambridge International Examinations and the International Baccalaureate (Fitzpatrick \& Locke, 2008).

\subsubsection{The impact of assessment reform}

The implementation of NCEA in New Zealand secondary schools has been described as a 'seismic' change in assessment (Hipkins et al., 2016) and the launch of the new qualifications system in 2002 was followed by the introduction of a new school curriculum in 2007. These policy reforms reflected high expectations for student achievement and anticipated a significant shift in secondary teachers' practice, requiring them to change their thinking about assessment and their classroom practice (Hipkins et al.). Hargreaves (1989) warned that assessment reforms would not automatically result in teachers changing their pedagogy with which Torrance (1995) agreed and added that expecting a straightforward relationship between assessment reform and improved teaching and learning is unrealistic. Such a relationship suggests that politicians make policy and teachers "simply do as they are told and put the intended policy into practice" (Thrupp, 2017, p. 12). In reality, policy is reinterpreted and implemented by teachers within the complexities of diverse school settings, along with other education policies and wider social issues (Ball, Maguire, \& Braun, 2012).

Fullan (2001) explained that education reform is complex because if teachers are to implement change as it is intended, they need the motivation to do so, and this may require a change in their beliefs. However, if they think that their core beliefs are challenged and contradicted, teachers may be resistant and very little actual change will take place. Furthermore, teachers may need to change their pedagogical practices and learn new skills, which creates further barriers to change, even if teachers endorse the reform. Finally, education reform takes time; teachers must add new knowledge to existing schema requiring sufficient resources to support any change taking place (Noble \& Smith, 1994). 
The challenge of implementing assessment and curriculum reform in New Zealand rested with secondary classroom teachers, because, as Senge (1990) claimed, the success of any reform hinges on what happens at the smallest unit of the organisation. For educational reform this is the classroom in which teachers were challenged to implement and embed change. Despite the major change to school-level qualifications, there is little empirical evidence regarding secondary teachers' beliefs about, and practices within, the current assessment regime, in particular its internallyassessed component.

On the other hand, the impact of assessment reform has been measured through publically reported assessment data. Percentages of students attaining each level of NCEA are gathered and published, and in 2012 the State Services Commission (New Zealand Government, 2012) announced a goal which declared that by $201785 \%$ of all 18-year olds would achieve NCEA Level 2. In addition, according to Hipkins et al. (2016), some secondary schools have set assessment achievement targets for teachers in response to the aforementioned goal. Broadfoot (2007) argues that using assessment data that are gathered for one legitimate purpose for another, arguably a less legitimate one, is an unfortunate function of assessment activities. Broadfoot provides the example of assessment data designed to measure the performance of individual students then being used to evaluate schools and subsequently to create league tables comparing schools and teachers, with penalties applied to those that do not show favourable data. Broadfoot contends this is the least helpful and most damaging use of assessment results because any evaluation of schools and teachers should be rigorous and carried out with consideration of its consequences. This point of view has long been argued. For example, in their historical overview of accountability and evaluation in education Madaus, Scriven, and Stufflebeam (1983) agreed that test scores should not be a sole measure of school accountability. That it is still being argued in 2016 (e.g., Nichols \& Harris, 2016) indicates that such use of assessment results still occurs despite the practice being manifestly unfair because it does not account for external factors that may affect student, and therefore school, performance. 
Broadfoot (2007) argues that using assessment data to evaluate schools is associated with performativity with performativity referring to a culture that employs judgements, comparisons, rewards and punishments as means of incentive and control. Broadfoot claims performativity is not compatible with the aims of standards-based and internal assessment, both of which aim to set clear learning goals for students and to assess a wide range of skills. Conversely, she claims, performativity encourages extrinsic motivation in students, is socially divisive, and appears to raise standards while at the same time driving out assessment for empowerment and learning. Broadfoot quotes the children's writer David Almond lamenting this trend:

There is an arrogance at work, the arrogance that we know exact ly what happens when so meone learns so met hing, that we can plan for it, that we can describe it, that we can record it and if we can't do these things, then the learni ng doesn't exist. (Al mond, cited in Broadf oot, 2007, p. 68)

Using assessment policy as a tool for educational reform creates dilemmas. In New Zealand, assessment reform in recent decades occurred against a background of unprecedented change in the education system and wider society, which some authors have argued was driven by a New Right agenda (Codd, McAlpine, \& Poskitt, 1995). The stated purposes of the assessment reform were to give students a better grounding for future learning, to provide a more comprehensive record of achievement, and to recognise, and give credit for, a greater range of knowledge and skills than the previous system (NZQA, n.d.a). However, data from those assessments are also used to evaluate schools' and teachers' performance, a practice that can create underlying tensions, contradictory purposes, and confusion for teachers (Bonner, 2016). Bonner considers that there is still work to do to understand the impact of major assessment change on teachers' perceptions of, and actions towards, assessment. 


\subsection{Teachers' beliefs}

Beliefs are judgements regarding the validity of truth claims (Pajares, 1992) and according to Bandura (1997), they guide our decisions and actions. Beliefs can facilitate or hinder practice by serving to filter, frame and guide practice (Fives \& Buehl, 2016). According to Borko and Putman (1996), teachers' beliefs are a major influence on what they do in the classroom. If policy change is to influence teachers' practice, then attention needs to be paid to the beliefs they currently hold, so that teachers can consider those beliefs and evaluate how they facilitate or hinder their practice (Fives \& Buehl, 2016).

A variety of terminology has been used to define beliefs, for example, cognition (Borg, 2003), perceptions (Bonner, 2016), values (James \& Pedder, 2006). Thompson (1992) suggested the use of the term conceptions because a conception is "a more general mental structure [than a belief], encompassing beliefs, meanings, concepts, propositions, rules, mental images, preferences, and the like" (p. 130). G.T.L. Brown (2002) also preferred this term because "conceptions represent different categories of ideas" and act as a framework "through which a teacher views, interprets, and interacts, with the teaching environment" (p. 2). Conceptions can be erroneous, contradictory and incomplete, but they do represent what we understand and believe, and they guide our actions and attitudes (G.T.L. Brown, 2008). In addition, conceptions of assessment are complex and suggest a dynamic relationship between beliefs and classroom practice in that beliefs guide actions, but alternatively actions can influence beliefs (Looney, Cumming, van Der Kleij, \& Harris, 2017).

Teachers hold conflicting conceptions of assessment that vary with context and the developmental position of students (Bonner, 2016). G.T.L. Brown and his colleagues have studied the underlying structure of teachers' beliefs about assessment and have developed a model that describes four predominant conceptions (e.g., G.T.L. Brown, 2004; Brown et al., 2011; Brown et al., 2009; Brown, Lake, \& Matters, 2011; Brown \& Remesal, 2012; Gebril \& Brown, 2013). 
G.T.L. Brown's (2002) doctoral dissertation used a series of qualitative and quantitative studies to test models of how teachers' conceptions of assessment were structured. He found that the views New Zealand teachers held about assessment aligned with a theoretical model comprising four broad categories. These are that: assessment is for the improvement of teaching and learning; assessment is for making schools accountable for their effectiveness; assessment is for making students accountable for their learning; and that assessment has no purpose and is irrelevant or detrimental to the life and work of teachers and students.

The improvement conception of assessment asserts that the purpose of assessment is to generate valid information that will lead to improved student learning, which may entail changes in teaching and/or student learning practices. As noted by G.T.L. Brown (2008), this conception assumes that unless improvement in learning takes place, assessment could be conceived as being irrelevant. This proposition aligns strongly with Wiliam's (1994) assertion that there is little point in carrying out assessment if there is no improvement to student learning and therefore the improvement conception encapsulates the formative function of assessment.

According to G.T.L. Brown (2008), the school accountability conception of assessment relates to the belief that assessment results can provide surety to the government that its resources are being used well in schools and that the mandated curriculum is being taught. In addition, the school accountability conception assumes that assessment data can make schools and teachers accountable for their work, and assessment results can lead to improved teaching and thereby raise educational standards. If teachers use assessment data to analyse their own practice, this can potentially lead to improvement in students' learning; therefore, according to Brown (2008), a positive correlation between this conception and the improvement conception could be expected. On the other hand, if the consequences of accountability are too high (e.g., schools vilified or teachers reprimanded for poor results) then this may lead to teachers considering assessment antithetical to their welfare and to conceiving of this function of assessment as irrelevant (G.T.L. Brown, 2008). 
The student accountability conception holds students responsible for their own learning through the assignment of grades and, in the senior secondary school, through the award of various qualifications (G.T.L. Brown, 2008). Grades signal that students have, or have not, attained a standard for entry into the next levels of education or employment, thus holding students accountable for having achieved a certain level of competence. This aspect of the student accountability conception would align with a summative purpose of assessment (G.T.L. Brown, 2008). According to G.T.L. Brown (2008), teachers attribute accountability to students because their effort and attention in class are seen to contribute to their learning. A further practice that may contribute to teachers conceiving of assessment as an indicator of student accountability is the increasing role some teachers give to students to determine their own learning goals (G.T.L. Brown, 2008). For example, in a secondary school this could include allowing students flexibility to choose which NCEA achievement standards they will attempt. Interviews with teachers could determine if this is the case and whether such practices are associated with student accountability.

There is also a conception that assessment has no legitimate place in education beyond the intuitive processes that teachers engage in with students. Under this conception, formal assessment is seen as irrelevant. This belief stems from the ideas that assessment has an unfair impact on some students, that assessment can be so inaccurate that it has no reliability, and that assessment is anchored in a "non studentcentred view of the educational world" (G.T.L. Brown, 2008, p. 29).

\subsubsection{Measuring teachers' conceptions of assessment}

G.T.L. Brown (2002) developed an instrument comprising an inventory of 50 statements to measure the dimensionality of teachers' conceptions of assessment and the degree to which teachers endorse each of the four conceptions. G.T.L. Brown used exploratory and confirmatory factor analysis over a series of studies to develop a model of how teachers' conceptions of assessment are structured. He concluded that the data gathered using the instrument "were consistent with the theoretical models on which they were based" (p.186). Subsequently, G.T.L. Brown (2006) reported on the effectiveness of an abridged version of only 27 items - the Teachers' Conception of Assessment Abridged (TCoAIIIA) Inventory. 
Quantitative research using the TCoAIIIA Inventory undertaken in New Zealand and Australia has supported the model (G.T.L. Brown, 2004, 2006, 2011a; Brown, Lake, $\&$ Matters, 2011). However, one key difference between primary and secondary teachers in these countries was noted. In Australia, Brown, Lake, and Matters reported that primary teachers agreed strongly with the improvement conception whereas secondary teachers had higher agreement with student accountability, findings which agreed with similar New Zealand research (G.T.L. Brown, 2011a). Despite this difference, G.T.L. Brown (2011a) and Brown, Lake, and Matters (2011) concluded that there was a strong similarity amongst the responses of primary and secondary teachers in New Zealand and Australia. Similarities included positive correlations between the improvement and student accountability conceptions, an inverse correlation between the irrelevant and improvement conceptions, and a positive correlation between the irrelevant and student accountability conceptions. G.T.L. Brown (2011a) explained these correlations as showing that primary and secondary teachers agreed that if assessment does not improve learning then it can be considered irrelevant. The positive correlation between irrelevant and student accountability indicated a predominant belief that making students accountable for their own learning is seen to be an irrelevant function of assessment. G.T.L. Brown (2011a) attributed the similarity between New Zealand primary and secondary teachers to common professional attitudes endorsing a child-centred curriculum and concluded that the qualifications system "did not greatly distort teachers' conceptions of assessment relative to primary teacher responses" (p. 63). This degree of commonality could be considered surprising given the strong focus on qualifications in the senior secondary school years. Further investigation, for example, with interviews, could explain more fully the choices secondary teachers made on the survey.

Quantitative studies with secondary teachers in more examination-oriented education systems have generally not supported the factor structure of G.T.L. Brown's (2006) model, for example, in Hong Kong (Brown et al., 2009), Egypt (Gebril \& Brown, 2013), southern China (Brown et al., 2011), and the Netherlands (Segers \& Tillema, 2011). Brown et al. (2009) found that, while secondary teachers in Hong Kong had similar conceptions of assessment reported to those of the New Zealand teachers identified by G.T.L. Brown (2011a), there were two notable differences. First, for Hong Kong teachers the correlation between the student accountability and 
improvement conceptions was .91 whereas for New Zealand teachers it was only .23. This strong positive correlation has also been reported in southern China (Brown et al., 2011) and Egypt (Gebril \& Brown, 2013). Gebril and Brown postulated that this correlation indicates that secondary teachers in Hong Kong, China and Egypt hold students accountable for their own improvement. However, there are many ways to interpret correlations, and positive correlations between these two conceptions could also be explained in terms of teachers considering indicators associated with student accountability (e.g., placing students in categories, assigning grades, and meeting qualifications) as evidence of improved learning. Alternatively, this correlation could be an indicator of a belief that students who take responsibility for their own learning improve more over time. Interestingly, in the Netherlands, Segers and Tillema, who used exploratory factor analysis, did not extract student accountability and improvement as two separate conceptions; they speculated that teachers in their study did not make a distinction between the formative and summative purposes of assessment. Without further investigation, for example by asking participants, it is not possible to state categorically why these factor structures and correlations exist.

A further difference between the findings of G.T.L. Brown (2011a) and other studies is varying correlations with the irrelevant conception. Data from teachers in Hong Kong (Brown et al., 2009), China (Brown et al., 2011) and Egypt (Gebril \& Brown, 2014) showed an inverse correlation between the irrelevant and student accountability conceptions, contrasting with a positive correlation for New Zealand teachers. This suggests that Hong Kong, Chinese and Egyptian teachers believe that assessment for student accountability has educational relevance, whereas New Zealand teachers are much more ambivalent in this regard.

\subsubsection{Differences in teachers' conceptions of assessment}

International differences in teachers' conceptions of assessment have been attributed to varying cultural expectations (Brown et al., 2009; Brown et al., 2011; Gebril \& Brown, 2013; Segers \& Tillema, 2011). The variations might also reflect the influence of national assessment policy on teachers' beliefs and, in turn, on their assessment practice. Alternatively, policy changes might affect practice first, leading to changes in belief, which would be in accordance with Bandura's (1986) theory of bi-directional influence. It is also possible that variations in teachers' conceptions of assessment are 
related to the age level at which they teach (Remesal, 2011). Internationally, research has elicited variation in teachers' conceptions of assessment, with secondary teachers showing different conceptions from primary teachers (Brown, Lake, \& Matters, 2011). Such differences could be influenced by the high-stakes nature of assessment for qualifications in secondary schools, or alternatively, by the nature of older students versus primary-aged students. Brown, Lake, \& Matters, who used G.T.L. Brown's (2006) TCoAIIIA to compare Queensland primary and secondary teachers' conceptions of assessment, attributed differences between the two groups to highstakes examinations in the senior secondary school which is "consistent with the notion that policy shapes conceptions" (p. 218).

Without asking teachers, researchers can only speculate on the reasons for their different conceptions of assessment. Research that includes interviews, as well as surveys, can provide such reasons because they afford participants an opportunity to elaborate on their survey responses. For example, in New Zealand, Brown and Harris (2009) carried out a mixed methods study, which reported that the introduction of a set of nationally provided resources to support teachers' use of assessment for learning moved teachers' beliefs from being predominantly improvement oriented to being more aligned with the idea that assessment measures school quality. Interviews were able to explain this unexpected result and revealed that some teachers could not reconcile the test-like nature of these resources with an improvement belief and that some schools did use the tool for their own, and their teachers', accountability.

A qualitative comparison between primary and secondary teachers in Spain (Remesal, 2011) showed that secondary teachers had a higher leaning towards accrediting conceptions of assessment (conceptions which focus on certification of achievement) than primary teachers. The qualitative nature of Remesal's study was able to reveal that the interviewed teachers hypothesised that their "conceptions could be related to the structure of the educational system and the external assessment policy demands" (p. 480). 
G.T.L. Brown's (2011a) argument that teachers adopt conceptions of assessment that are "ecologically rational in that they reflect the legal, cultural or social priorities placed on assessment for their work environment" (p. 65) supports the hypothesis that teachers' conceptions of assessment may vary with the level at which they teach. Remesal (2011) reinforced this interpretation and, in addition, speculated that conceptions might differ between teachers of different subjects at the high-school level because her research focussed on mathematics teachers and therefore could be content specific. Mizutani, Rubie-Davies, Hattie, and Philp (2011) certainly found that the subjects teachers taught played a role in influencing beliefs about NCEA assessment.

Teachers' conceptions of assessment are complex - they vary according to context and the level at which they teach, and are far from fully understood. Bonner (2016) notes that the assessment policy landscape has changed substantially in the last decade and we do not fully understand the implications of this on teachers' conceptions of assessment. Outstanding questions include how and whether teachers' conceptions of assessment vary with the level at which they teach and whether the nature of the academic discipline taught by a teacher has any impact on his or her conceptions of assessment. Remesal (2011), on the basis of her findings and speculations, also called for more research investigating links between teachers' conceptions of assessment, their educational contexts, and the subjects they teach.

\subsection{Teachers' assessment identity}

Looney et al. (2017) claim that teachers' conceptions of assessment, and their experiences, feelings and beliefs about assessment are significant influences on how teachers assess. They "propose a dynamic and interactive teacher assessment identity constituted by beliefs, feelings, knowledge and skills" (p. 14). Their model of teacher identity also includes the impact of the role of the teacher in the assessment process. $\mathrm{Xu}$ and Brown (2016) also discuss the idea of teachers having an assessment identity and claim that teachers "need to constantly negotiate their role as assessors (p. 158), especially during periods of change. They also claim a challenge to teachers' assessment identity is the positioning of teachers as assessors of formal qualifications. Discussing a socio-cultural approach, Pryor and Crossouard (2008) claim that 
teachers' identities "rather than being rooted in individual traits" (p. 9) are determined by socio-cultural and historical settings, because according to the socio-cultural approach people become who they are by participating in communities. Assessing students take place within the classroom community and the wider community of the school.

The notion of teacher assessment identity is still somewhat vague. There is a consensus in the literature that teachers have one, but little regarding what the elements of that identity might be, nor how identities might vary from one teacher to another. $\mathrm{Xu}$ and Brown (2016) claimed "there is no 'ideal' assessor identity" (p. 158) and that if teachers have a clear sense of who they are as assessors they are more likely to make justified decisions around their assessment practice and to engage in more selfreflection. Adie (2013) claimed that teachers themselves identify as a 'type' of assessor. She describes teachers who thought of themselves as either hard and nitpicky markers, or as easy and fair. While not especially discussing assessment identity, Horsley (2012) identifies three different teacher identities with regards students' success in the New Zealand Scholarship examinations; she describes teachers as either catalysts, mavericks or inhibitors to students' achievement.

Assessment identity can also be conferred by others. Foucault (1979) discussed the power of examinations to afford or deny opportunities to students, and their role in classifying students. Bourdieu (1991) claims that tests have power and Bachman and Purpura (2008) claimed that tests "serve as both door-openers and gatekeepers". Decisions based on assessments can either provide access to resources and opportunities (door-openers) or deny such access (gatekeepers). Shohamy (2001) invests that power with the testers who become powerful individuals able to give or deny access to further opportunity. The metaphors of gatekeeping and door-opening are therefore used to describe the individuals and their practices rather than just referring to the tests. Davison (2004) has also used metaphors to describe teachers' assessment practices; she refers to 'assessor-technicians' who followed procedures, rules and principles when assessing students and also 'assessors as God' who tended to make intuitive, subjective decisions about students' levels of achievement. While gatekeeping has negative connotations, Nagy (2000) argues that gatekeeping is a legitimate, historical role of assessment which acts a form of quality control. 
With respect to NCEA internal assessment, teachers are the testers with the power to open doors or to act as gatekeepers.

\subsection{Conclusion}

Two decades of educational reform are a lived experience for many New Zealand secondary teachers. The impact of this reform, in particular the controversial assessment for qualifications reform, on their beliefs and practices is yet to be fully investigated. This review has outlined the educational importance of assessment and the tensions that can arise because assessment results are put to multiple purposes. Assessment reform aims to improve teaching and learning, as well as student achievement, but on the other hand, assessment results are used as an accountability measure for teachers and schools. Teachers have to manage these multiple purposes and intentions, which at times are contrasting and contradictory and the literature suggests ongoing tensions and conflict for teachers trying to balance competing functions of assessment. Teachers' beliefs have important implications for their actions, and in order to understand their actions, we must therefore attempt to understand their beliefs.

\subsection{Research questions}

Literature searches found a limited number of mixed methods studies in relation to teachers' conceptions of assessment, and none exclusively focussing on New Zealand secondary school teachers. In addition, there is currently little research, either quantitative or qualitative, specifically about New Zealand secondary teachers' conceptions of assessment. This group of teachers are of interest because they are working in a unique assessment environment in which they have a substantial role in decisions regarding the format and content of assessment for qualifications. This level of responsibility is likely to affect their conceptions of assessment, and their beliefs about assessment may determine their actions with regard to their assessment-forqualifications programmes. 
This thesis begins to address this gap by reporting the conceptions of assessment and practices towards internal assessment of a group of New Zealand economics and accounting teachers. A mixed methods approach was used to investigate the conceptions of assessment of these teachers, how they assess the internally-assessed achievement standards for NCEA, and the reasons for the decisions they make. Specific questions are:

1 What are the conceptions of assessment for teachers of accounting and economics?

2 What are the reasons for teachers of accounting and economics making the decisions they do about internal assessment tasks they offer students?

3 What is the impact of their beliefs about assessment on their approaches to internal assessment design?

\subsection{Significance of the study}

NCEA signified sweeping changes to assessment for qualifications in New Zealand secondary schools. It recognises and gives credit for a broader range of knowledge and skills than did the previous assessment system. The internally-assessed component, particularly, allows a wide range of student performance to be assessed and reported, which has enabled higher levels of student success in attaining school qualifications (NZQA, 2017b). As Yung (2000) suggested, "good school-based assessment can be a powerful tool for improving teaching and learning" (p. 267); therefore, it is important that internal assessment practices maximise this potential. Although New Zealand secondary teachers arguably work in a qualifications-oriented education culture, they also have a substantial role in decisions regarding the format and content of assessment for qualifications in comparison with teachers in many other

nations. Furthermore, because a great deal of the assessment programme for NCEA is school-based, there is potential for this assessment to fulfil formative functions as well as contributing to awarding qualifications. 
This study will build on, and contribute to, work previously done by G.T.L. Brown and his colleagues on teachers' conceptions of assessment (e.g. G.T.L. Brown, 2004; Brown et al., 2011; Brown et al., 2009; Brown, Lake, \& Matters, 2011; Brown \& Remesal, 2012; Gebril \& Brown, 2013) by investigating a group of teachers not yet included in this research stream. The mixed methods design of this study adds a further dimension in investigating the reasons given by participants for their perspectives on, and conceptions of, assessment. This study contributes to ongoing research on NCEA and internal assessment by identifying the practices, and reasons for these practices, of a group of teachers towards the internally-assessed component.

This study is of significance to anyone (students, teachers, teacher educators, school managers, education officials) who is interested in realising the potential of internal assessment. The study will inform stakeholders of internal assessment practices of economics and accounting teachers in New Zealand schools. It will also highlight to stakeholders the enablers and barriers to teachers implementing 'good' internal assessment practice, which, in turn, can inform both initial teacher education and teacher professional development programmes. The findings of this research should be relevant to educationalists in other countries and regions wherever internal assessments inform the teaching and learning process as well as the awarding of secondary school qualifications. 


\section{CHAPTER 3}

\section{Methodology}

\subsection{Theoretical positioning of the study}

According to Mackenzie and Knipe (2006), unless researchers nominate a research paradigm there is "no basis for subsequent choices regarding methodology, literature or research design" (p. 195). Morgan (2007) also claims that "research inherently involves epistemological issues about the nature of knowledge" (p. 52) and that the choice of research paradigm is shaped by the researcher's preferences. The fundamental epistemic position underpinning the present research is a pragmatic world view. Pragmatism places methodology rather than philosophical stance at the centre of the research (Morgan) and allows the researcher to use whatever methods are appropriate to answer the research questions. Tashakkori and Teddlie (2003) argue that this is an appropriate approach for research in applied social sciences, and pragmatism offers an "alternative worldview to those of positivism/postpositivism and constructivism and focuses on the problem to be researched and the consequences of the research" (Feilzer, 2009, p. 7). Hence, using a pragmatic paradigm removes researchers from the post-positivist and constructivist dichotomy and allows them to see a world with both subjective and objective layers. As Dewey (1925, cited in Strauf, 2016) describes layers of "completeness, order, recurrences which make possible prediction and control, and singularities, ambiguities, uncertain possibilities, processes going on to consequences as yet indeterminate" (p. 47). The general focus of this research, NCEA internal assessment, is encompassed by Dewey's words.

\subsection{Research design}

This research used a mixed methods design. According to Creswell and Plano Clark (2007), the mixed methods approach involves collecting and analysing both quantitative and qualitative data. It is appropriate to use mixed methods because such a design provides a more complete picture with the quantitative analysis uncovering 
patterns and correlations, enriched by in-depth knowledge of perspectives provided by the qualitative analysis (Creswell \& Plano Clark).

The research was designed to explore teachers' conceptions of assessment, their internal assessment practices, the reasons that these practices are occurring, and to investigate any relationships among them; therefore, one data source was insufficient. Teddlie and Tashakkori (2010) also claim that mixed methods research is valuable when the research problem is in a complex educational context. By using mixed methods it may be possible to achieve "a richer and more complete description of a phenomenon" (Willig \& Stainton-Rogers, 2008, p. 14). To build a more comprehensive understanding of teachers' conceptions of assessment and the impact these have on their internal assessment practices, a survey exploring their conceptions of assessment was followed up with interviews. Willig and Stainton-Rogers (2008) warn that the results of the quantitative and qualitative elements of a mixed methods study may not necessarily converge, but note that they can nonetheless be used to critique each other.

Creswell and Plano Clark (2007) describe four major designs of mixed methods research: the triangulation design, the embedded design, the explanatory design, and the exploratory design. This research is most suited to the explanatory design because "the overall purpose of this design is that qualitative data help explain or build upon quantitative results" (Creswell \& Plano Clark, p. 71). This design, also known as the Explanatory Sequential Design, is a two-phase design that starts with the collection and analysis of quantitative data which is followed by the qualitative data collection. This is useful if the researcher wants to use the quantitative results to form groups, or for purposive sampling, for the subsequent qualitative stage (Creswell \& Plano Clark).

Creswell and Plano Clark (2007) describe this design as the most straightforward mixed methods design and one that can be carried out by a sole researcher because data are collected in separate phases and the research can be conducted as a single study. On the other hand, it may not be possible to specify how participants for the qualitative phase will be selected until the quantitative phase is complete. Furthermore, because of the inevitable delay between each of the phases, not all participants selected from questionnaires are likely to be available to take part in interviews. 


\subsection{Participants}

\subsubsection{Participant selection}

Participants were teachers of accounting and economics teaching in courses assessed by NCEA internal achievement standards. These disciplines are taught predominantly in the senior school, so the main, and often the sole, assessment focus for teachers of these subjects is on national qualifications. Thus, participants are teachers with a predominant focus on assessing for qualifications, with responsibility for designing and implementing a substantial portion of that assessment, and with the opportunity to use that assessment for formative purposes.

\subsubsection{Survey participants}

One hundred and thirty-five teachers completed the conceptions of assessment part of the survey, and 119 completed the demographic section, although some did not answer all questions. Some key points about participants who shared this information are: $65 \%$ were female; most $(80 \%)$ were experienced teachers with at least five years' experience; $98 \%$ had a graduate qualification; $86 \%$ were New Zealand trained teachers; $74 \%$ were New Zealand European; and all reported having some training in assessment. Half of the participants (50\%) worked in state co-educational schools, but other types of schools were also represented including private schools (9\%) and single-sex state schools (19\%).

\subsubsection{Interview participants}

Initially, 55 respondents agreed to take part in interviews. However, due to a range of factors, for example, changing their minds when asked to take part, not being able to find a compatible date, sickness, and not responding to requests, only 21 were ultimately available to be interviewed. It was originally intended to purposively select interview participants based on different patterns of responses to the questionnaire but, because the numbers were manageable it was decided to interview all 21 who were available. The 21 interviewees represented a range of responses to the survey. Table 3.1 summarises some characteristics of each interviewee. 
Table 3.1

Demographic characteristics of interviewees

\begin{tabular}{|c|c|c|c|c|c|}
\hline Pseudonym & $\begin{array}{c}\text { No. of years } \\
\text { teaching }\end{array}$ & Gender & Ethnicity & $\begin{array}{c}\text { School } \\
\text { decile }\end{array}$ & School type \\
\hline Angus & Over 20 & Male & NZ European & $\mathrm{High}$ & St ate Si ngle-sex \\
\hline Scot ai gh & Bt w $6 \& 10$ & Male & European & $\mathrm{High}$ & St ate single-sex \\
\hline Ai lsa & Bt w $11 \& 20$ & Fe male & NZ European & High & Int egrat ed si ngle-sex \\
\hline Barra & Over 20 & Male & NZ European & High & Int egrat ed si ngle-sex \\
\hline Catriona & Less than 2 & Fe male & NZ European & High & St at e co-ed \\
\hline Ei li dh & Bt w $6 \& 10$ & Fe male & Asian & Low & St at e co-ed \\
\hline Mhairi & Over 20 & Fe male & NZ European & High & St at e co-ed \\
\hline Fai lbhe & Over 20 & Male & NZ European & High & Pri vat e single-sex \\
\hline Is la & Over 20 & Fe male & NZ European & Low & St at e co-ed \\
\hline Kirsty & Bt w $2 \& 5$ & Fe male & NZ European & High & St at e co-ed \\
\hline Ceanag & Bt w $6 \& 10$ & Fe male & NZ European & $\mathrm{High}$ & St ate single-sex \\
\hline Maeve & Bt w $11 \& 20$ & Fe male & NZ European & $\mathrm{High}$ & St at e co-ed \\
\hline Morag & Over 20 & Fe male & NZ European & Low & St at e co-ed \\
\hline Malcol m & Over 20 & Male & NZ European & Low & St at e co-ed \\
\hline Ruai ri dh & Bt w $2 \& 5$ & Male & NZ European & High & Int egrat ed si ngle-sex \\
\hline Si onn & Bt w $2 \& 5$ & Male & Asian & Low & St at e co-ed \\
\hline Seonai d & Bt w $11 \& 20$ & Fe male & NZ European & High & Int egrat ed si ngle-sex \\
\hline Sor cha & Over 20 & Fe male & NZ European & $\mathrm{High}$ & Int egrat ed si ngle-sex \\
\hline Tearlag & Bt w $11 \& 20$ & Fe male & British & Medi um & St at e co-ed \\
\hline Wallace & Bt w $11 \& 20$ & Male & NZ European & $\mathrm{High}$ & Private co-ed \\
\hline Doi leag & Bt w $11 \& 20$ & Fe male & NZ European & $\mathrm{High}$ & St ate single-sex \\
\hline
\end{tabular}

\subsubsection{Sample limitations}

Table 3.2 summarises the demographic data of those who fully completed the survey and those who were interviewed, compared with national percentages of teachers. 
Table 3.2

Percentages of participants in demographic categories compared with national figures.

\begin{tabular}{|c|c|c|c|c|}
\hline Characteristics & Category & $\begin{array}{c}\text { Survey } \\
\%\end{array}$ & $\begin{array}{c}\text { Interview } \\
\%\end{array}$ & $\begin{array}{c}\text { National } \\
\%\end{array}$ \\
\hline Gender & $\begin{array}{l}\text { Male } \\
\text { Female }\end{array}$ & $\begin{array}{l}35 \\
65\end{array}$ & $\begin{array}{l}38 \\
62\end{array}$ & $\begin{array}{l}42 \\
58\end{array}$ \\
\hline $\begin{array}{l}\text { Teaching } \\
\text { experience }\end{array}$ & $\begin{array}{l}\text { Less than } 2 \text { years } \\
\text { Between } 2 \text { \& } 10 \text { yrs } \\
\text { Between } 11 \& 20 \\
20 \text { plus years }\end{array}$ & $\begin{array}{r}7 \\
26 \\
33 \\
35\end{array}$ & $\begin{array}{r}4 \\
43 \\
24 \\
29\end{array}$ & Not available \\
\hline $\begin{array}{l}\text { Education } \\
\text { level }\end{array}$ & $\begin{array}{l}\text { Diploma } \\
\text { Bachelors } \\
\text { Graduate Diploma } \\
\text { Post Grad Cert } \\
\text { Post Grad Diploma } \\
\text { Masters or higher } \\
\text { None }\end{array}$ & $\begin{array}{r}1 \\
30 \\
15 \\
7 \\
27 \\
20\end{array}$ & $\begin{array}{r}0 \\
33 \\
4 \\
9 \\
25 \\
29\end{array}$ & $\begin{array}{c}19 \\
\text { Not available } \\
\text { Not available } \\
\text { Not available } \\
75 \\
4 \\
2\end{array}$ \\
\hline $\begin{array}{l}\text { Teaching } \\
\text { subject }\end{array}$ & $\begin{array}{l}\text { Economics } \\
\text { Accounting } \\
\text { Both }\end{array}$ & $\begin{array}{l}43 \\
24 \\
33\end{array}$ & $\begin{array}{l}48 \\
19 \\
33\end{array}$ & $\begin{array}{l}\text { Not available } \\
\text { Not available }\end{array}$ \\
\hline $\begin{array}{l}\text { Overseas } \\
\text { trained }\end{array}$ & $\begin{array}{l}\text { No } \\
\text { Yes }\end{array}$ & $\begin{array}{l}86 \\
14\end{array}$ & $\begin{array}{r}96 \\
4\end{array}$ & $\begin{array}{l}84 \\
16\end{array}$ \\
\hline Ethnicity & $\begin{array}{l}\text { NZ European } \\
\text { NZ Māori } \\
\text { Pacific Nations } \\
\text { Asian } \\
\text { Other }\end{array}$ & $\begin{array}{r}77 \\
2 \\
2 \\
7 \\
12\end{array}$ & $\begin{array}{r}81 \\
0 \\
0 \\
14 \\
5\end{array}$ & $\begin{array}{r}79 \\
8 \\
2 \\
3 \\
7\end{array}$ \\
\hline $\begin{array}{l}\text { Assessment } \\
\text { training }\end{array}$ & $\begin{array}{l}\text { None } \\
\text { Pre-service } \\
\text { In-service } \\
\text { Undergraduate } \\
\text { Postgraduate }\end{array}$ & $\begin{array}{r}0 \\
17 \\
66 \\
6 \\
11\end{array}$ & $\begin{array}{r}0 \\
21 \\
64 \\
0 \\
15\end{array}$ & Not available \\
\hline $\begin{array}{l}\text { Types of } \\
\text { schools }\end{array}$ & $\begin{array}{l}\text { State co-ed } \\
\text { State single-sex } \\
\text { Integrated secondary } \\
\text { Private secondary }\end{array}$ & $\begin{array}{l}50 \\
19 \\
23 \\
10\end{array}$ & $\begin{array}{l}48 \\
19 \\
19 \\
14\end{array}$ & $\begin{array}{l}56 \\
10 \\
22 \\
12\end{array}$ \\
\hline Decile rating & $\begin{array}{l}1-3 \text { (low) } \\
4-7 \text { (medium) } \\
8-10 \text { (high) }\end{array}$ & $\begin{array}{r}9 \\
36 \\
55\end{array}$ & $\begin{array}{r}9 \\
14 \\
76\end{array}$ & $\begin{array}{r}7 \\
35 \\
58\end{array}$ \\
\hline
\end{tabular}

Table 3.2 indicates that the sample of teachers who took part in the survey is fairly representative of the secondary teaching population, although there are some discrepancies. For example, nationally, $58 \%$ of secondary school teachers are female whereas $65 \%$ and $62 \%$ of participants in the survey and interviews, respectively, were female. The New Zealand Teacher Census (Ministry of Education, 2005) surveys 
teachers by age, not years of experience, and links between age and years of experience can only be approximations, as older teachers may have started teaching later in life. However, if age can be considered a proxy for experience, the survey participants reflect the national averages fairly closely, although a preponderance of younger teachers (i.e., with $2-10$ years' experience) took part in the interviews.

Ethnically, participants were distributed similarly to the national population with a large majority being New Zealand Pākehā $\bar{a}^{3}$. There was similarity in terms of types of schools except that $19 \%$ of both survey and interview participants worked in state single-sex schools, whereas these types of schools represent $10 \%$ of the national total.

In terms of students studying economics and accounting, 7\% are in low decile schools, $35 \%$ in medium decile schools and $58 \%$ in high decile schools (Education Counts, n.d). The survey participants reflect this distribution quite well, although proportionately more teachers from high decile schools agreed to be interviewed.

Although interviewees represented a range of experience, school type and location these were not completely reflective of the national population. As Katzer, Cook, and Crouch (1998) comment, "volunteers are different from those who do not volunteer" (p. 168) and one could speculate that teachers who are confident in their practice would be more willing to be interviewed than those who are not.

\footnotetext{
${ }^{3}$ Pākehā is a Māori language word for New Zealanders who are of European descent.
} 


\subsection{Data collection methods}

The following data sources were employed:

- $\quad$ self-report questionnaires.

- semi-structured interviews.

\subsubsection{Self-report questionnaires}

G.T.L. Brown's (2006) TCoAIIIA Inventory (Appendix 1) was used to investigate participants' conceptions of assessment. The TCoAIIIA Inventory elicits self-reported responses to 27 Likert-type items scored on a positively-packed, six point scale ( $1=$ strongly disagree, 2 = mostly disagree, 3 = slightly agree, $4=$ moderately agree, $5=$ mostly agree and $6=$ strongly agree . The items canvas agreement with a range of statements that align with four conceptions of assessment: assessment for improvement; assessment for student accountability; assessment for school accountability; and assessment as irrelevant (G.T.L. Brown, 2002).

G.T.L. Brown (2006) reported data validating the TCoAIIIA, an abridged form of G.T.L. Brown's (2004) 50-question Conceptions of Assessment-III. After studying data from 525 New Zealand and 692 Queensland primary teachers he concluded that the abridged version provides information of a similar quality to the long version, but is more efficient.

The TCoAIIIA has been used internationally as a research tool to examine teachers' conceptions of assessment, for example in New Zealand (G.T.L. Brown, 2011a; Harris \& Brown, 2009), Hong Kong (Brown et al., 2009), China (Brown et al., 2011), the United States (Calveric, 2010), Cyprus (Brown \& Michaelides, 2011), the Netherlands (Segers \& Tillema, 2011), Australia (Brown, Lake, \& Matters, 2012), Colombia (Muñoz, Palacio, \& Escobar, 2012), Iran (Pishghadam, \& Shayesteh, 2012), Spain (Brown \& Remesal, 2012), Egypt (Gebril \& Brown, 2014), and Indonesia (Aziz, 2014). 
In addition to the TCoAIIIA, the survey (Appendix 1) contained a number of questions eliciting demographic information, such as years of experience, gender, school decile, and the source and nature of the internal assessment tasks the teachers were using. The full survey was trialled with eight teachers who would not be participants in the study, and some adjustments were made to the layout and the wording of demographic questions based on feedback from this trial.

\subsubsection{Survey administration and quantitative data collection}

The survey comprised 51 questions and both paper and online versions were prepared. The online version used Qualtrics software and a forced-completion was used for the TCoAIIIA questions because the data would have been less valid if not all questions had been answered by all respondents. However, the demographic questions did not use a forced completion approach and $12 \%$ of participants chose not to answer these.

\subsubsection{Survey qualitative questions}

The survey contained a number of questions that invited a qualitative answer, for example, why teachers chose the methods and form of internal assessment tasks they use. These data were extracted from the quantitative data and coded separately.

\subsubsection{Semi-structured interviews}

Interviews were conducted to probe more deeply into the reasons that teachers make the decisions they do about their internal assessment tasks, the major influences on these decisions, whether they would prefer a different approach to internal assessment, and if so, why they do not enact this. The interviews also elicited how the participants defined and conceived of assessment in general. See Appendix 2 for the full generic interview schedule.

The interviews were face-to-face and semi-structured, so all participants answered the same or similar questions, but they also had opportunities to offer their own views and ideas. Semi-structured interviews allow the interviewer to go into more depth and resolve misunderstandings (Cohen, Manion, \& Morrison, 2007) and give the researcher some control over the interview (Creswell, 2003). Face-to-face interviews give the interviewer the opportunity to judge the quality of responses, to give visual prompts such as nods and smiles, and to clarify if a question does not seem to have 
been fully understood (Walliman, 2005). Open-ended questions were used because this type of question is flexible and can elicit unexpected answers, which may suggest relationships not previously considered by a researcher (Cohen et al., 2007). In terms of Patton's (2002) classification of types of interviews, the interviews most closely resembled the General Interview Guide Approach under which topics and issues are specified in advance but the interviewer decides on the sequence and wording of the questions as the interview proceeds.

All survey participants were invited to be interviewed and those who volunteered were contacted by email and asked to take part. If they agreed, they were sent further information about the project and the interview consent form. Subsequently, meeting times were arranged to fit with my travel arrangements and the interviewees' teaching commitments. All interviews were conducted face-to-face in the area in which the participants lived.

Participants were interviewed once, and with their permission all interviews were digitally recorded. These were subsequently transcribed verbatim, either by the researcher or by a professional transcriber, and returned to each interviewee for member checking. Member-checking allowed participants to correct, clarify or withdraw statements if they had changed their minds.

The general interview protocol included meeting and introducing myself, if necessary, or reacquainting ourselves. A number of the participants were known to me through economics and accounting teacher networks, or were former teaching colleagues. I thanked them for participating and agreeing to meet with me, reminded them of the general purpose and interest of my research, asked them to sign the consent form and then began with the open-ended questions. The duration of the interviews ranged between 45 and 90 minutes.

Interviews are not without limitations. According to Creswell (2003), interviews only provide "indirect information filtered through the views of the interviewees" (p. 187); the presence of the interviewer may bias responses and not all participants are equally articulate. Fontana and Frey (1994) warned of the impossibility of neutral interviewing, and my position as a former teaching colleague now undertaking a 
doctoral dissertation may have elicited answers designed to impress, rather than participants' actual views and practices. Successful interviewing requires a researcher to build a relationship with an interviewee. Having been a teacher of economics and accounting in the NCEA assessment environment, I was able to establish rapport which enabled empathetic interviewing (Mertens, 2005). In order to mitigate some limitations of interviews, I used semi-structured questions so that all participants were asked the same or similar questions and all interviews were recorded so that the discussion could be verified. I also let the interviewees do the talking. According to Bogdan \& Biklen (1998) a good interview is one that belongs mostly to the interviewee. The transcripts can verify this.

\subsubsection{Data collection timetable}

Quantitative data collection spanned most of 2013 with the qualitative interviews taking place between January and April, 2014. The data collection timetable is outlined in Table 3.3.

Table 3.3

Data collection timetable

\begin{tabular}{|c|c|}
\hline \multicolumn{2}{|l|}{2013} \\
\hline February & $\begin{array}{l}\text { Attended NZCETA meeti ngs to inf or mand generate int erest about the } \\
\text { project }\end{array}$ \\
\hline 26 March & Et hics approved \\
\hline June & $\begin{array}{l}\text { Appr oached NZCETA head office to assist in cont acting econo mi cs and } \\
\text { accounting teachers. }\end{array}$ \\
\hline $4^{\text {th }}$ July & $\begin{array}{l}\text { NZCETA e mi } 1 \text { ne ws letter to me nbers with inf or mation regar di ng the } \\
\text { research and a link to the survey. }\end{array}$ \\
\hline $19^{\text {th }}$ July & 19 responses to the survey \\
\hline $9^{\text {th }}$ August & Et hics approved to offer incenti ve to partici pate in the sur vey \\
\hline $15^{\text {th }}$ October & 57 responses \\
\hline $29^{\text {th }}$ October & $\begin{array}{l}\text { All Ne w Zealand secondary schools e mai led direct ly and asked for the } \\
\text { e mai l to be for war ded to the relevant teacher }\end{array}$ \\
\hline $29^{\text {th }}$ October & $\begin{array}{l}\text { Li nk to the survey sent out on Google list serves for econo mics and } \\
\text { accounti ng teachers by list serve owners }\end{array}$ \\
\hline $8^{\text {th }}$ November & 135 useable surveys \\
\hline \multicolumn{2}{|l|}{2014} \\
\hline $\begin{array}{l}27^{\text {th }} \text { January - } \\
\mathbf{1 0}^{\text {th }} \text { April }\end{array}$ & All intervieus were conducted \\
\hline
\end{tabular}




\subsection{Ethical considerations}

Ethics approval was obtained from the Victoria University of Wellington Faculty of Education Ethics Committee on $26^{\text {th }}$ March, 2013: ethics approval no. SEPI/2013/10 RM RM 19669 (Appendices 3 \& 4). All participants were recruited by invitation, and participation was voluntary. Survey participation was anonymous, unless the participant willingly shared contact details. The interviewees were not anonymous but were confidential, and informed consent was obtained. All participants were allocated a pseudonym to preserve confidentiality, and their schools have not been identified in this thesis. All opinions and data have been reported in an aggregated form and individuals are not identifiable. The data were stored on my passwordprotected computer, and transcribers signed a confidentiality agreement.

\subsection{Quantitative data analysis}

\subsubsection{Factor analysis}

Factor analysis is a statistical procedure for reducing the dimensionality of data and to investigate any apparent underlying constructs that manifest statistically as factors (Walkey \& Welch, 2010). The key concept of factor analysis is that observed variables associated with the same latent variable (factor) will be correlated with one another more highly than they are with other observed variables. If items are associated sufficiently with the same factor they may be presumed to be (valid) measures of the same latent variable. Therefore, factor analysis can be used to aid understanding of the structure of correlations among items (Fabrigar, Wegener, MacCallum, \& Strahan, 1999). Ultimately, factor analysis helps to develop and refine models and theories of behaviour (Walkey \& Welch, 2010).

\section{Confirmatory factor analysis}

Confirmatory factor analysis (CFA) is a method of assessing the adequacy of a theoretical model to explain a set of empirical data (Walkey \& Welch, 2010). As the data for this study were gathered using a questionnaire based on an a priori model (G.T.L. Brown, 2006), CFA was carried out using AMOS software to evaluate the fit of the data to this model. 
A variety of fit indices have been developed to determine how well a set of data fits a model. Kline (2010) recommended reporting the chi-squared test, the RMSEA (Root Mean Square of Error Approximation), the CFI (Comparative Fit Index), and the SRMR (Standardised Root Mean Square Residual).

\section{Chi square test}

Chi-square is used for evaluating overall model fit (Hooper, Coughlan, \& Mullen, 2008) and "assesses the magnitude of discrepancy between the sample and fitted covariances matrices" (Hu \& Bentler, 1999, p. 2). However, chi-square is sensitive to sample size and nearly always rejects models when sample sizes are large (Hooper et al.). Conversely, researchers may accept an inappropriate model if the sample size is small (Gatignon, 2014) and with only 135 respondents the chi-square test may not be reliable for the present data. To be acceptable, the chi-square value should indicate a non-significant difference between the observed data and those expected for the model. Tabachnick \& Fidell (2007) recommended the use of chi-square per degrees of freedom $\left(\chi^{2} / \mathrm{df}\right)$ to counteract the effect of sample size, and if the value is less than two, the data and the model are considered similar and the model a good fit (Walkey \& Welch, 2010).

\section{Root Mean Square of Error Approximation}

To remove the population sample effect, RMSEA can be used (Steiger \& Lind, 1980, as cited by Steiger, 1990). The RMSEA is an index of the discrepancy between the model and the data per degree of freedom for the model. The RMSEA is regarded as an informative fit index because of its sensitivity to the number of estimated parameters in the model (Hooper et al., 2008). According to Hooper et al., the cut-off points for RSMEA have fallen from a range of 0.05 to 0.10 being considered a fair fit to Steiger's (2007) recommendation of a stringent upper limit of 0.07. A smaller RMSEA indicates a better fit of the model to the data, and a RMSEA equal to zero would indicate that the target model fits the data perfectly. 


\section{Comparative Fit Index}

The CFI was introduced by Bentler (1990) and also takes sample size into account. It performs well with small samples (Hooper et al., 2008). The CFI compares the fit of a target model to the fit of an independent model (Bentler, 1990). Fan, Thompson, and Wang (1999) claimed it was the fit index least affected by sample size and again, opinion has varied on optimum cut-off, with Hu and Bentler (1999) regarding 0.95 as indicative of a good fit. A larger value of CFI indicates a better fit to the model.

\section{Standardised Root Mean Square Residual}

The SRMR is the square root of the difference between the residuals of the sample correlation matrix and the hypothesised correlation (Hooper et al., 2008). The discrepancy between the sample correlation and the model correlation indicates the degree of fit between the model and the data. Generally, an SRMR of less than 0.8 indicates a good fit of the model (Hu \& Bentler, 1999).

\section{Cut-off values}

Optimal cut-off values are debated in the literature with $\mathrm{Hu} \&$ Bentler's (1999) suggestions being called into question by Sivo, Fan, Witta, and Willse (2006). Sivo et al. concluded optimal cut-off values vary with sample size, for example, for RSMEA the optimal value for a small sample of 150 is 0.06 , but may decrease to 0.02 if sample size is greater than 2,500. Measurement indices are also reported in terms of "goodness of fit" and "badness of fit" with "goodness of fit" indices requiring high values preferably between 0.95 and 1.00 , whereas "badness of fit" indices require small values, generally between 0.00 and 0.10 . G.T.L. Brown (2011b) proposed a range of acceptable fit statistics, which is reproduced in Table 3.4, although as warned by Sivo et al., small sample sizes need to err on the side of caution in terms of deciding on model fit. 
Table 3.4

Range of Acceptable Fit Indices In CFA

\begin{tabular}{lcccc}
\hline & \multicolumn{2}{c}{ Goodness of Fit } & \multicolumn{2}{c}{ Badness of Fit } \\
\hline Decision & $\mathrm{p}$ of $\chi^{2} / \mathrm{df}$ & CFI & RMSEA & SRMR \\
Good & $>.05$ & $>.95$ & $<.05$ & $<.06$ \\
Accept able & $>.05$ & $>.90$ & $<.08$ & $<.08$ \\
Margi nal & $>.01$ & $.85-.89$ & $<.10$ & \\
Poor & $<.01$ & $<.85$ & $>.10$ & $>.08$ \\
\hline
\end{tabular}

Reproduced from G.T.L. Brown (2011b)

Sivo et al. (2006) recommended with a sample size of 150 , models with statistically non-significant $\chi^{2}$ per $d f$, an optimal value of around .06 for root mean square errors of approximation (RMSEA), 0.12 for standardised root mean residuals (SRMR) and .95 for the comparative fit index (CFI) be considered the optimal cut-off values.

\section{Exploratory factor analysis}

As will be discussed fully in Chapter 4, the confirmatory factor analysis did not meet the recommended criteria to conclude that the data fit G.T.L. Brown's (2006) model. Brown and Remesal (2012) suggested that if models are inadmissible or poorly fitting, the model can be modified or exploratory factor analysis (EFA) carried out to develop a new model. Fabrigar et al. (1999) claimed there are five methodological issues to be considered when carrying out EFA:

1. Which variables to include in the study and what is the nature of the sample?

2. Is EFA the most appropriate form of analysis?

3. Which fitting procedure will be used?

4. Which method of rotation will be chosen?

5. How many factors should be extracted? 


\section{Variables included and nature of the sample}

There are some guidelines with regard to adequate sample size. Gorsuch (1983) recommended at least five participants per measured variable and not less than 100 overall while Comfrey and Lee (1992) suggested a sample of 300 was good, 1,000 as excellent and 100 as poor. However, there are limitations to sample size guidelines, Fabrigar et al. (1999) claimed sample size is not a function of the measured variables per se and that overly homogenous samples should be avoided. Thus, by these criteria, EFA is appropriate. At $n=135$, the present sample size is just adequate by Gorsuch's criterion; there were exactly five participants per survey item and more than the absolute minimum of 100 participants.

\section{Conditions for EFA}

The Kaiser-Meyer-Olkin (KMO) measure of sample adequacy can be calculated and values closest to one are desirable. Hutcheson (1999) suggested that a KMO over 0.60 is acceptable. A further measure to determine if there are correlations between the variables is Bartlett's test of sphericity, which indicates "whether the correlation matrix is significantly different from an identity matrix" (Field, 2013, p. 685). If the Sig. value for this analysis is less than 0.05 then the null hypothesis can be rejected and we can conclude there are correlations in the data that are appropriate for factor analysis.

The data in this study have a Kaiser-Meyer-Olkin (KMO) of 0.823 and Bartlett's test of sphericity ( $\mathrm{Sig}<0.001)$, and so EFA was considered an appropriate type of analysis.

\section{Fitting procedure}

A number of model-fitting methods are available in EFA, but two of the most commonly used approaches are Maximum Likelihood and Principal Axis Factoring (Yong \& Pearce, 2013). Osborne, Costello, and Kellow (2008) recommended either of these two methods would give the optimal results. Maximum likelihood estimation was used for the data in this thesis. 


\section{Method of rotation}

Factors are often rotated to remove ambiguity and to simplify the structure. Rotation can be orthogonal or oblique (Yong \& Pearce, 2013). Orthogonal rotation constrains the factors to being uncorrelated, while oblique rotation allows for the factors to be correlated and for the axes to rotate freely "rather than being fixed at right angles to each other" (Walkey \& Welch, 2010, p. 81). Osborne et al. (2008) recommended using an oblique rotation in social research because we can expect some correlation among factors, and according to Walkey and Welch, oblique rotation may provide a better solution and "a better representation of the factor structure" (p. 81). Field (2013) also recommended oblique rotation when theory suggests that the constructs relating to the factors might correlate and Osborne et al. suggested an orthogonal rotation might result in lost information if the factors are really correlated and suggested an oblique rotation should "render a more accurate and perhaps more reproducible solution" (p. 90).

An oblique rotation was chosen for the data in this research because G.T.L. Brown's (2006) model had already established correlations among the variables and factors. Within oblique rotation there are three methods of rotation (direct oblimin, quartimin and promax), although according to Fabrigar et al. (1999), all three tend to produce similar results. Yong and Pearce (2013) suggested that Promax may result in greater correlations, therefore Promax was chosen as the method of rotation for the data.

\section{Extracting the factors}

Researchers must decide how many factors to extract as not all possible factors are typically retained (Field, 2013), and in choosing the number of factors they must balance parsimony with plausibility (Fabrigar et al., 1999). There are a number of procedures that can be used when deciding on the number of factors to retain. Three commonly used are the Kaiser criterion of retaining all factors with an eigen value greater than one, the scree test where the scree plot is examined to determine the point of inflexion and where the slope of the line changes the number of factors above this point are retained (Field, 2013), and parallel analysis which is a method based on the generation of random variables, to determine the number of factors to retain (Ledesma \& Velero-Mora, 2007). According to Zwick and Velicer (1986), parallel analysis is 
the most appropriate method for deciding the number of factors to retain, so this was carried out using O’Connor's (2000) syntax.

\section{Summary of EFA}

An initial EFA using Maximum Likelihood Estimation with an Oblique Rotation (Promax) using parallel analysis and the Scree plot was carried out on the 27 items. This was followed up with further EFA reducing and fixing the number of factors, and subsequent analyses involved removing items to establish an acceptable model.

\subsection{Qualitative data analysis}

Qualitative data analysis is the systematic arrangement of interview transcripts and field notes; it involves organising and synthesising data to search for patterns (Bogdan $\&$ Biklen, 1998). Sorting the data into patterns involves developing a coding system which includes clustering like items together. Codes are labels or categories to which units of data are assigned and units can consist of single words, phrases, sentences or whole paragraphs (Miles \& Huberman, 1994). Codes can be either deductive, those previously developed, or inductive where codes are generated by the data (Teddlie \& Tashakkori, 2009). Inductive coding requires the use of a constant comparative method (Glaser \& Straus, 1967) which requires the comparison of data to be assigned a code with those already in the code, distinguishing differences between codes and integration of codes (Zhang \& Wildemuth, 2009).

Thematic analysis of qualitative data involves examining the codes for broader patterns of meaning and collating data to each potential theme (Braun \& Clarke, 2006). Themes need to be checked against the data set to ensure they answer the research questions, and then named and defined (Braun \& Clarke). 
Miles and Huberman (1994) suggested the following framework for analysing qualitative data:

- data reduction: simplifying and transforming the data into transcriptions which includes summarising and paraphrasing;

- data display: organising and compressing the data into matrices, charts, networks;

- drawing and verifying conclusions: deciding what the data means, noting patterns, explanations, propositions.

\subsubsection{Data Reduction}

The audio files of the interviews were transcribed into Word documents before being uploaded into NVivo 10. The initial coding process involved identifying ideas (made up of words, phrases and sentences) from interview transcripts and grouping like ideas together. These groupings of like ideas were paraphrased with codes and rechecked several times to ensure agreement with the initial codes, and that there was consistency when asked "what is this piece of data an example of"? Initial codes were analysed for underlying meaning and after several iterations five themes emerged to which data could be collated.

\subsubsection{Data display}

Data displays help to organise, compress and assemble information (Punch, 2005), therefore matrices and diagrams were used. Five themes were developed from the data and summarised in a diagrammatical overview.

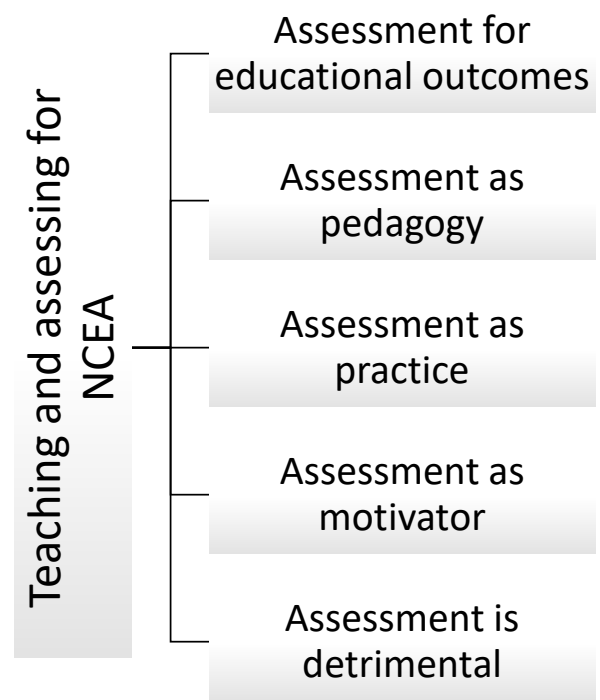

Figure 3.1. Overview of themes derived from qualitative data 
Each theme was then explained and compressed in a matrix. Figure 3.2 illustrates part of the matrix for the theme "Assessment as pedagogy". The left-hand side of the matrix is the theme with a description of the theme, while the right-hand side describes the data units assigned to that theme.

\section{Assessment as pedagogy}

Thi s the me includes all comments that relat e to assess ment being, or is, part of the teaching and learni ng process.
- Assess ment infor ms st udent learning

- Assess ment infor ms my teaching

- Int ernal assess ment can be integrated with teaching, but this can be proble matic

- I distingui sh bet ween assess ment in the juni or and seni or school

Figure 3.2. Example from matrix of themes and some codes contributing to that theme

\subsubsection{Drawing and verifying conclusions}

The development of five themes was an iterative process, carried out in conjunction with supervisors and tested with colleagues. Initial coding resulted in eight overarching codes with 21 sub-codes. For example, two initial codes were Course Design and Internal Assessment, but subsequent analysis of the data began to suggest that many teacher actions with regard to assessment and courses involved strategising to ensure student success and preparation for their next step - either educational or workforce. Therefore, the theme "Assessment for educational outcomes" was developed from these ideas.

Researchers can also develop typologies to help make sense of the data (Johnson \& Christensen, 2014). Analysis of the qualitative data suggested participants' beliefs and actions towards internal assessment for NCEA could be conceptualised along a continuum of maximising NCEA internal assessments for the benefit of students' achievement to treating internal assessment as an extension of the external examinations. There seemed to be three dimensions to these actions and beliefs - the conditions under which internal assessment was conducted, the types of assessment tasks teachers asked students to complete, and an overall attitude towards internal assessment. These typologies are summarised in a matrix. 


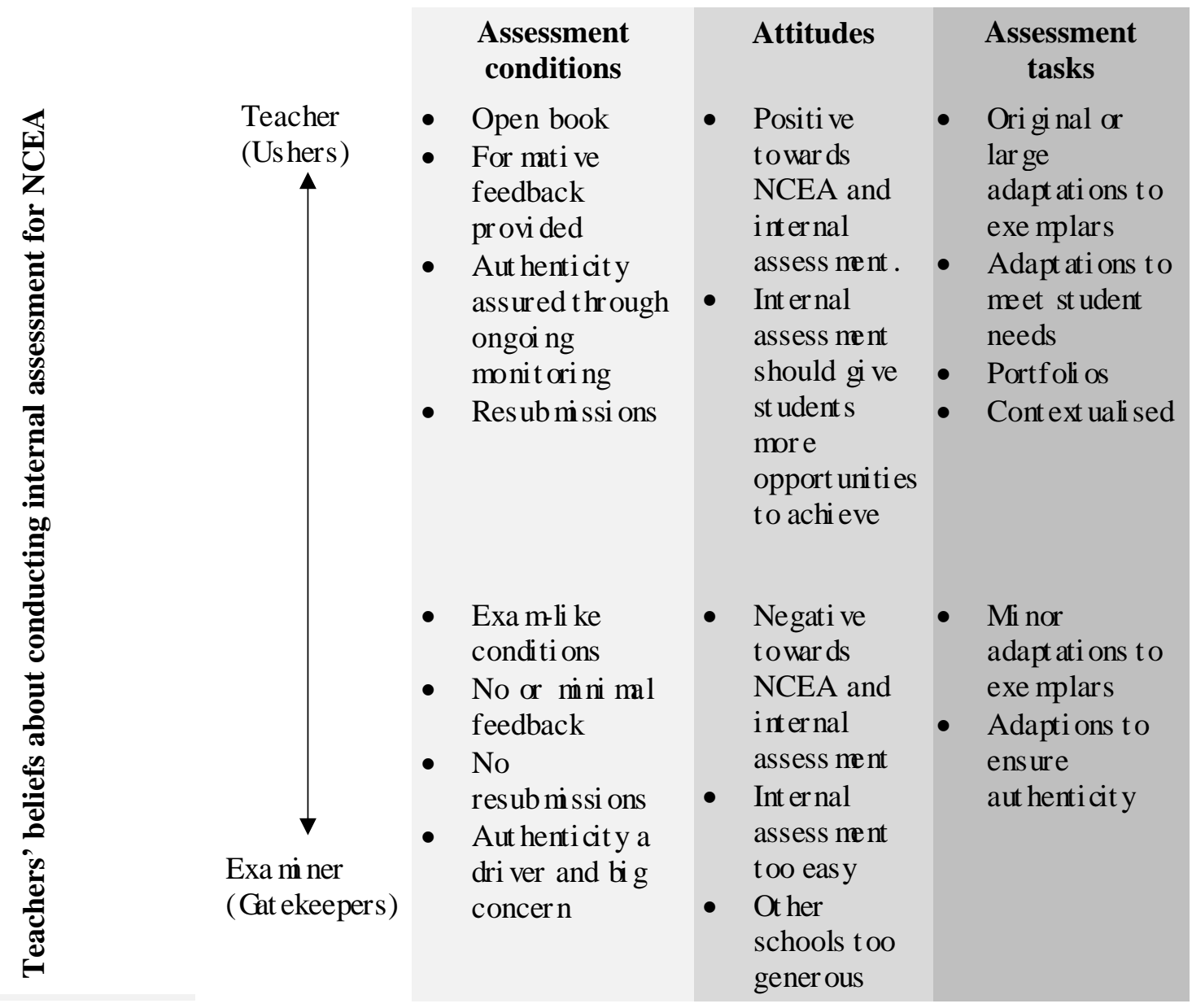

Figure 3.3. Typology of teachers' beliefs and actions towards NCEA internal assessment

\subsection{Validity and reliability in a mixed methods design}

\subsubsection{Validity and reliability in quantitative data}

In quantitative research, the concepts of validity and reliability are used as quality measures. Validity refers to the extent to which an instrument measures what it is intended to measure (Muijs, 2011). Abstract concepts such as conceptions of assessment cannot be directly measured, so an instrument to gather data associated with the concept is needed. A validated instrument, G.T.L. Brown's (2006) TCoAIIIA Inventory, was chosen to measure conceptions of assessment.

The reliability of an instrument refers to the consistency or stability of data measured using that instrument (Johnson \& Christensen, 2014). Reliability can be calculated using a coefficient, such as Cronbach's alpha, which is an estimate of the overall reliability of a questionnaire. Cronbach's alpha estimates the degree to which items 
are interrelated. A general 'rule of thumb' for reliability is that the coefficient alpha should be greater than 0.7 (Johnson \& Christensen). Cronbach's alpha was calculated for each factor identified in the exploratory factor analysis.

\subsubsection{Validity and reliability in qualitative data}

Lincoln and Guba (1985) suggested that for qualitative data trustworthiness replaces validity and suggested four criteria to ensure this: credibility, transferability, dependability and conformability. They suggested a number of strategies to ensure credibility, which include prolonged engagement, persistent observation, triangulation, peer debriefing, negative case analysis, referential adequacy, and member checking. In this study, the strategies of prolonged engagement, triangulation, peer debriefing, negative case analysis, and member-checking were used.

Prolonged engagement can refer to speaking with a range of people (Lincoln \& Guba, 1985) and was achieved through interviewing 21 participants from a wide variety of settings. Triangulation is the use of more than one data source. In this research, interview participants also completed the questionnaire, enabling comparisons between the two data sources. Peer debriefing is the process of discussing findings with peers to uncover biases, assumptions, and perspectives (Lincoln \& Guba) and this was carried out with my supervisors and colleagues who were formerly teachers in the NCEA assessment regime. Negative case analysis is discussing elements of the data that do not support general patterns and again this was carried out with my supervisors. Member checking involves inviting participants to comment on transcriptions and interpretations, to ensure that these were conveyed accurately, so all transcripts were returned to participants for checking and all agreed with their original comments.

Lincoln and Guba (1985) define transferability as showing that the findings have applicability elsewhere and claimed that this can be gained by describing the phenomena in sufficient detail for readers to determine whether the findings are transferable to other settings. Dependability determines whether the findings and conclusions are supported by the data and involves having another researcher examine the process and the product of the study which in this case was done by supervisors. 
Confirmability refers to the extent to which the findings are shaped by the participants and not researcher bias. Lincoln and Guba claim this can be achieved through audit, triangulation, or reflexivity. This study was audited by my supervisors and triangulated through mixed methods.

\subsubsection{The inference process}

Quantitative and qualitative approaches have their own criteria for evaluation, and Creswell (2012) stated that researchers must be mindful of these at all stages of the study. However, Heyvaert, Hannes, Maes, and Onghena (2013) argue that merely attending to the criteria for each strand is not enough "because an MM study is more than simply the sum of its qualitative and quantitative elements" (p. 316). Therefore, attention must be paid to the overarching analysis as the strands in mixed methods research do not just answer strand-specific questions; each should contribute to overall research questions.

According to Teddlie and Tashakkori (2009), "the main reason for using a mixed methods approach is to provide better understanding of the phenomenon under investigation" (p. 286). However, as they say, enhanced understanding is only possible if the outcomes, that is the conclusions and interpretations, of both strands (quantitative and qualitative) are effectively integrated. Teddlie and Tashakkori refer to these outcomes of research as inferences where inferences denote a process and an outcome. They describe three related concepts:

- the inference process - making sense of the results of data analysis;

- inference quality - the standards for evaluating the quality of conclusions. In quantitative terms internal validity and in qualitative terms credibility and trustworthiness;

- inference transferability - the degree to which conclusions may be applied to other settings (generalisability and transferability). 
Teddlie and Tashakkori (2009) provided some guidelines to make inferences that are credible and comprehensive. These include getting to know the participants, having a deep understanding of the literature, analysing data with the explicit intention of answering research questions, using respective quality criteria for the quantitative and qualitative strands, and integrating inferences from each strand into a credible metainference.

In 2010, O'Cathain, Murphy, and Nicoll provided a framework to assess the quality of mixed methods approaches in medical research, but their techniques also have relevance to educational research. The three techniques they suggested are using a triangulation protocol, following a thread, and a mixed methods matrix. To carry out the process of triangulation they suggest creating a matrix of findings from each part of the study and comparing for convergence, complementary information, and discrepancies. Following a thread refers to researchers selecting a theme from one component and following it across the other; however, this method tends to be more relevant when interviews are used to generate a hypothesis which is then tested in surveys. They also suggested that a mixed methods matrix can be used to compare data from both sources for the same participants, focusing on cases rather than themes.

Ivankova (2014) added to the discussion on quality assurance in mixed methods by specifically dealing with a sequential QUAN $\rightarrow$ QUAL design and provided a threestep process for securing quality of the meta-inferences. These are: a systematic process for selecting participants for the QUAL part of the study; elaborating on unexpected QUAN results; and observing the interaction between the two strands of the study. Creswell (2012) informed researchers using mixed methods that they must interpret their combined results, and for an explanatory sequential design that a display linking qualitative themes with quantitative results can be used.

To observe interaction between the qualitative and quantitative strands a matrix to display convergence and complements was constructed. 


\begin{tabular}{|c|c|c|}
\hline Quantitative factors & $\begin{array}{l}\text { Overarching } \\
\text { conceptions }\end{array}$ & Qualitative themes \\
\hline & $\begin{array}{l}\text { Assessment is for } \\
\text { learning }\end{array}$ & \\
\hline $\begin{array}{l}\text { Assessment for } \\
\text { improvement }\end{array}$ & $\begin{array}{c}\text { Assess ment for } \\
\text { i mprove ment } \\
\text { Assess ment as pedagogy } \\
\text { Assess ment as moti vat or }\end{array}$ & $\begin{array}{l}\text { Assessment as pedagogy } \\
\text { Assessment as a motivator }\end{array}$ \\
\hline $\begin{array}{l}\text { Assessment describes } \\
\text { learning }\end{array}$ & $\begin{array}{l}\text { Assessment is for } \\
\text { qualifications } \\
\text { Assess nent for } \\
\text { educati onal out co mes } \\
\text { Assess ment descri bes } \\
\text { lear ni ng }\end{array}$ & $\begin{array}{l}\text { Assessment for educational } \\
\text { outcomes }\end{array}$ \\
\hline Assessment has weaknesses & $\begin{array}{l}\text { Assessment is } \\
\text { detrimental } \\
\text { Assess ment has } \\
\text { weaknesses } \\
\text { Assess ment as } \\
\text { detri ment al }\end{array}$ & Assessment is detrimental \\
\hline $\begin{array}{l}\text { Assessment for school } \\
\text { accountability }\end{array}$ & $\begin{array}{l}\text { Assessment is for } \\
\text { accountability } \\
\text { Assess ment as practice } \\
\text { Assess ment for school } \\
\text { account abi lity }\end{array}$ & Assessment as practice \\
\hline
\end{tabular}

Figure 3.4. Convergence and complements among quantitative factors and qualitative themes 


\section{CHAPTER 4}

\section{Quantitative Findings}

“All models are wrong, but some are useful" (George Box, 1987, p. 424).

\subsection{Confirmatory analysis}

Confirmatory factor analysis was carried out to evaluate the fit of the data to G.T.L. Brown's (2006) model, but the analyses showed an inadmissable fit. Table 4.1 shows the fit indices for the data in this reseach. While the chi-squared-per-degrees-offreedom and RMSEA statistics show acceptable fit, the other fit statistics suggest rejecting the model. Chi-square per degrees of freedom was 1.729 and the RMSEA was 0.074. However, with the CFI at .83 and SRMR at .0848 the data collected for this research are considered a marginal-to-poor fit to G.T.L. Brown's model.

Table 4.1

Fit Indices for 135 Secondary Teachers of Accounting and Economics

\begin{tabular}{llllll}
\hline \multicolumn{2}{c}{ Model } & \multicolumn{4}{c}{ Fit statistics } \\
\hline$n$ & Group & $\chi^{2} / \mathrm{df}$ & CFI & RMSEA & SRMR \\
135 & Secondary teachers of & $537.674 / 311$ & 0.835 & 0.074 & .0848 \\
& $\begin{array}{l}\text { accounti ng and econo mics } \\
\text { r c } 1.729\end{array}$ & & & \\
& $p$ of $\chi^{2} / \mathrm{df}=.19$ & & & \\
\hline
\end{tabular}

In addition to examining fit statistics, Bowen and Guo (2011) recommend that researchers should also examine factor loadings for strength of loading. They did note that acceptable loadings are not as clearly defined as those for EFA, but suggesed rejecting loadings below one of the common EFA cut-offs, for example those below 0.4, a figure with which Bandalos and Finney (2010) agreed. Figure 4.1 illustrates factor loadings from the CFA. 


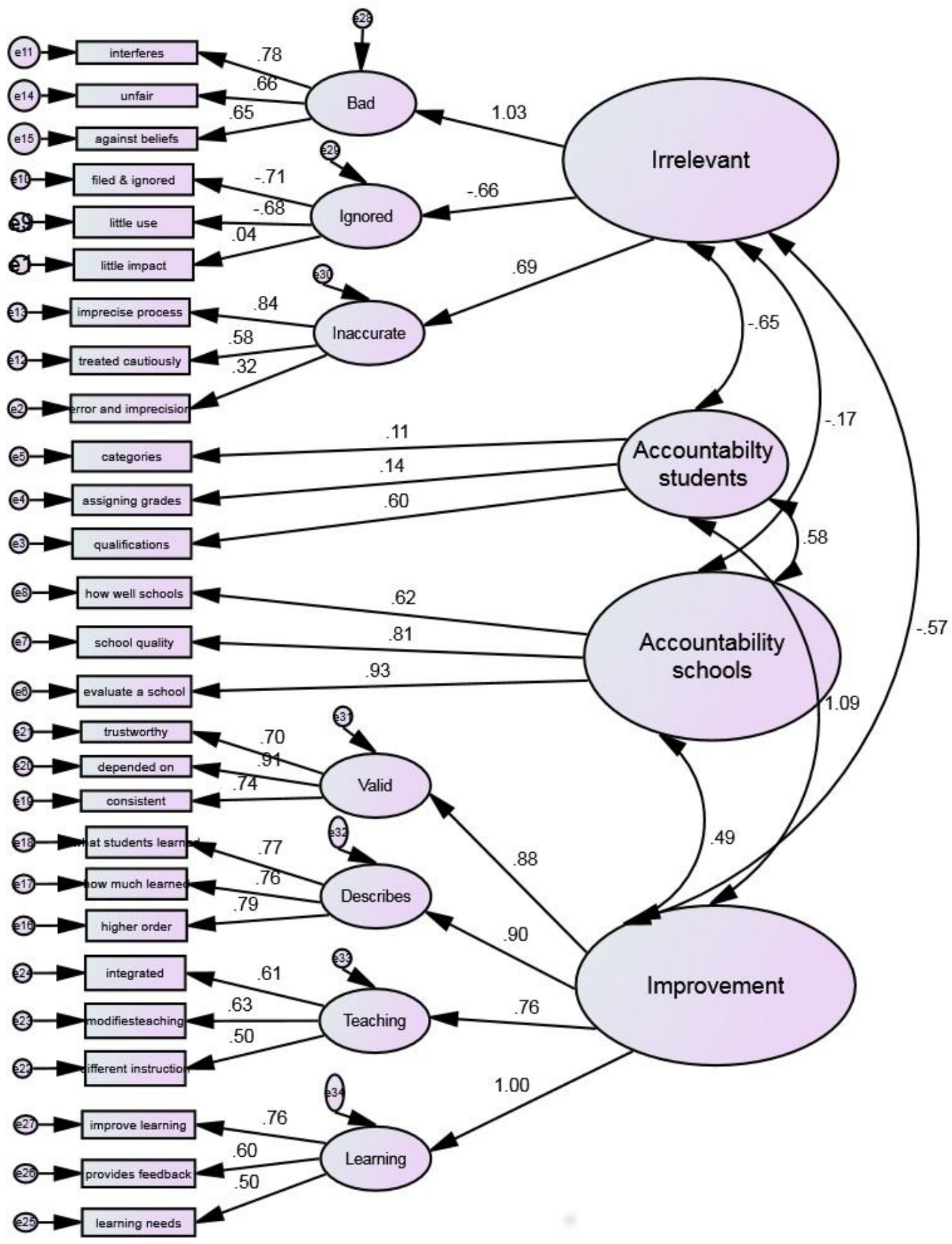

Figure 4.1. Measurement model of 135 economics and accounting teachers' conceptions of assessment 


\subsubsection{Strength of the present data loadings to factors}

While many loadings are above the acceptable weighting, some are below and others are greater than one. According to T.A. Brown (2006), the presence of such out-ofrange values, or Heywood cases, indicates that the model is not acceptable. However, Joreskog (1999) argued that with an oblique rotation the factor loadings are regression coefficients and not correlations "and as such can be greater than one in magnitude" (p. 1) and do not necessarily mean something is wrong. Bentler and Chou (1987) pointed out that such estimation errors are more likely with small samples.

\section{Assessment improves education second order factor}

Table 4.2 shows the first order factors that in G.T.L. Brown's (2006) model were associated with the assessment improves education second order factor.

Table 4.2

Items relating to first order factors which contribute to second order factor of "assessment improves education"

\begin{tabular}{|c|c|c|c|}
\hline $\begin{array}{l}\text { First order } \\
\text { factors }\end{array}$ & & Items loading to the factor & $\begin{array}{c}\text { Strength } \\
\text { of loading } \\
\text { to factor }\end{array}$ \\
\hline \multirow{3}{*}{$\begin{array}{l}\text { Assessment } \\
\text { is valid }\end{array}$} & Question 6 & Assessment results are trustworthy & .70 \\
\hline & Question 24 & Assessment results can be depended on & .91 \\
\hline & Question 15 & Assessment results are consistent & .74 \\
\hline \multirow{3}{*}{$\begin{array}{l}\text { Assessment } \\
\text { describes } \\
\text { abilities }\end{array}$} & Question 12 & $\begin{array}{l}\text { Assessment establishes what students have } \\
\text { learned }\end{array}$ & .77 \\
\hline & Question 3 & $\begin{array}{l}\text { Assessment is a way to determine how much } \\
\text { students have learned from teaching }\end{array}$ & .76 \\
\hline & Question 21 & $\begin{array}{l}\text { Assessment measures students' higher order } \\
\text { thinking skills }\end{array}$ & .79 \\
\hline \multirow{3}{*}{$\begin{array}{l}\text { Assessment } \\
\text { improves } \\
\text { teaching }\end{array}$} & Question 5 & Assessment is integrated with teaching practice & .61 \\
\hline & Question 14 & $\begin{array}{l}\text { Assessment information modifies ongoing } \\
\text { teaching of students }\end{array}$ & .63 \\
\hline & Question 23 & $\begin{array}{l}\text { Assessment allows different students to get } \\
\text { different instruction }\end{array}$ & .50 \\
\hline \multirow{3}{*}{$\begin{array}{l}\text { Assessment } \\
\text { improves } \\
\text { learning }\end{array}$} & Question 22 & $\begin{array}{l}\text { Assessment helps students improve their } \\
\text { learning }\end{array}$ & .76 \\
\hline & Question 4 & $\begin{array}{l}\text { Assessment provides feedback to students } \\
\text { about their performance }\end{array}$ & .60 \\
\hline & Question 13 & $\begin{array}{l}\text { Assessment feeds back to students their } \\
\text { learning needs }\end{array}$ & .50 \\
\hline
\end{tabular}


All items are moderately to strongly associated with their first order factors. There are also strong correlations between most of the first and second order factors. However, the correlation between the first order factor assessment improves learning and the second order factor assessment improves education is problematic at 1.0 (see Figure 4.1); Fabrigar et al. (1999) warned that this indicates issues with the data and the model fit.

\section{Assessment makes schools accountable first order factor}

In G.T.L. Brown's (2006) model, three items contribute to the first order factor of assessment makes schools accountable, shown on Table 4.3.

Table 4.3

Items relating to first order factor of "Assessment Makes Schools Accountable"

\begin{tabular}{lllr}
\hline $\begin{array}{l}\text { First order } \\
\text { factor }\end{array}$ & Items loading to the factor & \multicolumn{1}{c}{$\begin{array}{c}\text { Strength } \\
\text { of loading } \\
\text { to factor }\end{array}$} \\
\hline $\begin{array}{l}\text { Assessment } \\
\text { makes schools } \\
\text { accountable }\end{array}$ & Question 1 & $\begin{array}{l}\text { Assessment provides information on } \\
\text { how well schools are doing }\end{array}$ & .62 \\
& Question 10 & $\begin{array}{l}\text { Assessment is an accurate indicator of a } \\
\text { school's quality }\end{array}$ & .81 \\
& Question 19 & $\begin{array}{l}\text { Assessment is a good way to evaluate a } \\
\text { school }\end{array}$ & .93 \\
\hline
\end{tabular}

The present data show that the items load moderately to strongly to this factor at .62 , .81 and .93 respectively.

\section{Assessment makes students accountable first order factor}

According to G.T.L. Brown's (2006) model, three items contribute to the first order factor of assessment makes students accountable, shown on Table 4.4. 
Table 4.4

Items relating to first order factor of "Assessment Makes Students Accountable"

\begin{tabular}{lllr}
\hline First order factor & & Items loading to the factor & \multicolumn{1}{c}{$\begin{array}{l}\text { Strength } \\
\text { of } \\
\text { loading } \\
\text { to factor }\end{array}$} \\
\hline Assessment makes & Question 2 & Assessment places students in categories & .11 \\
students & Question 11 & $\begin{array}{l}\text { Assessment is assigning a grade or level } \\
\text { to students }\end{array}$ & .14 \\
accountable & Question 20 & $\begin{array}{l}\text { Assessment determines if students meet } \\
\text { qualifications standards }\end{array}$ & .60 \\
& & & \\
\hline
\end{tabular}

The data show items 2 and 11 are loading weakly to the student accountability factor at .11 and .14 (respectively), while item 20 loads strongly at .60.

\section{Assessment is irrelevant second order factor}

G.T.L. Brown's (2006) second order factor of assessment is irrelevant consists of three first order factors: assessment is bad; assessment is ignored; assessment is inaccurate. The items contributing to each of the first order factors are in Table 4.5.

Table 4.5

Items relating to first order factors which contribute to second order factor of "Assessment is Irrelevant"

\begin{tabular}{|c|c|c|c|}
\hline $\begin{array}{l}\text { First order } \\
\text { factors }\end{array}$ & & Items loading to the factor & $\begin{array}{l}\text { Strength of } \\
\text { loading to } \\
\text { factor }\end{array}$ \\
\hline \multirow[t]{3}{*}{ Assessment is bad } & Question 25 & Assessment interferes with teaching & .78 \\
\hline & Question 16 & Assessment is unfair to students & .66 \\
\hline & Question 7 & $\begin{array}{l}\text { Assessment forces teachers to teach in a } \\
\text { way that is against their beliefs }\end{array}$ & .65 \\
\hline \multirow{3}{*}{$\begin{array}{l}\text { Assessment is } \\
\text { ignored }\end{array}$} & Question 17 & Assessment results are filed \& ignored & .71 \\
\hline & $\begin{array}{l}\text { Question } 8 \\
\text { little }\end{array}$ & $\begin{array}{l}\text { Teachers conduct assessments but make } \\
\text { use of the results }\end{array}$ & -.68 \\
\hline & Question 26 & Assessment has little impact on teaching & .04 \\
\hline \multirow{3}{*}{$\begin{array}{l}\text { Assessment is } \\
\text { inaccurate }\end{array}$} & Question 27 & Assessment is an imprecise process & .84 \\
\hline & Question 9 & $\begin{array}{l}\text { Assessment results should be treated } \\
\text { cautiously because of measurement error }\end{array}$ & .58 \\
\hline & Question 18 & $\begin{array}{l}\text { Teachers should take into account the error } \\
\text { and imprecision in all assessment }\end{array}$ & .32 \\
\hline
\end{tabular}


The data show that the first three items relating to the assessment is bad factor load moderately to that factor, at .78, .66 and .65. Item 26, assessment had little impact on teaching, loaded weakly to the assessment is ignored factor. One item (27) loaded well to the assessment is innaccurate factor at .84, but item 9 had a moderate loading at .58 , while item 18 loaded below the recommended level at 32 .

\section{Loading between first and second order factors}

The first order factor of assessment is ignored correlated inversely with the second order factor assessment is irrelevant, whereas in G. T. L. Brown (2006) this was a positive correlation. Also the out-of-range (Heywood) loading between the first order factor of assessment is bad and the second order factor of assessment is irrelevant is problematic; it might indicate a mis-specified model or that "the data violate the assumptions of the common factor model" (Fabrigar et al., 1999, p. 276).

\subsection{Acceptability of G.T.L. Brown's (2006) model}

Overall, the fit statistics indicate that the original model of G.T.L. Brown (2006) should be rejected, but on closer examination of the CFA model (Figure 4.1) some aspects of the original model have been reproduced. Furthermore, inter-correlations among the factors have similarities with G.T.L. Brown's model that showed: the student and school accountability factors were positively correlated; the improvement factor was positively correlated with school and student accountability factors; and the irrelevant factor inversely correlated to the improvement factor but had a statistically insignificant correlation with the school accountability factor.

G.T.L. Brown (2011a) reported a study that included New Zealand secondary teachers and which showed similar inter-correlations with his previous work undertaken solely with primary teachers. In both G.T.L. Brown's (2011a) research and the present study, the improvement factor correlated positively with school and student accountability, but inversely with the irrelevant conception. School and student accountability were positively correlated, and irrelevance and school accountability inversely correlated. It should be noted, however, for the present data, the correlation between improvement and student accountability is greater than one and therefore problematic. 
An important difference from G.T.L. Brown's (2011a) research is the inverse correlation between the irrelevant factor and the student accountability factor. G.T.L. Brown (2011a) explained the positive correlation between these two factors as showing that "the more teachers agreed that assessment was irrelevant, the more they saw it as a means of grading students summatively" (p. 113). He argued that for primary teachers, making students accountable was linked to irrelevance. However, for secondary teachers assessing students for summative accountability is not an irrelevant use of assessment because it has consequences for students' attainment of qualifications, a contextual factor of secondary but not primary education. This may explain the inverse correlation in the present data. Table 4.6, conceptions of assessment inter-correlations: New Zealand primary and secondary teachers (G.T.L. Brown, 2011a) compared with conceptions of assessment inter-correlations: economics and accounting teachers, shows the similarities and differences to G.T.L. Brown's model.

Table 4.6

Conceptions of assessment inter-correlations: New Zealand primary and secondary teachers (G.T.L. Brown, 2011a) compared with economics and accounting teachers

\begin{tabular}{lllllllll}
\hline & \multicolumn{3}{c}{ G.T.L. Brown's model } & \multicolumn{4}{c}{ Present data } \\
\hline Conceptions & 1 & 2 & 3 & 4 & 1 & 2 & 3 & 4 \\
1. Improve ment & - & -.74 & .47 & .23 & - & -.57 & .49 & 1.09 \\
2. Irrelevance & & - & -.14 & .30 & & - & -.17 & -.65 \\
3. School Account abi lity & & & - & .45 & & - & .58 \\
4. St udent Account abi lity & & & & - & & & & - \\
\hline
\end{tabular}

The relatively small sample size of 135 might also be part of the explanation for the data not fitting models previously reported by G.T.L. Brown (2006, 2011a). However, the group of participants in this study is distinctive in that their main, sometimes sole, focus is teaching specific subjects in the senior secondary school and awarding NCEA qualifications. Therefore, it is also possible that their conceptions of assessment differ from participants in previous studies. 


\subsection{Exploratory factor analysis}

Because of the poor fit of the data with G.T.L. Brown's (2006) model, EFA was carried out to attempt to find a better fitting model. An initial analysis using Maximum Likelihood Estimation with an Oblique Rotation (Promax) was carried out on the 27 items. An oblique rotation was used because this type of rotation allows for correlation among the factors and, as Osborne et al. (2008) stated, we can expect correlation among factors in the social sciences. The KMO index at 0.823 and Bartlett's test of sphericity $(\operatorname{Sig}=0.000)$ verified that the sample was adequate for EFA. The initial analysis identified eight factors with Eigen-values greater than one, whereas the point of inflexion on the Scree plot suggested four factors be retained, as did the parallel analysis using O'Connor's (2000) syntax.

\subsubsection{Four factor analysis}

The Factor Matrix (Appendix 5) for a four factor solution showed four items not loading to any factor (Item 2 - assessment places students in categories, Item 11 assessment is assigning a grade, Item 18 - teachers should take into account error and imprecision in all assessment, and Item 26 - assessment has little impact on teaching). The anti-image correlation matrix (Appendix 6) showed two variables (Items $18 \& 26$ ) having values less than 0.5 . The diagonal of the anti-image correlation matrix shows the KMO values for each individual variable, and Field (2013) recommended that all values in the anti-image correlation matrix should be above a bare minimum of 0.5 . The Pattern Matrix, Table 4.7, shows three items with cross-loadings, but all four factors have at least three items. 
Table 4.7

Pattern matrix extracted using Maximum Likelihood Estimation with an Oblique rotation (Promax) with a four-factor solution

\begin{tabular}{|c|c|c|c|c|}
\hline & & & & \\
\hline & 1 & 2 & 3 & 4 \\
\hline $\begin{array}{l}\text { Assessment is a way to determine how much students have } \\
\text { learned from teaching }\end{array}$ & .841 & & & \\
\hline $\begin{array}{l}\text { Assessment determines if students meet qualifications } \\
\text { standards }\end{array}$ & .763 & & & \\
\hline Assessment results can be depended on & .753 & & & \\
\hline Assessment helps students improve their learning & .710 & & & \\
\hline Assessment establishes what students have learned & .709 & & & \\
\hline Assessment results are trustworthy & .686 & & & \\
\hline Assessment measures students' higher order thinking skills & .665 & & & \\
\hline Assessment results are consistent & .581 & & & \\
\hline Assessment is unfair to students & -.534 & .321 & & \\
\hline Assessment results are filed $\&$ ignored & -.449 & & & \\
\hline $\begin{array}{l}\text { Assessment allows different students to get different } \\
\text { instruction }\end{array}$ & .433 & & & \\
\hline Assessment is integrated with teaching practice & .327 & & & .323 \\
\hline Assessment is an imprecise process & & .743 & & \\
\hline Assessment forces teachers to teach in a way against their beliet & & .730 & & \\
\hline $\begin{array}{l}\text { Assessment results should be treated cautiously because of } \\
\text { measurement error }\end{array}$ & & .636 & & \\
\hline Assessment interferes with teaching & & .627 & & \\
\hline $\begin{array}{l}\text { Teachers conduct assessments but make little use of the } \\
\text { results }\end{array}$ & & .486 & & \\
\hline Assessment is a good way to evaluate a school & & & .897 & \\
\hline Assessment is an accurate indicator of a school's quality & & & .823 & \\
\hline Assessment provides information on how well schools are doing & & & .478 & \\
\hline Assessment places students into categories & & & & \\
\hline Assessment information modifies ongoing teaching of students & & & & .769 \\
\hline $\begin{array}{l}\text { Assessment provides feedback to students about their } \\
\text { performance }\end{array}$ & .417 & & & .477 \\
\hline Assessment feeds back to students their learning needs & & & & .396 \\
\hline $\begin{array}{l}\text { Teachers should take into account the error and imprecision } \\
\text { assessment }\end{array}$ & & & & \\
\hline Assessment has little impact on teaching & & & & \\
\hline Assessment is assigning a grade or level tc & & & & \\
\hline
\end{tabular}

Extraction Method: Maximum Likelihood.

Rotation Method: Promax with Kaiser Normalization.

a. Rotation converged in 6 iterations.

\begin{tabular}{lcccc} 
Eigen values & 7.669 & 2.614 & 1.93 & 1.61 \\
\% of variance & 28.4 & 9.68 & 7.17 & 5.98 \\
\hline
\end{tabular}


Osborne et al. (2008) and Yong and Pearce (2013) recommend that multiple factor analyses be run at numbers above and below the predicted number of factors. So, analyses with three and five factors were also run to see if that produced a more appropriate result.

\subsubsection{Three factor analysis}

The Factor Matrix for a three factor solution showed the same four items not loading to any factors (Item 2 - assessment places students in categories, Item 11 - assessment is assigning a grade, Item 18 - teachers should take into account error and imprecision in all assessment, and Item 26 - assessment has little impact on teaching). The antiimage correlation matrix also showed two variables (Items $18 \& 26$ ) having values less than 0.5. The Pattern Matrix, Table 4.8, does show all factors with at least three items loading and only one item cross-loading. 
Table 4.8

Pattern matrix extracted using Maximum Likelihood Estimation with an Oblique rotation (Promax) with a three-factor solution

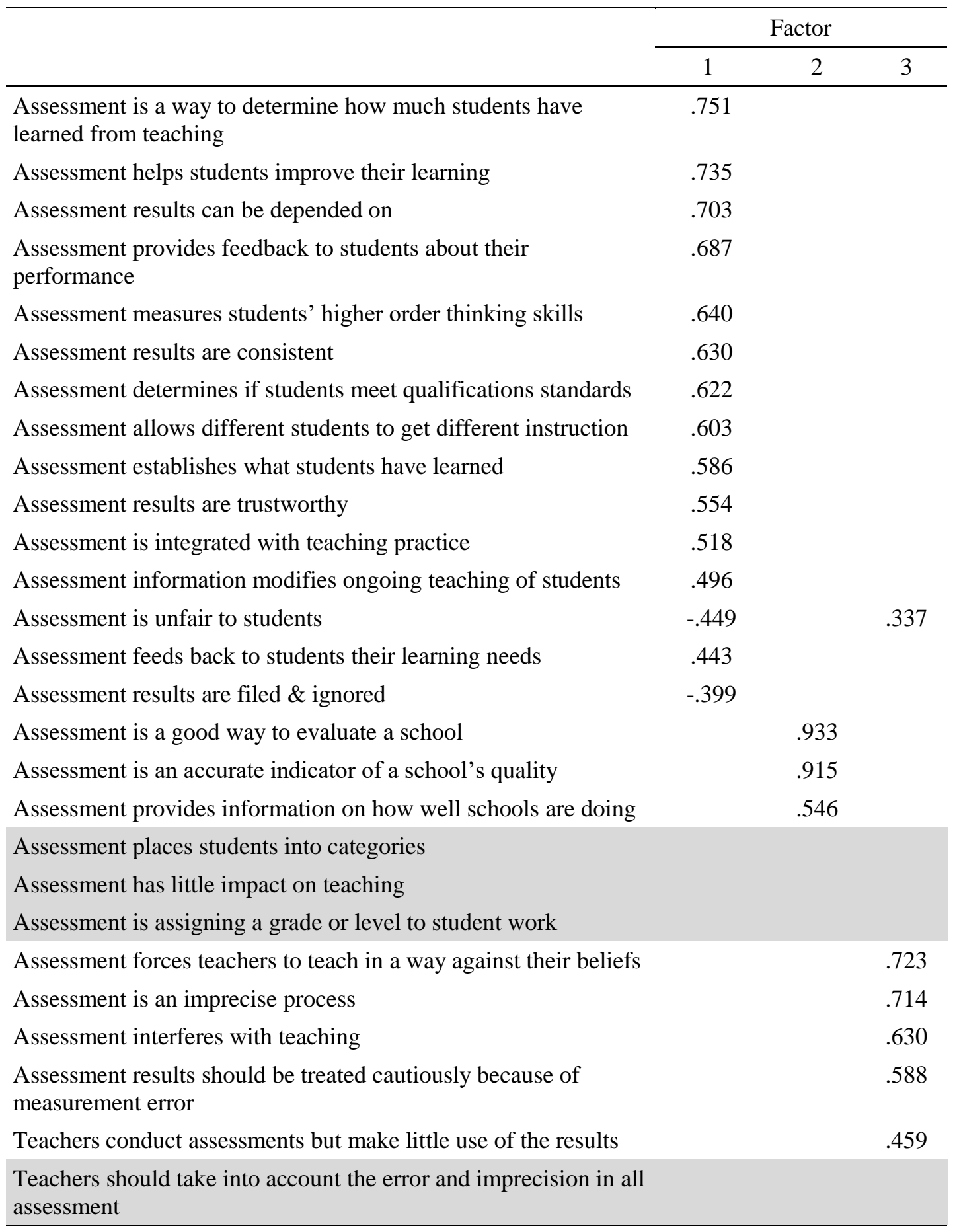

Extraction Method: Maximum Likelihood.

Rotation Method: Promax with Kaiser Normalization.

a. Rotation converged in 6 iterations.

\begin{tabular}{lccc} 
Eigen values & 7.669 & 2.614 & 1.93 \\
$\%$ of variance & 28.4 & 9.68 & 7.17 \\
\hline
\end{tabular}




\subsubsection{Five factor analysis}

A five factor analysis was also carried out but the Factor Matrix also showed the same four items not loading to any factor and the anti-image correlation matrix with the same two variables (Items $18 \& 26$ ) having values less than 0.5 . This analysis also produced six items with cross-loadings, and a number of items loading below the recommended .4 weighting, but factors had at least three items.

\subsubsection{Removing items}

If the results are still difficult to interpret, Costello and Osborne (2005) recommended removing problematic items; however, researchers have to consider whether this will compromise the data. G.T.L. sBrown (2011b) also warned that such modifications have to be theoretically defensible. In considering each extraction, the same four items did not load to any factors (Item 2 - assessment places students in categories, Item 11 - assessment is assigning a grade, Item 18 - teachers should take into account error and imprecision in all assessment, and Item 26 - assessment has little impact on teaching). As both the three-factor analysis and the four-factor analysis produced a similar number of issues, it was decided to follow the scree plot and parallel analysis recommendations of extracting four factors.

The analyses was run again with a four-factor extraction removing these items one by one. After multiple analyses, a four-factor solution with items 2, 11, 18 and 26 removed resulted in the most plausible structure. The pattern matrix, Table 4.9, shows all four factors have at least three items with loadings of an acceptable magnitude and the Cronbach's alpha for each factor is within an acceptable range as defined by George and Mallery (2003). There are, however, three items cross-loading to more than one factor. 
Table 4.9

Pattern matrix extracted using Maximum Likelihood Estimation with an Oblique rotation (Promax) with a four-factor solution and items $2,11,18$ \& 26 removed

\begin{tabular}{lcccc}
\hline & \multicolumn{4}{c}{ Factor } \\
\cline { 2 - 5 } & 1 & 2 & 3 & 4 \\
\hline Assessment determines if students meet qualifications & $\mathbf{. 7 8 7}$ & &
\end{tabular}
standards

Assessment is a way to determine how much students have learned from teaching

Assessment results can be depended on .770

Assessment results are trustworthy .722

Assessment establishes what students have learned .700

Assessment helps students improve their learning .665

Assessment measures students' higher order thinking skills .645

Assessment is unfair to students

Assessment results are consistent

Assessment results are filed \& ignored

Assessment forces teachers to teach in a way against their beliefs

Assessment is an imprecise process

Assessment interferes with teaching

Assessment results should be treated cautiously because of measurement error

Assessment information modifies ongoing teaching of students

Assessment provides feedback to students about their

performance

Assessment feeds back to students their learning needs

Assessment is integrated with teaching practice

Assessment allows different students to get different instruction

Assessment is a good way to evaluate a school

Assessment is an accurate indicator of a school's quality doing

Extraction Method: Maximum Likelihood.

Rotation Method: Promax with Kaiser Normalization.

a. Rotation converged in 6 iterations.

\begin{tabular}{lcccc} 
Eigen values & 7.669 & 2.614 & 1.93 & 1.61 \\
$\%$ of variance & 28.4 & 9.68 & 7.17 & 5.98 \\
Cronbach's alpha & .730 & .766 & .741 & .813 \\
\hline
\end{tabular}




\subsubsection{Factors extracted}

Each factor may be associated with a latent variable. The items loading to Factor 1 seem to describe actions relating to a summative function of assessment. The codimensionality of assessment determines if students meet qualifications standards with items such as assessment measures students higher order thinking skills, establishes what they have learned, and that assessment results are trustworthy, dependable and consistent, but assessment is not ignored, nor unfair, suggests a legitimate summative function of assessment. The association of assessment helps students improve their learning with these other items could indicate that participants believe summative functions of assessment can have a formative use. This could possibly relate to their role as assessors of NCEA where teachers award qualifications but are aware that this process may also help student learning.

The survey responses to the items contributing to this factor show general agreement with assessment determines if students meet qualifications standards and is a way to determine how much students have learned from teaching. There is less agreement that results are trustworthy, consistent and can be relied upon, and that assessment helps students improve their learning. Participants did not agree that assessment is unfair to students, nor that results are filed and ignored. This is a logical association because, if assessment has a useful summative function then it cannot be unfair or ignored. The responses to each item are in Figure 4.2. 
Assessment determines if students meet qualifications standard

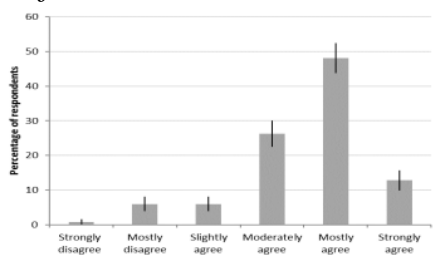

Assessment results are trustworthy

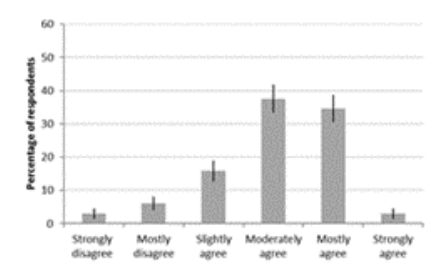

Assessment measures students' higher order thinking skills

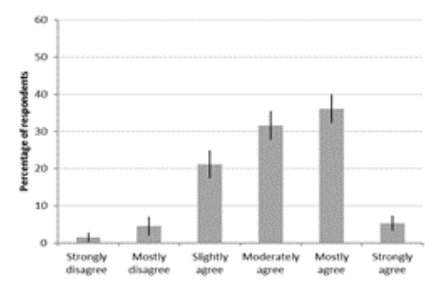

Assessment results can be depended on

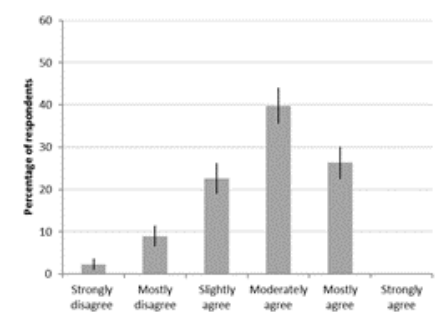

Assessment results are filed and ignored

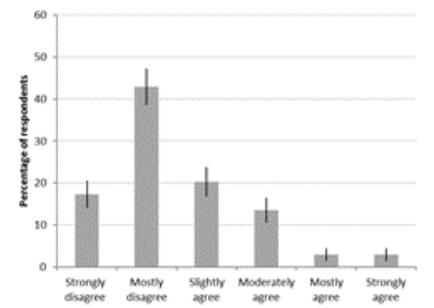

Assessment is a way to determine how much students have learned from teaching

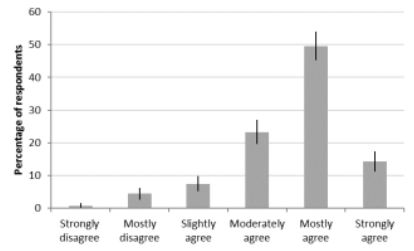

Assessment establishes what students have learned

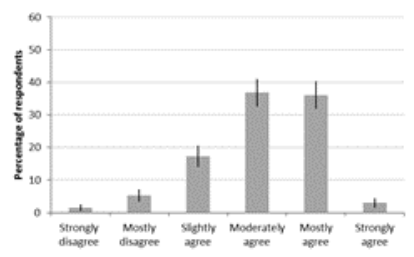

Assessment results are consistent

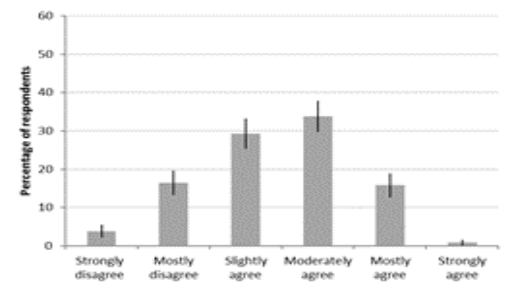

Assessment helps students improve their learning

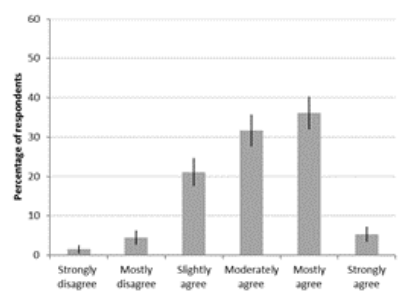

Assessment is unfair to students

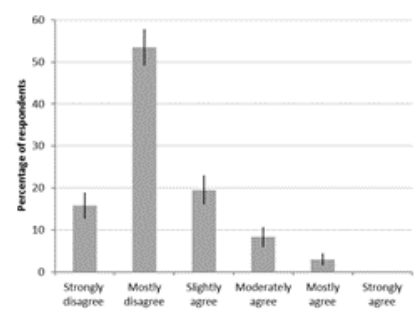

Figure 4.2. Distribution of responses from items contributing to factor - assessment describes learning. 
In G.T.L. Brown's (2006) model, the items loading on Factor 2 relate to the concept of assessment being detrimental to teaching and learning. However, participants were not in general agreement with these items. There is only some tendency towards believing assessment has detrimental aspects, therefore this factor has been named Assessment has weaknesses.

Assessment forces teachers to teach in a Assessment is an imprecise process way against their beliefs

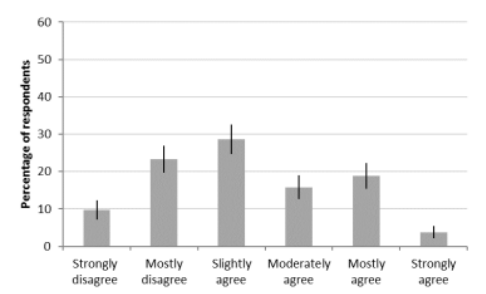

Assessment interferes with teaching

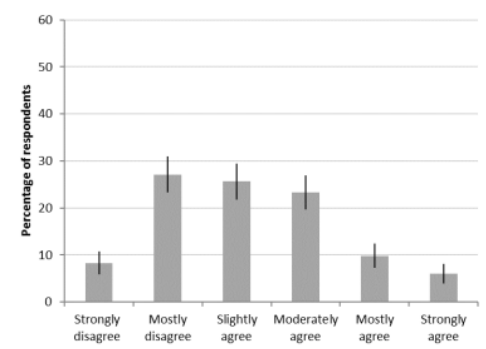

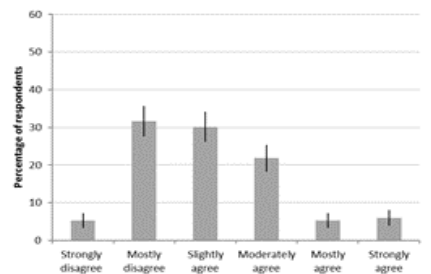

Assessment results should be treated cautiously because of measurement error

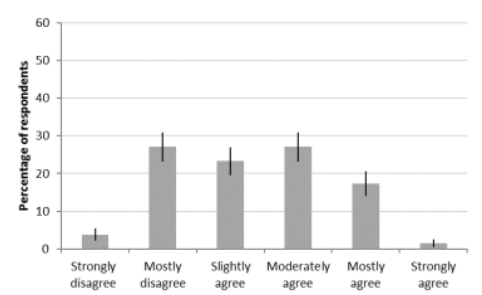

Teachers conduct assessments but make little use of the results

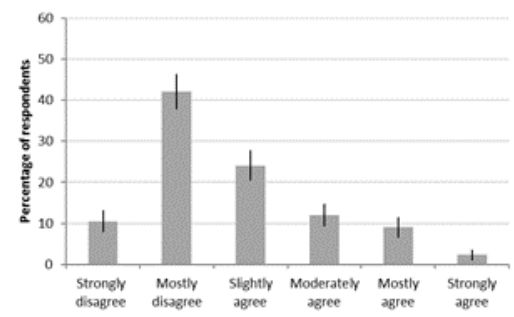

Figure 4.3. Distribution of responses from items contributing to factor - assessment has weaknesses 
Items loading to Factor 3 all relate to the idea that assessment can improve learning and teaching and therefore has formative functions. The individual items show general agreement with formative functions of assessment, apart from item 23 - assessment allows different students to get different instruction.

Assessment information modifies

ongoing teaching of students

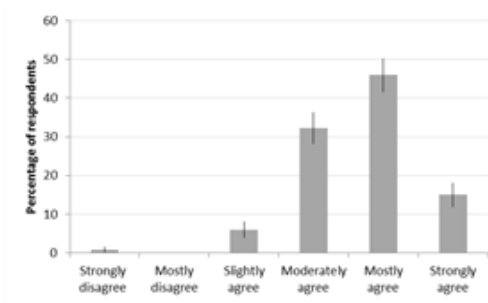

Assessment provides feedback to students about their performance

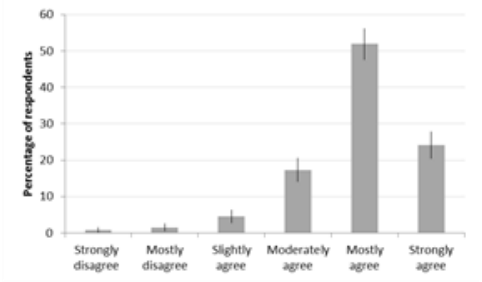

Assessment allows different students to get different instruction

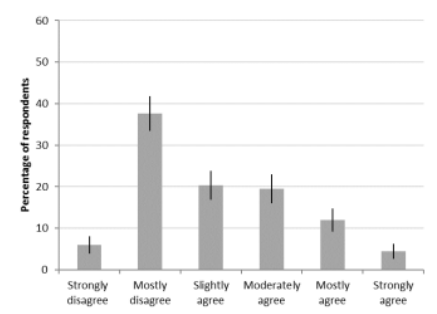

Assessment is integrated with

teaching practice

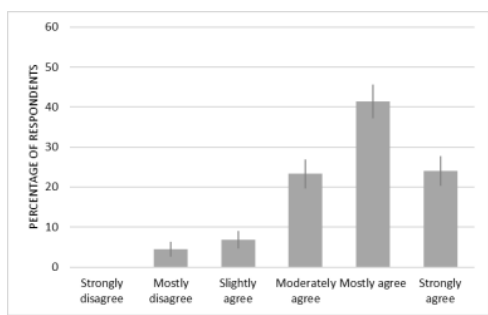

Assessment feeds back to students their learning needs

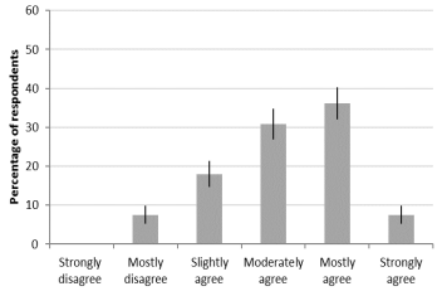

Figure 4.4. Distribution of responses from items contributing to factor - assessment improves learning and teaching. 
The items loading to Factor 4 clearly align with G.T.L. Brown's (2006) conception of school accountability. However, responses to the items in this factor are varied and not necessarily showing general agreement that assessment results can be a measure of school quality.

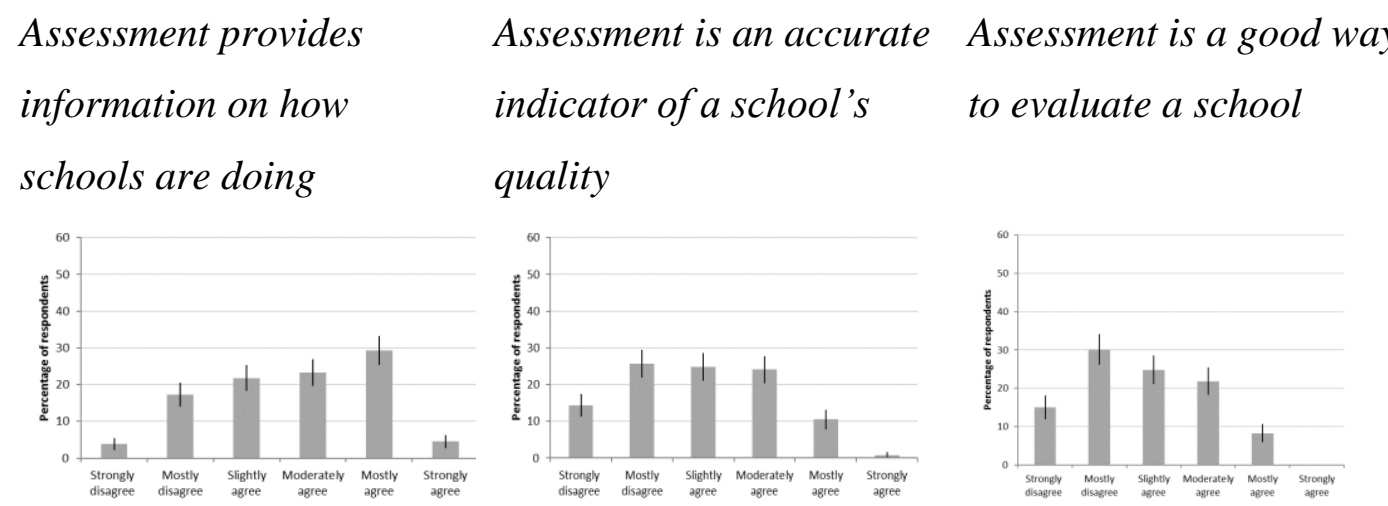

Figure 4.5. Distribution of responses from items contributing to factor - assessment for school accountability

The correlation matrix, Table 4.10, describes logical correlations. Factor 2 assessment has weaknesses - is inversely correlated with all of the other factors. This is logical because if assessment has useful summative and formative functions and is possibly an indicator of school quality then its weaknesses should not be so great as to render the assessment unfit for its purposes. Factor 1 - assessment describes learning correlates positively with assessment improves learning and assessment for school accountability. This indicates that teachers agreed, somewhat, with the idea that assessment results could be an indicator of school quality, and that improving learning and measuring learning are compatible with each other. The weak positive correlation between factors 3 and 4 suggests that participants who believe assessment improves learning are not in strong agreement that that same assessment information is an indicator of school quality. 
Table 4.10

Conceptions of assessment inter-correlations: economics and accounting teachers

\begin{tabular}{|c|c|c|c|c|}
\hline Fact or & 1 & 2 & 3 & 4 \\
\hline 1 Assess ment describes learning & & -.422 & .533 & .416 \\
\hline 2 Assess ment has weaknesses & & & -.320 & -.039 \\
\hline 3 Assess ment i mproves learning & & & & .180 \\
\hline 4 Assess ment for school account abi lity & & & & \\
\hline
\end{tabular}

Extraction Method: Maxi mu m Li keli hood.

Rot ati on Met hod: Promax wit h Kai ser Nor mali zation.

\subsection{Conclusion}

The factor analysis sought to investigate the conceptions of assessment of teachers of senior accounting and economics, and whether these conceptions are similar to those held by teachers reported by G.T.L. Brown (2006). While, overall, the fit statistics suggest the model should be rejected, CFA reproduced some aspects of G.T.L. Brown's model, in particular, the improvement and school accountability conceptions; however, the data showed a poor fit to G.T.L. Brown's irrelevant and student accountability factors. Four of the six factor inter-correlations were also similar. Agreements were inverse correlations between the improvement conception and the irrelevance conception, and between the irrelevance conception and the school accountability conception; and positive correlations between improvement and school accountability and school accountability and student accountability. The differences were an inverse correlation between irrelevance and student accountability and a correlation greater than one between improvement and student accountability.

Exploratory factor analysis revealed a four-factor model that reproduced similarities to G.T.L. Brown's (2006) model, but also had some significant differences. Similarities and differences are summarised in Table 4.11. The exploratory factorassessment describes learning - contains all of the items that in G.T.L. Brown's model load to assessment is valid and assessment describes learning. Items relating to G.T.L. Brown's improvement, student accountability and irrelevant factors also load to Factor 1. These associations can be explained because the teachers in this study work almost exclusively at the senior level of secondary schools where they have a focus 
on awarding internally-assessed achievement standards. If teachers award qualifications then the assessment needs to be considered valid and not unfair.

Factor 2 assessment has weaknesses has items that contributed to G.T.L. Brown's (2006) irrelevant factor. Notably, G.T.L. Brown's student accountability factor was not reproduced. Two items from this factor - assessment places students into categories and assessment is assigning a grade or level to student work, did not load to any factors in the EFA.

Factor 3 is essentially a combination of G.T.L. Brown's two first order factors of assessment improves learning and assessment improves teaching. Factor 4 has the same items as G.T.L. Brown's school accountability factor, but while these items loaded to the same factor, survey results did not show a very strong degree of agreement with this concept. For example, $40 \%$ of participants did not agree that assessment is an accurate indicator of school quality and $45 \%$ did not agree that assessment is a good way to evaluate a school. 
Table 4.11

Comparison of items and factors of G.T.L Brown's (2006) model with factors and items for economics and accounting teachers.

\begin{tabular}{|c|c|c|c|c|}
\hline \multicolumn{3}{|c|}{ Factors and items for G.T.L Brown's (2006) TCoAIIIA } & \multicolumn{2}{|c|}{ Factors and items for economics and accounting teachers } \\
\hline $\begin{array}{l}\text { Second } \\
\text { order } \\
\text { factors }\end{array}$ & $\begin{array}{l}\text { First order } \\
\text { factors }\end{array}$ & Items loading to the factor & First order factors & Items loading to the factor \\
\hline \multirow{19}{*}{ 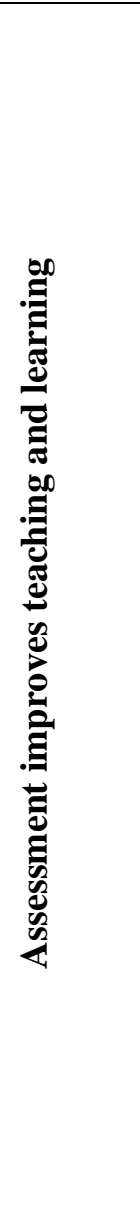 } & $\begin{array}{l}\text { Assessment is } \\
\text { valid }\end{array}$ & $\begin{array}{l}\text { Item } 6 \text { Assessment results are trustworthy } \\
\text { Item } 24 \text { Assessment results can be }\end{array}$ & \multirow[t]{13}{*}{$\begin{array}{l}\text { Assessment describes } \\
\text { learning }\end{array}$} & $\begin{array}{l}\text { Item } 20 \text { Assessment determines if students me } \\
\text { qualifications standards }\end{array}$ \\
\hline & & depended on & & Item 3 Assessment is a way to determine how \\
\hline & & Item 15 Assessment results are consistent & & $\begin{array}{l}\text { much students have learned from teaching } \\
\text { Item } 24 \text { Assessment results can be depended }\end{array}$ \\
\hline & \multirow{7}{*}{$\begin{array}{l}\text { Assessment } \\
\text { describes abilities }\end{array}$} & \multirow{6}{*}{$\begin{array}{l}\text { Item } 12 \text { Assessment establishes what } \\
\text { students have learned } \\
\text { Item } 3 \text { Assessment is a way to determine } \\
\text { how much students have learned from } \\
\text { teaching } \\
\text { Item } 21 \text { Assessment measures students' } \\
\text { higher order thinking skills }\end{array}$} & & Item 6 Assessment results are trustworthy \\
\hline & & & & Item 12 Assessment establishes what students \\
\hline & & & & have learned \\
\hline & & & & $\begin{array}{l}\text { Item } 22 \text { Assessment helps students improve th } \\
\text { learning }\end{array}$ \\
\hline & & & & $\begin{array}{l}\text { Item } 21 \text { Assessment measures students' highe } \\
\text { order thinking skills }\end{array}$ \\
\hline & & & & Item 16 Assessment is unfair to students \\
\hline & & \multirow{5}{*}{$\begin{array}{l}\text { Item } 5 \text { Assessment is integrated with } \\
\text { teaching practice } \\
\text { Item } 14 \text { Assessment information modifies } \\
\text { ongoing teaching of students } \\
\text { Item } 23 \text { Assessment allows different } \\
\text { students to get different instruction }\end{array}$} & & Item 15 Assessment results are consistent \\
\hline & \multirow{4}{*}{$\begin{array}{l}\text { Assessment } \\
\text { improves teaching }\end{array}$} & & & \multirow{2}{*}{$\begin{array}{l}\text { Item } 17 \text { Assessment results are filed \& } \\
\text { ignored }\end{array}$} \\
\hline & & & & \\
\hline & & & & $\begin{array}{l}\text { Item } 14 \text { Assessment information modifies } \\
\text { ongoing teaching of students }\end{array}$ \\
\hline & & & Assessment improves & Item 4 Assessment provides feedback to \\
\hline & \multirow{5}{*}{$\begin{array}{l}\text { Assessment } \\
\text { improves learning }\end{array}$} & \multirow{5}{*}{$\begin{array}{l}\text { Item } 22 \text { Assessment helps students improve } \\
\text { their learning } \\
\text { Item } 4 \text { Assessment provides feedback to } \\
\text { students about their performance } \\
\text { Item } 13 \text { Assessment feeds back to students } \\
\text { their learning needs }\end{array}$} & learning & students about their performance \\
\hline & & & & $\begin{array}{l}\text { Item } 13 \text { Assessment feeds back to students } \\
\text { their learning needs }\end{array}$ \\
\hline & & & & Item 5 Assessment is integrated with \\
\hline & & & & teaching practice \\
\hline & & & & $\begin{array}{l}\text { Item } 23 \text { Assessment allows different } \\
\text { students to get different instruction }\end{array}$ \\
\hline
\end{tabular}


Factors and items for G.T.L Brown's (2006) TCoAIIIA

Factors and items for economics and accounting teachers

\begin{tabular}{|c|c|c|c|c|c|}
\hline $\begin{array}{l}\text { Second } \\
\text { order } \\
\text { factors }\end{array}$ & $\begin{array}{l}\text { First order } \\
\text { factors }\end{array}$ & \multicolumn{2}{|c|}{ Items loading to the factor } & First order factors & Items loading to the factor \\
\hline & $\begin{array}{l}\text { Assessment makes } \\
\text { students } \\
\text { accountable }\end{array}$ & $\begin{array}{l}\text { Item } 2 \\
\text { Item } 11 \\
\text { Item } 20\end{array}$ & $\begin{array}{l}\text { Assessment places students in } \\
\text { categories } \\
\text { Assessment is assigning a } \\
\text { grade or level to students } \\
\text { Assessment determines if } \\
\text { students meet qualifications } \\
\text { standards }\end{array}$ & & \\
\hline & $\begin{array}{l}\text { Assessment makes } \\
\text { schools } \\
\text { accountable }\end{array}$ & $\begin{array}{l}\text { Item } 1 \\
\text { Item } 10 \\
\text { Item } 19\end{array}$ & $\begin{array}{l}\text { Assessment provides } \\
\text { information on how well } \\
\text { schools are doing } \\
\text { Assessment is an accurate } \\
\text { indicator of a school's quality } \\
\text { Assessment is a good way to } \\
\text { evaluate a school }\end{array}$ & $\begin{array}{l}\text { Assessment for school } \\
\text { accountability }\end{array}$ & $\begin{array}{l}\text { Item } 1 \text { Assessment provides information on how } \\
\text { well schools are doing } \\
\text { Item } 10 \text { Assessment is an accurate indicator of a } \\
\text { school's quality } \\
\text { Item } 19 \text { Assessment is a good way to evaluate a } \\
\text { school }\end{array}$ \\
\hline
\end{tabular}




\begin{tabular}{|c|c|c|c|c|}
\hline \multicolumn{3}{|c|}{ Factors and items for G.T.L Brown's (2006) TCoAIIIA } & \multicolumn{2}{|c|}{ Factors and items for economics and accounting teachers } \\
\hline $\begin{array}{l}\text { Second } \\
\text { order } \\
\text { factors }\end{array}$ & $\begin{array}{l}\text { First order } \\
\text { factors }\end{array}$ & Items loading to the factor & First order factors & Items loading to the factor \\
\hline \multirow{10}{*}{ 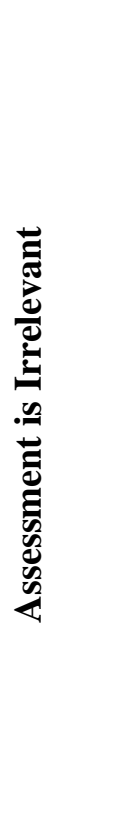 } & Assessment is bad & $\begin{array}{l}\text { Item } 25 \text { Assessment interferes with } \\
\text { teaching }\end{array}$ & $\begin{array}{l}\text { Assessment has } \\
\text { weaknesses }\end{array}$ & \multirow{10}{*}{$\begin{array}{l}\text { Item } 7 \text { Assessment forces teachers to teach in a } \\
\text { way against their beliefs } \\
\text { Item } 27 \text { Assessment is an imprecise process } \\
\text { Item } 25 \text { Assessment interferes with teaching } \\
\text { Item } 9 \text { Assessment results should be treated } \\
\text { cautiously because of measurement error } \\
\text { Item } 8 \text { Teachers conduct assessments but make } \\
\text { little use of the results }\end{array}$} \\
\hline & & $\begin{array}{l}\text { Question } 16 \text { Assessment is unfair to } \\
\text { students }\end{array}$ & & \\
\hline & & Item 7 Assessment forces teachers to teach & & \\
\hline & & in a way against their beliefs & & \\
\hline & & Item 17 Assessment results are filed \& & & \\
\hline & Assessment is & ignored & & \\
\hline & ignored & $\begin{array}{l}\text { Item } 8 \text { Teachers conduct assessments but } \\
\text { make little use of the results }\end{array}$ & & \\
\hline & & $\begin{array}{l}\text { Item } 26 \text { Assessment has little impact on } \\
\text { teaching }\end{array}$ & & \\
\hline & $\begin{array}{l}\text { Assessment is } \\
\text { inaccurate }\end{array}$ & $\begin{array}{l}\text { Item } 27 \text { Assessment is an imprecise process } \\
\text { Item } 9 \text { Assessment results should be treated } \\
\text { cautiously because of measurement error }\end{array}$ & & \\
\hline & & $\begin{array}{l}\text { Item } 18 \text { Teachers should take into account } \\
\text { the error and imprecision in all assessment }\end{array}$ & & \\
\hline
\end{tabular}




\section{CHAPTER 5}

\section{Qualitative findings}

This chapter discusses the findings from the analysis of the interviews. The first section discusses the findings that interviewees' beliefs and actions towards internal assessment for NCEA could be conceptualised along a continuum. The second section describes the five key themes that emerged from the analysis: assessment as pedagogy; assessment for educational outcomes; assessment as practice; assessment as motivator; and assessment is detrimental.

\subsection{Gatekeepers and ushers}

Analysis of the qualitative data suggests that teachers' beliefs about, and actions towards, internal assessment for NCEA may be conceptualised on a continuum from usher (door-opener) behaviour to gatekeeper behaviour. Usher behaviour was epitomised by maximising internal assessment for the benefit of students' achievement - that is using NCEA internal assessment to open doors to achievement. Gatekeeper behaviour, on the other hand, was treating internal assessment as an extension of external examinations. There seemed to be three dimensions to these actions and beliefs: relating to the conditions under which internal assessment was conducted, the types of assessment tasks that teachers asked students to complete, and teachers' general attitude towards internal assessment. These typologies are summarised in a matrix (Figure 5.1) but described as a continuum because not all individual teacher actions typified the extremes. 
Table 5.1

Typology of teachers' beliefs and actions towards NCEA internal assessment

\begin{tabular}{|c|c|c|c|c|}
\hline & & $\begin{array}{l}\text { Assessment } \\
\text { conditions }\end{array}$ & Attitudes & $\begin{array}{l}\text { Assessment } \\
\text { tasks }\end{array}$ \\
\hline 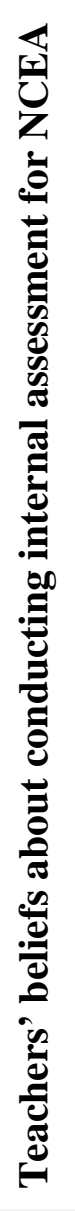 & \begin{tabular}{c}
\multicolumn{1}{c}{} \\
Examiner \\
(Gatekeeper)
\end{tabular} & $\begin{array}{ll}\text { - } & \text { Open book } \\
\text { - } & \text { Formative } \\
\text { feedback } \\
\text { provided } \\
\text { - Authenticity } \\
\text { assured } \\
\text { through } \\
\text { ongoing } \\
\text { monitoring } \\
\text { - Resubmissions }\end{array}$ & $\begin{array}{l}\text { Positive } \\
\text { towards } \\
\text { NCEA and } \\
\text { internal } \\
\text { assessment } \\
\text { - Internal } \\
\text { assessment } \\
\text { should give } \\
\text { students } \\
\text { more } \\
\text { opportunities } \\
\text { to achieve }\end{array}$ & $\begin{array}{l}\text { - Original or } \\
\text { large } \\
\text { adaptions to } \\
\text { exemplars } \\
\text { - Adaptions to } \\
\text { meet student } \\
\text { needs } \\
\text { - Portfolios } \\
\text { - Contextualised }\end{array}$ \\
\hline
\end{tabular}

The majority of participants $(n=15)$ tended towards maximising the use of internal assessment for students, thus displaying usher behaviour. They used internal assessment to create opportunities for students to succeed. Their attitude towards internal assessment was positive, and they were positive about the opportunities that internal assessment affords to students to achieve. They created courses in which a majority of credits could be gained through internal assessment and favoured tasks and assessment conditions that maximised student success. They designed assessment tasks to appeal to students' interests, used a portfolio approach where students could receive ongoing feedback, and allowed reassessment opportunities. One participant described the process she used for an internal assessment: 
I made a booklet that gi ves the $m$ dat a and the tasks. The booklet spells it out, a) do the calculations, b) do the graphs, c) identify the trends. Then I mark that, because there's no poi nt movi ng on if that's not correct. So I mark the calculati ons, because if they're not correct there will be followthrough errors. But if they don't get it ri ght the first time I use that as an opport unit $y$ for the mt o resub mit. (Tear lag)

Usher behaviour also included carrying out internal assessment in open-book conditions. While this could raise concerns about the authenticity of students' work, those participants who used open-book approached authenticity through ongoing monitoring of the students' work, by knowing students' general capabilities, and by having different topics for different students. As Sionn explained:

Ho we ver if you breakit up, have a checklist and ask them about it - where di $d$ you get that inf or mation from can you explai $n$ why you have got this here? We let the mchoose (the topic). And then of course if they choose different thi ngs then that will lend itself to being their own work.

Ailsa believed students should be encouraged to collaborate and did not see this as a threat to authenticity:

If st udents go a way at interval and find out fromthe others they have done so met hi ng wrong -isn't that learni ng? I acti vely encourage the st udents to collaborate. I would rather teach the students about the ethics of plagi arising.

A minority $(n=7)$ of interview participants' attitudes and actions towards internal assessment were more akin to the role of a gatekeeper. They tended to treat internal assessments as being similar to examinations rather than recognising different purposes, forms and pedagogical meanings associated with internal assessment. Authenticity of student work was a driver and major concern, and many gatekeeper actions around internal assessment were determined by authenticity concerns. For example, a rationale for making modifications to the TKI exemplars was not to accommodate students' needs but rather to prevent students accessing answers on the internet:

Our concern right fromt he beginni ng was that st udents could go ont o the NZQA website and just get everything in advance, so it was really i mportant we changed the m (Isla)

So we modify all our internals - the ans wers are just there - on the web. (Ceanag) 
Gatekeeper behaviour also included elaborate mechanisms for ensuring authenticity, such as students gathering data for research projects outside of class but bringing the data to class and writing up their reports in test-like conditions.

\begin{abstract}
At Year 13 we're going to do the research-based internal, but we're maki ng the $\mathrm{m}$ bring the st uff in and they will do their report. So they can research it as mich as they $i$ ke, but they have to bring it in and then at a stage they can't bring any more in. (Ruairidh)

I try to avoi d copyi ng issues by doi ng it in test conditions. (Sor cha)
\end{abstract}

Furthermore, gatekeeper behaviour included giving very little feedback during the internal assessment process. Students were given practice internal assessments, which were imitations of the actual assessment. Feedback on the practice assessment was provided, but once students had completed the actual internal assessment, the grade was final:

\footnotetext{
We gi ve the ma practice internal, we gi ve the mexe mplars, then we gi ve the $\mathrm{mt}$ he real thi ng. (Ceanag)

So me would say to me - I've only made a s mall mistake can I fix it? And I've sai $d$ no - you can't. To me - do you get a chance to fix it at the end of the year? (Ruairidh)
}

Participants were not necessarily dichotomous within the typology, but rather had a mix of beliefs and actions; in some cases their actions contradicted their beliefs. For example, Ceanag, who displayed mostly gatekeeper tendencies, expressed disappointment at not being able to conduct internal assessment with an open-book, portfolio approach:

\footnotetext{
So they do their investi gation, they bring their dat a back and they do their write-up in a test situation. I don't li ke it because it really puts pressure on ki ds who don't do well in exa ms and Ithink one of the reasons for internal assess ment was so that they could be done at home.
}

Others who described their internal assessment practice in terms of gatekeeping also described actions that supported a desire to meet students' interests through internal assessment. Sorcha described how she had introduced a Business Studies internallyassessed achievement standard because the students found it more interesting and that she used local businesses as case studies. Failbhe, who seemed quite negative towards 
NCEA overall, described giving feedback and resubmission opportunities to ensure that students gained the internally-assessed standards.

Participants displaying mostly usher behaviour sometimes expressed more gatekeeperlike views. For example, Morag believed very little feedback on internal assessments was permitted:

Say a student got Not Achieved and they are working on a resub mit, we're not supposed to provi de much in the way of feedback - if at all.

This included using a combination of approaches. Participants assessed some standards through portfolios and other standards through a combination of portfolios and formal in-class tests. Some standards were assessed solely through testing. As Mhairi explains:

There is a combi nation. Often they are done under some for mal in-class ti ne, and it depends on the assess ment. The government policy one at Level 2 is a combi nation of in-class and out of class ..... Market failure at Level 3 is in $t$ wo different parts, one is a project they do on their own and the second part is a peer review where I have created a fake person and they have to analyse and write up what is right and if it was wrong what they would do to correct it. That's the bit they do in class.... One at Level 2 is goi ng to be three tests - pretty mich.

Eilidh, who generally described her internal assessment practice as usher behaviour, had actions seemingly contrary to her beliefs in that she used test-like conditions for some internal assessments. However, this was to ensure students completed the internal assessments and gained the credits, as she had found in previous years that students omitted to submit parts of a portfolio:

I can finish the test in mabe $t$ wo or three classes, whereas research wi ll take $t$ wo to three weeks. And everyone will do the test because when they're sitting in the class, they can't say I a m not goi ng to do it. With research you are waiting for three weeks and then they haven't done it. So not hi ng is done and they don't get the credits.

All participants, whether they tended more towards gatekeeper or more towards usher behaviour appeared to be genuine and thorough in their administration of internal assessments; their differing views stemmed from their beliefs about being a professional assessor. Those with gatekeeper tendencies believed ensuring authenticity, giving little feedback, and allowing few resubmission opportunities 
created validity and fulfilled their roles as guardians of the qualification. Participants who displayed more usher-like behaviours tended to believe that the ability to internally assess students was designed to enable greater student achievement in NCEA and actively used the system to achieve that goal. They expressed support for the NCEA and preference for it over the previous New Zealand qualification system and other international systems.

\subsection{Thematic analysis of the interviews}

Five overarching themes were developed from thematic analysis of the interviews.

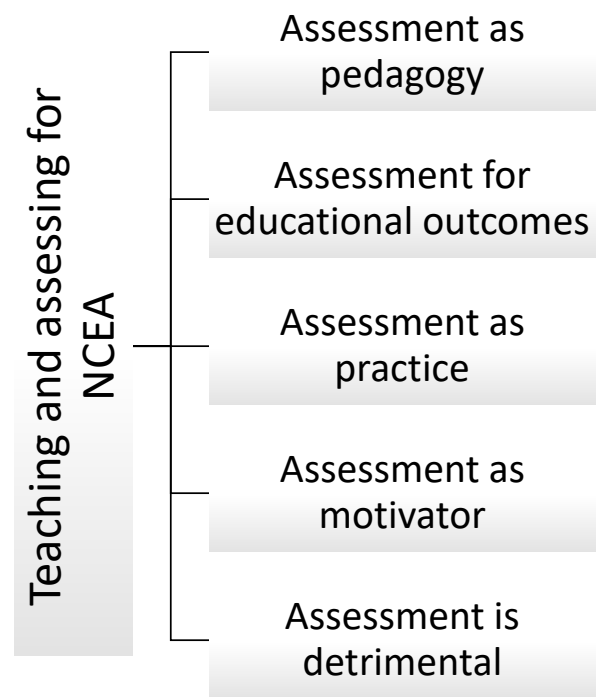

Figure 5.1. Overview of themes derived from the qualitative data

Table 5.2 gives a general description of each theme. 
Table 5.2

Themes and their general description

\begin{tabular}{ll}
\hline Theme & \multicolumn{1}{c}{ Description } \\
\hline Assessment as pedagogy & $\begin{array}{l}\text { Assessment is part of the teaching and learning process in } \\
\text { the senior school. }\end{array}$ \\
\hline $\begin{array}{l}\text { Assessment for } \\
\text { educational outcomes }\end{array}$ & $\begin{array}{l}\text { Int ernal and ext ernal standards provi de tools to enable } \\
\text { student to achi eve NCEA with the maxi mu mossible } \\
\text { grades, and mast ery of subjects, and to prepare them for } \\
\text { uni versity, the wor kf orce, and so on. }\end{array}$ \\
\hline Assessment as practice & $\begin{array}{l}\text { Assessment has an impact on teachers' practice. There are } \\
\text { practical and professional issues with assessing for national } \\
\text { qualifications. }\end{array}$ \\
\hline Assess ment as moti vat or & $\begin{array}{l}\text { Assessment can motivate students and connect with their } \\
\text { interests. }\end{array}$ \\
\hline $\begin{array}{l}\text { Assess ment is } \\
\text { detri mental }\end{array}$ & $\begin{array}{l}\text { Assessment is detrimental to teaching and learning, and } \\
\text { adds to teachers' workloads. }\end{array}$ \\
\hline
\end{tabular}

\subsubsection{Assessment as pedagogy}

All participants recognised that assessment, including NCEA internal assessment, is part of the learning and teaching process. The comments in this section show sound assessment literacy - that is, participants seemed aware of the various functions of assessment and the part they play in enacting these.

\section{Assessment is for learning}

All participants agreed in principle that a primary function of assessment is to ascertain students' learning. When asked what they thought the purpose of assessment is, most gave an answer reflecting a formative function. For example:

The pur pose of assess ment is to discover whet her the st udents have learned anyt hing and to judge what they've learned and to what ext ent they've learnt. (Scot ai gh)

It's when st udents have the opport unity to showt heir lear ni ng - what they know and what they don't know. And they should be able to apply the concepts we' ve covered. (Catriona)

To provi de feedback as to where they are at, where they are going, what they need to learn. (Ruairidh)

It has several purposes, it's a way of establishing if a student has reached a certain level of skill or knowledge, it's both for mative and summative assess ment. It's a signal to the teacher of how well the student is progressing and it's a signal to the student of how well they are progressing. (Malcolm) 
Some added that assessment also served the function of evaluating their own teaching:

To inf or myour teaching and lear ni ng practice. To see whet her the st udents are learning what you think they're learning, to see how effective your teaching programme is, to help identify areas they seem to be understanding well and areas you night need to cover agai n. It lets you know whet her you're being effective or not. (Angus)

I think it is partly to see where the kids are at and the progress they are making and also you can reflect on how you're goi ng as a teacher. (Maeve)

All gave examples of formative assessment in action that suggested this was very much a part of the teaching and learning process. They spoke of constantly checking students' learning, questioning them and providing feedback for the students' next learning steps. Some gave examples of how they track each student's learning and have mechanisms such as spreadsheets to document this:

My understandi ng of for mative assess ment is all that assess ment that goes on ri ght throughout a unit of nor k and it could be anyt hing that is observed, general feedback from students, anything like that all contributes to for mati ve assess ment. (Maeve)

There's the infor mal assessment that you're constant ly doing to see how the kids are going and whether you extend something or you move on because they've got the grasp of it. (Barra)

I ask poi nted questi ons to vari ous people and I know who is ans weri ng the questions. I keep track of who is ans wering questions and the sort of ans wers they gi ve. (Seonai d)

Several gave examples of teaching the students to self-assess, whereby students ascertain their strengths and weaknesses by comparing their own work with criteria. Mhairi specifically identified the increase in achievement this produced:

So they have to do a lot of evaluati on of their perfor mance. It has i mproved my results because I just used to do a bit of revision and some tests and di dn't really get the mt o evaluate fromthere ... They have to say these are the things they are good at and these are the things I was weak at. And it can't be more st udy, it needs to be specific. For exa mple, label the graphs correctly or showt he debits and credits etc., but it has to be really specific. 


\section{NCEA as part of teaching and learning}

Many participants attempted to integrate NCEA internal assessment into the teaching and learning process, recognising the advantage to students of doing so. Examples were conducting assessment proximal to the teaching so the material is fresh in students' minds and having them complete internally-assessed standards as portfolios to enable ongoing feedback. Angus explained he uses several small assessment items or portfolios to alleviate anxiety and pressure to perform as a way to make assessment a more natural part of learning. He also commented that using this approach allows opportunities for feedback and for students to revisit learning. Sionn explained that by using an integrated approach he can provide feedback to students as they work and they can also reflect on their own progress:

I think it creates a lot of learning opport unities when you have that oneon-one conversation. It's not only about the assessment, it's about the relationship bet ween myself and the student, and it's about getting the st udent tothink or tot hink creati vely or to so meti mes questi on the mselves. It allows the mt o reflect on what they've done or it allows the mt o reflect on their practices, the way they've approached things and naybe next ti me they should do it different ly. So they (int ernal assess ments) create a lot of valuable opport unities.

Those who used a portfolio approach also spoke of guiding the students through the task rather than expecting students to complete these independently. They emphasised students need scaffolding and without it often failed to submit anything. As Tearlag and Maeve explained:

\footnotetext{
If I left the mt o do that they would just fai l. So I scaffold it. So one week we do xxx and I mark it over the weekend and anybody who needs to do it agai $n$ can resub mit. Then we move on. (Tearlag)

I li ke to keep the ti mefra me ti ght. If you don't, too many wi 11 leave it until the ni ght before it's due to do it. (Maeve)
}

Sorcha described how she breaks the teaching and assessment of internally-assessed standards into several assessable events, allowing resubmission if needed. Her description of the portfolio approach actually appeared to be teaching interspersed with a series of tests but did include a feedback loop with opportunities for students to learn through the assessment: 
I' $\mathrm{m}$ doing a lot of portfoli o things now, because you can do things separat ely. You can fi nishteachi ng so met hi ngthen do the assess ment. You can give the ma test, mark it and give the resubs then move on - rather than doi ng a big long assi gn ment.

These actions show some participants were attempting to find synergies between the formative and summative functions of assessment and to use internal assessment as valuable learning opportunities.

\subsubsection{Assessment for educational outcomes}

Assessment for educational outcomes refers to teachers' rational strategies to enable students to gain qualifications with the highest possible grades as well as to prepare them for their future lives.

\section{Assessment is for qualifications}

All participants believed the ultimate aim of assessment in the senior secondary school is for students to achieve NCEA, with many stating that was the expectation of the students, their parents, and the school:

That's what they are here for! (Ei li dh)

So they are prepared for the summati ve assess ment. (Ruairi dh)

But the overarching purpose, I guess, especially for Years 11-13 is wor ki ng to war ds an NCEA qualification. (Morag)

The focus on NCEA in the senior secondary school became even more apparent when participants explained the differences between assessment in the senior secondary school and that in the junior school. Some described assessment in the junior school as formative and that feedback was to generate confidence and self-esteem. They emphasised the need to teach basic skills to the juniors and to continually revisit these until the students were competent:

At the juni or level it's mainly for mative and it's a si gnal to the students and the teacher of how well they are going. Maybe as an incenti ve, maybe to bui ld their confi dence. (Malcol m)

The purpose of assess ment in the juni or school is very mich to build up their ski lls and in the seni or school you tend to be concentrating on what's mi ssing and the next steps but always with an eye on NCEA. (Tearlag) 
Others described assessment in the junior school as preparation for the senior school and NCEA. Junior assessment mirrored NCEA with students being awarded the NCEA grades of Achieved, Merit, and Excellence for their work and students taught how to answer in the NCEA way of 'explain' and 'fully explain':

\begin{abstract}
As a faculty we decide what we want our kids to be able to do in Year 11 and how can we make that happen? Things li ke 'fully explain' - are they learni ng howto 'fully explain' in Years 9 and 10? (Catri ona)

We're working it the same - we assess just like an achieve ment standard. We need to teach the mthe skills. That at Merit you can do this. They start economics at Year 9 so we may as well start assessing the way they are later. There's lots of ways with 8 poi nt scales we can mark the work. So we' ve uritten our mark schedules using those. (Doi leag)
\end{abstract}

In addition to gaining qualifications, participants agreed they wanted to enable students to attain the best possible results including endorsements:

\footnotetext{
We have what's called a scholar's tie here, and so if you get over so many credits at excellence level you get a scholar's tie, and they (the st udents) li ke that idea, so they stri ve totry - some of the mdo. (Barra)

Defi nitely, a huge push to get subject endorse ments ... the moti vati on to get that ext ernal endorse ment is huge. (Catri ona)

At a deci le 10 school our focus is on acade mic success so our mai $\mathrm{n}$ goal is to ensure that the st udents achi eve ... and get the credits that they need for endorse ment with excellence. (Doi leag)
}

\title{
Strategies for educational outcomes
}

Participants identified a number of strategies they used to enhance students' educational outcomes including managing the curriculum, increasing internal assessment, differentiating assessment, and students designing their own curriculum.

\section{Managing the curriculum}

A key strategy to achieve educational outcomes was to manage the curriculum by reducing the overall number of standards offered to students to enable them to achieve credits with endorsement rather than a high quantity of credits. Some reported that their schools had policies limiting the maximum number of credits permitted in each subject (often about 18 to 20), but participants themselves were the ultimate decision-makers over curriculum design. Schools with several classes of economics and/or accounting at the same level tended to have each class completing the same curriculum, so 
participants spoke of negotiating with fellow teachers to determine which standards would be used. Mhairi summarises these thoughts and actions:

It is point less to do quantity and not quality so I a mall about quality. I want the mto get the best grade they can, they don't need 24 credits, they need 14 to 18 credits and for Endorsement 14 credits. We don't need mi lli ons of credits, we want quality credits so gi ve them enough ti me in the exa mto write a quality ans wer and not be rushed.

In deciding which aspects of the curriculum to offer, participants tended to remove standards or topics that they thought students find challenging or uninteresting, or those that the teacher deems unnecessary. Nonetheless, their comments also reveal gender stereotyping and their own intuitive theories of motivation, rather than evidence-based decision-making. For example, many participants reported no longer teaching accounting concepts at Levels 2 (AS9117) and 3 (AS91404). As Kirsty explains:

Level 2 Concepts is boring and boys are not really concepts ki nd of people. I do things like invent ory and MYOB as they are practical skills my st udents can use. So me don't go on to Level 3, they go and work in an office, so they need skills not concepts.

Barra agreed that boys, in general, did not like studying accounting concepts, but also thought this content was unnecessary until university level study:

I've dropped Concepts at Level 3, because the boys struggle with writing, most of the guys enjoy the numbers side, they find the concepts hard. I don't particularly li ke teaching it - Ithi nk that's more for uni versity level accounting.

Angus agreed, although for slightly different reasons:

We've taken the Concepts standard out - the language is too difficult, es pecially for the internati onal st udents. And it's too dry.

In economics, Ceanag and Scotaigh had removed AS91226 Analyse statistical data relating to two contemporary issues because it did not make sense to teach the statistics separately from the topic:

The st udent s don't underst and statistics,inter $\mathrm{ms}$ of the li nks bet ween the $\mathrm{m}$ and they get really conf used about causes and effect s, they just find it really hard. (Scot ai gh) 
Other participants explained that they still taught the whole curriculum but at some point they, or the students, decided whether to attempt the assessment. Participants either used their knowledge of students' achievement to counsel them about which external standards to attempt, or left students to make this decision themselves:

I' 11 teach the whole lot and be strat egic for st udents. Indi vi duals wi ll look at where they're at and what they need and they mingt not attempt one in the final exam Or I withdrawthe mfromstandards if they only need one or $\mathrm{t}$ no standards. (Doi leag)

I do the Trade ext ernal but they don't sit the exa m I withdrawthe mfrom it, but I want the mto learn about the balance of payments, exchange rates and ter $\mathrm{ns}$ of trade so they've heard of the $\mathrm{m}$ and got a gras of the $\mathrm{m}$ (Fai lbhe)

Failbhe went on to explain that to gain Excellence in some standards students needed knowledge from other standards, so studying the whole curriculum was necessary, with which Kirsty agreed:

You need Trade to get Excellence because they can say ho w anot her aspect of the econo my would change if the exchange rate was different. It means they can compare and contrast. (Fai lbhe)

And usually it's those extra layers (of kno wedge from ot her topi cs) that help st udents get Excellence. (Kirsty)

\section{Increasing internal assessment}

A further strategy was to increase internal assessment and reduce the number of credits examined externally with a number claiming to offer up to $70 \%$ of available credits through internal assessment. All participants considered the internally-assessed standards more achievable and believed that students could gain higher grades because they are often given a reasonable timeframe in which to complete the internal assessment, they receive ongoing feedback, and teachers are able to offer resit opportunities:

So with internal assess ment, even if they mess up, they still have a chance to resub nit in ter mt wo or ter mthree. (Ei li dh) 
Internal assessment was also considered a more appropriate type of assessment for some students:

Int ernal assess ment gi ves those students who don't me morise well the opport unit y to pass so met hing. (Si onn)

On a particular day how is that kid feeling? Maybe the exa mis in the afternoon and in the morning they had another exa $m$ and they are tired. Maybe they're not feeling well, naybe something has happened in the fa mily - all those fact ors affect the external. (Ei li dh)

For some kids the external process just doesn't suit the $\mathrm{m}$ - for what ever reason. Every year I' 11 have couple of ki ds who just don't do very well and you can't put your finger on it. (Ruairi dh)

All participants agreed that students increased their likelihood of a higher overall course grade and more likelihood of success if they attempted fewer external standards. They claimed it was more advantageous to attempt only one or two standards in a three-hour examination rather than all three as it gave students more time to write in-depth answers. This strategy also increased students' ability to gain endorsements as endorsement favours fewer credits completed to a higher level. The three hour examination period was often perceived as not enough time to write three answers to Excellence level:

To get Excellence, whi ch they really are stri ving for, they need more than an hour in the exa $\mathrm{m} .$. . we want quality credits so gi ve the menough ti me in the exa mso they can write a quality ans wer. (Mhairi)

I do t wo externals, they've only got three hours, and you can't compet e if you do three with kids doing t wo. Ulti mat ely doing one is better but then you don't cover enough of the course. (Fai lbhe)

So me of my students last year in Level 3 said they spent $t$ no and a half hours doi ng just the company state ments. NZQA have tried to make it so that each exa mshould take an hour but if a student wants to do it properly a standard takes more than an hour. (Kirsty)

Participants who taught economics had a further reason to increase internal assessment as some expressed dissatisfaction with the external assessment process:

There see ms to be a real anomaly with the Level 3 externals, I've had st udents who are outstanding, but they only get one Excellence out of the three ... and last year the exa $\mathrm{m}$ was a wful ... you look at the papers and you can't figure out howthey are marked. (Angus) 
I think the external assessment in Econom cs is rui ning the subject. Well you know everyone is saying how pedantic the markers are, and howit's turning st udents off the subject, it's really difficult to get Excellence, and now there is a huge a mount of writing in the exa ns, so really hi gh literacy require ments to pass. The graphing and maths si de of it see mt o have been di minished. But also the thought processes that have to go into writing three short essays in three hours is just too hard. (Ai lsa)

\section{Differentiating assessment}

Some participants described how they differentiated the curriculum and assessment to meet individual student needs and to ensure positive educational outcomes. Numerous techniques of differentiation were described such as multi-level study, extra tuition, blended learning techniques, school cluster groups (especially for Scholarship), teacher-created and proprietary resources:

I have made self-st udy units, both printed booklets and stuff onli ne, for those more experienced ki ds. (Mhairi)

So I gave the st udents a taster (of the standard) and said if you want to sit this exa myou need to come to tut orials ... about half chose to do that and half di dn't. And that's fine. (Kirsty)

I have at least one (standard) up my sleeve just in case a Level 3 st udent needs it to go to uni but doesn't get the first one (i nt ernal standard). Maybe the resub missi on didn't work out and so the st udent will ask to pick up so met hi ng else. (Si onn)

In addition, participants directed students to publicly available teaching resources such as YouTube, bought additional proprietary online and paper-based resources, and spoke of creating their own video teaching modules and posting these to the school intranet.

\section{Student-designed curriculum}

Participants reported that students, too, use NCEA standards to design courses with less assessment and decide whether to attempt internal and external achievement standards. Students too, are strategic in ensuring their own success and many students, once they have achieved the required number of credits, choose not to complete any further assessment: 
We are noticing that st udents tai lor their own courses and deci de not to do 24 credits. They, too, want to do fe wer credits and achieve better grades. Also, kids are very a ware of where they are credit-wise and whet her they need to sit any ext ernals. (Morag)

So me ki ds think they' ve got enough credits and they don't even atte mpt the exa ns. There are always those that have no intention of getting endorse ment. So us ually they will pick one ext ernal and complet ely leave out the ot her one. (Si onn)

Two of my st udents just did the $t$ wo nicro papers and left the macro paper. Many of the m go into ext ernals having passed already, so they pick and choose whi ch they'll do to get endorse ment. (Seonai d)

As Barra explains, this is a rational decision on the students' part and Sionn believed students making their own choices is a skill to be encouraged:

It makes sense because say I' moffering 20 credits and the ot her 5 subjects offer 20 then that's 120 total. But how many do they have to get? We know it's 80 , so there's 40 that they don't have to do. So is there any wonder that they're not goi ng to do them all? (Barra)

To be honest I mean it's their learning and Ithink if they' ve got strat egi es around which to do and it works for the $m$ they meet the require ments. I think it is a good skillisn't it? We may not like it as teachers but if it's an inf or med decisi on then I guess we should let the m (Sionn)

\section{Next steps in life}

Participants were very aware of their responsibility to prepare students for their next steps in life - whatever they might be. While many focussed on preparing students for tertiary study, generally university, others realised this would not be the destination for all.

In terms of preparing students for university, some spoke of relationships they had with the local university and the expectations this imposed:

There is a strong relati onship bet ween us, Price Waterhouse and the uni the girls have a direct career pathin accounting. So, Italk to the uni before I change my accounting courses because the st udents have to meet what the uni wants. And Price Wat erhouse gi ves scholarships to the st udents to study accounting at uni and they now have seven of my ex-students wor ki ng for the $\mathrm{m}$ (Ai lsa)

When the kids leave here they go to uni versity and I want the mt o be able to dothe work. I want the uni tothink -that st udent comes from my school and they knowt heir stuff. (Barra) 
My daught er has just finished four years at uni doi ng accounting and that's been really good feedback for me. Even in her st age three accounting she was still using some of the kno wledge she lear nt at school. So it was good to knowt hat what we do in school is usef ul. (Maeve)

Some teachers also wanted students to understand the subject for the sake of it, not just to gain a qualification. Barra wanted his students to have a good understanding of economics, and Failbhe and Kirsty spoke of useful life skills:

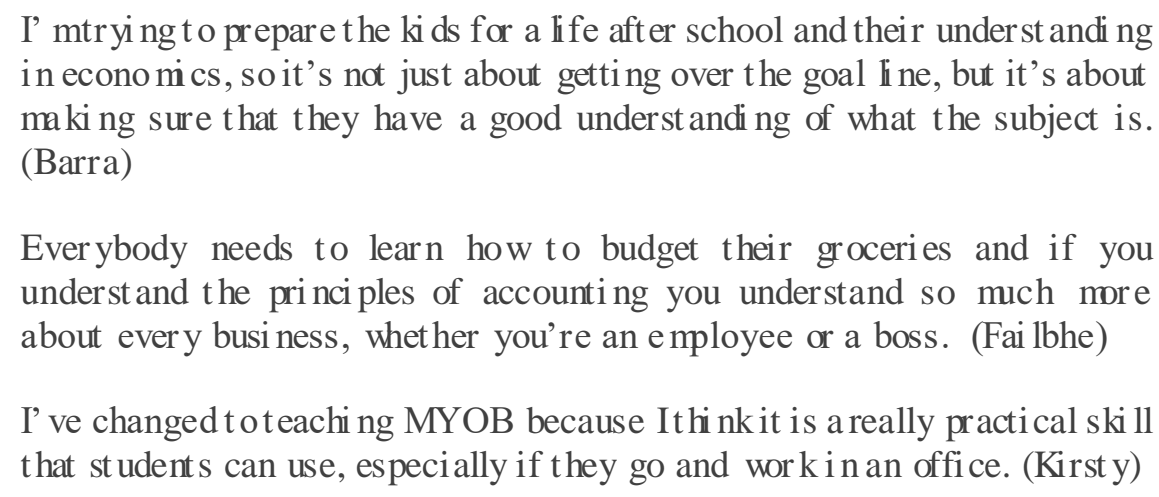

Everybody needs to learn how to budget their groceries and if you understand the principles of accounting you understand so mich more about every busi ness, whether you're an employee or a boss. (Fai lbhe)

I' ve changed toteaching MYOB because Ithink it is a really practical ski ll that st udents can use, especially if they go and work in an office. (Kirst y)

This theme describes a summative view of assessment and the strategies teachers implement to ensure that students achieve NCEA with the highest possible grades. The strategies implemented and the reasons for these seem based on participants' intuitive theories about motivation and gender stereotypes, rather than an evidential base.

\subsubsection{Assessment as practice}

This theme reflects the major responsibility participants have in implementing and managing internal assessment for NCEA. Implementing NCEA internally-assessed standards has an impact on teachers' professional practice because teachers must choose assessment materials and the conditions under which the tasks are administered. The professional development offered to support NCEA also influences their practice as do the competing assessment regimes that have been established since the introduction of NCEA. 


\section{Implementing internally-assessed standards}

\section{Choosing tasks}

Teachers have the choice to create their own NCEA internal assessment tasks, use the exemplars provided by the Ministry of Education (TKI exemplars), or buy commercial tasks. Most participants chose to use the TKI exemplars as a basis but to adapt them in some way; others said they created original tasks or used commercial materials with most using a combination of these approaches. They provided various reasons for adapting the TKI exemplars one of which seemed to be related to accountability in terms of meeting moderation requirements and also in terms of ensuring authenticity of student work. They also claimed they wanted to provide a relevant context for the assessment tasks, although their ideas about relevance were again linked to their own theories of motivation.

All participants agreed that they thought about what their students were interested in and tried to find suitable contexts for the internally-assessed tasks. As three said:

\footnotetext{
Well I defi nitely don't use the weddi ng planner exe mplar at a boy's school! (Doi leag)

We're more of a far mschool, so I do try and use agri cult ural exa mples. (Kirst y)

Lots of the boys in this school have a background in the wi ne industry so I use that. (Barra)
}

Further examples of adapting for school context included simplifying the exemplars because, according to Scotaigh, "the exemplars on TKI are too verbose and too complicated". Ailsa agreed stating "the exemplars on TKI are too complex, especially at Level 1." Catriona wanted to "make sure they are kid friendly" and Tearlag did not think the exemplars suitable for students with English as a second language and "more than $50 \%$ of my classes are international students with poor to extremely poor English". Wallace also stated that he was rarely happy with the exemplars and adapted them to appropriate reading levels and structure. 
Three participants from lower decile schools said they made modifications to the exemplars because the exemplars make assumptions about students' access to resources such as the internet at home for research, access to bank accounts or the availability of business owners to interview. Their modifications included providing mock interviews, newspaper articles to analyse or bank accounts to examine rather than expecting students to provide these for themselves.

A further reason for modifying the TKI exemplars is the ease of access to the answers. Scotaigh sums up the problem saying, "If you use a TKI resource and you don't modify it the answers are on the internet and the kids can plagiarise". And for accounting, as Ailsa comments "you at least have to change the figures because the answers are on the web". Several participants reported that the National Moderators had recommended this approach at professional development days (Best Practice Workshops), saying original tasks were unlikely to meet moderation requirements.

Those who did create original tasks had the confidence and expertise to do so. Angus wrote most of his own as "the TKI ones have been riddled with problems from the start". He admitted to being one of the initial writers of exemplars saying "we didn't really know what we were doing back then", but the experience gave him the skills and confidence to write his own assessments. Other participants believed that internal assessment should be relevant to the students in the particular class and school, revealing their belief that if assessment is relevant, students are more likely to be engaged with it. Maeve thought students need to examine real, local businesses and therefore did not use other teachers' resources, Scotaigh believed economics should use contemporary events, and that "it was just as easy to write your own". He felt quite confident and spent time ensuring everything was right, but "if the moderator says I'm wrong, I'm wrong, but we were $100 \%$ on moderation last year". Seonaid thought that as long as the achievement standards were clearly written she can interpret them correctly and create her own assessment tasks:

I read the achi eve ment standard, I read the schedule. It's all set out what you have to do for Achi eved, Merit and Excellence, I don't need anyone else's schedule or task. I' ve never had to ask the moderat or for advi ce and I get reasonably good moderat or reports, so I feel confident I can do it myself. 
Tearlag also explained the process for creating her own assessments which included reading the standard, the criteria, and the explanatory notes to make sure she understood what it all meant. She also referred to the Social Sciences curriculum, the Teaching and Learning guides, the conditions of assessment and the TKI exemplars. As she said, "I'm pulling stuff in from everywhere".

\section{Setting assessment conditions}

The internally-assessed achievement standards do not necessarily specify the assessment conditions under which they must be completed, so teachers are able to decide these for themselves. Participants described a range of approaches such as closed-book, in-class tests, open-book but in-class tests, and open-book projects/portfolios. Individual participants did not subscribe to only one approach; they mixed these to suit the standards and to suit their own and the students' workloads.

The rationale for conducting in-class tests varied, but was generally related to authenticity of student work, workload issues, and preparing students for end-of-year examinations.

\footnotetext{
We do the mall in class, so just all class tests, most ly for aut henticity. (Is la)

It's all done int he classroom wit hout a comput er. Each portfoli oitemtakes an hour, or three hours over the week and the work doesn't leave the classroom That's the only way I can control it. (Sorcha)

At the end of the year they go and sit exa ns so you have to prepare the $m$ properly. Why should we assess the mdifferent ly? (Scot ai gh)

The reality is, if you get the kids to do research it's a lot of work as you have to do it yourself, but an assess ment you can put toget her in a few hours and it's mich qui cker to mark. (Ruairi dh)
}

For some participants the in-class test was a one-off opportunity to achieve the standard, but others carried out several tests spread over a period of time:

\footnotetext{
If we do have tests, it's a series so it's more integrated with the teaching. It takes the anxiety a way fromt he $\mathrm{m}$ this whole high stakes thing where you have to perfor mt his particular day in this particular test. (Angus)
} 
A further mode is for students to complete part of the assessment in their own time and the rest under test conditions. Students bring their data to class (e.g., interviews, statistics, newspaper articles) to write a report or answer questions:

So out of class they identify some government policies and the i mpacts on different areas, they come up with a sheet which they bring back to class and then they write it up for mally in class. So, sort of a project leading to a closed-book sub mission. (Mhairi)

At Year 13 they do the research-based internal, but we're making the $m$ bring their st uff in and they will do a report in class. They can gat her as much as they want and then for four lessons they will wite about it and that will be sitting by the ns elves - not allowed to talk. (Ruairi dh)

Teachers reported using open-book, ongoing assessments to provide formative feedback to students, with some managing authenticity by not allowing students to take their work out of class and others by using their knowledge of the students:

I do the Employ ment one over a nu mber of peri ods in class, sot he int egrity of their nork is not called into question, which it can be if they do it at home. And this way I see what they are working on and I give the m feedback as they go. (Barra)

They do it at home and in class. We give the msay, three or four classes to get start ed, not test conditions. I' mt here to help them, they can discuss with each ot her, even share dat a collection. I break it up i in o bits, have a checklist and ask the $\mathrm{m}$ about it. So, that works both ways. They get feedback and get on the ri ght track and I knowt hat it is act ually their work. (Si onn)

The thing is with open book assess ments it's a little bit worrying that st udents can cheat but it is up to the teacher to take in those drafts and know where the st udents are act ually at, so when you are readi ng their fi nal assess ment you have an idea what level they should be. (Ai lsa)

The majority of participants allowed students an opportunity to reattempt an internal standard if it was not achieved initially, but some seemed to offer minimal feedback in the resubmission process. They described allowing students one opportunity to correct minor errors within a limited timeframe:

You gi ve the st udent the paper back, poi nt the mt owards the proble $m$ they identify the proble $m$ and it should be fixed within a range of about 20 mi nut es. (Si onn) 
I' ve got a feeli ng that if students are working on an internal there can't be much in the way of feedback, in particular if they are doing a resub mit. (Morag)

We don't act ually mark the script so they can't see what is right or wong, we say can you see an issue or a proble m? (Doi leag)

Others described how their practice towards resubmissions had changed:

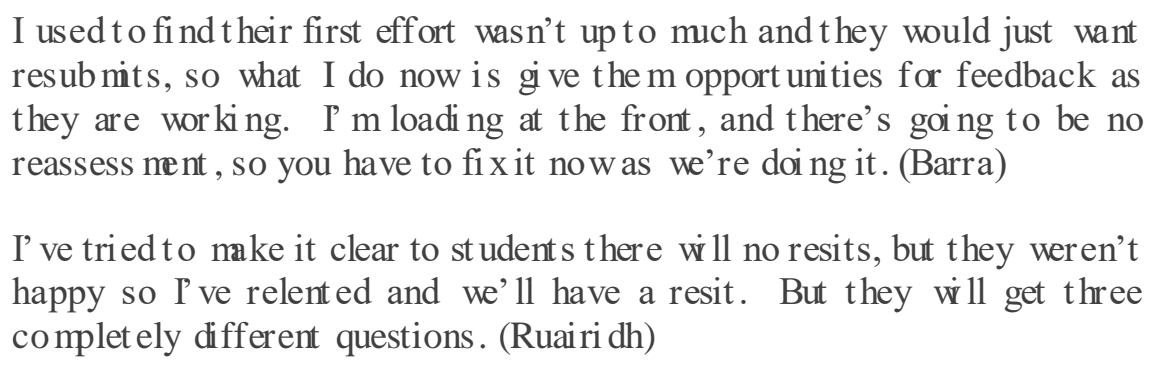
resub nits, so what $I$ do now is gi ve the $\mathrm{m}$ opport unities for feedback as they are working. I' m loading at the front, and there's goi ng to be no reassess ment, so you have to fix it now as we're doi ng it. (Barra)

I' ve tried to make it clear to st udents there will no resits, but they weren't happy so I've relented and we' 11 have a resit. But they will get three completely different questions. (Ruairi dh)

Setting assessment conditions appear to be guided by a range of pragmatic decisions related to individual standards and workload issues, along with beliefs (that are possibly erroneous) about how much formative feedback they are permitted to give to students in relation to internal assessment.

\section{Professional learning and support}

The two main sources of professional learning and support for internal assessment were provision from NZQA and informal teacher networks.

\section{NZQA provision}

NZQA provides support to teachers through Best Practice Workshops and through moderators giving feedback on assessment tasks and marked work. NZQA also employs teachers as moderators and previous experience as moderators was cited as a key professional support. Angus explained that his previous experience as a moderator and exemplar writer provided him with skills to execute the internal assessment process effectively. Maeve and Isla also believed being a moderator enabled them to know what was required, and Malcolm thought previous experience as a moderator not only gave him confidence to produce his own materials but also to seek advice from the moderator if required. He considered that he had a good relationship with the moderator and would phone him for advice if necessary. 
There were mixed responses regarding the usefulness of Best Practice Workshops and moderator feedback. Teachers appreciated the visibility of the National Moderator, as Sorcha says "I think she has done quite a good job because she is so visible. Previously, we didn't always know who the moderator was". Malcolm agreed that the workshops had been useful and had led to a change in the relationship between moderators and teachers. On the other hand, some questioned the ability of moderators to provide sound professional advice. As Ailsa said, "What they say goes, they run the best practice workshops so people have to listen to them. But I do sometimes wonder how they get that job". Others agreed that the moderators did not necessarily have more expertise. Mhairi claimed, "Sometimes I think I have got more experience than the moderator in this area and I think I am right. Just because you have the name 'moderator' does that mean you know it all?'

Other reasons for not respecting professional advice from the moderation process included a perceived change in moderation expectations when the National Moderator changed:

Of course the moderat or changes and so does the standard. (Barra)

You get changes in the moderat or and they change what is seen as the nati onal standard. (Is la)

Similarly, outcomes from attending Best Practice Workshops were not always positive:

I di d go to one and I di dn't feel I got the ans wers. I like things to be black and white because I want to get things right. (Sorcha)

I wasn't happy with the m(the BPW). We had exe mplars and none of us could agree on the grade -it just ended in a big argu ment. (Tearlag)

It did get frustrating because the moderat or would just say go back to the st andard, go back to the st andard and not gi ve defi nite ans wers. (Is la)

I go to all the Best Practice Wor kshops and listen, then take that a way and do my own thing. I did ask a question once - can I do this? Is this accept able? The moderat or just said 'look at the standard'. Well that's not helpful, I've already done that. (Seonai d) 


\section{Teacher networks}

All participants thought networking with other teachers was a valuable source of professional advice. They spoke of numerous ways they do this, such as formally through NZCETA meetings and informally through former colleagues and other economics and accounting teachers known to them or through online Google groups:

I belong to the local CETA group, so we just got together and wrote our o wn internal assess ments. (Seonai d)

I collaborate with my ex-boss. I sent her my internals and she sends me hers. (Scot ai gh)

We're lucky here as we have a net work of really good teachers. There are a couple who are very good at writing assess ments and so we all share. (Kirsty)

Even though I' $m$ the only economics teacher here I don't feel like it because there is so much support out there. You just ask a questi on on the Google group and people start replying and sending you their st uff. (Ei li dh)

A good thing about the Best Practice workshops was the collegiality and meeting other teachers. You get really good ideas, not necessarily from the moderat or, but fromthe other teachers there. (Is la)

\section{Competing assessment regimes}

A further consideration for practice was the presence of several assessment regimes within their school revealing the complex nature of assessment in New Zealand secondary schools. These included NCEA, New Zealand Scholarship, International Baccalaureate and Cambridge International Exams:

This school has a dual pathway so the st udents get strea med at the end of Year 10 int o either Ca mbridge or NCEA. Those doing Ca mbri dge are the ones most li kely to sit Scholarship, but the curriculum isn’t the sa me, so we need to run separate scholarship classes. (Ceanag)

The school doesn't like to put the teachers int o one or the ot her (NCEA or Ca mbri dge) so we end up teachi ng both. (Scot ai gh)

As IB is a t wo-year course I have to separate the mfor the first year and teach all the st uff that is uni que to each and then in the second year (Year 13) they can combi ne as there is a lot of crossover. Alt hough someti mes we take the mas $t$ wo separate classes at Year 13 as well! (Barra) 
New Zealand scholarship examinations cover a more extensive curriculum than Level 3 NCEA and teachers with students completing both have to make special provisions. These included extra tutorials and combining with nearby schools for scholarship classes.

\subsubsection{Assessment as motivator}

Participants shared many ways they believed they used NCEA assessment to motivate students and to connect with student interests. All participants wanted students to take and like their subject, but teaching an optional subject in the senior secondary school means first attracting students to those subjects. Participants thought that the flexibility of NCEA helps as it gives options to them and to the students. They also described various other ways in which they motivate and interest students, through field trips, enterprise studies programmes and connecting their courses to reality as much as possible.

\section{Adjusting the curriculum to create interest}

The flexibility of NCEA has allowed teachers to create courses that they think will appeal to their students. Participants did this through choosing what they consider the most interesting (and achievable) standards from within the same domain:

\footnotetext{
We used to do supply, de mand and the market (standards) at Level 1, but the st udents were really bored, and I mist ad nit these topics are not very engaging. So now we do de mand, production and the circular flow and we' ve found the st udent engage ment is way hi gher. (Kirst y)

We' ve changed fromthe statistics standard to e mployment, because the st ats one just doesn't make sense and is boring. But everyone gets the i dea that there are e mployed and une mployed people. (Ceanag)

We act ually do a combi nation of achieve ment standar ds and unit standar ds for our Level 2 Busi ness course because we want to appeal to a wi de range of st udents, not just those who are acade mic. (Isla)
}

Participants also spoke of omitting standards that assess generic skills such as carrying out research projects or making decisions due to their repetition among subjects:

In accounting I' ve dropped the decisi on-making standards, because they do that in econo mics and they do that in a lot of the other subjects as well, and because they're going to get it here, here and here - they get bored wi t h that . (Barra) 
I don't think my kids are that turned on with big research projects - they do the min so many subjects and by the ti me they get to Year 13 they are over the m-so that's why I drop the m (Sorcha)

A further strategy used to motivate student interest is to mix domains. Most commonly, teachers of accounting and economics have introduced Business Studies standards into their courses. Accounting teachers saw the Business Studies Level 2 achievement standard 90848, Carry out, review and refine a business activity within a community context with guidance, as an authentic opportunity around which to base accounting:

We are looking at introducing the Busi ness Standard (AS90848) because the student $\mathrm{s}$ il ke it. They really li ke all that enterprise st uff - setting up a busi ness, making things, having a market day and we can build the accounting ar ound that. (Ailsa)

I used to have Young Enterprise as extra-curricula, but now we have the Busi ness St udies standard, so I've put it in my course and we' ve based Invent ory ar ound it. (Maeve)

Other participants provided examples that were designed to interest and motivate students in their subjects:

I've put the human resources standard (from Busi ness St udies) int o Level 1 Accounting so the kids will see what happens about e mploying people and the other $\mathrm{t}$ wo Business internals for Level 1 are in our Econo mics course. It gi ves the ma broader underst andi ng. (Maeve)

We' ve developed a course called Commerce St udies and it has taken bits from Econo mi cs, Accounting, Legal Studies and Business Studies. It's tot ally internal at levels 1 and 2, so it appeals to a wi de range of st udents. (Morag)

At level 1, the econo mics teacher and Iteach a combo of economics and accounting - so the kids get anintroducti on to both. I's great because ne can choose the best standards fromeach subject. And Soci al St udi es do a Busi ness standard at Level 2 for moti vation. (Kirsty)

Achieving NCEA credits was also considered a motivating factor and two participants explained how they ensured students complete some internally-assessed standards early in Year 11 to provide them with the confidence that they can achieve. As one shared:

I do the internals first. Then the ki ds knowt hey can do it, it i ncreases their morale. They get an Achieved or Merit and can think "I" m not crap after all". (Ei li dh) 


\section{Connecting with life}

Participants also believed it was important to motivate interest in accounting and economics by connecting assessment tasks with students' interests and real life. The ability to write their own internally-assessed tasks and to adapt TKI exemplars allowed participants to contextualise assessment to local issues or students' interests. Catriona shared, "We definitely spend a lot of time thinking about our students and what they like to do and then rewrite the internals to suit". Barra also used examples that he thought appealed to his students, saying:

\footnotetext{
At Level one you' ve got to do a community organisation, so I choose a club they mingt know or have an affinity with, a surf-lifesaving club, a sports club, a foot ball club or so met hing they will know. A good thing is that you can tai lor it to what the kids know.
}

All participants from Christchurch spoke of using the rebuild of the city after the devastating 2011 earthquake as a context for the employment topic in economics. As one said, "it would be silly to miss the opportunity the Christchurch rebuild is bringing for employment here". Two participants from Dunedin, had used the restructuring at the Invermay Agricultural Research Centre as a context for the employment topic and the Cadbury factory for studying producers. Scotaigh, who taught in a boy's school, had used the 2011 Rugby World Cup as a context to study employment, as he believed it interested the boys and was topical at the time.

Eilidh used a school community issue for Level 1 economics where students investigated the costs and benefits of making the school canteen food healthier. They then gave their research information to the school principal and "he actually changed the food, so the students did something real". Participants who teach accounting gave numerous examples of using local businesses as sites to study topics such as inventory, job costing or cash management. Using local supermarkets was popular because they closely monitor inventory; as Doileag said:

Their turnover is so high, and they knowif there is an event at the local park in summer they will need to st ock more cold drinks - the kids li ke that kind of st uff -it's so real. (Doi leag)

I take my students to see a stock and feed business - this is real life Cant er bury and I base the invent ory inter nal ar ound that . (Ai lsa) 
In Level 3 Accounting the students have to write a report for the Analysi s standard - I let mine pick their own company, so it's a company that act ually interests the m A couple of years ago a few did Pumpkin Patch and act ually bought so me of their shares. This year quite a fe wchose Xero and agai $\mathrm{n}$ want to buy some shares. So, I think that's pretty authentic lear ning. (Kirsty)

I' $m$ hoping to use the local marae ${ }^{4}$ for the community organisation standard at level 1. Maybe they won't give me their exact financials but they could give some general figures that we can turn into a report. (Doi leag)

Participants sometimes included field trips as part of the internal assessment process. Those who used supermarkets as a context to study inventory also included a visit to see this in action. Doileag, who worked in a boy's school, also took her students to Repco (a car parts and accessories retailer) as she believed this type of business appealed to the boys. Her plans to use the local marae as an example of accounting in a community organisation would include a visit to the marae.

Ailsa organises field trips to Wellington that include visiting the Treasury and the Reserve Bank for students at Level 3 to see economic policy in action, and at Level 1 she uses trips to local businesses for the production standard. Maeve tries to include visits to businesses, particularly those that belong to students' parents.

\section{Creating businesses}

Participants believed that having students create their own business was a further way to enhance students' motivation to study economics and accounting. This process can form part of an NCEA assessment programme, can be entered in various competitions offered by the Young Enterprise Scheme (YES), or can be informal. The Lion Foundation YES is a programme in which students set up a company, create their own product or service and sell it in a market. YES can be part of an NCEA qualification or offered as a co-curricular option. Participants described using Business Studies standards simultaneously with YES:

\footnotetext{
${ }^{4}$ A marae is a communal and sacred meeting place which provides space for religious, educational, and community activities.
} 
Young Enterprise works really well within accounting. Because what ever the kids come up with they have to do Invent ory, so I do that with the m for the internal. They've got to process financial infor mation so that's where the MYOB processing internal can come in. (Maeve)

The Young Enterprise programme pretty mich underpins all those standards in Year 13 accounting. (Mhairi)

Those who did not formally assess the students' businesses included them in their programmes or as co-curricular activities due to their perceived motivational impact. Sorcha was particularly supportive of YES but ran it outside the curriculum. However, she thought taking part could be life-changing for students and spoke of students who had changed career plans after successfully running businesses. Her students' successes in national competitions brought prestige to her subject and motivated them to study accounting and economics. She believed students were motivated by the competitive nature of the scheme as well as by the potential to make money, citing a student who had bought a car with her share of profits.

Angus said his students no longer entered YES competitions but they still created businesses and ran market days within their own school. He did not use NCEA standards to assess the businesses but gave students feedback on the process. He said he was always impressed by the students' confidence to order goods and outsource screen-printing and then sell their products either at school market days or on public internet markets such as Trademe. He also believed creating these opportunities for students increased their motivation for studying accounting and economics.

\subsubsection{Assessment is detrimental}

This theme encompasses views regarding possible negative consequences and undesirable effects of NCEA internal assessment, including concerns that NCEA internal assessment was not useful to the teaching and learning process and/or was damaging to teachers' working conditions and professionalism. Implementing internal assessment has had undesirable consequences for teachers. 


\section{Not useful to teaching and learning}

Aspects of internal assessment that could be considered not helpful to teaching and learning included conducting internal assessment as testing which related closely to concerns about authenticity of student work. The reliability of internal assessment was questioned, and teacher participants expressed doubts about teaching students to be assessed and students being over-assessed.

\section{Assessment as testing}

Internal assessment for NCEA was seen by some participants as a form of testing and administered as an extension of the examinations. Many conducted some, if not all, internal assessment as tests, rather than allowing students to complete project-based tasks. Even formative processes in preparation for internal assessment included elements of testing:

\footnotetext{
At our school teachers are putting some of their internal assess ment as part of the nid-year exa ns, so I' mcertainly going to do that this year because it will reduce my marking load. (Scot ai gh)

Even if it's open book we do it under test conditions - for authenticity. (Mhairi)
}

I' ve gone the way of an assess ment - a one hour assess ment, just li ke the end of the year. (Ruairi dh)

With the internals we try to do the for mati ve assessment early, so if we need to, we can go back over things. (Is la)

For the internals what I usually do inter ns of for mative assess ment is gi ve the $m$ quick qui zzes throughout the teaching sequence and before an assess ment I wi ll al ways do a practice assess ment. (Ceanag)

They evaluate their practice tests, what they have done well and what they need to work on bef ore they sit the act ual test. (Mhairi)

Those who taught in schools with more than one class at a year level spoke of all students completing the same or similar internal assessments, under the same conditions and on the same day, negating the ability for internal assessment to meet individual student needs:

It depends on the depart ment but for our depart ment we assess the mthe same because we think they are going to get assessed by the same assess ment at the end of year so why should we assess the mdifferently? (Scot ai gh) 
When it comes to internals they're written and moderated by one or $t$ wo people and then they're sent out to all the teachers teaching that. There's no alt ering for specific types of learners and it's all done on the sa me day. You could be assessing in week 4 if your class finished early, but instead everyone assesses in week 6. I d rather do things like presentations or debates or blogs, but instead it is paper-based tests. Ithi nk our ki ds could definitely be doi ng some varied ki nd of assess ment. (Catri ona)

\section{Authenticity of student work}

The authenticity of student work for internal assessment was a major concern for all participants, and they used varying approaches to ensure authenticity. For some, this concern led to implementing internal assessment as tests. Dealing with past incidences of plagiarism and cheating had made participants wary, but some also lamented that assessment had to be carried out this way. For others, authenticity was managed through closely monitoring students' work, rather than necessarily implementing testlike conditions:

We run the munder test conditions - for authenticity purposes - we have had cheating trouble, so we've become mandat ory on that, which is a bit sad. I' msad we can't do it in a freer way. (Ceanag)

I try to avoi d copyi ng issues by doi ng it under test conditions. These girls could easi ly get a lot of help, it's a boar ding house, so they could wor k together. So I don't put tempt ation in their way. And without computers there's no plagi aris meit her. So that's the way I deal with the whole issue. (Sorcha)

There's a real issue with kids sharing each ot her's work, they don't care. You repeat edly tell the m not to do it, but they just i gnore you. Last year I had this kid who let another copy his nork and I said "why did you let hi $\mathrm{m}$ do it? and he sai $\mathrm{d}$ he felt sorry for hi $\mathrm{m}$ (Ruairi dh)

Ceanag indicated that plagiarism had reached new levels due to students accessing the internet, saying:

Previ ously, when we di dn't have the inter net so freely avai lable, you had to find so met hing to copy, so you can't i magi ne how they could do that . Maybe you had mu mand dad helping you, but good for the m they were probably learning somet hing too. But now, we have students paying for essays over the internet. 
As a result, schools had created extensive mechanisms to prevent plagiarism or to catch culprits. Scotaigh described how his school had instituted Turnitin to detect plagiarism, and a number indicated they required students to sign authenticity statements and school management expected to know assessment conditions for all internally-assessed tasks. But, as Wallace describes, discovering non-authentic work is not without its own problems:

I realised one had copied fromthe other, had reordered paragraphs and changed sentences a bit. But finding that doesn't win me friends - the parents don't li ke it, it's a hassle for me, and it's ti ne-consuming, so the easy thing would be for me toignore it and I wonder if people do. I have to establish that they copied - which is not always easy. And then one had to own up, the whole thing took a whi le, and eventually one got Not Achi eved.

Other participants approached things differently. Catriona describes how she teaches students to use the internet to find information and to paraphrase in their own words. She thought it important to teach them not to plagiarise at all:

I show the m how to use Google, but also how to show they understand
what they are talk ng about. I did an exe mplar paragraph for one of my
st udents. I googled the ter mand we found a nice meaning so Ire wr ot e that
so they knew what to do and how to nake it their own work ... It's
i mportant to teach the kids not to do that (plagi arise) because they can't
get a way with it at uni if that's where they're goi ng. So why shouldn't we
be carryi ng that down and sayi ng we're gi vi ng you this opport unity to use
the internet, to word process this report, do it in your own ti me and then
hand it in? And with that comes responsibility and if you get caught thi s
is what happens.

Barra and Sionn described how they closely monitored students as they completed internal assessment tasks, which served the purposes of providing formative feedback and ensuring authenticity of students' work:

For the Employ ment standard, I do that over a number of peri ods in class, the advantage of that is the integrity of their nork is not brought into question. Whereas if they do it at ho me, that can be anissue. Alt hough, even if they do bits at ho me I get the mt o show me what they are working on and I will gi ve the mfeedback as they go. I mnot sure if that's the right thing to do, but I can see that they are norking a way. I' ve seen what they are doing so when they hand it in I kno wit's their nork. (Barra)

In economics for exa mple, we let them choose which industry they wi 11 investi gate and then of course they all choose different thi ngs, so that lends itself to being their own work. But somebody could produce me some work and I could just ask the m a couple of questions and I would know whet her it's theirs or not. (Si onn) 


\section{Teaching them to be assessed}

While participants did not say they actively taught towards the test, there were hints of NCEA assessment driving curriculum and pedagogy. Tearlag summed up a general feeling by saying "Even though they say you should teach as though NCEA wasn't there, the reality is that you've always got your eye on the assessments and you've always got your eye on time". Others agreed with comments such as:

We're supposed to teach the m to learn but someti mes I think we teach the mt o be assessed. (Scot ai gh)

And probably I teach now more to assess ment than I would have done when I first started teaching. I want the mt o get the results so st uff that is superfluous to the standard - a lot has gone which I feel sad about. (Doi leag)

Eilidh did not believe she taught to the assessment, but the following comments suggests her feedback and instruction to the students is focused on achieving NCEA:

When I give the m the assess ment, the first thing I do is explain the questions, tell the mt o read the mone by one and ask - what do you think this assess ment is about? So they read the title and gi ve some vi eus. Then we read the first question and work out what this is about. And if they don't get it - I can gi ve them an exa mple.

Other comments explained a focus on guiding students towards the higher grade levels of NCEA by explaining what they need to improve for Merit or Excellence. This included teaching the terminology of NCEA assessments:

We need to teach the mt he skills. That at Merit you can do this. (Sorcha)

I will gi ve it (a for mati ve assess ment) back to the st udents with a model ans wer and I' ve taught them howt oread the marking schedule. So we can really look at it and see where do Ithink they sit and what they need to do to get better. They' 11 look at it and gi ve the nselves a grade, and then write three thi ngs down that they think they need to do next to bring this grade up. (Catri ona)

When I do tests, for mative tests in accounting I will break it up into ledgers, balance adjust ments and state ments. So I can say to the st udent you are really good at doi ng fi nancial state ments, but you need to work on getti ng ledgers to Excellence level. (Kirst y)

They need to understand what in depth' is and what's going to gi ve you the better grades. (Doi leag) 
I explain to the m what 'describe' neans, what 'explai n' means and whenever they are doing exercises in class I just say that little thing, descri be, explai n. (Ei li dh)

However, as Ruairidh and Catriona shared, it is an imperative of their job that students pass NCEA assessments:

I could sit in my classroomand talk about the economy all day and get the ki ds involved and have really int eresting econo mi c conversations, but that won't help the mpass at the end of the year. (Ruairidh)

What Ifind really hard is some of my students saying const ant ly from day one -is this what we need to do to get Excellence? I feel il ke sayi ng can we just take a step back, let me teach you the basics, underst and those then we' 11 go deeper and then once you understand that you'll be able to get Excellence. But they're under the i mpressi on that here's your model ans wer, me morise this and in the exam you'll be fine. But then, if they understand it but don't know how to write an NCEA ans wer they won't pass.... So it's a toss-up between teaching the mt o underst and the cont ent and then teaching the m how to show that they understand the content. (Catriona)

\section{Too much assessment}

Some participants expressed concern about the amount of assessment required of students and students themselves made decisions about how much assessment they would complete. As some explained:

The students are in danger of being over-assessed because they're continually doing internals. They've always got internals on the go and tryi ng to balance the load bet ween what they're doing and what they're not doing. (Scot ai gh)

They can be under so mich pressure. If you do si x subjects and there's t wo internals for each subject -that's 12 internals. You have 40 weeks ninus weeks for all the other things ilke exa ms, and ter $\mathrm{m} 4$ is pretty mich revisi on. So you have about 30 weeks to do $12 \mathrm{int}$ ernals. So they're having to deal with an internal every couple of neeks. Ho mework is just about a thing of the past as the st udents always have an internal they have to work on. (Wallace)

I think our kids are assessed so mich that maybe we could just drop the exa ns and three internals or four internals would be enough. (Catri ona)

As discussed in Section 5.2.2 on assessment for educational outcomes, a student may react to too much assessment by not attempting standards. While this practice, referred to as "opt-out", was considered rational by some participants, others introduced mechanisms to limit it because students either risked not achieving enough credits or 
not studying enough of the curriculum. Strategies to reduce opt-out included conducting internally-assessed achievement standards in class time to compel students to at least attempt these, reducing the number of credits overall, and completing internal assessments early in the school year:

The more credits you offer the more 'picky' the students can get - they don't do the externals because they have enough credits. (Kirsty)

When you're doi ng your internals towards the end of the year the st udents have already got the credits they need. Last year only about half handed the last one in. So this year I did the internals near the beginning. (Scot ai gh)

Others also expressed concern about removing assessment standards from their programmes as this amounted to reducing the curriculum. Ceanag thought that this approach led to subjects being too compartmentalised, and students missed the big ideas and were not able to make connections between and among topics. She was also concerned that schools could make themselves look good in terms of NCEA results but thought "the reality is we're teaching a lot less," and that while students could achieve more highly over fewer standards she wondered "whether that created a better educated student - I don't know". Barra agreed a downside to not teaching the whole curriculum was teachers creating their own curriculum, stating "it becomes my decision as to what I think is important, which might be completely different to your decision". Wallace was also concerned that students would miss key content, citing the example of excluding accounting concepts would deny students an understanding of the theoretical basis of accounting. Doileag agreed that not teaching accounting concepts was akin to "playing rugby without the rules". And Tearlag thought student opt-out compounded a lack of curriculum coverage:

What is happeni ng is that I wi 11 choose not to do all the standards, then the st udents will choose not to do so me, soin the end they only have 14 credits - they haven't done mich econo mics at all. 


\section{Reliability and validity}

A number of comments were made that related to reliability and validity of internal assessment for NCEA. In terms of reliability, participants expressed concerns about how much help other teachers may give students to pass internal assessment, how much help they themselves were giving the students, and whether all students in New Zealand had equal opportunities to achieve:

There's no consistency, some people are naking it easier for their kids, so me people are making it harder for their kids. Everyone's marking is different. (Ei li dh)

We have the sit uation where you have internals done at dfferent schools under different conditions with different assess ments. People are goi ng to want their kids to do well. So, for example, I could offer the girls here resub nits untilthey gi ve up. I ve got $15 \mathrm{ki}$ ds int hat class and $15 \mathrm{in}$ anot her class, so I can do that. But if P ve got $37 \mathrm{kids}$, like when I was at my previ ous school and $37 \mathrm{kds}$ in another class - can I really get the mto resub nit, resub nit, resub mit? (Fai lbhe)

I gi ve st udents one practice and an act ual, whereas some schools gi ve three practices then the internal. So - it's not fair on all the st udents. But there are some teachers who abuse the systemt o get their kids a better mark. (Kirsty)

At my previous school my perception was that the challenge is a lot harder than what is goi ng on in other schools. We di dn't gi ve second chances no resub mits. You sat the assess ment and you got your mark. That was it. (Ruairi dh)

Anot her proble m withint ernals is that I don't know what ot her Ec ono mi cs teachers are doi ng, how mich help are they gi vi ng their st udents? I don't knowif ot her teachers gi ve that specific feedback because there is pressure on teachers to get the st udent through. (Wallace)

Tearlag and Barra expressed concerns about the amount of feedback students should receive for an internally-assessed standard. Tearlag wondered if her scaffolding was in fact spoon-feeding, and Barra had concerns about at what point the work ceased to be that of the students and became his:

But when the kid comes in and wants a resub missi on, and so I say "you' ve got this wrong can you explain it to me?" So, they sit there and can't, but if I ask the mthe ri ght questions they probably could. But di d the st udent knowit or di they just give you ans wers to the questions that you asked? (Barra) 
If they don't get it right the first ti ne I use that as an opport unity for the m to resub mit. So then the next point I have to scaffold the m but someti mes it's a bit like spoon-feedi ng. (Tearlag)

The validity of teacher created assessments and exemplar assessments provided by the Ministry of Education was called into question by some:

To get Excellence a student must be able to describe the different wei ghtings allocated to decisions. Then it co mes back fromt he moder at or - it would have been a stronger Merit if they had discussed that (t he wei ghtings). But it's not clear in the TKI task st udents have to do that, so I thought that's really du mb. (Mhairi)

I don't really understand what they want ed out of the TKI ones, or I don't think they do it well enough. (Sorcha)

Wit hout exception, I' ve found the TKI ones need si gnificant modificati on. They are poor examples of what students need to do to achieve the st andard. (Ceanag)

Further threats to validity were the lack of exemplar tasks, exemplars of student answers for some standards, and unevenness in teachers' abilities to adapt exemplars appropriately:

Quite a few subjects di dn't have exe mplars of st udent nork, but quite a few didn't have any tasks either which makes it so dependent on professi onal judge ment. That can be difficult. (Isla)

Probably the one thing I do find frustrating is that we're all modifying them we're all doing the same. But I think that it's crazy that we're changi ng these tasks, and then NZQA expects that we will all get it ri ght I just can't see the logi c in that. (Barra)

\section{NCEA assessment is professionally damaging}

All participants spoke of aspects of NCEA internal assessment that had negative consequences on their workload and their professionalism.

\section{Assessment is a workload issue}

All participants agreed that internal assessment required increased workload demands, including creating tasks, marking internally-assessed work, and monitoring compliance (e.g., sending samples for moderation): 
I focus on creating one new assess ment at a ti me, because I a mt he head of depart ment and my department's really s mall. I a monly getting one noncontact ... I teach all of the Economics so I can only work on one assess ment for each level every year. (Ei li dh)

I make up my own, but it takes up all of my holi days and then so me ... it's so hard pulling all the infor mation toget her, witing all the ans wers ... it takes so long to get it all done. (Tearlag)

One of the proble ms is ti me, teachers are often so damn busy that we just don't have the ti me to prepare exciting, ne wthings. (Malcolm)

Marking and providing feedback is also time consuming:

The internals have added a lot of wor $\mathrm{k}$ for teachers inter $\mathrm{ns}$ of the marking load. I mreserving judge ment on the portfoli o approach, It hi nk it's better for the st udents but worse for the teachers. (Scot ai gh)

Scotaigh's reasons were keeping track of resubmissions, parts of portfolios being handed in at different times, keeping consistency in marking when it was spread over a period of time and dealing with absentee students. Tearlag and Doileag also explained the time-consuming nature of marking:

I'll mark over the weekend and anybody who needs to can resub mit. But this approach takes up all your ti me - it means you have assess ments running through lunch ti me and after school. So metimes I have study groups on a Sat urday - anyt hing like that. Pri vate tutorial sessi ons - and that's what it's become. (Tearlag)

That's the trouble. When people think this is what I do, they're thinking fi ve to ten kids and I' ve got 46 -that's 46 internals to mark each ti me. I mean it's fantastic because you get a class that has diverse personalities and all those things. But the workload is quite big. (Doi leag)

Both Scotaigh and Isla expressed a preference for offering more external assessment as it entails less work for teachers, but their schools had policies to which they had to adhere and, as Isla said, the internal assessment topics tend to be more authentic learning:

It's one of those difficult things because I have to ad mit, that I would mich rather drop an internal - the interpretation, company analysis one, the marking of it takes almost a week of the holi days. So if I was to drop one I'd rat her drop that and do concepts. But in fact that is probably the most aut hentic real ife thing that we cover, looking at a real co mpany. (Is la) 
And as Ruairidh explains, workload considerations are partly why he conducts internal assessment as a series of tests:

Froma purely selfish poi nt of view what I do is easier on my ti me. At my last school I used to work really long hours ... But my home life was suffering ... I was new and I had to create a lot. It's easier now, but I' $\mathrm{m}$ here at $7 \mathrm{a}$ mevery day and I' mstill here at $4 \mathrm{pm}$ you do your co-curricula, and still working on Sundays. So the reality is if the kids do research it's a lot of nork as you have to do it yourself, but an assessment (test) you can put toget her in a few hours and it's mich qui cker to mark. (Ruairi dh)

At the time of the interviews, a major realignment of the NCEA standards with the NZC had occurred and had exacerbated participants' workload. Several participants suggested that the increased internal assessment may have been motivated at least in part to reduce costs for NZQA at the expense of teachers' workloads:

The realignment has brought new standards and it's given us the opport unity to change some of the standards we were doing. But it is a workload issue to change topics too mich and develop ne wassess ments. (Angus)

There has been a big change with the reali gn ment and little recogniti on in ter ns of the i mpact that has had. To all of a sudden go from $25-30 \%$ internally assessed to $50 \%$ internally assessed, the norkload has gone up and there has been litt le recognition fromt he uni on and from NZQA. I $\mathrm{m}$ probably being cynical but I think one of the biggest reasons (for more internal assess ment) is that exans are very expensi ve for NZQA and if they don't have to employ as many markers and exa mi ners then they save money. (Mhairi)

But us doing all that extra internal assess ment on the cheap is pretty annoying, all the extra moderation - that is quite a lot of extra worry and work for no extra pay. (Sorcha)

Mhairi added that adding one more internal per subject nay not see mlike much, but as she explai ns:

What has been the i mpact on courses and workload with at least one more internal? It's pretty mich the same content, but the process of assessing an internal is mich longer than assessing an external. You can teach the st uff for an external in about four to fi ve neeks and you will have a couple of tests and that's it. But for an internal you nim ght teach the st uff for four to five weeks and it night take you another t wo or three weeks to get through that whole process of assess ment and re-submission, and then the workload to mark it all. (Mhairi) 


\section{Moderation damages professionalism}

Internal assessment allows teachers to award credits towards national qualifications so NZQA monitor the process and teachers are held accountable for their decisions. For a number of participants this system has been professionally damaging with many using emotive language such as "hammered" or "slammed" by the moderator, or being "hauled over the coals" and "given a big stick" by school management.

A key issue is the reaction of school management to moderation reports. There seems to be an expectation from school management that teachers will receive one hundred percent agreement on their awarding of grades and require few, if any, modifications to the tasks they have designed:

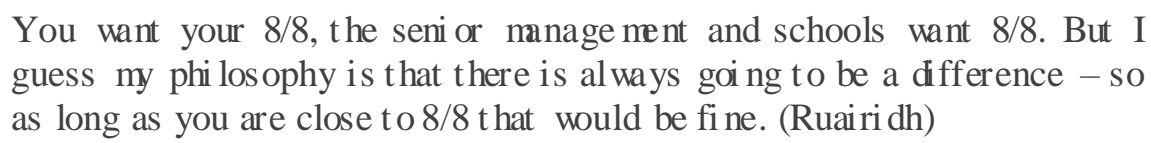

Scotaigh indicated that he was confident but he spent time "making sure the marking is right", because "if you're wrong you get hauled over the coals ... the school wants to know what is going on". He added "I suppose management could argue we're professional teachers and should be getting that right but I thought we were allowed to make mistakes as well".

This sentiment was echoed by a number of others where Tearlag was "petrified it's (moderation) going to fail miserably" and Sorcha shared that "you can get into a bit of trouble if you don't get it right". Catriona also explained that her department had "one terrible moderation. I think it was 0 out $8 \ldots$ we definitely had to explain that to our head of faculty and show him what we had done to fix it". And Kirsty felt "you are judged by your moderation".

Some considered themselves to be equally, if not more, qualified than the current moderator and disagreed with moderator decisions: 
So meti mes Ithink I have more experience than the moderat or in this area and It hi nk I a mri ght. But I still have to justify it (t o school manage ment). (Mhairi)

I had one last year where I only got $2 / 8$, so I' ma bit worried about that this year. Because usually I have 8/8. I did some facilitating when NCEA ca me in -so I was pretty ont oit .... I don't necessarily thi nk she was ri ght. I thi nk I did what she said I was supposed to do. P d sent it to a teacher in anot her school and he didn't fault my judge ments - so he must be wrong as well! We can't have it goi ng back to our schools looki ng li ke there is a fault with us. It's a professional thing. (Sorcha).

Isla and Failbhe explained the issue of changing moderators and standards:

When there was a change in moderat or there was a major change in expectations and suddenly the nord 'describe', act ually means 'explai n' and that was huge, and a lot of people got slammed on that one. The proble $m$ with it is the reaction of seni or manage ment, but when you explai $n$ the new moderat or decided that they want this instead of that, you're okay but it is frustrating. (Isla)

The year bef ore, the year before, the year before $100 \%$ agree ment, $100 \%$ agree ment, $100 \%$ agree ment. But last year 0 out of 8 , all of the m were Excellence under the old syste $\mathrm{m}$ but none of the $\mathrm{m}$ had introduced an additi onal piece of inf or mation. They were all Merit, but the school goes that's not great. (Fai lbhe)

Eilidh described a similar situation where she had used an assessment activity designed by another teacher which had been approved by the moderator, but her moderation report recommended changes:

The assess ment was moderated already, so meone else was teaching it, he had it moderated three ti mes, nothing, no complai nts, not hi ng. So that's why I adopted it. And I got that I had to change a question. Maybe the moderat or was different? But I was conf used.

Ensuring professional safety was a key mechanism in determining participants' decisions to use TKI exemplar materials rather than creating original assessments:

It is risky for moderation if we make too many changes or write our own. (Ai lsa)

I tend to use TKI, modify it a s mall bit - so change the context. The reas on I don't go for developing my own is that if you stray too far then you get ha mmered fromthe moderat or, and the school manage ment get on your back. (Barra) 
According to Mhairi the national moderator encouraged such practice and had informed teachers to expect alterations to their original assessments and that it could take up two or three iterations before they would meet the standard. However, designing original materials that are then critiqued by the moderators leaves teachers vulnerable to school managers' adverse reactions:

He was saying you have to expect that there is going to be revisions required but you have to explai nto your school why you fai led moder ation. He's saying it shouldn't be about failing or passing, it's about making it better for next ti me. But you have this difference of opi ni on or ideas of what moderation is about.

Past experience had left Tearlag fearful:

It was terrible, it was terrible until more recently. But even then I don't knowif $\mathrm{P}$ ve had enough rounds of moderati on to get my confi dence back. Because they were pinging us on the actual assessment and we'd just do wnloaded those from TKI - so we were being criticised for somet hi ng we di dn't wite but we were told to use.

\section{Pressure to perform}

In addition to expectations with regards moderation agreement rates school managements also had expectations with regard to grades and pass rates that teachers and students would achieve. Participants voiced negative consequences that occurred if these expectations were not met:

Our facult y goals are at level one to have $45 \%$ of st udent s achievi ng Merit or Excellence. Then level two I thi nk is to have $80 \%$ Achi eved. (Catri ona)

They expect everyone to pass and at level one - 20-25\% Excellence, at level t wo and three $-10 \%$ mi ni mu m Excellence. There is a report written for the Board of Trustees and when the results come out they are compared agai nst the rest of New Zealand. And because we are decile 10 we're expect ed to be better that the average. (Ruairi dh)

You get knifed in the back by your own school for having Merits, not Excellence ... you're being judged on your results. (Failbhe)

Here, at level one, the results were very, very good, at levelt wo they were not too bad, and at level three -they were poor. That's why I' mhere. The ot her teacher is gone ... Same at my ot her school - you di dn't act ually lose your job, but there are huge expectati ons that you will perfor $\mathrm{m}$ (Ruairi dh) 
Participants also expressed an accountability to their students and internalised the students' pressure to perform.

I' ve taught the m what to do and then they don't pass. They could say it's my teaching, I didn't teach them properly. So I find that reasonably diffi cult. (Barra)

But you do feel the pressure if they haven't done as well as they should have and anot her teacher's class has done better. (Catriona)

You' ve got to look at the subject next door. And if Music is gener ating 10 excellences out of $15 \mathrm{kids}$ and you are generating one then what would you do as a student, which way would you go? (Fai lbhe)

We spend more ti ne on st uff sothey have a better chance of getting good marks. It's very competitive here, all the schools are good but there's not enough ki ds to go round. So then you get the issue of which school has the hi ghest marks. (Tearlag)

\subsection{Conclusion}

This chapter has described the five key themes that were derived from the qualitative interviews. The themes indicate conceptions or beliefs participants have about NCEA internal assessment. These are: assessment as pedagogy; assessment for educational outcomes; assessment as practice; assessment as motivator; and assessment is detrimental. Participants shared many positive outcomes of assessing for NCEA. They discussed how internal assessment is an integral aspect of their pedagogy and that they considered it part of the teaching and learning process. They managed internal assessment to enhance educational outcomes for their students because success in NCEA is an expectation from students, their parents, school management and society at large. Participants recognised the potential motivational impact of internal assessment and strove to connect assessment with student interests and designed programmes and tasks to engage students in learning. However, some participants also believed that implementing internal assessment could be damaging to their professional reputations and decisions with regards the types of tasks used were made in light of this potential damage. Being an assessor of national qualifications requires accountability and responsibility and these were key drivers in determining participants' approach to internal assessment. 


\title{
CHAPTER 6
}

\section{Discussion of the strands}

The purpose of this mixed methods explanatory sequential design was to investigate the conceptions of assessment of teachers of economics and accounting, how they assess the internally-assessed achievement standards for NCEA and the reasons for the decisions they make. Specific questions were:

1. What are the conceptions of assessment for teachers of accounting and economics?

2. What are the reasons for teachers of accounting and economics making the decisions they do about the internal assessment tasks they offer students?

3. What is the impact of their beliefs about assessment on their approaches to internal assessment design?

\begin{abstract}
A goal of mixed methods research is to integrate effectively the data from both strands of the research to provide greater understanding of the phenomenon under investigation (Teddlie \& Tashakkori, 2009). Fetters, Curry, and Creswell (2013) describe three approaches to integrating the data: integrating through narrative; integrating through data transformation; and integrating through joint displays. This thesis will primarily integrate the data through narrative with some use of joint displays. Within a narrative approach, the two data strands can be reported contiguously and/or through a weaving approach. Firstly, this chapter will report the two strands contiguously in order to answer the first two research questions. Chapter 7 will consider how the data from both methods connect and converge (Creswell, 2012).
\end{abstract}




\subsection{Discussion of the quantitative findings}

\subsubsection{Confirmatory factor analysis}

The quantitative aspect of this study explored economics and accounting teachers' conceptions of assessment using G.T.L. Brown's (2006) TCoAIIIA Inventory: CFA was used to evaluate the fit of the data to G.T.L Brown's model. The analysis reproduced some aspects of the model, in particular, the improvement and school accountability conceptions of assessment. However, the data showed a poor fit to the irrelevant and student accountability conceptions and, overall, the fit statistics suggest that G.T.L. Brown model does not adequately fit the present data. The reproduction of the improvement conception shows that teachers in this study agree that assessment information is used in a formative way to improve student learning and to modify teaching. This finding supports the view that despite having a strong focus on external qualifications, participants still reflect the emphasis on assessment for learning in New Zealand's educational culture (G.T.L. Brown, 2011a; Ministry of Education, 2007, 2011)

It is not surprising that the school accountability conception of assessment was also reproduced, given the competition among schools that was established from 1990 onwards. Secondary schools compete for students and qualification pass rates are used as a marketing tool to attract them (Wylie, 2012), with those gaining higher pass rates considered better schools, which has a positive impact on roll numbers (Wylie \& Bonne, 2016). NCEA pass rates are publicised in national newspapers (e.g., Dougan, 2016), making secondary schools publicly accountable for their assessment results. The Better Public Service Target (New Zealand Government, 2012), which introduced a target that $85 \%$ of all young people attain NCEA level 2 by 2017 , has reinforced the concept of using NCEA results as an accountability tool for the education system.

It could be predicted that New Zealand secondary teachers would have expectations of student accountability and thus reproduce this factor. However, two of the three items in this factor (Item 2 - Assessment places students into categories and Item 11Assessment is assigning students grades) loaded weakly (.11 and .14 respectively), whereas G.T.L. Brown's (2011a) research on a more general sample of primary and secondary teachers reported these items loading strongly (.67 and .64 respectively). 
The weak loadings reflect similar international research into secondary teachers' conceptions of assessment; for example, Gebril and Brown (2013) reported .32 and .15 loadings respectively for Egyptian teachers and Brown et al. (2009) reported 24 and .23 loadings for teachers in Hong Kong. It is likely that secondary teachers do hold a student accountability conception of assessment but that the items used by G.T.L. Brown (2006) to measure this conception are not appropriate in this context. Participants were in general agreement with all three items, that is, they agreed that assessment places students into categories, assessment is assigning a grade to students and assessment determines if students meet qualifications standards, but these beliefs do not cohere into a construct. It is unsurprising that participants agreed with these statements because, for teachers assessing senior students for NCEA qualifications, these statements are essentially facts. They are functions of assessment that participants in this research routinely carry out.

The assessment is irrelevant factor in G.T.L. Brown's (2006) model consists of three first-order factors: assessment is bad; assessment is ignored; assessment is inaccurate. While the CFA showed strong loadings of the items to the assessment is bad and assessment is inaccurate first order factors, the items contributing to the assessment is ignored factor (assessment is filed and ignored, of little use and has little impact) all loaded weakly. This finding has similarites to research carried out with secondary teachers in high-stakes assessment environments, such as Hong Kong, Queensland and Egypt where some items did not load well to the assessment is irrelevant first order factor (Brown et al., 2009; Brown \& Lake, 2006; Gebril \& Brown, 2013). Responses to individual items contributing to this factor also show general disagreement with several aspects of the assessment is irrelevant factor. For example, there was general disagreement that assessment interferes with teaching, that assessment is unfair to students, that assessment results are filed and ignored, that teachers conduct assessments but make little use of the results and that assessment has little impact on teaching. These disagreements, and weak loadings, are possibly to be expected for teachers in this study, as well as those in Hong Kong and Queensland, because for all three groups of teachers, assessment results (internal assessment in particular) have substantial utility because they are required to award qualifications. Another explanation is that this finding may also reflect the assessment for learning culture in New Zealand schools (G.T.L. Brown, 2011a; Ministry of Education, 2007, 2011); not 
only does internal assessment for NCEA have utility for qualifications, it can also contribute to student learning.

The inter-correlations between the conceptions specified in the CFA also differ from G.T.L. Brown (2006) and align more with findings from international examination jurisdictions. The CFA revealed a highly positive correlation between the student accountability and improvement conceptions, a finding similar to the results of research carried out in Hong Kong ( $r=.91$; Brown et al., 2009), China ( $r=.80$; Brown et al., 2011) and Egypt ( $r=.95$; Gebril \& Brown, 2013). In contrast, G.T.L. Brown's (2011a) research with New Zealand primary and secondary teachers found a relatively weak correlation between these conceptions ( $r=.23)$. G.T.L. Brown (2011a) attributed the weak correlation to an assessment for learning culture in New Zealand schools, whereas the high correlation shown for other jurisdictions could be attributed to teachers expecting students to be more accountable for their own learning. Brown et al. (2009) concluded that the Hong Kong examination system has a large impact in that Hong Kong teachers consider making students accountable as a means of improving their learning, notions with which New Zealand accounting and economics teachers apparently agreed. A further explanation could be that teachers consider improved assessment results to be an indication of improved learning. These explanations would be consistent with teachers expecting senior secondary students to be more responsible for their own performance than younger students, and with secondary teachers more typically using grades to recognise learning. The strong correlation between improvement and student accountability is also consistent with Dann's (2014) explanation of assessment as learning, in which Dann promotes the prospect of assessment enabling students to understand and gain agency in their own learning. The structure of NCEA certainly encourages student accountability by allowing students to influence their own learning and assessment pathways (Absolum, Flockton, Hattie, Hipkins, \& Reid, 2009; Nusche et al., 2012).

The CFA also established an inverse correlation between the irrelevant and student accountability conceptions of assessment, which suggests that utilising assessment results for student accountability is considered a relevant use of assessment by the teachers in this study. This aligns with findings from Hong Kong (Brown et al., 2009), which similarly found an inverse correlation and concluded that the Hong Kong 
examination system has a large impact on beliefs about the relationship between student accountability and the relevance of assessment. The findings contrast with positive correlations between these conceptions for teachers not necessarily involved in preparing students for qualifications (G.T.L. Brown 2006, 2011a). Taken together, these results suggest that teachers tend to believe that use of assessment for student accountability is more relevant when those results are used for qualifications.

The participants in this study are distinctive in that their main, sometimes sole, focus is teaching in the senior secondary school and awarding NCEA qualifications which could explain why their conceptions of assessment differ from those of participants in previous New Zealand studies. G.T.L. Brown (2011a) compared New Zealand secondary and primary teachers and concluded that "the only statistically significant difference was the mean score for the student accountability conception which was more strongly endorsed by secondary teachers" (p. 45) which he attributed to their role in awarding qualifications. However, G.T.L. Brown's report does not indicate whether or not secondary teachers in his study were solely focused on NCEA. Secondary teachers, when thinking about Year 9 and 10 students, may have conceptions of assessment more similar to those of primary teachers, because these students are generally not assessed for NCEA.

\subsubsection{Exploratory factor analysis}

A subsequent EFA resulted in a four-factor model which, in part, agrees with G.T.L. Brown's (2006) previous work, but includes differences that appear to be linked to the role of teachers in assessing for qualifications, and differing from those identified by G.T.L. Brown. Factor1 assessment describes learning relates to a summative conception of assessment whereby assessment determines what students have learned and whether they have met required standards, but also includes items that relate more to the improvement of learning as well as the validity and usefulness of assessment. Similarities with G.T.L. Brown are that all the items his model associated with assessment describes abilities and assessment is valid are present in this factor. The association of validity concepts with summative concepts of assessment can be explained: assessment must be valid in order to perform a summative function for the award of qualifications. 
In G.T.L. Brown's (2006) model the item assessment determines if students meet qualifications standards is associated with a student accountability conception. However, for the teachers in this study, meeting qualifications standards is part of the summative process. The item assessment helps students improve their learning is associated with an improvement conception in G.T.L. Brown, and its association with more summative functions of assessment for participants in this study may relate to the idea that teachers can make formative use of summative tests (Black et al., 2003). Black et al. describe situations where tests are opportunities to improve students' learning, because students will learn material to succeed in the tests. In addition, once tests are completed, feedback can be provided on the tests, and so formative use is made of summative assessment.

Two items (assessment results are filed and ignored and assessment is unfair to students) are associated with G.T.L. Brown's (2006) assessment is irrelevant factor. Participants in this study were in general disagreement with both statements, signalling that they regarded assessment results as neither ignored nor unfair. Their association with a summative conception of assessment is logical for teachers in this study because if assessment has a valuable summative function then the results are not filed and ignored and neither is assessment unfair to students. This indicates concurrence with Sadler's (1989) view that summative assessment is often geared to certification and this function of assessment has value for students and teachers (Madaus \& Russell, 2011).

The association of these ten items into one factor could relate to the role participants have in assessing internally-assessed standards for NCEA because assessment for internally-assessed achievement standards can involve providing feedback as part of the summative process. A hallmark of the summative use of assessment is determining if students meet qualifications standards, and the co-dimensionality of this item with assessment helps students improve their learning could describe actions that relate to assessing NCEA internally-assessed achievement standards. Teachers awarding internally-assessed achievement standards do determine whether students meet qualifications standards, and may consider that this process helps students' learning. The co-dimensionality of these items could indicate a belief that internal assessment for NCEA can be used for formative purposes, despite its role in the awarding of 
qualifications, which again is consistent with the assessment for learning culture prevalent in New Zealand schools (G.T.L. Brown, 2011a; Ministry of Education, 2007, 2011). It could also be consistent with teachers believing that formative and summative functions of assessment can be compatible and not necessarily "two isolated and completely different functions" (Black \& Wiliam, 1998, p. 35). Teachers in this study may be developing synergies between the two functions of assessment, as Maxwell (2004) and Harlen (2006) claimed is possible. On the other hand, this codimensionality may signal that teachers are providing feedback to students to enable them to pass assessments rather than to improve their learning. This would support Torrance's (2007) view that compliance with assessment criteria can be a proxy for actual improvement of learning. Because the teachers in this study are concerned with assessment contributing to the award of qualifications, they arguably have a strong motive to take this approach.

Although Factor 2 aligns with G.T.L. Brown's (2006) assessment is irrelevant conception, the responses to the items contributing to this factor showed general disagreement or mixed responses to these negative aspects of assessment. The strong disagreement with the item teachers conduct assessments but make little use of the results is unsurprising because the accounting and economics teachers who participated in this study teach almost exclusively at the senior level of secondary school where there is a strong focus on assessing for qualifications, so they would obviously consider that the results are used. Because assessment results are required to award students' qualifications, they are viewed as highly relevant and not ignored. This disagreement could also indicate consistency with the assessment for learning culture prevalent in New Zealand schools (G.T.L. Brown, 2011a; Ministry of Education, 2007, 2011); assessment results are needed to improve student learning, thus the results are useful. The mixed responses to assessment forces teachers to teach in a way against their beliefs, assessment interferes with teaching, and assessment results should be treated cautiously because of measurement error indicates varying views of the relationship between assessment and teaching. They could also indicate varying views with regard to the impact of assessing for internally-assessed standards on their teaching practice and the different practices teachers adopt towards internal assessment. This proposition is certainly supported by the limited literature on teacher practices for NCEA internal assessment whereby teachers have been reported as 
conducting internal assessments as separate tests (East, 2016; Hume, 2006; Moeed, 2010). The practice of separating assessment into individual events could be seen to interfere with teaching and possibly forcing teachers to teach against their beliefs. On the other hand, East reported on teachers who provided multiple and ongoing opportunities over the year to attain the requirements of internally-assessed standards. Teachers in this study who adopted the latter stance could consider that conducting NCEA internal assessment in a progressive and more integrated way does not interfere with teaching.

Factor 3, assessment for improvement, is similar to two of G.T.L. Brown's (2006) first order factors assessment improves teaching and assessment improves learning, with one exception: the item assessment helps students improve their learning associated with G.T.L. Brown's conception did not load to this factor. Participants in this study did not seem to separate the assessment improves learning conception from the assessment improves teaching conception, rather, seeing them as integral to each other. This would align with Black et al.'s (2002) view that for formative assessment to occur the evidence gathered during an assessment process must be used to adapt teaching to meet learning needs. The agreement from participants to the items assessment modifies the ongoing teaching of students, assessment is integrated with teaching practice, assessment provides feedback to students about their performance and assessment feeds back to students their learning needs supports the notion that participants are adapting teaching based on evidence from assessment. However, disagreement with assessment allows different students to get different instruction suggests that this is not at a personal, student level, but rather that modification of teaching is carried out at the whole class level.

Factor 4, assessment for school accountability, is identical to that of G.T.L. Brown (2006), but responses to the items contributing to this factor did not necessarily show strong endorsement of this function of assessment (40\% of participants did not agree that assessment is an accurate indicator of school quality and $45 \%$ did not agree that assessment is a good way to evaluate a school). This aligns with Wylie and Bonne (2016), who claimed secondary school teachers in New Zealand are reluctant to make this connection between assessment results and school quality. The range of responses to these items indicates that some participants did not consider assessment results a 
useful measure of schools and agree with the argument that to use assessment in this way is damaging and unhelpful (Broadfoot, 2007; Madaus, Scriven \& Stufflebeam, 1983; Nichols \& Harris, 2016).

The factor structure and responses to the items show that participants hold both formative and summative conceptions of assessment and that formative use can be made of summative assessments. They are reluctant to agree that assessment information should be used to measure a school's quality, or that assessment is irrelevant.

Inter-correlations between the factors would support these claims. The positive correlation of .53 between assessment awards qualifications and assessment improves learning indicates that participants who endorse one of these conceptions also tend to endorse the other; they may consider that assessment can serve both formative and summative purposes. For NCEA internally-assessed standards this is certainly possible, as teachers decide on the nature of the internal assessment tasks, on the conditions for the assessment (in general), and on resubmission policies that will influence the formative opportunities available. For example, schools (or teachers) can allow students to resubmit assessments to improve grades which provides an opportunity for formative feedback to occur. Similarly, the type of task chosen may provide formative opportunities; for example, a portfolio of evidence gathered over time would allow for the summative function of assessment to be integrated with the formative function. Harlen (2006) and Maxwell (2004) speculated that it is possible to use internal assessment to fulfil both functions of assessment, and empirical studies from New Zealand (East, 2016) and Hong Kong (Yung, 2012) have reported that some teachers do provide multiple and ongoing opportunities throughout the year to attain the requirements of internal assessment. Teachers in this study who adopted this latter stance would consider that NCEA internal assessment can contribute formatively to student learning.

Factor 2 assessment has weaknesses has negative correlations with all of the three other factors. This is logical because, if participants believe assessment has useful functions such as awarding qualifications, improving learning, and indicating school quality, then it is obviously not irrelevant. These inter-correlations have similarities 
to, and differences from, those previously reported. Research on conceptions of assessment undertaken with secondary school teachers internationally (Brown et al., 2011; Brown et al., 2009; Gebril \& Brown, 2013) has similarly reported that using assessment results for accountability is a relevant use, as opposed to research undertaken with primary school teachers, which has shown that using assessment to measure students was more associated with assessment as being unfair (G.T.L. Brown, 2008).

Correlations with factor 4, assessment for school accountability, reflect the mixed agreements with items in this factor. On the one hand, there is a positive correlation of .53 with Factor 1, assessment awards qualifications, suggesting that participants believed that assessment results can be (or are) used as an indicator of school quality, in agreement with Egyptian secondary school teachers (Gebril \& Brown, 2013). This is in contrast with their primary colleagues in New Zealand who rejected the notion that schools should be held accountable for their assessment results (G.T.L. Brown, 2011a) and with Wylie and Bonne (2016), who claimed that secondary teachers in New Zealand similarly rejected this function of assessment. On the other hand, the weak inter-correlation of .18 between assessment results can indicate school quality and assessment improves learning indicates that participants do not believe the more formative functions of assessment can be an indicator of school quality. There are conflicting pressures when teachers are making assessment judgements for student learning and the quality of their teaching and their school is also judged by those assessment results. Participants seemed to be in agreement with Broadfoot (2007) who signalled a fundamental incompatibility between these two functions of assessment. Making schools accountable for assessment results, Broadfoot claimed, is associated with performativity with an emphasis on teaching for better results rather than improving learning.

\subsubsection{Participants' conceptions of assessment}

According to analysis of the quantitative data, the group of teachers participating in this study displayed conceptions of assessment similar to, but not identical with, the more general sample of teachers in G.T.L. Brown's $(2008$, 2011a) research. In general, their conceptions of assessment align more closely with those of teachers in high-stakes qualifications jurisdictions (Brown et al., 2011; Brown et al., 2009; Gebril 
\& Brown, 2013). The differences from the primary teachers in G.T.L. Brown's (2008) and Brown and Lake's (2006) studies support Remesal's (2011) assertion that teachers' conceptions of assessment may be related to the ages of their students. The extraction of a different conception from G.T.L Brown (2006), assessment describes learning, which describes both summative and formative beliefs about assessment, reinforces an ecological approach whereby teachers' conceptions of assessment are influenced by the assessment environment in which they work (Brown \& Harris, 2009; Brown, Lake \& Matters, 2011). Accounting and economics teachers teach almost exclusively at the senior level of secondary school and have a strong focus on assessing for qualifications, which includes carrying out a substantial amount of assessment for national qualifications. Despite this focus on qualifications, teachers in this study also showed a strong tendency to hold a conception of assessment that relates to the formative function of assessment; they agreed that internal assessment for qualifications could fulfil both formative and summative functions.

\subsection{Discussion of qualitative themes}

The qualitative aspect of this thesis explored reasons for teachers making the decisions they do about the internal assessment tasks they offer students. Analysis revealed five key descriptions of internal assessment: assessment as pedagogy; assessment as motivator; assessment for educational outcomes; assessment as practice; and assessment is detrimental.

\subsubsection{Assessment as pedagogy}

The theme assessment as pedagogy reflects a formative view of assessment - learning is a key purpose of assessment (Black \& Wiliam, 1998; Harlen, 1994; Sadler, 1989). Some participants recognised the potential for internal assessment to be integrated with learning in authentic ways and strove to make it part of the teaching and learning process. As such, they were enacting the theoretical possibilities for the formative and summative functions of assessment to be integrated (Maxwell, 2004; Harlen, 2006). They described giving students ongoing feedback and scaffolding their learning to complete internal assessments. This process included teaching students how to selfassess against criteria, allowing them to collaborate with each other and giving them more than one opportunity to achieve. These actions exemplify several aspects of the 
formative use of assessment: involving students in the process (Harlen, 2006); using feedback to improve the work (Taras, 2010); and identifying gaps in students' knowledge (Sadler, 1989). Actions were also indicative of a socio-cultural view of learning (Vygotsky, 1978) whereby external supports are a key element in learning and assessment, and teachers and students collaborate to obtain students' best performance (Gipps, 1994). Using portfolios and multiple opportunities to achieve standards can add validity to the teachers' judgements because they build a picture of student achievement over time (Davison \& Leung, 2009; Harlen, 2004; Maxwell, 2004). While these actions may not meet the vision of Hipkins et al. (2016) that internal assessment within NCEA be enmeshed with learning, some participants in this study were integrating internal assessment with their pedagogy as much as they considered possible.

\subsubsection{Assessment as motivator}

Black and Wiliam (1998) emphasised the importance of involving students in the assessment process and Klenowski and Wyatt-Smith (2014) added to the sociocultural view of assessment by including the proposition that assessment is used to engage students in their learning and to admit them to the community of learners. Thus, the theme assessment as motivator recognises the potential to connect assessment with students' interests which, in turn, would provide motivation for students to complete the tasks and achieve well (Hulleman, Durik, Schweigert, \& Harackiewicz, 2008). Some participants understood the notion that interest in activities would lead to motivation (Deci \& Ryan, 1985; Dewey, 1913) and that motivation and achievement are linked (Nicholls, 1979). Numerous examples were given of teachers contextualising assessment to students' local areas or interests, for example, through using local businesses for case studies and field trips, and drawing on standards from other subjects, such as Business Studies, to create interest and authentic contexts in which to study accounting and economics. These practices show that participants were enacting assessment policy (Ministry of Education, 2007, 2011) as intended; they were using the National Qualifications Framework to design and deliver programmes that attempt to "engage students and offer them appropriate learning pathways" (Ministry of Education, 2007, p. 41). 
In addition, participants considered that achieving NCEA credits, and achieving them well, was a motivating factor for students. They ensured that students achieved some internally-assessed credits early in the year, recognising the relationship between success and motivation (Weiner, 1985). While performance approaches to achievement are linked to extrinsic motivation, there is evidence this approach can lead to more intrinsic motivation later in the learning (Meyer et al., 2007). Participants certainly observed that early success in NCEA led students to have more confidence and more willingness to try. They also believed that the ability to gain course and certificate endorsements was highly motivating for some students, as predicted by Meyer et al. (2007) and confirmed by findings of Meyer, McClure, Weir, Walkey, and McKenzie (2009) who reported that students considered endorsements important and found a "positive relationship of availability of endorsements to motivation" (p. 3).

In contrast to previous research (NZQA, 2014; PPTA, 2007) that raised concern about NCEA endorsements restricting flexible course design, participants in this study were increasingly innovative in their course design, and those who did not already use standards from other domains shared their plans to consider this in the future. Participants tended to offer more innovative and mixed courses at Levels 1 and 2 of NCEA, whereas at Level 3 a pure disciplinary course of either economics or accounting was the norm.

Harris and Brown (2009) also reported that teachers in their study talked about motivation being a purpose of assessment, but their participants conceived of this as external motivation whereby competition, pressure and praise were used to motivate students to work harder. In contrast, participants in this study seemed to be describing the desire to create intrinsic motivation; they did not mention competition nor pressure, but rather wanted to create a desire to complete and succeed by appealing to students' interests, and by enhancing motivation through early success. 


\subsubsection{Assessment for educational outcomes}

Assessment for educational outcomes reflects a summative view of assessment, in that assessment results provide opportunities for students in the future. This theme describes the rational, strategic choices that teachers make in order to maximise life chances for students. Key aims of NCEA were to achieve higher proportions of students staying in school and for more students to gain qualifications, particularly those who had previously been excluded (Hipkins et al., 2016; Hipkins \& Spiller, 2012; Meyer et al., 2007). Participants certainly agreed that they must enable most, if not all, students to gain national qualifications with the highest possible grades, and they implemented many strategies to ensure this occurs. They were aware that students may perform better in internal assessment than in external examinations and increased internally-assessed opportunities while reducing the number of external standards students would attempt. Most participants advised their students to attempt fewer than the maximum number of three external examinations, citing there was no need for more credits or the difficulty of achieving high grades if all three were attempted. A further strategy included reducing the amount of assessment altogether by removing standards and topics that students find challenging, or uninteresting, or those the teacher deems unnecessary. The drive for fewer, high quality credits (i.e., those gained at Merit or Excellence level) was a result of the 2007 and 2010 changes to NCEA that allowed for certificate and course endorsements of Excellence and Merit (NZQA, n.d.d), and also of New Zealand universities requiring a minimum number of Merit and Excellence grades (in addition to University Entrance) for admission to restricted courses (Hipkins \& Spiller, 2012).

Klenowski and Wyatt Smith (2014) described how teachers might adapt assessment to cater for students' diverse needs and to promote participation of students into the learning community. Some participants provided evidence that they attempted a more student-centred, socio-cultural approach to assessment by having differentiated assessment opportunities. They allowed students to choose additional or different standards against which they could be assessed, thus improving participation and outcomes for those students. They achieved this through providing extra tuition and blended learning techniques, which included using proprietary and teacher-made resources for students to work on semi-independently. These actions could also be 
seen to approximate the vision of Hipkins et al. (2016) for NCEA which calls for schools and teachers to use the flexibility of NCEA to provide "lifeworthy learning for each and every student" (p. 206).

Rata and Taylor (2015) put forward a contrasting view with regard to offering different NCEA standards to different students, expressing concerns that restricting students' access to epistemological knowledge is inequitable. They argued that offering differentiated knowledge to students who were considered to have lower ability was based on teachers' value judgements and was likely to perpetuate social and economic inequities. Similarly, Riley (2014) hypothesised a correlation between school decile and the rigour of standards offered. Teachers in this study appeared to be aware of the need to balance the demands of meeting students' needs while still teaching the discipline of the subject. Participants considered that students learn important life skills, such as financial literacy, from economics and accounting and consequently attempted to ensure that students achieved these. Some narrowing of the curriculum had occurred, in particular with many accounting teachers removing the accounting concepts topic, but teachers in both high and low decile schools had removed this topic; this decision was based on teachers' perceived value of that topic and/or student interest, not necessarily on ideas about students' ability to achieve the standard. The economics teachers tended to teach the whole curriculum at Levels 2 and 3 but at some point either they, or the students, decided which assessments students would attempt.

Participants who did teach the whole curriculum were attempting to ensure that students learned the epistemological knowledge of the disciplines. Rather than narrowing the curriculum to that which will be assessed, as described by Broadfoot (2007), Pedulla et al. (2003), and Stobart (2008), teachers in this study were concerned that students be provided with a strong pedagogic framing. They chose content to provide a sound grounding in the discipline (Bernstein, 2000, cited in Rata \& Taylor, 2015). They were aware that students' decisions can undermine this pedagogic aim and were concerned that when students chose which standards to attempt they could be denying themselves important disciplinary knowledge. As one teacher said, "I will choose not to do all the standards, then the students will choose not to do some, so in the end they haven't done much economics at all". Consequently, teachers attempted 
to minimise student opt-out from assessment and adopted a range of practices to ensure maximum curriculum coverage.

Participants seemed aware of their students' possible next steps in life and did everything possible to enable their students to achieve these. If university was the chosen path, teachers ensured entrance requirements would be met, including those teaching in low decile schools - a finding that differs from previous research (Madjar, McKinley, Jensen, \& Van Der Merwe, 2009; Turner, Irving, Li, \& Yuan, 2010). Both Madjar et al. and Turner et al. reported that students from low decile schools did not achieve university entrance at the same rates as students from medium and high decile schools. Madjar et al. concluded that the flexibility and choice associated with NCEA led some students and their teachers to make inappropriate choices in terms of students' ability to gain University Entrance. There were only five participants from low decile schools, but all reported managing NCEA assessment to ensure their students met the necessary requirements. One gave an example of conducting internal assessments under test-like conditions so students could not opt out (as they did when they were expected to complete portfolios) and another always had additional internally-assessed standards "up my sleeve in case a Level 3 student needs it to go to university". Nonetheless, this could be a case of espoused rather than actual practice.

Participants made a number of rational choices to ensure positive educational outcomes for their students. This included a differentiated and student-centred approach to structuring the curriculum and the subsequent NCEA assessment.

\subsubsection{Assessment as practice and is detrimental}

Assessment as practice reflects the major responsibility the participants have in implementing and managing the internally-assessed NCEA standards. Closely related to assessment practice are actions and beliefs, which reflect the detrimental or negative aspects of assessment; therefore, these two themes will be discussed concurrently. As pointed out earlier by NZQA (n.d.d), teachers have the freedom to create assessment tasks that suit their students and teaching programmes. The Ministry of Education and NZQA provide exemplar assessment tasks, assessment schedules, and examples of student work at the different NCEA levels of achievement, but there is no requirement to use these exemplar tasks. In addition, the Conditions of Assessment for internal 
achievement standards (Ministry of Education, 2017) are liberal, suggesting that: flexibility can be exercised when gathering assessment evidence; separate assessment events are not needed for each standard; and the assessment method should not be the same as that for external examinations. Despite this freedom, most participants preferred to use or modify proprietary tasks, or the exemplars, rather than creating their own, a finding that aligns with previous literature reporting on teachers' NCEA internal assessment practices (Alison, 2005; Edwards, 2013; Kane \& Fontaine, 2008; Moeed, 2010). Most reported using in-class tests for at least one internal assessment task. The key reasons given for this were perceived expectations from NZQA or their school management, their own professional confidence and safety, workload issues, and ensuring authenticity of students' work.

\section{Professional confidence and safety}

Negative experiences of external moderation and the subsequent actions taken by school management if moderation reports were considered to be 'poor' had eroded some participants' confidence and led to self-doubt; consequently, they worked to minimise professional risk by using, or strongly imitating, TKI exemplars. Many considered it too risky professionally to design original tasks only to have them "ripped apart by the moderator". These findings concur with previous research (Brooks, 2010; East, 2016; Mizutani, 2009; NZQA, 2014; Taylor et al., 2007; Wylie \& Bonne, 2016) in which teachers have reported critical feedback from moderators, a process which Hipkins et al. (2016) suggested may make teachers risk-averse and reluctant to use innovative approaches. Dissonance between participants' ideas of acceptable assessment tasks and those of the moderator, whose judgements may be no more valid than those of the teacher (Johnson, 2013), had caused some participants to retreat to safer practice (Pedder \& Opfer, 2013). Hipkins (2015) claims this practice is understandable, but unfortunate, because it is unlikely to achieve a variety of ways of gathering assessment evidence. Participants in this study reinforced the views of Hipkins et al. (2016) and Hipkins (2015) in that none shared what could be considered innovative ways of carrying out internal assessment, although some expressed a desire to do so, citing external demands to conform with moderators and school management as key barriers. Participants claimed that moderators actively discouraged innovative assessment design, instead recommending that teachers use, or adapt, the exemplars 
provided by the Ministry of Education, stating that original tasks were unlikely to meet moderation requirements.

Research for NZQA itself (NZQA, 2014) and the Office of the Auditor General (2012) has also reported that moderation procedures have left teachers dispirited and feeling threatened when moderators do not agree with their judgements. Validity and reliability issues understandably have dominated the moderation process because internal assessment results contribute to national qualifications and so must be valid, and marking consistent among teachers, to ensure fairness for all students. However, participants perceived this process to be heavy-handed rather than educative, expressing feelings of resentment, anger and cynicism, rather than respect towards the moderators.

While some participants maligned the moderation processes, the subsequent actions taken by school management if moderation reports were deemed unacceptable was of as much concern. Participants expressed the opinion that their school management seemed to view not 'passing' moderation as an indication of professional incompetence and held teachers accountable. Despite the NZQA (2014) claim that the purpose of moderation is educative and intended to provide feedback to teachers and schools about assessment decisions, not just agreement rates, schools operationalise the feedback as 'passing' or 'failing' moderation. Moderation reports had ceased to be informative about ways in which teachers might improve their practice, and had become mechanisms by which teachers and schools exhibit accountability. All participants were held accountable if the moderator disagreed with their marking or assessments tasks. For example, Scotaigh's school "wanted to know what was going on", Kirsty felt judged by moderation, and Mhairi had to justify herself to her school management even when she thought the moderator was wrong. The combined effect of seemingly negative feedback from moderation, and the associated negative reaction of school management, appear to be examples of what Codd (2005) described as a managerialist culture, whereby schools are more concerned with what can be recorded and documented about teaching and learning than with learning itself. According to Codd, managerialism "treats teachers as functionaries rather than professionals and thereby diminishes their autonomy and commitment to the values and principles of education" (p. 201). Some participants and their schools seemed to value 'passing' 
moderation more than providing pedagogically sound, meaningful and innovative internal assessment tasks, suggesting that the summative, accountability function of internal assessment was dominating any possible learning functions.

Hall (2005) had warned that although the NCEA assessment reform intended to involve teachers more in the assessment process, central control did not diminish; subsequent monitoring limited teachers' freedom. One could argue that central control has actually increased. Some participants who were confident to produce their own assessment materials did so in consultation with the moderator, and, rather than describing a collegial conversation, such consultation seemed more like adviceseeking with the power and control residing with the moderator. Further evidence of NZQA asserting power and control is in the provision of Best Practice Workshops. While the provision of these is welcomed by teachers (Hipkins, 2013; NZQA, 2014; Office of the Auditor General, 2012; PPTA; 2016), the fact that the national moderator is the facilitator of the workshops can further position him or her as the sole expert.

\section{Professional support}

In contrast to previous research on Best Practice Workshops which elicited generally favourable perceptions (Hipkins, 2013; NZQA, 2014; Office of the Auditor General, 2012; PPTA, 2016), participants in this study highlighted the inadequacy of professional support that is provided for implementing NCEA internal assessment. Some considered the Best Practice Workshops useful professional development, while others found them frustrating, describing situations in which the workshop descended into dissenting disarray. The useful aspects were meeting the national moderator, which had led to a more positive working relationship, and networking with other teachers. It seems that the purpose of achieving consistency was less successful with some questioning the ability of the moderator to provide sound professional advice and believing that changes in the national moderator led to expected standards changing. NZQA (2014) has reported similar concerns regarding "how the wisdom of the solo expert moderator gets transferred to the successor" (p. 12) and questioned the expertise that existing national moderators had with the 2010-2012 revised internal standards. Comments by participants, such as "Sometimes I think I have more experience than the moderator", "I wonder how they got the job", and "Just because 
you have the name 'moderator', does that mean you know it all?" certainly confirm previous opinions.

Workshop delivery ignores previous preferences expressed by teachers for a more personalised approach to NCEA professional development (Starkey et al., 2009; Taylor, Yates, Meyer, \& Kinsella, 2011). The international literature (e.g., Dall'Alba \& Sandberg, 2006; Hoekstra, Brekelmans, Beijaard, \& Korthagen, 2009) agrees that, because many different practices are occurring among teachers when reform is being embedded, there are many different professional development needs and therefore support for teacher learning needs to be differentiated. All participants agreed that they preferred the more individual approach of working with selected colleagues from other schools, citing networking with other colleagues as a valuable source of professional support.

Participants described moderation procedures and professional development for internal assessment as control rather than professional support, which resulted in feelings of self-doubt, anger, and distrust. Instead of teachers and the national moderator coming to shared understandings about how standards might be assessed, the national moderator has the power to determine this. This situation is less than ideal when the competency of the national moderator is called into question, and even if the national moderator is highly competent, participants questioned allowing this level of power to reside in one person. NZQA (2014) claims it has "well articulated processes for inducting new moderators and for supporting their practice" (p. 13) but also admits that 'building teachers' assessment practices relies on the concurrent building of moderator practices" (p. 13). An avenue for future research would be to provide empirical evidence regarding national moderators' pedagogically sound (or otherwise) understandings of how internal assessment should or could be carried out and investigation into national moderators' practice in relation to policy and standards. 


\section{Pragmatic decision-making}

A further aspect of participants' internal assessment practice that seemed to be influenced by detrimental or negative aspects of assessment was the tendency for some, if not all, internal assessment tasks to be conducted as in-class tests. Despite the Conditions of Assessment (Ministry of Education, 2017) actively discouraging examination-like conditions for internal assessment, participants reported continued use of this method. This practice is the antithesis of the aims of internal assessment, which are to allow assessment to be integrated with teaching and learning and to assess a much greater range of skills (Davison \& Leung, 2009; Harlen, 2006; Maxwell, 2004; NZQA, n.d.a). However, the practice is not unusual and aligns with findings on teachers' practices with internal assessment in Hong Kong (Yung, 2012) and other studies on the New Zealand system (East, 2016; Moeed, 2010). Yung claimed that teachers' beliefs seemed to be a key driver in how the teachers in his study operationalised internal assessment; however, participants in this study seemed to understand that alternative forms of assessment, such as portfolios, were more pedagogically defensible, but cited pragmatic reasons for not using them. East and Moeed similarly reported on the prevalence of pragmatics as a driver for decisions on how to assess the NCEA internally-assessed standards.

Pragmatic reasons that dominated participants' decisions to use tests for internal assessment were fear of student dishonesty and teacher workload issues. Student dishonesty, either through students sharing answers with each other, by accessing answers to the exemplars that are available on the NZQA website, or, in one school, students using online ghost-writing services, was cited as a key reason for conducting internal assessments as in-class tests. The increasing opportunities the internet affords for student dishonesty was a proposition put forward by several participants. Murdock, Stephens, and Groteweil (2016) claim it is difficult to gauge the prevalence of academic cheating because of the reliance on institutions self-reporting, but there is general opinion that it is on the rise along with evidence that up to $50 \%$ of secondary school students in New Zealand admit to cheating or collaboration (Colmar Brunton, 2012, cited in Murdock et al.). NZQA (n.d.h) assigns the responsibility of ensuring the authenticity of students' work to assessors, who in this case are the teachers - a role they take seriously. Participants and their schools cited elaborate mechanisms to 
ensure the authenticity of students' work, but for most, the use of an in-class test was seen as the most expedient way to ensure students' work was authentic.

However, not all participants expressed such strong opinions about student dishonesty. Those who did not, favoured more open methods of assessment that ensured authentic work through: knowing the students and their work well; providing on-going monitoring and feedback to students as they progressed; designing internal assessment tasks to appeal to student interests or allowing students to work on self-selected topics; and teaching students the ethics of plagiarism. Some authors have rationalised that a student's personality determines the level of dishonesty (Giluk \& Postlethwaite, 2015), but others have suggested it could be a function of the classroom context with classrooms that value personal improvement and risk-taking, as opposed to competition and goal setting, displaying lower incidences of cheating (Anderman, Griesinger, \& Westerfield, 1998; Murdock, Hale, \& Weber, 2001).

Other researchers have claimed that students' attitudes towards cheating are affected by the quality of their relationships with teachers (Anderman, Freeman, \& Mueller, 2007), and the pedagogical competence and personal commitment the teacher displays (Rabi, Patton, Fjortoft, \& Zgarrick, 2006). Findings from this study would support these claims. Participants who reported carrying out all their internal assessment under test-like conditions also reported making minimal changes to the exemplars to prevent plagiarism (not to meet students' needs), allowed few or no resubmission opportunities, and some had a generally negative attitude towards NCEA. It is interesting that the seven participants who reported these actions and beliefs worked in high-decile schools with six of them in single-sex schools. These types of schools typically achieve more highly in NCEA (Thrupp \& Alcorn, 2010) and could be seen to favour testing; in the 1990s they lobbied to maintain external examinations rather than internal assessment (Strachan, 2016, cited in Hipkins et al., 2016). This aligns with Anderman et al.'s (1998) and Murdock et al.'s (2001) propositions that the culture of schools plays a major role in fostering different rates of cheating.

Workload issues have been raised in many assessment jurisdictions that include an internal assessment component (e.g., East, 2016; Stanley et al., 2009; Yan, 2014; Wylie \& Bonne, 2016; Yip \& Cheung, 2005), and participants in this study were no 
exception. Managing internal assessment creates considerable workload as teachers must write or adapt multiple assessment tasks, which they subsequently mark. Therefore, workload considerations influence the choice of internal assessment tasks. The use of in-class tests, in conjunction with other forms of assessment (e.g., portfolios), was justified by some participants on the basis that the combination of assessment types balances students' opportunities to achieve with their own workloads. Xu and Brown (2016) discuss similar compromises required to ensure that teachers' assessment practice is feasible. Several participants agreed with the example provided in $\mathrm{Xu}$ and Brown that large class sizes limit the manageability of too much portfolio-based assessment and limit their provision of resubmission opportunities.

A further concern is that excessive workload can lead to negative feelings about internal assessment (Jaba, 2013; Majid, 2011). Some participants expressed such negative feelings and a desire to revert to more external assessment, but said they were prevented from doing so by school policies. The 2010-2012 changes to NCEA standards, which increased the internal assessment component to at least $50 \%$ for each subject, had led to resentment towards NZQA. For some participants, this change was regarded as a cost-saving measure on the part of NZQA; by reducing the external component, NZQA would pay fewer external markers, a cost that some saw was transferred to teachers who now had more marking responsibility but no corresponding monetary reward. Whatever the validity of this claim, it points to negative attitudes and distrust that have built towards NZQA. Additionally, when teachers perceive their workload to be excessive they may not produce quality work (Qian, 2014), and actions such as participants making minimal, or no, changes to exemplars, and conducting internal assessment as tests are indicative of this occurring.

\section{Performance expectations}

The increasing pressure from schools for teachers to meet performance targets was another negative impact on participants' practice. Participants and their colleagues were held accountable by the school's management for their students' achievement rates in NCEA. As one rather bluntly said, "you get knifed in the back by your own school for having Merits, not Excellences" and another suggested his predecessor had been "moved on" due to students not meeting expected achievement rates. Some participants reported that their schools had expectations that certain percentages of students would achieve 
Merit and Excellence at each NCEA level and that their school's achievement would at least be comparable with other similar schools. Hipkins et al. (2016) claimed that teachers were indicating that schools set them individual achievement rates and participants in this research have supported this. An issue that can arise from having performance expectations is an inclination to teach to the test (Wyse \& Torrance, 2009), which some participants reported trying to avoid, whereas others admitted that at times they felt they were "teaching the students to be assessed". It seems that, as Broadfoot (2007) warned, if assessment data are used to evaluate schools and teachers, a culture of performativity is likely to arise.

Achieving certain pass rates could be considered a legitimate aim of schools, as teachers should have accountability for their practice, but if the consequences are too high this could lead to beliefs that this function of assessment is irrelevant (G.T.L. Brown, 2008). Participants were not in favour of this practice and felt under pressure to meet these demands. The literature has reported on the stress students experience around assessment and performing well (e.g. Locker \& Cropley, 2004), but less is written about the stress teachers experience when preparing students for assessment. In addition to workload stress associated with NCEA, participants also experienced stress with respect to meeting achievement targets.

\subsubsection{Internal assessment practices}

The preceding discussion has revealed that teachers' internal assessment practices are multiple and varied. Their practices can be conceptualised on a continuum from complying with an assessment culture to enacting a testing culture (Wolf, Bixby, Glenn, \& Gardner, 1991). Internal assessment within a testing culture tended to be in-class, separate assessment events with little or no feedback or reassessment opportunities. In an assessment culture, portfolios with ongoing feedback and reassessment opportunities were provided, practices that align more closely to the philosophy behind incorporating internal assessment into qualifications (Davison \& Leung, 2009; Harlen, 2006; Maxwell, 2004). Although, even within an assessment culture, the NCEA internal assessment was separated from normal classroom learning. East (2016) reported there was a perception among teachers that high-stakes assessment needs to be separated from normal work and claimed teachers need support to accept the validity of lessonembedded evidence. Data from this research support that claim but suggest that the 
national moderators also need such guidance. Their advice that teachers use internal assessment tasks that closely resemble the exemplars reinforces this interpretation. If national moderators tell teachers that teacher-created tasks are unlikely to 'pass' moderation, and teachers fear for their professional safety if moderation is not passed, then a cycle of safe, rather than innovative, practice is encouraged.

Participants did tend to situate themselves in either an assessment or a testing paradigm, but these behaviours have been described as a continuum; not all individual teacher actions were typified by the extremes. Most of the participants $(n=15)$ described behaviours that were more at an assessment culture end of the continuum, behaviour that has been analogised as acting as ushers because they opened doors to create opportunities for students to achieve. At the other extreme, seven participants behaved more like gatekeepers in that they treated internal assessment as extensions of examinations. However, participants were not necessarily dichotomous within the continuum, illustrating the complexity of behaviours and beliefs associated with assessment (Bonner, 2016; Brown, 2011a; Harris \& Brown, 2009; Remesal, 2011; Wyatt-Smith, Klenowski, \& Gunn, 2010). The aim, however, was not an attempt to pigeon-hole the participants into a narrow assessment identity (Looney et al., 2017) but to focus on assessment behaviours that clustered around certain ideas and behaviours. As with previous literature (e.g. Adie, 2013; Davison, 2004; Horsley, 2012; Shohamy, 2001) metaphors were used to describe these behaviours.

East (2016), Mizutani (2009) and Moeed (2010) have described varying practices of teachers in relation to NCEA, and the findings from this study concur that different teachers actualise internal assessment in different ways. The findings from this study also show teachers themselves vary in their assessment practices. At times, individual teachers would capitalise on the opportunities afforded by internal assessment and provide formative and innovative opportunities. On other occasions, and with different standards, they would not. 


\section{CHAPTER 7}

\section{Discussion - Converging the data strands}

The confirmatory factor analysis showed an inadmissible fit of the data to G.T.L. Brown's (2006) model, although the confirmatory and exploratory factor analysis reproduced aspects of the model. When the quantitative and qualitative data are considered together, greater similarities with G.T.L. Brown's model emerge. Convergence of the data from both strands of the research shows that participants in this study agree with most of the conceptions of assessment as identified by G.T.L. Brown. On the other hand, one conception was not reproduced and a different conception of assessment related to being an assessor for qualifications emerged. The interviews provide further explanations for patterns and relationships extracted from the qualitative analysis.

Table 7.1 summarises the quantitative factors and qualitative themes and how they converge and complement each other 
Table 7.1

Convergence and complements among quantitative factors and qualitative themes

\begin{tabular}{|c|c|c|}
\hline Quantitative factors & $\begin{array}{l}\text { Overarching } \\
\text { conceptions }\end{array}$ & Qualitative themes \\
\hline $\begin{array}{l}\text { Assessment for } \\
\text { improvement } \\
\text { Assess ment provi des } \\
\text { feedback t o st udents about } \\
\text { their perfor mance, teachers } \\
\text { modify teachi ng to meet } \\
\text { needs i dentified from } \\
\text { assess ment and assess ment } \\
\text { can be int egrat ed wit h } \\
\text { teachi ng practice. } \\
\text { Assessment describes } \\
\text { learning } \\
\text { Assess ment est abli shes what } \\
\text { students have lear ned, is not } \\
\text { i gnored, nor unf air, measures } \\
\text { hi gher order thi nki ng ski lls } \\
\text { and det er ni nes if st udents } \\
\text { meet quali fi cati ons. } \\
\text { Assessment has weaknesses } \\
\text { Assess ment forces teachers to } \\
\text { teach in ways agai nst their } \\
\text { beli efs, i it erferes with } \\
\text { teachi ng, and is i mprecise. } \\
\text { Assessment for school } \\
\text { accountability } \\
\text { Assess ment can be an } \\
\text { indi cat or of school quality. }\end{array}$ & $\begin{array}{c}\text { Assessment is } \\
\text { detrimental } \\
\text { Assess ment has } \\
\text { weaknesses. } \\
\text { Assess ment is } \\
\text { detri mental. } \\
\text { Assessment is for } \\
\text { accountability } \\
\text { Assess ment as practice. } \\
\text { Assess ment for school } \\
\text { account abi lity. }\end{array}$ & $\begin{array}{l}\text { Assessment as pedagogy } \\
\text { Assess ment is part of the } \\
\text { teachi ng and learni ng } \\
\text { process, but achi evi ng } \\
\text { int egrati on of NCEA i it o } \\
\text { learni ng is not } \\
\text { strai ghtfor ward. } \\
\text { Assessment as a motivator } \\
\text { Int ernal assess nent can be } \\
\text { used to moti vate st udents and } \\
\text { to connect with their out si de } \\
\text { interests. } \\
\text { Assessment for educational } \\
\text { outcomes } \\
\text { Teachers work so that } \\
\text { st udents achi eve NCEA with } \\
\text { maxi mu m grades, show } \\
\text { mastery of subjects and are } \\
\text { prepared for uni versity etc. } \\
\text { Assessment is detrimental } \\
\text { Aspects of assess ment are } \\
\text { irrelevant and not usef ul to } \\
\text { teachi ng and learni ng and/or } \\
\text { da mgi ng to working } \\
\text { conditi ons and } \\
\text { prof essi onali s m } \\
\text { Assessment as practice } \\
\text { Assess ment is part of } \\
\text { teachi ng practice, whi ch is } \\
\text { inf luenced by professi onal } \\
\text { develop ment. }\end{array}$ \\
\hline
\end{tabular}




\subsection{Overarching conceptions}

\subsubsection{Assessment is for learning}

The qualitative and quantitative data showed that teachers participating in this study hold a strong agreement with the formative, or improvement, conception of assessment. The qualitative themes assessment as pedagogy and assessment as motivator align with the quantitative factor assessment for improvement to support an overall belief that assessment is used to improve student learning. Items that contributed to the factor assessment is for improvement - which are that assessment feeds back to students their learning needs, information modifies ongoing teaching of students, is integrated with teaching, provides feedback about their performance, and allows different students to get different instruction - were reinforced in the qualitative interviews, whereby teachers described a range of strategies such as giving students feedback, new work and extra tuition to their improve learning. These actions align with previous literature on the formative use of assessment. For example, feeding back to students their learning needs and using assessment information to modify teaching are considered prerequisites for the formative use of assessment (Black, Harrison et al., 2002; Sadler, 1989). This strong association with an improvement conception of assessment aligns with previous research on teachers' conceptions of assessment (G.T.L. Brown, 2002, 2004; Brown \& Gao, 2015; Brown et al., 2011; Brown et al., 2009; Brown \& Michaelides, 2011; Chen \& Brown, 2013; Remesal, 2011), and reflects New Zealand's formative assessment culture (Ministry of Education, 2007, 2011).

Despite the belief that assessment should improve students' learning, and all participants being able to explain the formative function of assessment, findings revealed that some participants had difficulty conceptualising how to implement the formative function of assessment in the context of internal assessment for NCEA. The quantitative data showed conflict, some participants generally disagreeing that assessment interferes with teaching and agreeing that it is integrated with teaching, whereas others did not. The qualitative interviews can provide some explanation for this contrary finding. Participants experienced tensions with regard to how much (if any) feedback they were able to give students, and described varying practices with regard to the types of internally-assessed tasks they provided for the students. As a result, at times some teachers were giving students feedback on internally- 
assessed standards and incorporating these into classroom learning, but on other occasions they were not. Other participants rarely gave feedback and tended to assess internally-assessed standards through tests. These different practices can account for the mixed beliefs that feedback on internal assessment may, or may not, provide opportunities for student learning. Black and Wiliam (1998) and Broadfoot (2007), albeit not referring to NCEA, predicted that teachers would experience tensions in implementing both the formative and the summative functions of assessment, and this was the case for participants in this study. Bonner (2016) agrees that teachers experience ongoing tension and conflict trying to balance the expectations of external assessment with "beliefs that support AfL" (p.35).

It is not surprising that tensions and confusion existed among the participants; NZQA itself gives contradictory advice on the administration of internal assessment. Information from NZQA (n.d.i) supports a belief that teachers can provide feedback over a period of time as students work on portfolios or performance tasks, but suggests that the feedback should "become less specific the closer the student is to the submission date". In terms of giving students resubmission opportunities, NZQA categorically states that any resubmission "must take place before the teacher gives any feedback to the whole class (or any student)"; however, further assessment opportunities can be preceded by more teaching if a new assessment opportunity is provided. This advice is clearly supporting the use of a separate internal assessment task that, at some point, will be submitted for marking and it is also actively discouraging using internal assessment in a formative way by not allowing feedback to be given. However, this is contrary to information provided on other sections of the NZQA website (e.g., NZQA, n.d.j) where comments such "Learning is not increased by repeated summative assessment, but by extensive feed forward and feedback" and "where evidence is accumulated over time, assessors will provide feedback at regular intervals during the preparation for a final version for assessment". Teachers referring to these different web pages would be left confused as to acceptable practice for internal assessment and it appears there is little support or guidance on how teachers might integrate assessing internally-assessed standards more with teaching. Participants themselves had to work out how, and if, they could integrate assessment with learning, but innovative and experimental internal assessment design was considered professionally risky. 


\subsubsection{Assessment is for qualifications}

The exploratory factor analysis identified a dimension - assessment describes/measures learning - that appears to reflect the significant role participants play as assessors for NCEA, with which the theme assessment is for educational outcomes converges. The assessment describes/measures learning factor included the items assessment determines if students meet qualifications standards, assessment is a way to determine how much students have learned, assessment results are trustworthy, assessment establishes what students have learned, assessment measures students' higher order thinking skills, assessment results are consistent, assessment results can be depended on, assessment helps students improve their learning, assessment results are not ignored nor unfair. All of these could relate to teachers implementing internal assessment for NCEA, and the theme assessment is for educational outcomes refers to strategies teachers adopted to enable students to gain qualifications with the highest possible grades, as well as to prepare them for their future lives. Together these ideas signal the role that teachers represented in this study have in awarding, and teaching students to achieve, national qualifications.

This conception of assessment has not been previously reported in the literature, but it is in some respects similar to G.T.L. Brown's (2006) student accountability conception in that it includes the item assessment determines if students meet qualifications standards, and Remesal (2011) reported a "societal-accreditation" conception of assessment. G.T.L. Brown's (2008) student accountability conception holds “students individually accountable for their learning” (p. 23) whereas the conception derived from this research also incorporates teachers' accountability towards that learning. Remesal's "societal-accreditation" conception also has elements of student accountability and summative functions of assessment, but a fundamental difference is that the conception derived from this study includes the teachers' role in awarding qualifications and encompasses the idea that assessment for qualifications can be integrated with classroom learning. Remesal claimed that her "extreme pedagogical" and "societal-accreditation" conceptions were two distinct aspects of teachers" conceptions, whereas the assessment is for qualifications conception acknowledges that the summative purpose of assessment can help students learn, and that through assessment teachers manage students' learning, so that students achieve qualifications. 
This conception also bears similarities with previous studies (e.g. Brown et al., 2009; Brown et al., 2011; Hui, Brown \& Chan, 2017) where teachers had conceptions of assessment in which improvement is strongly linked to making students accountable. A further similarity is with Brown, Chaudhry \& Dhamija (2015) who found that accountability was a driving factor in teacher decision-making with regards assessment.

This conception also reflects a summative purpose of assessment, recognises that this purpose of assessment is an integral part of the New Zealand secondary education system, and that it has positive outcomes for students in the form of qualifications attainment (Madaus \& Russell, 2011). Participants acknowledged the importance to students of gaining such qualifications and the profound consequences of not achieving these (Harlen, 2006; Sadler, 1989). The co-dimensionality of the item assessment helps students improve their learning, along with assessment strategies participants discussed in the interviews such as using portfolios and/or allowing students to resubmit assessments, show that internal assessment for summative purposes can be integrated with teaching and learning as Davison and Leung (2009) claimed.

\subsubsection{Assessment is detrimental}

The quantitative data reproduced G.T.L. Brown's (2006) assessment is irrelevant conception but there was low agreement with the individual items relating to that factor; which are that assessment forces teachers to teach against their beliefs, interferes with teaching, is imprecise, treated cautiously, and made little use of. Negative views towards assessment expressed in the interviews, such as there being too much assessment, assessment considered to be testing, and the teachers' vulnerability with regard to internal assessment do not align directly with G.T.L. Brown's irrelevant conception, but show some similarities. For example, too much assessment, and assessment interfering with teaching, are similar concepts, and echo the thought that aspects of summative assessment are not useful to learning and teaching, supporting the claim of incompatibility between the formative and summative functions of assessment (Black \& Wiliam, 1998; Sadler, 1989). 
Participants' vulnerability regarding internally-assessed standards is more reminiscent of Stiggins' (1995) fear of assessment that results from accumulated negative feelings towards assessment. These negative feelings have their origins in teachers' experience of assessment as students, and can carry on into their professional lives if they have to prepare students for assessments they may not agree with, or have to assess in ways they do not believe in.

Moderation processes for NCEA have certainly led to increased negative feelings about internal assessment, and rather than the process being educative for teachers, it has often resulted in resentment if there is disagreement from the moderator. According to Stiggins (1995), fear of assessment could lead to barriers that prevent teachers from analysing and improving their assessment practice. Therefore, participants who resented, rather than learned from, disagreement could be setting up barriers to improved practice. The impact of imposing accountability mechanisms on top of assessing for NCEA is having a detrimental impact on teachers' beliefs about assessment.

\subsubsection{Assessment is for accountability}

The quantitative data reproduced G.T.L. Brown's (2006) factor that assessment is for school accountability and, while the theme assessment as practice does not converge exactly with the quantitative factor, aspects of the factor and the theme do complement each other. Participants described actions of their schools indicating that assessment results are important indicators of accountability. Mutch (2012) has similarly reported that despite New Zealand not having official league tables, school management recognises that assessment results play a major role in stakeholders' judgements of the quality of schools. Mutch describes a chain of accountability from taxpayers to the government, government to the Ministry of Education, Ministry of Education to schools and from schools to teachers, which aligns with aspects of accountability described by participants. Schools have expectations of certain percentages of students passing various levels of NCEA and expectations of Excellence and Merit grades. Schools also expect teachers to write valid internal assessment tasks, mark students' work accurately according to the national standard (as determined by the moderators), and hold teachers accountable for 'poor' moderation reports. Qualitative data can explain the varied responses on the surveys to the school accountability items; participants recognised that 
schools put assessment data to accountability uses, but did not necessarily agree that this is appropriate. For example, Failbhe's comment about pressure from the school for students to achieve Excellence and not Merit grades, Tearlag describing the pressure to achieve good grades so as to attract new students to the school, and Barra commenting that his teaching could be called into question if students achieved poor results.

Interestingly, neither data source revealed a student accountability conception of assessment and the Heywood-case correlation (i.e., greater than 1) between the student accountability factor and the improvement factor contributed to G.T.L. Brown's (2006) model being rejected as a good fit to the present data. This differs from previous research in New Zealand and Australia in which this conception has been reproduced (G.T.L. Brown, 2004, 2006, 2011; Brown, Lake, \& Matters, 2011), but is consistent with studies of international high-stakes assessment regimes (Brown et al., 2009; Gebril \& Brown, 2013), and also with a smaller qualitative study from New Zealand (Harris \& Brown, 2009). Two items that G.T.L. Brown (2006) considered indicators of student accountability (assessment places students in categories, and assessment is assigning a grade or level to students) did not load on any factors in the exploratory factor analysis, and assessment determines if students meet qualifications standards loaded to an assessment describes learning factor. The lack of association among these items in the EFA suggests they were not measuring the same construct in the participants' minds.

In the interviews, participants did not give a sense of expecting students to be individually responsible for their own learning; on the contrary, they described elaborate mechanisms that they instituted to ensure that students achieved NCEA credits. Many indicated that students needed guidance and surveillance to complete internally-assessed standards and, if left to their own devices, many would not submit and therefore not achieve. As with Harris and Brown (2009), participants in this study described their practices in terms of their roles in improving student learning and achievement, rather than expecting students to be accountable. This finding differs from G.T.L. Brown's (2008) claim that an indicator of student accountability is the increasing role teachers give to students to determine their own learning. Participants in this study gave little indication that they allowed students substantial control; rather, they tended to decide which standards to assess and design their programmes to minimise what they called 
"opt-out". These actions are understandable if schools have expectations of individual teacher accountability because it is in the teachers' professional interests to ensure high achievement rates for their students. Many of their actions with regards NCEA internal assessment seem to indicate that teachers are ensuring their work achieves the expected outcomes as indicated by school management and government policy. This aligns strongly with the power of external accountability as discussed by Lerner and Tetlock (1999) who claimed that accountability is a complex construct that produces a range of effects - only some of which are beneficial.

It is possible that by not expecting students themselves to be responsible that this stance is a further indication of the formative assessment culture in New Zealand schools. According to Black et al. (2002) formative assessment require teachers to use assessment information to alter their teaching to improve student learning, rather than expecting students to be entirely responsible.

Convergence of the data from both strands of the research has shown similarities with, and differences from, previous research on teachers' conceptions of assessment. The differences reinforce the findings of Brown and Harris (2009), Brown, Lake, and Matters (2011) and Remesal (2011) who have argued that teachers' conceptions of assessment are consistent with their use of assessment. In particular, the conceptions of assessment for participants in this study reflect the substantial role they have in assessing students for national qualifications.

\subsection{Influences on teachers' internal assessment practice}

Participants revealed a range of influences on their internal assessment practice, as well as tensions that can arise when teachers are responsible for awarding qualifications. Frameworks have been proposed to understand teachers' assessment practice more clearly. Fulmer, Lee, and Tan (2015) conjectured that there are three levels of influence on teachers' assessment beliefs and practices: the micro-, meso- and macro-levels. The macro-level focuses on national policies and cultural influences, the meso-level on factors related to the school and the school community with the micro-level residing with individual teachers' characteristics. Xu and Brown (2016) provided a framework whereby teachers' knowledge of assessment provides a basis for their actions and is 
filtered by their conceptions of assessment. According to $\mathrm{Xu}$ and Brown, only knowledge that is compatible with conceptions is accepted and used, and assessment practice is also influenced by micro- and macro-contexts which results in teachers having to make compromises that lead to a teacher assessment identity. Xu and Brown's framework is cyclical, so a teacher's assessment identity will, in turn, influence the compromises they make. Looney et al. (2017) extend these frameworks to include how teachers feel about assessment, that is, do they have the confidence to apply their knowledge and skills of assessment in the ways they prefer? Alternatively, they have skills, knowledge and confidence but may not believe certain assessment processes are effective. Looney et al. claim teachers' self-efficacy and their sense of control, in terms of assessment, are determinates of their assessment practice. The internal assessment practices of participants and their conceptions of assessment align with these frameworks. Their knowledge, skills, beliefs and feelings about assessment were reflected in the decisions they made in response to accountability pressures imposed by the micro-, meso- and macro-contexts within which they worked, and differences in these appear to result in different assessment practices.

\subsubsection{The macro-context}

Participants operate within the macro-context of the New Zealand education system and, within that, a macro-subsystem of national school level qualifications. Two overarching conceptions reflect this macro-context: assessment is for learning aligns with the formative assessment culture of the New Zealand education system, and assessment is for qualifications is indicative of the considerable role participants have in assessing for NCEA. The factor and thematic analysis found common responses to the macro-system but, in addition, the interviews revealed that teachers react individually to the influences of the macro-system. Teachers are compelled to comply with changes suggested by the national moderators, but attitudes towards the required changes varied. Some complied willingly, possibly acknowledging errors on their part, whereas others believed that the moderator is often wrong, but had no choice but to make the indicated changes.

From the participants' points of view, the macro-system of NCEA (including moderation) determined whether they were considered competent or incompetent assessors, which was framed as 'passing moderation' (or not). This feedback is public; school managers and NZQA personnel have access to moderation reports, which can 
increase feelings of vulnerability, and as such has an impact on teachers' assessment identities. These common and individual responses to the macro-system support $\mathrm{Xu}$ and Brown's (2016) theorisation that teachers make assessment compromises that vary by teacher and context, but also there can be generalised decisions that are applicable to a wider range of teachers.

\subsubsection{The meso-level context}

According to Fulmer et al. (2015), the meso-level is the school community in which the teachers work and asserted that in the field of assessment research "relatively little prior work has paid explicit attention to these influences" (p. 485). Two of the conceptions derived from this research reflect the influence of the meso-system on those conceptions. The conception assessment is detrimental represents negative accountability influences from the macro-context, but also the strong impact of accountability expectations within the meso-level of the school. Assessment is for accountability embodies the culture of competition among New Zealand schools that has emerged since 1989. The reforms to New Zealand schools that began in 1989, known as Tomorrow's Schools, focussed on granting schools more autonomy, but also increased their accountability. More emphasis was put on competition among schools for students, with funding based on per-student formulas (Wylie, 1999). Schools assign this accountability to individual teachers in their expectations of NCEA performance.

The meso-level of the school imposed expectations with regard to the implementation of NCEA internal assessment, for example, there were policies on how the authenticity of student work should be guaranteed and the amount of internal assessment that could, or could not, be offered. Accountability towards school management was a strong driver influencing the choice of assessment tasks and the conditions under which these were completed. Practices within schools were shared and adopted by teachers even if they were not policy. For example, Scotaigh knew that his colleagues included part of the internal assessment in the mid-year examinations and indicated he would adopt that practice the following year. Participants who work in schools with departments of several economics or accounting teachers reported being required to comply with the demands of the department, for example, all students at a year level having to attempt the same internal task, at the same time, regardless of the suitability of the task or their readiness for it. A general pattern emerged with regard to the impact of the school type 
on participants' assessment identity: those who aligned more with a testing regime tended to work in single-sex, high-decile schools, whereas those whose assessment identity was more associated with an assessment paradigm (Wolf et al., 1991) were more likely to be teaching in a mid to low-decile, state co-educational school.

Brown and Harris (2009) have similarly identified differing impacts of meso-level differences in the use of assessment data in primary schools and Remesal (2011) speculated that the school level of the students influences teachers' conceptions of assessment. However, the bulk of previous literature on conceptions of assessment has emphasised the impact of macro-level national assessment policy and culture on teachers' conceptions of assessment (Brown et al., 2015; Brown \& Gao, 2015; Brown et al., 2011; Brown et al., 2009; Brown \& Michaelides, 2011; Chen \& Brown, 2013; Gebril \& Brown, 2013). For example, Gebril and Brown attributed differences in Egyptian teachers' conceptions of assessment from New Zealand teachers to the highstakes examination system in Egypt, and similarly in China, Brown et al. claimed Chinese cultural values and practices were responsible for differences from Western teachers. However, within a culture, teachers are not a homogeneous group and this research has shown that the meso-context of individual schools has an important influence on teachers' conceptions of assessment and their NCEA internal assessment practices.

In New Zealand it may not be possible to classify teachers as one cultural group; even among the 21 teachers interviewed for this research two identified as Indian, one as English and one as Scottish. Also, since 1990, New Zealand secondary schools have been self-governing, and have been encouraged to compete against each other for students (Wylie, 2012). As a result, schools have marketed themselves as having a distinct culture, for example non-uniformed, co-educational schools who portray a modern outlook, compared with uniformed, single-sex schools who espouse to values that are more traditional. Teachers within different secondary schools may adopt the beliefs and values of that school (or alternatively work in schools that are congruent with their own beliefs) rather than adopting more generic system-wide values. This research has shown that the meso-level of the school seems to be the over-riding influence on teachers' internal assessment practice. 
The macro-system of NCEA and the meso-level of school actions, policy and accountability measures were key determinants of participants' feelings (confidence) and their perceived levels of skill (knowledge). These actions either affirmed teachers' self-efficacy as assessors or raised doubts and reduced confidence. $\mathrm{Xu}$ and Brown (2016) conceptualised teachers' assessment practice as a constant compromise between their knowledge and beliefs about assessment, and the contexts within which they work. Participants described many compromises among the competing influences on their assessment practice that support this claim. They also described tensions in making these compromises. The macro-context of the New Zealand education system advocates the use of assessment to improve teaching and learning, yet a sub-set of that system, NCEA, measures achievement and awards qualifications. Furthermore, an aspect of the macro-system uses NCEA pass rates to measure the effectiveness of education in New Zealand (New Zealand Government, 2012) and NCEA results are used as an accountability tool. Teachers in this study work in these contexts and experience the tensions between using assessment for formative purposes and at the same time for summative qualifications. These opposing purposes of assessment influence their conceptions of assessment and their assessment practices. Additionally, accountability measures within this macro-system, and the meso-system of their school, affected their knowledge of, and feelings and beliefs about themselves as assessors. Knowledge, beliefs, feelings and contexts differed between participants; therefore, the compromises reached varied by context and by teacher (Xu \& Brown, 2016).

\subsubsection{Beliefs about assessment}

Participants revealed that their actual practices did not always align with their preferred practices and that external influences, such as NZQA requirements (or perceived requirements), authenticity of student work, school policy and workload dominated the rationales for their actions. Literature on teachers' beliefs (e.g., Bandura, 1997; Fives \& Buehl, 2016) and teachers' conceptions of assessment (G.T.L. Brown, 2002) contends that beliefs and conceptions guide teachers' actions. Participants in this study revealed that this is not always the case and that external accountability measures can over-ride beliefs in terms of influencing the practices teachers adopt. Rokeach (1968) explains that newly-acquired beliefs are less likely to influence practice and it may be that for some teachers, beliefs relating to internal assessment are relatively new, rather than long-held. Sannino (2008) describes these as dominant and non-dominant 
teaching behaviours. Dominant behaviours are those that are tried-and-true and well supported, whereas non-dominant behaviours relate to new initiatives that require change to existing practices and may not be adequately supported. While internal assessment for NCEA can no longer be considered a new initiative, it was a change to existing practice for most participants, and beliefs as to how it should be carried out are relatively newly acquired. Fives and Buehl (2016) explain how explicit and implicit beliefs either knowingly, or unknowingly, affect teachers' decisions. It is possible that participants' implicit beliefs determine their acceptance of, and compliance with, external accountability influences and that such beliefs explain some of the variation in individual participants' practices. It must be considered that teachers do not always have the autonomy to act according to their beliefs; in the present context teachers must balance their beliefs with the systemic realities of NCEA requirements.

This study has shown that there is not a straightforward relationship between teachers' beliefs and their internal assessment practices, because beliefs are only one influence on that practice. The macro- and meso-systems within which teachers operate are also dynamic and unstable; NCEA itself is not static. Numerous changes have occurred, such as the introduction of endorsements, the change in the relative proportions of internal and external assessments, changes in the nature and number of credits for standards, and changes to moderation procedures and personnel. The number of changing and conflicting influences in play at any point in time have resulted in a wide range of practices between teachers, and for individual teachers over time.

\subsection{Enacting and embedding assessment reform}

Educational change does not always occur as predicted because, as Senge (1990) claimed, the success of educational reform hinges on what individual teachers do in the classroom. The present research has shown that teachers' practices vary, and that teachers themselves are not consistent in their application of change. At its launch, NZQA (n.d.a) claimed that the internal assessment component of NCEA would provide a more comprehensive record of students' achievement, and give students credit for a greater range of skills and knowledge. For this to occur teachers needed to significantly change their practice and thinking about assessment (Hipkins et al., 
2016); however, this study has shown that teachers have many unstable reactions to change and a simple, linear, cause and effect explanation is not possible. Some participants described changes they have made and continue to make to their assessment practices that allow the theoretical possibilities of internal assessment to be realised, and students are given credit for a much greater range of knowledge and skills than they were under the previous assessment system. But, even for individual teachers, allowing for the theoretical possibilities of internal assessment was not a consistent practice; at times teachers limited possibilities for students by carrying out internal assessment as if they were external examinations.

A complex picture of teachers' assessment practices and the reasons for them emerged. These mixed reactions reflect the complexity of assessing students' learning, while also awarding national qualifications. They also reflect the difficulty of enacting and embedding educational reform and support Fullan's (2001) claim that the multidimensional nature of change accounts for mixed outcomes of educational reform. Fullan argued that there are at least three dimensions involved in the implementation of new polices and that teachers may alter none, one, two or all three dimensions. In the context of assessment reform these would be new assessment materials or technologies, new teaching and assessment strategies, and an alteration of beliefs about assessment. Hoekstra et al. (2009) added that during reform some teachers successfully integrate change but others actively resist it. The practices of teachers in this study show agreement with Fullan and Hoekstra et al., but add that making change is not as simple as having the motivation, beliefs and knowledge to do so. Teachers also need permission from the macro- and meso-systems within which they work and they need professional support to make such changes. 


\section{CHAPTER 8}

\section{Conclusion}

\subsection{Summary of the study}

This study used an exploratory, sequential mixed methods research design to investigate the relationships between economics and accounting teachers' beliefs about assessment and their practices in relation to NCEA internally-assessed achievement standards. Participants' conceptions of assessment were explored through the TCoAIIIA Inventory (G.T.L. Brown, 2006). The quantitative data gathered by this inventory were analysed using confirmatory and exploratory factor analysis. Interviews were carried out with 21 volunteers to investigate further their practices for the internally-assessed component of NCEA and the reasons for making the decisions they do about the internal assessment tasks they offer students. The qualitative interviews were analysed thematically. The quantitative factors and the qualitative themes converged to describe the overarching conceptions of assessment of the participants. Interview data were also used to explain findings from the quantitative strand of the research.

\subsection{Research outcomes}

\subsubsection{Conceptions of assessment}

Participants revealed four overarching conceptions of assessment: assessment is for learning; assessment is for qualifications; assessment is for accountability; and assessment is detrimental. These conceptions have similarities with, and differences from, existing findings from research on teachers' conceptions of assessment.

The conceptions assessment is for learning and assessment is detrimental align strongly with G.T.L. Brown's (2006) conceptions of assessment for improvement of teaching and learning and assessment is irrelevant. These conceptions have also been found internationally (Brown et al., 2015; Brown \& Gao, 2015; Brown et al., 2011; Brown et al., 2009; Brown \& Michaelides, 2011; Chen \& Brown, 2013; Gebril \& Brown, 2013) which confirms that teachers recognise the importance of the formative 
use of assessment, but also believe assessment has irrelevant aspects. While it might seem contradictory that teachers hold these conceptions simultaneously, it is rational for teachers to think in this way because there are multiple, and sometimes competing, purposes associated with assessment. As discussed by Brown and Michaelides (2011), teachers can think assessment is essential to teaching and learning, but at the same time be aware of the potential for the misuse of assessment results.

The assessment is for accountability conception reflects the idea that schools and teachers are held accountable for assessment results, which has some similarities with previous literature on conceptions of assessment (Brown et al., 2009; Gebril \& Brown, 2013; Harris \& Brown, 2009). A key difference is that the accountability conception found in this research did not include ideas of student accountability. This finding is consistent with an assessment regime that holds teachers responsible for student achievement and reflects the increasing accountability placed on teachers to measure student learning (Codd, 2005; Mutch, 2012).

A substantially different conception of assessment was held by teachers in this study that assessment is for qualifications which reflects the considerable role they have in assessing students for NCEA qualifications. This finding reinforces an ecological approach whereby teachers' conceptions of assessment are influenced by the assessment environment under which they work (G.T.L. Brown, 2011a; Brown \& Michaelides, 2011; Remesal, 2011).

Findings also suggest that New Zealand high school teachers' conceptions of assessment align more with those in high-stakes assessment regimes than those previously reported for their primary colleagues in New Zealand and Australia. This supports Brown and Michaelides' (2011) contention that changes to assessment environments or contexts may lead to different conceptions of assessment and different pathways among those conceptions. 


\subsubsection{Internal assessment practices}

Participants' internal assessment practices were varied, but could generally be described as 'safe' rather than innovative (Hipkins, 2015). Most participants used the Ministry of Education exemplars as a base for designing their own tasks; these were modified to differing extents. Some participants reported extensive modifications to meet the needs and interests of their students, whereas others reported minor modifications to prevent plagiarism. Conditions of assessment varied from in-class tests, with few feedback opportunities, to a more portfolio-orientated approach where formative opportunities were provided. While this tendency of teachers to reproduce the exemplars as their method of assessing the internally-assessed standards has previously been reported by other researchers investigating NCEA (East, 2016; Hume, 2006; Moeed, 2010), this finding reinforces this as a general approach to NCEA internal assessment.

Internal assessment practices could be conceived on a continuum from a testing paradigm to an assessment paradigm. However, individual teachers did not necessarily fit neatly into a place on that continuum. Rather, they described a variety of practices that were determined by pragmatics. For example, several justified the use of a portfolio approach in combination with in-class tests because it balanced their workload with students' opportunities to achieve. Previous research has tended to align teachers with an assessment identity (Fulmer et al., 2015; Looney et al., 2017; Xu \& Brown, 2016) whereas this research has shown teachers can have more than one assessment identity.

Innovative aspects of practice that were revealed included the use of internallyassessed standards to create interesting and motivational courses for the students. This involves using standards from different domains. One popular example was the use of the Business Studies achievement standard 90848, Carry out, review and refine a business activity within a community context with guidance, as an authentic opportunity around which to base accounting and economics. Further practices were to discard standards that teachers thought uninteresting, and to maximise the numbers of credits that could be achieved through internal assessment, as opposed to external assessment. 


\subsubsection{The impact of accountability on internal assessment practices}

Participants described a range of influences on their internal assessment practice, but it was the meso-level of school practice, policy and accountability that seemed to dominate. The pressure of school policy and accountability expectations over-rode expressed, preferred internal assessment strategies and also seemed to over-ride teachers' beliefs about assessment. The strongly held conception that the formative function of assessment is foremost was not reconciled with carrying out internal assessment for qualifications. This latter role seems dominated by external and internal policies and accountability. The meso-level of school policy and accountability measures with regards internal assessment seem to be directing teachers actions with regards their internal assessment practices.

\subsection{Contributions to the field}

\subsubsection{Conceptions of assessment are ecologically rational}

The use of mixed methods enabled the quantitative data to be considered within the context of the thematic analysis of interviews and revealed converging and complementary associations with four conceptions of assessment. The online survey gathered responses from a greater numbers of teachers than the qualitative interviews alone, and the data from the qualitative interviews were used to explain, reinforce, and elaborate findings from the survey. Both strands of the mixed methods reinforced the view that teachers' conceptions of assessment are ecological (G.T.L. Brown, 2011a; Brown \& Michaelides, 2011; Remesal, 2011), because a distinct conception of assessment that relates to participants' role in assessing for NCEA emerged from both the quantitative and qualitative data. In addition, despite this focus on assessing for qualifications, the mixed methods approach revealed a strong affiliation with a formative conception of assessment. The conceptions of assessment of New Zealand secondary school teachers who focus on the senior level of the school have not previously been investigated, and this thesis contends that the strong focus on assessing for qualifications has resulted in a unique conception of assessment for this group of teachers. 


\subsubsection{Contradictory conceptions are rational}

Data from the interviews were also able to explain some seemingly contradictory quantitative findings, such as the simultaneous finding that teachers think the formative function of assessment can be incorporated within internally-assessed achievement standards, but then again it might not. The varying practices among teachers, and of teachers themselves, explains that at times teachers are providing formative opportunities when conducting internal assessment, but at other times and with different standards they are not. To a certain extent this relates to the tensions that teachers face when implementing the formative and summative functions of assessment simultaneously (Irving et al., 2011), but reinforces Newton's (2007) view that teachers attribute intrinsic properties of the assessment process to the terms formative and summative, rather than seeing formative and summative as functions of assessment. It also highlights that teachers do not necessarily have one assessment identity, but rather act in different ways at different times (Fulmer et al., 2015; Looney et al., 2017; Xu \& Brown, 2016).

Furthermore, an explanation was provided for the strong correlation between the student accountability and improvement conceptions in the CFA. This high correlation could be due to numerous causes, such as teachers expecting students to be more accountable for their own learning, teachers considering improved assessment results to be an indication of improved learning, or aligned with Dann's (2014) explanation of assessment as learning under which Dann promotes the prospect of assessment enabling students to understand and gain agency in their own learning. Interview data revealed that the most likely explanation is participants considering improved grades to be an indication of improved learning which supports Torrance's (2007) claim that compliance with assessment criteria can be a proxy for improvement in learning. Participants gave little indication of expecting students to be accountable, neither did they give students much agency in their own learning.

Interview data were also able to explain why teachers can conceive of assessment as having useful formative and summative functions while, at the same time, considering it to have detrimental aspects. Participants shared many examples of the flawed aspects of assessment, such as invalid assessment tasks being provided by the Ministry 
of Education and inconsistency in the application of standards, but accepted these as inevitable features of assessment for qualifications. Brown and Michaelides (2011) speculated in their quantitative investigation of Cypriot teachers' conceptions of assessment that teachers consider assessment as indispensable, but at the same time are aware of the misuses. This study supports this speculation.

\subsubsection{Vision for NCEA yet to be realised}

This research reveals that realisation of the vision for NCEA internal assessment is still some way off. It was envisaged that internal assessment for NCEA would provide students with opportunities to achieve, to work in familiar surroundings, to have ample time to show what they can achieve and to assess a wide range of skills and knowledge (Education Review Office, 2007; NZQA, n.d.e). Hipkins et al. (2016) have also proposed that internal assessment should be enmeshed with learning and that NCEA should provide life-worthy learning experiences for all students. It is contended that moderation procedures and processes, and the use of moderation reports as accountability measures by school managers have encouraged teachers into a cycle of safe, rather than innovative, practice. The vision for internal assessment to be both formative and summative in its function creates dilemmas for schools and teachers, and this research indicates that a greater emphasis is being put on the summative function of internal assessment rather than the learning function. This aligns with Bonner's (2016) conclusion that assessment for summative purposes and assessment for formative purposes create situations of tension and conflict, and that teachers vary in the time and space they allocate to each purpose.

\subsubsection{The meso-level is a dominant impact}

Teachers' internal assessment practices are influenced by a complex, dynamic range of factors. These include their beliefs about how assessment for qualifications should be carried out, but other important factors are the impact of national and school policies, accountability measures imposed on teachers, students' actions in terms of plagiarism, and teachers' own workload issues. However, a dominant factor influencing teachers' internal assessment practices is the impact of the meso-level of school managers using moderation reports as a measure of accountability. As a result, teachers did not follow one set of practices, but rather used different practices at different times, while always being mindful that their practices had to be acceptable to 
their school management. While the summative function of internal assessment remains dominant, and moderation reports and students' achievement results are used as accountability measures, it is unlikely that teachers' internal assessment practices will meet the vision intended.

\subsubsection{Teachers are responsible in their role as assessors}

Teachers in this research took their role as assessors seriously. Many of the practices and procedures they instigated were to ensure the validity and reliability of internal assessments and the authenticity of students' work. They adopted practices that gave students the maximum opportunity to achieve NCEA, but at the same time reported that they taught the epistemological knowledge of their respective subject. They also used NCEA to motivate and involve students in their own learning and assessment, and as such could be seen to be enacting a socio-cultural approach towards assessment.

\subsubsection{Teachers are vulnerable in their role as assessors}

Internal assessment for NCEA deprivatises teachers' assessment practices and opens them up to scrutiny. Negative experiences from external moderation had eroded some participants' confidence, led to self-doubt, and increased their vulnerability. While these findings concur with previous research which has reported that moderation procedures have left teachers dispirited (Brooks, 2010; East, 2016; Mizutani, 2009; NZQA, 2014; Office of the Auditor General, 2012; Taylor et al., 2007; Wylie \& Bonne, 2016), this study contributes new knowledge that the reactions at the mesolevel of the school compound the vulnerability. Accountability measures imposed on top of the NCEA qualifications system have led to feelings of vulnerability when assessing for NCEA. Meeting these accountability measures caused participants stress and concern, which aligns with Nicols' and Harris' (2016) claim that the nature of assessment can affect teachers' well-being, commitment, satisfaction and professional identities. As reported by Parr and Timperley (2016) the degree of autonomy afforded teachers forms "an integral part of teacher identity" (p. 101) and that external accountability can leave teachers feeling undermined. This study supports those claims. 


\subsection{Limitations of this study}

\subsubsection{Sampling}

One hundred and thirty-five survey participants is considered at the lower end of acceptability for factor analysis (Gorsuch, 1983), and a low response rate is considered a drawback of online questionnaires (Aitken, Power, \& Dwyer, 2008). The relatively low number of participants could be an explanation for G.T.L. Brown's (2006) model not being supported. However, after nearly six months of encouraging participation through various accounting and economics teachers' networks, it was considered that all who were willing to take part had done so. In addition, as all participants who volunteered and were available were interviewed, purposive sampling did not take place. This research specifically chose to investigate only accounting and economics teachers and as such does not claim to generalise to the wider population of secondary school teachers.

\subsubsection{Instruments}

\section{Questionnaires}

Questionnaires are not without limitations. Participants can respond to questionnaires in various ways and there is no way of knowing if answers are accurate and truthful (Zohrabi, 2013). In self-administered questionnaires, if misunderstandings arise due to the wording of questions these cannot be clarified and may lead to inaccurate responses. There is a potential that some participants may not have answered accurately and that if the questionnaire had been administered by the researcher, different responses could have been obtained.

\section{Interviews}

Interviews are not a neutral tool that elicit rational responses and uncover truths; in fact, there is no guarantee that interviewees are truth tellers (Qu \& Dumay, 2011). The interviewer creates an interview situation and the resulting information depends on the characteristics of the interviewer (Denzin \& Lincoln, 1998). In semi-structured interviews, the interviewer is required to probe and follow up on questions; these may differ from one participant to another. Also, different interviewers may evoke different responses from the interviewees depending on the traits of the interviewer and the way 
questions are asked and probed (Qu \& Dumay). Therefore, the data gathered through the semi-structured interviews only relate to the data shared between the interviewer and the interviewees at that particular time.

\subsubsection{Analysis}

Exploratory factor analysis requires a level of subjectivity because the researcher must make a range of choices and decisions to enhance the quality of the resulting solution (Fabrigar et al., 1999), so the accuracy of the results is dependent on these decisions (Henson \& Roberts, 2006; Tabachnick \& Fidell, 2007). Choices include the number of factors to retain, type of rotation, and whether to remove items. While the literature was used (e.g., Field, 2013; Osborne et al., 2008; Walkey \& Welch, 2010) to guide these decisions, they could still be considered subjective and thus may have an impact on the final outcomes. Naming the factors from EFA can be subjective and was influenced by my understandings of the data and previous research. More testing of the factor structure is required to support this structure, but was beyond the scope of this study. However, according to Beavers et al. (2013), a lack of further testing of a factor structure does not negate its current usefulness and the solution can be meaningful and contribute to research.

Thematic analysis is sometimes critiqued for its simplicity and it relies on the researcher to provide adequate examples from the full data set to persuade readers of the argument (Braun \& Clarke, 2006). Naming of the themes is a subjective process, and as with the EFA, those names that I have chosen may not be what another researcher would choose. There is always a level of subjectivity in the interpretation of what participants say. Both inductive and deductive coding was used. For example, the research aimed to find out how teachers conduct internal assessment, so were directly asked this question, and answers coded into the assessment as practice theme. Other codes were derived inductively from the data, but these are subject to my "epistemological commitments, and data are not coded in an epistemological vacuum" (Braun \& Clarke, p. 12). So while the aim of inductive coding is to code the data without putting it into a pre-existing coding frame, and to allow the themes to be driven by the data, the researcher's beliefs can influence the final structure. 


\subsection{Implications of this study}

\subsubsection{Changes to internal assessment practice are needed}

While this research has limitations and further research is needed with New Zealand secondary school teachers, it raises some important issues with regard to the internallyassessed component of NCEA.

The conceptualisation of teachers into the metaphors of ushers and gatekeepers illustrates two overarching paradigms in which teachers had a disposition to situate their internal assessment practice. One paradigm illustrates the potential of internal assessment to meet the needs of a diverse range of students. Key aims of NCEA, and, in particular, the internally-assessment component, were to provide more opportunities for young people to achieve qualifications and to allow a wide range of student performance to be assessed (NZQA \& OECD, 2004). This study has shown that these aims can be achieved, with some participants asserting their control over the assessment process to ensure students achieved national qualifications. Klenowski and Wyatt Smith (2014) described how teachers might adapt assessment to cater for students' diverse needs and promote student involvement in a learning community. Participants provided evidence that they attempted a student-centred approach by offering differentiated assessment opportunities and student choice about assessment tasks or topics. Allowing choice and contextualising assessment can also mean that assessment is more culturally responsive because the knowledge and experiences of students are incorporated into learning and assessment, which can be expected to progress social justice goals (Berryman \& Bishop, 2016; Klenowski, 2009).

On the other hand, some participants' behaviour reinforced earlier studies on NCEA internal assessment that have shown that teachers tend to implement separate assessment events that strongly imitate the exemplars provided on TKI (East, 2016; Hume, 2006; Moeed, 2010). One purpose of internal assessment is for students to have a form of assessment that is appropriate to them and their context. Widespread usage of the exemplars negates this aim, but is encouraged by NZQA moderators and school management. NZQA needs to consider how much it wants to realise the original vision for internal assessment within NCEA and how this could be achieved. 
Currently, teachers do not seem to be encouraged, nor have any incentive to use innovative assessment practices, in fact their good intentions can be thwarted by macro-level and meso-level policy. Teachers need to be empowered, rather than disillusioned, in their role as assessors of internally-assessed standards for NCEA.

\subsubsection{Professional development is needed}

Professional development can be one source of empowerment and, as Stiggins (2010) claimed, "assessment illiteracy abounds" (p. 233) because too little attention is paid to assessment in initial teacher education and in-service professional development in assessment is infrequent. In addition, professional development on assessment tends to focus on technical aspects of marking or grading and test construction (Campbell, 2013). Best Practice Workshops, which NZQA promote as "support to help with good assessment practice for internally-assessed standards" (NZQA, n.d.k), also seem to be restricted to supporting technical aspects of meeting moderation requirements, making judgements about samples of student work, and interpreting achievement standards. Best Practice Workshops are offered annually and in various locations around New Zealand, so the availability of professional development is not the issue, rather, it is the nature of the professional development available that needs to be addressed.

Current approaches to professional development for internal assessment are not promoting powerful use of internal assessment. If all students are to have a meaningful and useful internal assessment experience, this needs to change. According to $\mathrm{Xu}$ and Brown (2016), teacher learning occurs in two main ways: through critical reflective practice (Schön, 1983) or through participation in learning communities (Westheimer, 2008). However, it is possible that neither of these will disrupt teachers' current practice. Participants in this study who made few modifications to exemplars and set examination-like conditions for assessment accepted this practice as the only viable option. Self-reflection consisted of examining assessment results and, if these were acceptable, few changes were made. Teachers need criteria other than assessment results and moderation agreement rates against which to reflect. Xu and Brown claim that participation in learning communities can engage teachers in professional conversations which may lead them to change their assessment practice, but such communities can also reinforce current practice. Participants provided evidence that 
this did occur, such as following a colleague's lead and putting parts of internallyassessed standards into mid-year examinations.

What is needed is for teachers to be challenged on their internal assessment practices, which may entail challenging their beliefs. Although, Guskey (1986) argued that changes in practice follow changes in beliefs, if teachers adopt new practices that are successful, beliefs may also change (Ertmer, 2005). This idea is supported by selfefficacy literature (e.g., Bandura, 1997) whereby successful experiences with change build confidence to make greater change. In terms of changing internal assessment practices this would involve teachers being exposed to successful alternative models because "teachers' practices are unlikely to change without some exposure to what teaching actually looks like when it's being done differently" (Elmore, Peterson, \& McCarthey, 1996, p. 241). Teachers providing professional development for other teachers has been used and deemed successful for NCEA internal assessment (Yates, 2012) and could be reinstated. Working with successful colleagues can prompt a perceived need for change as well as assure teachers that changes are possible (Zhao \& Cziko, 2001). In addition, more expert teachers can both challenge and support their colleagues during a change process.

Although there is debate about whether beliefs change practice or practice changes beliefs (Guskey, 2006), or whether these are bi-directional (Bandura, 1986) it is clear one cannot be changed without considering the other (Ertmer, 2005). Understanding teachers' conceptions of assessment is integral to changing their assessment practice and professional development facilitators need to be prepared to examine and challenge beliefs. The range of beliefs and practices exhibited by participants shows differentiated professional development is needed for different teachers; a one-sizefits-all approach, such as that currently provided, is unlikely to be successful in affecting change. A model of NCEA professional development such as that trialled in the Senior Subject Advisor pilot and evaluated by Taylor et al. (2007) whereby personalised professional development was provided by teachers, who possessed both disciplinary and NCEA expertise, is more likely to successfully bring about change. 


\subsubsection{Leadership of internal assessment}

School leadership has a central role in the development of teachers' assessment capabilities and leaders, as well as teachers, should participate in professional development (Absolum et al., 2009; Robinson, Hohepa, \& Lloyd, 2009; Timperley, Wilson, Barrar \& Fung, 2007). School leaders need to examine current assessment practices; they need to resolve conflict about assessment issues; and they need to be able to interpret assessment data to ensure their decisions are well informed (Cowie $\&$ Penney, 2016; Scott, Scott, \& Webber, 2016). School principals, and other senior managers, need knowledge of effective assessment practice so they can show leadership by encouraging teachers to adopt innovative practices. Some actions (such as moderation reports being used as an accountability measure) of school leaders reported in this study suggested this was not the case. Given the strong influence of the school meso-system on participants' internal assessment practices, change needs to occur at that level for teachers to incorporate innovation into their practice. As Hargreaves (2003) opined, school cultures can be feudal and paternalistic environments that cultivate loyalty and compliance, yet professionals need to be able to disagree, question and critique. School managers need to consider the environments they are cultivating in their schools and whether they are fruitful for students' learning and achievement, or are they encouraging performativity.

Leadership of internal assessment from NZQA also needs to change. NZQA needs to be consistent in its messages to teachers and also to examine its own philosophy towards internal assessment. Hipkins (2013) questions whether the original intent of NCEA is still intact, given that changes such as course endorsements requiring some externally-assessed standards "have arguably made the qualification appear more similar to the previous examination-based system" (p. 19). Hipkins calls for the original intent of NCEA to now be promoted, with which I agree. If internal assessment is conducted as one-off tests, using similar assessment materials, then its aims of meeting the needs of a range of learners are being negated. 
Much of the internal assessment material provided by NZQA promotes use of a separate, single event assessment. Changes are needed in NZQA documentation on its website to promote alternative approaches to NCEA internal assessment and the NZQA website also needs to provide consistent information.

NZQA also exerts strong pressure over teachers' beliefs about assessment, beliefs that Rokeach (1968) calls Type D beliefs, that is, those beliefs that are derived from an authority in which we believe. According to Rokeach, these beliefs can be changed if the suggestion for change comes from that authority. If this is the case, NZQA can promulgate a different approach to internal assessment, one that truly does assess students in authentic ways, provides opportunities to show what students can achieve, provides ample time, and gives credit for a wider range of knowledge and skills than the previous school qualification system (Education Review Office, 2007; NZQA, n.d.a, n.d.e). This could start with the way moderators are trained, prepared and deployed.

\subsubsection{Teacher education}

The findings of this study also have implications for initial teacher education. Teacher educators need to consider that student teachers will enter initial teacher education with a range of experiences and conceptions of assessment. A one-size-fits-all approach is likely to have limited success with student teachers, yet this is the general approach. Student teachers may have naïve understandings about assessment based on their limited experience of being assessed, rather than being assessors. G.T.L Brown (2011c) reported that student teachers did indeed have quite different conceptions of assessment from practising teachers, and concluded that existing conceptions of assessment may create dilemmas for teacher educators in helping student teachers to use assessment in a formative way. Barnes, Fives, and Dacey (2017) explicitly called for student teachers' conceptions of assessment to be considered and for teacher educators to work in tandem with student teachers' belief systems to increase beginning teacher assessment literacy and to use assessment in ways that benefit student learning. 
Despite research indicating that teacher educators have little influence on assessment practice due to the short time they spent with student teachers (Deneen \& Brown, 2016), teacher educators do have a responsibility to try to affect change. They can support and encourage student teachers to implement NCEA internal assessment innovatively, although student teachers will have varying views about how this should be done based on their own experiences. Teacher educators may also need to consider their own conceptions of assessment and beliefs about how internal assessment should be implemented. To break the practice of using the TKI exemplars as a first reference, teacher educators and student teachers could work together using the NZC and achievement standards to tease out what learning students need to demonstrate and collate ideas about how that could potentially be done. Using a model such as Creative Problem Solving (Isaksen \& Treffinger, 1985) to create tasks to assess internallyassessed standards could lead to divergent thinking and innovative practices.

\subsubsection{Assessment policy should work for teachers and students}

Assessment is complex and multi-faceted, and assessment systems must balance a need to measure and monitor student achievement with the need to improve their learning (Clarke, 2012). This requires consideration of all uses and users of assessment at the policy, school and classroom levels (Cowie \& Penney, 2016). Thematic and factor analysis in this study has shown that participants hold a strong view that a key purpose of assessment is to improve student learning, and also to measure their learning through external qualifications. The existence of a conception of assessment that clearly relates to the participants' roles as assessors for NCEA is indicative of the impact that assessment policy has on teachers' conceptions of assessment.

Given that the formative function of assessment is a key support in student learning (Black \& Wiliam, 1998), assessment policy should support this function, but Brown and Harris (2009) found that policies that promote the use of assessment data as external accountability mechanisms lead teachers to lose their positive orientation towards the improvement function of assessment. Likewise, Brown and Michaelides (2011) suggested that strong external monitoring polices might not be needed in New Zealand as teachers are already committed to improving the learning of their students. Findings from this study show participants did not endorse the use of assessment results to 
measure school quality; therefore, the continuation of such polices is likely to be counter-productive with student learning. As G.T.L. Brown (2008) argued, policymakers should consider the strong commitment New Zealand teachers have to the improvement conception of assessment and take advantage of this by reducing the accountability stakes associated with assessment data, and rather, use policy to strengthen the formative functions of assessment. The latter emphasis is more likely to lead to genuine improvements in student learning, whereas the former can encourage surface learning and teaching to the test. As Hargreaves (2003) argued, education policy should empower, not constrain teachers, it should be "the wind beneath their wings not the albatross around their necks" (p. 53).

\subsection{Areas for future research}

This study focussed on teachers of accounting and economics, so an obvious area for further research is to investigate the conceptions of assessment and internal assessment practices of a greater number of secondary teachers which would allow comparisons across subjects and between different groups of teachers. This would enable a biggerpicture view of teachers' internal assessment practices and whether these are meeting the original aims of NCEA, or rather, are they reverting to imitating the previous examination-based system as Hipkins (2013) claims. A larger sample could support (or not) the factor structure from the exploratory factor analysis and support whether secondary school teachers in New Zealand do have different conceptions of assessment from their primary school colleagues. In particular, is the absorption of a conception of assessment which relates to secondary teachers' role as assessors of national qualifications widespread?

Further research with NZQA moderators and other NZQA personnel would also be interesting and useful. We need to know their conceptions of assessment and views on how internal assessment should be implemented, also, whether NZQA espoused policy is supported by its actual practice. Moderation reports and feedback from moderators have a powerful influence on teachers' internal assessment practice and change is unlikely to occur without authority from NZQA. 
As the meso-level of school policy wielded a significant influence on teachers' internal assessment practices, further research with school principals and middle managers would be useful to ascertain their beliefs about internal assessment. Are they more focussed on the accountability pressures at the expense of potential learning opportunities? And if this is the case why do they hold such views? School managers are held publically accountable through the Better Public Service Target (New Zealand Government, 2012) of at least $85 \%$ of students achieving NCEA Level 2, accountability is also asserted through the media release of NCEA league tables which compare the achievement rates of students and also the associated pressure to recruit students to their schools to ensure financial viability. How do school managers react to such accountability measures and why?

Student voice in relation to internal assessment within NCEA is also relatively rare, and that which exists predates major changes that have occurred in NCEA standards and alignment with the NZC. It would be useful to know what value students place on internal assessment, the feedback they find useful, and conditions of assessment that support learning.

\subsection{Significance of the thesis}

This study has provided insight into the conceptions of assessment of a group of New Zealand secondary teachers who teach predominantly at the senior level of the school and who have a substantial responsibility in assessing for national qualifications. A major contribution is that the findings from the convergence of the quantitative and qualitative strands show that teachers in this research have absorbed a conception of assessment which relates directly to their role as assessors for a national qualification. In addition, results show that participants' conceptions of assessment align more closely with those of teachers in international high-stakes assessment jurisdictions than they do with their primary colleagues in New Zealand and Australia. These two findings reinforce the ecological approach to teachers' conceptions of assessment whereby these conceptions are influenced by the assessment environment under which they work (G.T.L. Brown, 2011a; Brown \& Michaelides, 2011; Remesal, 2011). 
This research has also shown that teachers' internal assessment practices for NCEA are influenced by a complex, dynamic range of factors. These include: their beliefs about how assessment for qualifications should be carried out; the impact of macrolevel, national and meso-level, school policies; students' actions in terms of plagiarism; and teachers' own workload issues. However, the dominant influence seems to be the accountability pressures exerted at the meso-level of the school. As a result, teachers' internal assessment practices could be described as safe rather than innovative, and dominated by the summative function of assessment of internal assessment, rather than its potential formative function. Participants were responsible in their roles as assessors, but various accountability measures led to feelings of vulnerability.

From this work I have concluded that the vision for NCEA internal assessment is not yet being realised. For this realisation to occur, change is required at a number of levels. This includes a change in approach from NZQA in relation to moderation practices, for school management to encourage rather than (possibly inadvertently) stifle innovative approaches to assessment, as well as professional development for teachers focussed on improving the formative function of their assessment practices.

Good internal assessment can be a powerful tool for improving teaching and learning (Yung, 2000), and through contextualising and allowing choice internal assessment can lead to assessment that is more culturally responsive, which progresses social justice goals (Berryman \& Bishop, 2016; Klenowski, 2009). It is important that assessment in the twenty first century maximises these opportunities. 


\section{References}

Absolum, M., Flockton, L., Hattie, J., Hipkins, R., \& Reid, I. (2009). Directions for assessment in New Zealand (DANZ): Developing students' assessment capabilities. Wellington: Ministry of Education.

Aitken C., Power R., Dwyer R. (2008). A very low response rate in an on-line survey of medical practitioners. Australian and New Zealand Journal of Public Health, 32(3), 288-289.

Adie, L. (2013). The development of teacher assessment identity through participation in online moderation The development of teacher assessment identity through participation in online moderation. Assessment in Education: Principles, Policy \& Practice, 20(1), 91-106, doi:

10.1080/0969594X.2011.650150

Adie, L., Klenowski, V., \& Wyatt-Smith, C. (2012). Towards an understanding of teacher judgement in the context of social moderation. Educational Review, 64(2), 223-240. doi.10.1080/00131911.2011.598919

Alison, J. (2005). Teachers talk about NCEA: Research report on focus groups with secondary teachers. Wellington: Post Primary Teachers Association.

American Educational Research Association, American Psychological Association, and National Council on Measurement in Education. (2014). Standards for educational and psychological testing. Washington, DC: American Educational Research Association.

American Psychological Association, American Educational Research Association, and National Council on Measurements Used in Education. (1954). Technical recommendations for psychological tests and diagnostic techniques.

Psychological Bulletin, 51(2), 1-38. doi.org/10.1037/h0053479

Anderman, E. M., Griesinger, T., \& Westerfield, G. (1998). Motivation and cheating during early adolescence. Journal of Educational Psychology, 90, 84-93. doi.org/10.1037/0022-0663.90.1.84

Anderman, L., Freeman, T., \& Mueller, C. (2007). The "social" side of social context: Interpersonal and affiliative dimensions of students' experiences and academic dishonesty. In E. Anderman \& T. Murdock (Eds.), Psychology of academic cheating (pp. 203-228). Burlington, MA: Elsevier Academic Press. 
Aziz, A. (2014). Indonesian junior secondary school teachers' conceptions of assessment: A mixed methods study (Doctoral diss.). Victoria University of Wellington, NZ.

Bachman, L. F., \& Purpura, J. E. (2008). Language assessments: Gate-keepers or gate-openers? In B. Spolsky \& F. M. Hult (Eds.), The Handbook of Educational Linguistics (pp. 456-468). Oxford, UK: Blackwell Publishing.

Baker, R. (2001, February). Challenge for educational transformation: Achieving the aim of 'thinking and acting locally, nationally and globally' in a devolved education system. Paper presented at the International Forum on Education Reforms in the Asia-Pacific Region: Globalisation, Localisation and Individualisation for the Future, The Hong Kong Institute of Education, HKSAR, Hong Kong. Retrieved from http://www.nzcer.org.nz/research/publications/challenge-educationaltransformation-achieving-aim-thinking-and-acting-locally

Ball, S. J., Maguire, M., \& Braun, A. (2012). How schools do policy: Policy enactment in the secondary school. London, England: Routledge.

Bandalos, D. L., \& Finney, S. J. (2010). Factor analysis: Exploratory and confirmatory. In G. R. Hancock \& R. O. Mueller (Eds.), The reviewer's guide to quantitative methods in the social sciences (pp. 93-114). New York, NY: Routledge.

Bandura, A. (1986). Social foundations of thought and action. New Jersey: Prentice Hall.

Bandura, A. (1997). Self-efficacy: The exercise of control. New York, NY: Freeman.

Barker, A. (1995). Standards-based assessment: The vision and broader factors. In R. Peddie, \& B. Tuck (Eds.), Setting the standards: The assessment of competence in national qualifications (pp. 15-31). Palmerston North, NZ: Dunmore Press.

Barnes, N., Fives, H., \& Dacey, C. (2017). U.S. teachers' conceptions of the purposes of assessment. Teaching and Teacher Education, 65, 107-116.

Beavers, A., Lounsbury, J., Richards, J., Hucks, S., Skolits, G., \& Esquival, S. (2013). Practical considerations for using exploratory factor analysis in educational research. Practical Assessment, Research \& Evaluation, 18(6). Available online: http://pareonline.net/pdf/v18n6.pdf

Bentler, P. M. (1990). Comparative fit indexes in structural models. Psychological Bulletin, 107(2), 238-246. doi.org/10.1037/0033-2909.107.2.238 
Bentler, P. M., \& Chou, C-P. (1987). Practical issues in structural modeling. Sociological Methods Research, 16(1), 78-117. doi.10.1177/0049124187016001004

Berryman, M. \& Bishop, R. (2016). A culturally responsive pedagogy of relations. In D. Fraser \& M. Hill (Eds.), The professional practice of teaching in New Zealand (pp. 180-197). Australia: Cengage Learning.

Black, P., Harrison, C., Hodgen, J., Marshall, B., \& Serret, N. (2011). Can teachers' summative assessments produce dependable results and also enhance classroom learning? Assessment in Education: Principles, Policy and Practice, $18(4), 451-469$.

Black, P., Harrison, C., Lee, C., Marshall, B., \& Wiliam, D. (2002). Working inside the black box. London: GL Assessment.

Black, P., Harrison, C., Lee, C., Marshall, B., \& Wiliam D. (2003). Assessment for learning: Putting it into practice. Maidenhead: Open University Press.

Black, P., \& Wiliam, D. (1998). Assessment and classroom learning. Assessment in Education: Principles, Policy and Practice, 5(1), 7-74. doi.10.1080/0969595980050102

Bogdan, R. C., \& Biklen, S. K. (1998). Qualitative research in education: An introduction to theory and methods ( $3^{\text {rd }}$ ed.). Needham Heights, MA: Allyn \& Bacon.

Bonner, S. (2016). Teachers' perceptions about assessment: Competing narratives. In G. T. L. Brown \& L. Harris (Eds.), Handbook of social conditions in assessment (pp. 21-40). New York: Routledge.

Borg, S. (2003). Teacher cognition in language teaching: A review of research on what language teachers think, know, believe, and do. Language Teaching, 36, 81-109. doi.org/10.1017/S0261444803001903

Borko, H., \& Putnam, R. (1996). Learning to teach. In D. Berliner \& R. Calfee (Eds.), Handbook of educational psychology (pp. 673-708). New York: Macmillan.

Bourdieu, P. (1991). Language and Symbolic Power. Cambridge: Harvard University Press.

Bowen, N. K., \& Guo, S. (2011). Structural equation modeling. New York, NY: Oxford University Press. 
Box, G. E. P., \& Draper, N. R. (1987). Empirical model-building and response surfaces. New York, NY: John Wiley.

Braun, V., \& Clarke, V. (2006). Using thematic analysis in psychology. Qualitative Research in Psychology, 3(2), 77-101.

Broadfoot, P. (2007). An introduction to assessment. New York, NY: Continuum International.

Brookhart, S. (2003). Developing Measurement Theory for Classroom Assessment Purposes and Uses. Educational Measurement: Issues and Practice, 22(4), $5-12$.

Brooks, Z. (2010). Assessing creativity: Teachers' perceptions of the effect of the National Certificate of Educational Achievement (NCEA) on teaching and learning in the secondary drama classroom (Doctoral diss.). Massey University, Palmerston North, NZ.

Brown, G. T. L. (2002). Teachers' conceptions of assessment (Doctoral diss.). University of Auckland, NZ.

Brown, G. T. L. (2004). Teachers' conceptions of assessment: Implications for policy and professional development. Assessment in Education: Principles, Policy \& Practice, 11(3), 301-318. doi.10.1080/0969594042000304609

Brown, G.T. L. (2006). Teachers' conceptions of assessment: Validation of an abridged version. Psychological Reports, 99, 166-170. doi.org/10.2466/PR0.99.5.166-170

Brown, G. T. L. (2008). Conceptions of assessment: Understanding what assessment means to teachers and students. New York: Nova Science.

Brown, G. T. L. (2011a). Teachers' conceptions of assessment: Comparing primary and secondary teachers in New Zealand. Assessment Matters, 3, 45-70.

Brown, G. T. L. (2011b). An introduction to confirmatory factor analysis and structural equation modelling: Presentation to Research and Development Office, Continuing Professional Development Programme, HKIEd. Retrieved from https://www.scribd.com/document/281952342/2011-An-Introduction-toConfirmatory-Factor-Analysis-CFA-pdf

Brown, G. T. L. (2011c). New Zealand prospective teacher conceptions of assessment and academic performance: Neither student nor practicing teacher. In R. Kahn, J. C. McDermott, \& A. Akimjak (Eds.), Democratic access to 
education (pp.119-132). Los Angeles, CA: Department of Education. Antioch University Los Angeles.

Brown, G. T. L., Chaudhry, H., \& Dhamija, R. (2015). The impact of an assessment policy upon teachers' self-reported assessment beliefs and practices: A quasi experimental study of Indian teachers in private schools. International Journal of Educational Research, 71, 50-64. doi.org/10.1016/j.ijer.2015.03.001

Brown, G. T. L., \& Gao, L. (2015). Chinese teachers' conceptions of assessment for and of learning: Six competing and complementary purposes. Cogent Education, 2, 1-19. http://dx.doi.org/10.1080/2331186X.2014.993836

Brown, G. T. L., \& Harris, L. R. (2009). Unintended consequences of using tests to improve learning: How improvement-oriented resources engender heightened conceptions of assessment as school accountability. Journal of MultiDisciplinary Evaluation, 6(12), 68-91.

Brown, G. T. L., Hui, S. K. F., Yu, W. M., \& Kennedy, K. J. (2011). Teachers' conceptions of assessment in Chinese contexts: A tripartite model of accountability, improvement, and irrelevance. International Journal of Educational Research, 50, 307-320. doi.10.1016/j.ijer.2011.10.003

Brown, G. T. L., Kennedy, K. J., Fok, P. K., Chan, J. K. S., \& Yu, W. M. (2009). Assessment for student improvement: Understanding Hong Kong teachers' conceptions and practices of assessment. Assessment in Education: Principles, Policy \& Practice, 16(3), 347-363. doi.10.1080/09695940903319737

Brown, G. T. L., \& Lake, R. (2006). Queensland teachers' conceptions of teaching, learning, curriculum and assessment: Comparisons with New Zealand teachers. Paper presented at Engaging Pedagogies, the Annual Conference of the Australian Association for Research in Education (AARE), Adelaide. Retrieved from http://www.aare.edu.au/publicationsdatabase.php/4974/queensland-teachers-conceptions-of-teaching-learningcurriculum-assessment-comparisons-with-new-zealand

Brown, G. T. L., Lake, R., \& Matters, G. (2011). Queensland teachers' conceptions of assessment: The impact of policy priorities on teacher attitudes. Teaching and Teacher Education, 27(1), 210-220. doi.10.1016/j.tate.2010.08.003

Brown, G. T. L., \& Michaelides, M. P. (2011). Ecological rationality in teachers' conceptions of assessment across samples from Cyprus and New Zealand. 
European Journal of Psychology of Education, 26(93), 319-337.

doi.10.1007/s10212-010-0052-3

Brown, G. T. L., \& Remesal, A. (2012). Prospective teachers' conceptions of assessment: A cross-cultural comparison. The Spanish Journal of Psychology, 15(1), 75-89. doi.org/10.5209/rev_SJOP.2012.v15.n1.37286

Brown, T. A. (2006). Confirmatory factor analysis for applied research. New York: The Guilford Press. Retrieved from http://www.kharazmistatistics.ir/Uploads/Public/book/Methodology\%20in\%20the\%20Social\%20Sci ences.pdf

Calveric, S. B. (2010). Elementary teachers' assessment beliefs and practices (Doctoral diss.). Virginia Commonwealth University, Richmond, VA.

Campbell, C. (2013). Research on teacher competency in classroom assessment. In J. H. McMillan (Ed.), Sage handbook of research on classroom assessment (pp.71-84). Thousand Oaks, CA: Sage.

Carless, D. (2011). From testing to productive student learning: Implementing formative assessment in Confucian-Heritage settings. London: Routledge.

Chen, J., \& Brown, G. T. L. (2013). High-stakes examination preparation that controls teaching: Chinese prospective teachers' conceptions of excellent teaching and assessment. Journal of Education for Teaching: International Research and Pedagogy, 39(5), 541-556. doi.10.1080/02607476.2013.836338

Clarke, M. (2012). What matters most for student assessment systems: A framework paper. Washington, DC: The World Bank, The International Bank for Reconstruction and Development.

Codd, J. (2005). Teachers as 'managed professionals' in the global education industry: The New Zealand experience. Educational Review, 57(2), 193-206. doi.10.1080/0013191042000308369

Codd, J., McAlpine, D., \& Poskitt, J. (1995). Assessment policies in New Zealand: Educational reform or political agenda? In R. Peddie \& B. Tuck (Eds.), Setting the standards: The assessment of competence in national qualifications (pp. 32-59). Palmerston North: Dunmore Press.

Cohen, L., Manion, L., \& Morrison, K. (2007). Research methods in education (6 $^{\text {th }}$ ed.). New York: Routledge.

Comfrey, A. L., \& Lee, H. B. (1992). A first course in factor analysis. Hillsdale, NJ: Lawrence Erlbaum. 
Costello, A., \& Osborne, J. (2005). Best practices in exploratory factor analysis: Four recommendations for getting the most from your analysis. Practical Assessment, Research and Evaluation, 10(7), 1-9.

Cowie, B. \& Penney. D. (2016) Challenges, tensions and possibilities: An analysis of assessment policy and practice in New Zealand. In S. Scott et al. (Eds.), Leadership of assessment, inclusion, and learning, the enabling power of assessment 3 (pp. 287-304). Switzerland: Springer Publishing International. doi. 10.1007/978-3-319-23347-5_12.

Creswell, J. (2003). Research design: Qualitative, quantitative, and mixed methods approaches ( $2^{\text {nd }}$ ed.). Thousand Oaks, CA: Sage.

Creswell, J. (2012). Educational research: Planning, conducting, and evaluating quantitative and qualitative research ( $4^{\text {th }} \mathrm{ed}$.). Boston: Pearson.

Creswell, J. W., \& Plano Clark, V. L. (2007). Designing and conducting mixed methods research. Thousand Oaks, CA: Sage.

Crombie, W. (1995). Assessing language competencies. In R. Peddie, \& B. Tuck (Eds.), Setting the standards: The assessment of competence in national qualifications (pp. 99-119). Palmerston North: Dunmore Press.

da Costa, L., \& Remedios, R. (2014). Different methods, different results: Examining the implications of methodological divergence and implicit processes for achievement goal research. Journal of Mixed Methods Research, 8(2), 162179. doi.org/10.1177/1558689813495977

Dall'Alba, G., \& Sandberg, J. (2006). Unveiling professional development: A critical review of stage models. Review of Educational Research, 76(3), 383-412. doi.org/10.3102/00346543076003383

Dann, R. (2014). Assessment as learning: Blurring the boundaries of assessment and learning for theory, policy and practice. Assessment in Education: Principles, Policy \& Practice, 21(2), 149-166. doi.10.1080/0969594X.2014.898128

Davison, C. (2004). The contrary culture of teacher-based assessment: ESL teacher assessment practices in Australian and Hong Kong secondary schools. Language Testing, 21, 305-334.

Davison, C., \& Leung, C. (2009). Current issues in English language teacher-based assessment. Tesol Quarterly, 43(3), 393-415. doi.org/10.1002/j.15457249.2009.tb00242.x 
Deci, E. L., \& Ryan, R. M. (1985). Intrinsic motivation and self determination in human behavior. New York: Plenum Press.

Deneen, C. C., and Brown, G. T. L. (2016). The impact of conceptions of assessment on assessment literacy in a teacher education program. Cogent Education, 3, 1225380. doi:10.1080/2331186X.2016.1225380

Denzin, N. K., \& Lincoln, Y. S. (1998). The landscape of qualitative research: Theories and issues. Thousand Oaks: Sage.

Department of Education. (1976). Towards partnership: The report of the Committee on Secondary Education. Wellington: Department of Education.

Department of Education. (1989). Assessment for better learning: A public discussion document. Wellington: Author.

Department of Education. (1986). Learning and achieving: Second report of the commission of inquiry into curriculum, assessment and qualifications in forms 5 to 7 (CICAQ). Wellington, NZ: Author.

Dewey, J. (1913). Interest and effort in education. Cambridge, MA: Riverside Press. Dougan, P. (2016, April). NCEA results: How did your school rate? New Zealand Herald. Retrieved from http://www.nzherald.co.nz/nz/news/article.cfm?c_id=1\&objectid=11619826

East, M. (2016). Assessing foreign language students' spoken proficiency: Stakeholder perspectives on assessment innovation. Singapore: Springer.

Education Counts. (n.d.). Subject enrolment. Retrieved from https://www.educationcounts.govt.nz/statistics/schooling/studentnumbers/subject-enrolment

Education Review Office. (2007). The collection and use of assessment information: Good practice in secondary schools. Retrieved from http://www.ero.govt.nz/National-Reports/The-Collection-and-Use-ofAssessment-Information-Good-Practice-in-Secondary-Schools-June2007/Examples-of-good-practice

Edwards, F. (2013). Assessing New Zealand high school science: Considerations for teachers' assessment literacy. Asia-Pacific Forum on Science Learning and Teaching, 14(2), 1-17.

Elley, W. (1995). What is wrong with standards-based assessment? In R. Peddie \& B. Tuck (Eds.), Setting the standards: The assessment of competence in national qualifications (pp. 78-98). Palmerston North: Dunmore Press. 
Elmore, R., Peterson, P., \& McCarthy, S. (1996). Restructuring in the classroom. San Francisco: Jossey-Bass.

Ertmer, P. (2005). Teacher pedagogical beliefs: The final frontier in our quest for technology integration? Educational Technology Research and Development, 53(4), 25-40.

Fabrigar, L., Wegener, D., MacCallum, R., \& Strahan, E. (1999). Evaluating the use of factor analysis in psychological research. Psychological Methods, 4(3), 272299. doi.org/10.1037/1082-989X.4.3.272

Fan, X., Thompson, B., \& Wang, L. (1999). Effects of sample size, estimation methods, and model specification on structural equation modeling fit indexes. Structural Equation Modeling: A Multidisciplinary Journal, 6(1), 56-83. doi.10.1080/10705519909540119

Feilzer, M. Y. (2009). Doing mixed methods research pragmatically: Implications for the rediscovery of pragmatism as a research paradigm. Journal of Mixed Methods Research, 4(1), 6-16. doi.org/10.1177/1558689809349691

Fetters, M., Curry, L., \& Creswell, J. (2013). Achieving integration in mixed methods designs: Principles and practices. Health Services Research, 48(6), 2134-2156. doi.10.1111/1475-6773.12117

Field, A. (2013). Discovering statistics using IBM SPSS statistics. London: Sage.

Fitzpatrick, K., \& Locke, T. (2008). Sir, do we get credits for this? NCEA, class and ethnicity in New Zealand. In A. St. George, S. Brown, \& J. O'Neill (Eds.), Facing the big questions in teaching: Purpose, power and learning (pp. 8798). Melbourne: Cengage Learning.

Fives, H., \& Buehl, M. (2016). Teachers' beliefs, in the context of policy reform. Policy Insights from the Behavioral and Brain Sciences, 3(1), 114-121. doi.10.1177/2372732215623554

Fontana, A., \& Frey, J. (1994). Interviewing the art of science. In N. Denzin \& Y. Lincoln (Eds.), Handbook of qualitative research ( $2^{\text {nd }}$ ed., pp. 361-376). Thousand Oaks, CA: Sage.

Foucault, M. (1977). Discipline and Punish: The Birth of the Prison. New York: Vintage.

Fullan, M. (2001). The new meaning of educational change ( $3^{\text {rd }}$ ed.). New York: Teachers College, Columbia University. 
Fulmer, G., Lee, I., \& Tan, K. (2015). Multi-level model of contextual factors and teachers' assessment practices: An integrative review of research. Assessment in Education: Principles, Policy \& Practice, 22(4), 475-494. doi.10.1080/0969594X.2015.1017445

Gao, M. (2009). Students' voices in school-based assessment of Hong Kong. In D. M. McInerney, G. T. L. Brown, \& G. A. D. Liem (Eds.), Student perspectives on assessment: What students can tell us about assessment for learning (pp. 107-130). Greenwich: Information Age.

Gatignon, H. (2014). Statistical analysis of management data ( $3^{\text {rd }}$ ed.). New York: Springer.

Gebril, A., \& Brown, G. T. L. (2013). The effect of high-stakes examination systems on teacher beliefs: Egyptian teachers' conceptions of assessment. Assessment in Education: Principles, Policy \& Practice, 21(1), 16-33. doi.10.1080/0969594X.2013.831030

George, D., \& Mallery, P. (2003). SPSS for Windows step by step: A simple guide and reference. 11.0 update (4th ed.). Boston: Allyn \& Bacon.

Giluk, T., \& Postlethwaite, B. (2015). Big five personality and academic dishonesty: A meta-analytic review. Personality and Individual Differences, 72, 59-67. http://dx.doi.org/10.1016/j.paid.2014.08.027

Gipps, C. (1994). Beyond testing: Towards a theory of educational assessment. London: Falmer Press.

Glaser, B., \& Strauss, A. (1967). The discovery of grounded theory strategies for qualitative research. London: AldineTransaction. Retrieved from http://www.sxf.uevora.pt/wp-content/uploads/2013/03/Glaser_1967.pdf

Gorsuch, R. L. (1983). Factor analysis (2 ${ }^{\text {nd }}$ ed.). Hillsdale, N.J: Erlbaum.

Guskey, T. R. (1986). Staff development and the process of teacher change. Educational Researcher, 15(5), 5-12.

Hall, C. (1998). The National Qualifications Framework green paper: What future for the framework? New Zealand Annual Review of Education, 7, 29-57.

Hall, C. (2005). National certificate of educational achievement (NCEA): Is there a third way? In J. Codd \& K. Sullivan (Eds.), Education policy directions in New Zealand (pp. 154-176). Palmerston North, NZ: Thomson Dunmore Press.

Hargreaves, A. (1989). Curriculum and assessment reform. Toronto: OISE Press. 
Hargreaves, A. (2003). Teaching in the knowledge society: Education in the age of insecurity. New York: Teachers College Press.

Harlen, W. (1994). Towards quality in assessment. In W. Harlen (Ed.), Enhancing quality in assessment (pp. 139-145). London: Paul Chapman.

Harlen, W. (2004). A systematic review of the evidence of the impact on students, teachers and the curriculum of the process of using assessment by teachers for summative purposes. In Research Evidence in Education Library. London: EPPI-Centre, Social Science Research Unit, Institute of Education.

Harlen, W. (2006). On the relationship between assessment for formative and summative purposes. In J. Gardner (Ed.), Assessment and learning (pp. 87102). London: Sage.

Harlen, W. (2007). The role of teachers in assessment for learning. London: Nuffield Foundation. Retrieved from http://www.nuffieldfoundation.org/sites/default/files/assessment_booklet.pdf

Harris, L., \& Brown, G.T. L. (2008, December). New Zealand teachers' conceptions of the purpose of assessment: Phenomenographic analyses of teachers' thinking. Paper presented to the Australian Association for Research in Education (AARE) Annual Conference, Brisbane, Australia. Retrieved from http://www.aare.edu.au/publications-database.php/5659/New-Zealandteachers'-conceptions-of-the-purpose-of-assessment:-Phenomenographicanalyses-of-teachers'-thinking

Harris, L. R., \& Brown, G. T. L. (2009). The complexity of teachers' conceptions of assessment: Tensions between the needs of schools and students. Assessment in Education: Principles, Policy and Practice, 16(3), 365-381. doi.org/10.1080/09695940903319745

Hay, P. J. \& Macdonald, D. (2008). (Mis) appropriations of criteria and standardsreferenced assessment in a performance-based subject. Assessment in Education: Principles, Policy \& Practice, 15(2), 153-168.

Henson, R. K., \& Roberts, J. K. (2006). Use of exploratory factor analysis in published research. Educational and Psychological Measurement, 66(3), 393416.

Heyvaert, M., Hannes, K., Maes, B., \& Onghena, P. (2013). Critical appraisal of mixed methods studies. Journal of Mixed Methods Research, 7(4), 302-327. doi.org/10.1177/1558689813479449 
Hipkins, R. (2010). The evolving NCEA: Findings from the NZCER national survey of secondary schools 2009. Wellington: New Zealand Council for Educational Research.

Hipkins, R. (2013). NCEA one decade on: Views and experiences from the 2012 NZCER National Survey of Secondary Schools. Wellington: New Zealand Council for Educational Research.

Hipkins, R. (2015). Learning to learn in secondary classrooms. Wellington: New Zealand Council for Educational Research.

Hipkins, R., \& Spiller, L. (2012). NCEA and curriculum innovation: Learning from change in three schools. Wellington: New Zealand Council for Educational Research.

Hipkins, R., Johnston, M., \& Sheehan, M. (2016). NCEA in context. Wellington: New Zealand Council for Educational Research.

Hoekstra, A., Brekelmans, M., Beijaard, D., \& Korthagen, K. (2009). Experienced teachers' informal learning: Learning activities and changes in behavior and cognition. Teaching and Teacher Education, 25, 663-673.

Hooper, D., Coughlan, J., \& Mullen, M. (2008). Structural equation modelling: Guidelines for determining model fit. Electronic Journal of Business Research Methods, 6(1), 53-60.

Horsley, J. (2012). Teacher catalysts: Characteristics of teachers who facilitate high academic success. Australian Journal of Gifted Education, 21(1), 23-31.

Hu, L.T., \& Bentler, P. M. (1999). Cutoff criteria for fit indexes in covariance structure analysis: Conventional criteria versus new alternatives. Structural Equation Modeling, 6(1), 1-55. doi.org/10.1080/10705519909540118

Hulleman, C., Durik, A., Schweigert, S., \& Harackiewicz, J. (2008). Task values, achievement goals, and interest: An integrative analysis. Journal of Educational Psychology, 2, 398-416. doi.10.1037/0022-0663.100.2.398

Hume, A. (2006). Carrying out a practical investigation: The student-experienced curriculum (Doctoral diss.). University of Waikato, NZ.

Hume, A., \& Coll, R. K. (2009). Assessment of learning, for learning, and as learning: New Zealand case studies. Assessment in Education: Principles, Policy \& Practice, 16(3), 269-290, doi.10.1080/09695940903319661

Hutcheson, G. (1999). Factor analysis. In G. Hutcheson \& N. Sofroniu (Eds.), The multivariate social scientist (pp. 218-253). London: Sage. 
Irving, S. E., Harris, L. R., \& Peterson, E. (2011). 'One assessment doesn't serve all the purposes' or does it? New Zealand teachers describe assessment and feedback. Asia Pacific Educational Review, 12, 413-426.

Isaksen, D. \& Treffinger, D. (1985). Creative problem solving: The basic course. Buffalo, NY: Bearly Limited.

Ivankova, N. (2014). Implementing quality criteria in designing and conducting a sequential QUAN! QUAL mixed methods study of student engagement with learning applied research methods online. Journal of Mixed Methods Research, 8(1), 25-51. doi.org/10.1177/1558689813487945

Jaba, S. (2013). Acceptance towards school-based assessment among agricultural integrated living skills teachers: Challenges in implementing a holistic assessment. Journal of Technical Education and Training, 5(1), 44-51.

James, M., \& Pedder, D. (2006). Beyond method: Assessment and learning practices and values. Curriculum Journal, 17, 109-138. doi.10.1080/09585170600792712

Johnson, R., \& Christensen, L. (2014). Educational research: Quantitative, qualitative and mixed approaches $\left(5^{\text {th }} \mathrm{ed}\right.$.). Thousand Oaks, CA: Sage.

Johnson, S. (2011). A focus on teacher assessment reliability in GCSE and GCE. Coventry: Office of Qualifications and Examinations Regulation.

Johnson, S. (2013). On the reliability of high-stakes teacher assessment. Research Papers in Education, 16(1), 91-105. doi.10.1080/02671522.2012.754229

Joreskog, K. G. (1999). How large can a standardized coefficient be? (Unpublished report). Chicago: Scientific Software International. Retrieved from http://www.ssicentral.com/lisrel/techdocs/HowLargeCanaStandardizedCoeffici entbe.pdf

Kane, R., \& Fontaine, S. (2008). How prepared are New Zealand secondary teachers? Results from a national graduate survey. New Zealand Journal of Educational Studies, 43(2), 29-45.

Katzer, J., Cook, K. H., \& Crouch, W. (1998). Evaluating information: A guide for users of social science research (4 ${ }^{\text {th }}$ ed.). Boston: McGraw Hill.

Klenowski, V. (2009). Australian indigenous students: Addressing equity issues in assessment. Teaching Education, 20(1), 77-93.

Klenowski, V., \& Wyatt-Smith, C. (2014). Assessment for education: Standards, judgement and moderation. London: Sage. 
Kline, R. B. (2010). Principles and practice of structural equation modeling ( $3^{\text {rd }}$ ed.). New York, NY: Guilford Press.

Kohn, A. (1993). Punished by rewards. Boston: Houghton Mifflin.

Ledesma, R., \& Velero-Mora, P. (2007). Determining the number of factors to retain in EFA: An easy-to-use computer program for carrying out parallel analysis. Practical Assessment, Research \& Evaluation, 12(2). Available online: http://pareonline.net/getvn.asp?v=12\&n=2

Lerner, J. S. \& Tetlock, P.E. (1999). Accounting for the effects of accountability. Psychological Bulletin, 125(2), 255-275.

Lincoln, Y., \& Guba, E. (1985). Naturalistic inquiry. Newbury Park, CA: Sage.

Linn, R. (1993). Linking results of distinct assessments. Applied Measurement in Education, 6(1), 83-102.

Locker, J., \& Cropley, M. (2004). Anxiety, depression and self-esteem in secondary school children: An investigation into the impact of standard assessment tests (SATs) and other important school examinations. School Psychology International, 25(3), 333-345. doi.10.1177/0143034304046905

Looney, A., Cumming, J., van Der Kleij, K., \& Harris, K. (2017). Reconceptualising the role of teachers as assessors: Teacher assessment identity. Assessment in Education: Principles, Policy \& Practice. doi.10.1080/0969594X.2016.1268090

Mackenzie, N., \& Knipe, S. (2006). Research dilemmas: Paradigms, methods and methodology. Issues in Education Research, 16(2), 193-205.

Madaus, G., \& Russell, M. (2011). Paradoxes of high-stakes testing. Journal of Education, 190, 21-30.

Madaus, G., Scriven, M., \& Stufflebeam, D. (1983). Evaluation models: Viewpoints on educational and human services evaluation. Boston: Kluwer-Nijhoff.

Madjar, I., McKinley, E., Jensen, S., \& Van Der Merwe, A. (2009). Towards university: Navigating NCEA course choices in low-mid decile schools. Auckland: Starpath Project, The University of Auckland.

Majid, F. (2011). School-based assessment in Malaysian schools: The concerns of the English teachers. US-China Education Review, 8(10), 393-402.

Matters, G., \& Masters, G. (2014). Redesigning the secondary-tertiary interface: Queensland review of senior assessment and tertiary entrance. Melbourne: ACER. 
Maxwell, G. (2004, March). Progressive assessment for learning and certification: Some lessons from school-based assessment in Queensland. Paper presented at the Third Conference of the Association of Commonwealth Examination and Assessment Boards, Redefining the Roles of Educational Assessment, Nadi, Fiji. Retrieved from https://www.qcaa.qld.edu.au/downloads/publications/paper_progressive_assess ment_qld.pdf

Mertens, D. M. (2005). Research methods in education and psychology: Integrating diversity with quantitative and qualitative approach $\left(2^{\text {nd }} \mathrm{ed}\right.$.). Thousand Oaks: Sage.

Messick, S. (1975). The standard problem: Meaning and values in measurement and evaluation. American Psychologist, 30(10), 955-966. doi.org/10.1037/0003066X.30.10.955

Messick, S. (1989). Validity. In R. L. Linn (Ed.), Educational measurement (pp. $13-$ 103). Washington, DC: American Council on Education/Macmillan.

Meyer, L. H., McClure, J., Walkey, F., McKenzie, L., \& Weir, K. (2007). The impact of the NCEA on student motivation: Final report to the Ministry of Education. Wellington: Ministry of Education and Victoria University.

Meyer, L. H., McClure, J., Weir, K. F., Walkey, F., \& McKenzie, L. (2009). Motivation and achievement at secondary school: The relationship between NCEA design and student motivation and achievement: A three year follow-up summary report. Wellington: Ministry of Education and Victoria University.

Miles, M., \& Huberman, M. (1994). Qualitative data analysis: An expanded sourcebook ( $2^{\text {nd }}$ ed.). Thousand Oaks: Sage.

Mills, M., \& McGregor, G. (2016). Learning not borrowing from the Queensland education system: Lessons on curricular, pedagogical and assessment reform. The Curriculum Journal, 27(1), 113-133, doi.10.1080/09585176.2016.1147969

Ministry of Education. (n.d.a). Economics matrix. Retrieved from http://ncea.tki.org.nz/Resources-for-Internally-Assessed-AchievementStandards/Social-sciences/Economics

Ministry of Education. (n.d.b). Accounting matrix. Retrieved from http://ncea.tki.org.nz/Resources-for-Internally-Assessed-AchievementStandards/Social-sciences/Accounting 
Ministry of Education (1994). Assessment: Policy to practice. Wellington: Learning Media.

Ministry of Education. (1996). Towards making achievement cool: Achievement in multicultural high schools (AIMHI). Retrieved from https://www.educationcounts.govt.nz/publications/maori/english-mediumeducation/towards_making_achieving_cool_achievement_in_multi_cultural_hi gh_schools_aimhi

Ministry of Education. (1997). A future qualifications policy for New Zealand: A plan for the national qualifications framework. Green Paper. Wellington: Author.

Ministry of Education. (1999). The National Qualifications Framework of the future: White paper. Wellington: Author.

Ministry of Education. (2005). Teacher census. Retrieved from http://www.educationcounts.govt.nz/publications/schooling/teacher_census Ministry of Education. (2007). The New Zealand curriculum. Wellington: Learning Media.

Ministry of Education. (2011). Ministry of Education Position Paper: Assessment (schooling sector). Wellington: Crown. Retrieved from assessment.tki.org.nz/content/.../5539/.../MOEAssessmentPositionPaper_Octob er11.pdf

Ministry of Education. (2017). Conditions of assessment. Retrieved from http://ncea.tki.org.nz/Resources-for-Internally-Assessed-AchievementStandards/Social-sciences/Accounting/Level-1-Accounting

Mizutani, S. (2009). The mechanism of washback on teaching and learning (Doctoral diss.). University of Auckland, NZ.

Mizutani, S., Rubie-Davies, C., Hattie, J., \& Philp, J. (2011). Do beliefs about NCEA and its washback effects vary depending on subject? New Zealand Journal of Educational Studies, 46(2), 47-59.

Moeed, H. (A). (2010). Science investigation in New Zealand secondary schools: Exploring the links between learning, motivation and internal assessment in year 11 (Doctoral diss.). Victoria University of Wellington, NZ.

Morgan, D. (2007). Paradigms lost and pragmatism regained: Methodological implications of combining qualitative and quantitative methods. Journal of Mixed Methods Research, 1(1), 48-76. doi.org/10.1177/2345678906292462 
Muijs, D. (2011). Doing quantitative research with SPSS. London: Sage.

Muñoz, A. P., Palacio, M., \& Escobar, L. (2012). Teachers' beliefs about assessment in an EFL context in Colombia. PROFILE, 14, 143-158.

Murdock, T. B., Hale, N. M., \& Weber, M. J. (2001). Predictors of cheating among early adolescents: Academic and social motivations. Contemporary Educational Psychology, 26, 96-115. doi.org/10.1006/ceps.2000.1046

Murdock, T., Stephens, J., \& Groteweil, M. (2016). Student dishonesty in the face of assessment: Who, why, and what we can do about it. In G. T. L. Brown \& L. Harris (Eds.), Handbook of social conditions in assessment (pp. 187-203). New York: Routledge.

Mutch, C. (2012). Assessment for, of and as learning: Developing a sustainable assessment culture in New Zealand schools. Policy Futures in Education, 10(4), 374-385. doi.org/10.2304/pfie.2012.10.4.374

Nagy, P. (2000). The Three Roles of Assessment: Gatekeeping, Accountability, and Instructional Diagnosis. Canadian Journal of Education, 25(4), 262-279.

New Zealand Commerce and Economics Teachers Association. (2006). Submission to the Ministry of Education on the Draft New Zealand Curriculum. Retrieved from https://nzcurriculum.tki.org.nz/content/download/725/4515/file/sec72.pdf

New Zealand Government. (2012). Delivering better public services: Boosting skills and employment by increasing educational achievement for young people.

Wellington: Author. Retrieved from

https://education.govt.nz/assets/Documents/Ministry/BPS/BPSYoungPeopleW EB.pdf

New Zealand Post Primary Teachers' Association. (1969). Education in change: Report of the curriculum review group. Auckland: Longman Paul.

New Zealand Post Primary Teachers Association. (2007, September). Nothing endures but change. Paper presented to PPTA Annual Conference. Retrieved from http://ppta.org.nz/publication-library/annual-conference-papers/

New Zealand Post Primary Teachers Association. (2015, April). The NCEA: Can it be saved? Paper presented to PPTA Annual Conference. Retrieved from http://ppta.org.nz/publication-library/annual-conference-papers/

New Zealand Post Primary Teachers Association. (2016). PPTA Workload Taskforce Report: Report of the 2015 investigation into issues of workload intensification 
for secondary school teachers in New Zealand. Retrieved from http://ppta.org.nz/advice-and-issues/teacher-workload/

New Zealand Qualifications Authority \& Organization for Economic Cooperation and Development. (2004). The role of national qualifications in promoting lifelong learning: Background report for New Zealand. Paris: OECD.

New Zealand Qualifications Authority. (1991). Designing the framework: A discussion document about restructuring national qualifications. Wellington: NZQA. Retrieved from http://files.eric.ed.gov/fulltext/ED354327.pdf

New Zealand Qualifications Authority. (1992). Learning to learn: An introduction to the National Qualifications Framework. Wellington: NZQA. Retrieved from http://www.voced.edu.au/content/ngv\%3A20914

New Zealand Qualifications Authority. (2011). Guidelines for assessing Level 1 literacy and numeracy unit standards. Retrieved from http://www.nzqa.govt.nz/assets/qualifications-andstandards/qualifications/ncea/NCEA-subject-resources/Literacy-andNumeracy/Resources/Planning-implementation-and-assessement/Guidelinesfor-assessing-Literacy-and-Numeracy-unit-standardsJan13.pdf

New Zealand Qualifications Authority. (2014). An independent review of the effectiveness of NZQA's implementation of the 2007 NCEA enhancements:

Report of the panel. Retrieved from http://www.nzqa.govt.nz/assets/qualifications-andstandards/qualifications/ncea/Report-of-the-NCEA-enhancements-review.pdf

New Zealand Qualifications Authority. (2016). Annual report on NCEA and New Zealand scholarship data and statistics (2015). Wellington: Author.

New Zealand Qualifications Authority. (2017a, March). Initial teacher educators:

Quality assurance. Powerpoint presentation to initial teacher education student teachers, Victoria University, School of Education.

New Zealand Qualifications Authority. (2017b). QA News Issue 95-31. Retrieved from http://www.nzqa.govt.nz/about-us/publications/qa-news/issue95/\#NCEAresultsrelease

New Zealand Qualifications Authority. (n.d.a). The National Certificate of Educational Achievement: An introduction for parents and students. Wellington. (not dated but thought to be published in 2000). 
New Zealand Qualifications Authority. (n.d.b). How NCEA works. Retrieved from http://www.nzqa.govt.nz/qualificationsstandards/qualifications/ncea/understanding-ncea/how-ncea-works

New Zealand Qualifications Authority. (n.d.c). Fact Sheet \#2: NCEA and education in New Zealand. Retrieved from http://www.nzqa.govt.nz/qualificationsstandards/qualifications/ncea/understanding-ncea/the-facts/factsheet-2/

New Zealand Qualifications Authority. (n.d.d). Factsheet \# 3: How does NCEA's standards-based system challenge, motivate and reward students? Retrieved from http://www.nzqa.govt.nz/qualificationsstandards/qualifications/ncea/understanding-ncea/the-facts/factsheet-3

New Zealand Qualifications Authority. (n.d.e). NCEA endorsements. Retrieved from http://www.nzqa.govt.nz/qualificationsstandards/qualifications/ncea/understanding-ncea/how-nceaworks/endorsements/

New Zealand Qualifications Authority. (n.d.f). Factsheet \# 8: Why are some achievement standards externally assessed and some internally assessed? Retrieved from http://www.nzqa.govt.nz/qualificationsstandards/qualifications/ncea/understanding-ncea/the-facts/factsheet-8/

New Zealand Qualifications Authority. (n.d.g). Where did NCEA come from? Retrieved from http://www.nzqa.govt.nz/qualificationsstandards/qualifications/ncea/understanding-ncea/history-of-ncea/where-didncea-come-from/

New Zealand Qualifications Authority. (n.d. h). External moderation. Retrieved from http://www.nzqa.govt.nz/providers-partners/assessment-andmoderation/managing-national-assessment-in-schools/secondarymoderation/external-moderation/

New Zealand Qualifications Authority. (n.d.i). Assessment opportunities in schools. Retrieved from http://www.nzqa.govt.nz/providers-partners/assessment-andmoderation/assessment-of-standards/generic-resources/gathering-evidence-ofachievement/assessment-opportunities-in-schools/

New Zealand Qualifications Authority. (n.d j). Gathering evidence of achievement. Retrieved from http://www.nzqa.govt.nz/providers-partners/assessment-andmoderation/assessment-of-standards/generic-resources/gathering-evidence-ofachievement/ 
New Zealand Qualifications Authority. (n.d.k). Best practice workshops and assessor support: for internal standards. Retrieved from http://www.nzqa.govt.nz/about-us/events/assessor-support/

Newton, P. (2007). Clarifying the purposes of educational assessment. Assessment in Education: Principles, Policy \& Practice, 14(2), 149-170, doi.10.1080/09695940701478321

Newton, P., \& Shaw, S. (2014). Validity in educational and psychological assessment. London: Sage.

Nicholls, J. G. (1979). Quality and equality in intellectual development: The role of motivation in education. American Psychologist, 34, 1071-1084. doi.org/10.1037/0003-066X.34.11.1071

Nichols, S., \& Harris, L. (2016). Accountability assessment effects on teachers and schools. In G. T. L. Brown \& L. Harris (Eds.), Handbook of social conditions in assessment (pp. 111-129). New York: Routledge.

Noble, A. J., \& Smith, M. L. (1994). Old and new beliefs about measurement-driven reform: 'The more things change, the more they stay the same' (Tech. Rep. No. 373). Tempe, AZ: Center for the Study of Evaluation, Arizona State University.

Nusche, D., Laveault, D., MacBeath, J., \& Santiago, P. (2012). OECD reviews of evaluation and assessment in education: New Zealand 2011. Paris: OECD. http://dx.doi.org/10.1787/9789264116917-en

O’Cathain, A., Murphy, E., \& Nicoll, J., (2010). Three techniques for integrating data in mixed methods studies. BMJ, 341, c4587. Retrieved from http://www.bmj.com/content/341/bmj.c4587.full

O'Connor, B. P. (2000). SPSS and SAS programs for determining the number of components using parallel analysis and Velicer's MAP test. Behavior Research Methods, Instrumentation, and Computers, 32(3), 396-402.

Office of the Auditor General. (2012). New Zealand Qualifications Authority: Assuring the consistency and quality of internal assessment for NCEA. Wellington: Author.

Osborne, J. W., Costello, A. B., \& Kellow, J. T. (2008). Best practices in exploratory factor analysis. In J. W. Osborne (Ed.), Best practices in quantitative methods (pp. 205-213). Thousand Oaks, CA: Sage. 
Pajares, M. (1992). Teachers' beliefs and educational research: Cleaning up a messy construct. Review of Educational Research, 62(3), 307-332. doi.org/10.3102/00346543062003307

Parr, J., \& Timperley, H. (2016). Section discussion: Teachers and assessment. Enhancing assessment capability. In G. T. L. Brown \& L. Harris (Eds.), Handbook of social conditions in assessment (pp. 21-40). New York: Routledge.

Patton, M. (2002). Qualitative research and evaluation methods $\left(3^{\text {rd }}\right.$ ed.). Thousand Oaks, CA: Sage.

Pedder, D., \& Opfer, D. (2013). Professional learning orientations: Patterns of dissonance and alignment between teachers' values and practices. Research Papers in Education, 28(5), 539-570. doi.org/10.1080/02671522.2012.706632

Pedulla, J., Abrams, L., Madaus, G. F., Russell, M., Ramos, M., \& Miao, J. (2003). Perceived effects of state-mandated testing programs on teaching and learning: Findings from a national survey of teachers. Chestnut Hill, MA: National Board on Educational Testing and Public Policy, Boston College. Retrieved from http://www.bc.edu/research/nbetpp/

Pishghadam, R., \& Shayesteh, S. (2012). Conceptions of assessment among Iranian EFL teachers. The Iranian EFL Journal, 8, 9-23.

Pryor, J. \& Crossouard, B. (2008). A socio-cultural theorisation of formative assessment. Oxford Review of Education, 34(1), 1-20. DOI: $10.1080 / 03054980701476386$

Punch, K. F. (2005). Introduction to social research: Quantitative and qualitative approaches. Thousand Oaks, CA: Sage.

Qian, D. (2014). School-based English language assessment as a high stakes examination component in Hong Kong: Insights of frontline assessors. Assessment in Education: Principles, Policy \& Practice, 21(3), 251-270. doi.10.1080/0969594X.2014.915207

Qu, S., \& Dumay, J. (2011). The qualitative research interview. Qualitative Research in Accounting \& Management, 8(3), 238-264. doi.org/10.1108/11766091111162070

Rabi, S. M., Patton, L. R., Fjortoft, N., \& Zgarrick, D. P. (2006). Characteristics, prevalence, attitudes, and perceptions of academic dishonesty among pharmacy 
students. American Journal of Pharmaceutical Education, 70(4), 73-81. doi.org/10.5688/aj700473

Raman, K., \& Yamat, H. (2014). English teachers' voices on the challenges of the school-based assessment. Frontiers of Language and Teaching, 5, 66-74.

Rata, E., \& Taylor, A. (2015). Knowledge equivalence discourse in New Zealand secondary school science. New Zealand Journal of Education Studies, 50, 223-238. doi.10.1007/s40841-015-0020-1

Rawlins, P. (2008). Unlocking the formative potential of NCEA. New Zealand Journal of Teachers' Work, 5(2), 105-118.

Remesal, A. (2011). Primary and secondary teachers' conceptions of assessment: A qualitative study. Teaching and Teacher Education, 27(2), 472-482. http://dx.doi.org/10.1016/j.tate.2010.09.017

Richardson, V., \& Placier, P. (2001). Teacher change. In V. Richardson, Handbook of research on teaching ( $4^{\text {th }}$ ed., pp. 905-950). Washington, D. C.: American Education Research Association.

Riley, B. (2014). Science, data and decisions in New Zealand's education system. Wellington: Fulbright New Zealand. Retrieved from https://www.fulbright.org.nz/wpcontent/uploads/2014/08/axford2014_riley.pdf

Robinson, V., Hohepa, M., \& Lloyd, C. (2009). School leadership and student outcomes: Identifying what works and why. Auckland, NZ: New Zealand Ministry of Education. Retrieved from: http://www.educationcounts.govt.nz/_data/assets/pdf_file/0015/60180/BESLe adership-Web.pdf

Rokeach, M. (1968). A theory of organisation and change within value-attitude systems. Journal of Social Issues, XXIV(1), 13-33. doi.org/10.1111/j.15404560.1968.tb01466.x

Sadler, D. R. (1989). Formative assessment and the design of instructional systems. Instructional Science, 18(2), 119-144. doi.org/10.1007/BF00117714

Sannino, A. (2008). Sustaining a non-dominant activity in school: Only a utopia? Journal of Educational Change, 9(4), 329-338. doi.10.1007/s10833-0089080-z

Schön, D. (1983). The reflective practitioner: How professionals think in action. New York: Basic Books. 
Scott, S., Scott, D. E., \& Webber, C. F. (2016). The assessment KSA learning journey: Expanding the $4 \mathrm{~L}$ - Life-Long Learning Leader - Framework. In S. Scott et al. (Eds.), Leadership of assessment, inclusion, and learning, the enabling power of assessment 3 (pp. 201-230). Switzerland: Springer. doi.10.1007/978-3-319-23347-5_12.

Scriven, M. (1966). The methodology of evaluation. Social Science education consortium, Publication 100. Retrieved from http://www.comp.dit.ie/dgordon/Courses/ILT/ILT0005/TheMethodologyOfEv aluation.pdf

Segars, M., \& Tillema, H. (2011). How do Dutch secondary teachers and students conceive the purpose of assessment? Studies in Educational Evaluation, 37, 49-54. doi.org/10.1016/j.stueduc.2011.03.008

Senge, P. M. (1990). The fifth discipline: The art \& practice of the learning organization. New York: Doubleday Business.

Sheehan, M. (2013). "Better to do than receive”: Learning to think historically through internally assessed course work. Wellington, NZ: Teaching and Learning Research Initiative.

Shohamy, E. (2001). The Power of Tests: A Critical Perspective on the Uses of Language Tests. Essex: Longman.

Shulruf, B., Hattie, J., \& Tumen, S. (2010) New Zealand's standard based assessment for secondary schools (NCEA): implications for policy makers. Asia Pacific Journal of Education (30)2, 141-165. doi. $10.1080 / 02188791003721598$

Sivo, S., Fan, X., Witta, E. L., \& Willse, J. T. (2006). The search for “optimal” cutoff properties: Fit index criteria in structural equation modeling. The Journal of Experimental Education, 74(3), 267-288. doi.10.3200/JEXE.74.3.267-288

Stanley, G., MacCann, R., Gardner, J., Reynold, L., \& Wild, I. (2009). Review of teacher assessment: What works best and issues for development. UK:

Qualifications and Curriculum Authority.

Starkey, L., Stevens, S., Taylor, M., Toia, R., Yates, A., Hall, C., McKenzie, L., \& Meyer, L. H. (2006). School/cluster based secondary qualifications professional development: Review of secondary schools' use of NCEA 
professional development resources, 2005-2006. Wellington: Ministry of Education.

Starkey, L., Yates, A., Meyer, L. H., Hall, C., Taylor, M., Stevens, S., \& Toia, R. (2009). Professional development design: Embedding educational reform in New Zealand. Teaching and Teacher Education, 25(1), 181-189. doi.org/10.1016/j.tate.2008.08.007

Steiger, J. H. (1990). Structural model evaluation and modification. Multivariate Behavioral Research, 25, 214-212. doi.org/10.1207/s15327906mbr2502_4

Steiger, J. H. (2007). Understanding the limitations of global fit assessment in structural equation modelling. Personality and Individual Differences, 42(5), 893-898. doi.org/10.1016/j.paid.2006.09.017

Stewart, S., Gray, S., \& Pilcher, E. (2007). Assessment practices of Level 3 NCEA teachers (2004-2006). Wellington: New Zealand Qualifications Authority.

Stiggins, R. (1995). Assessment literacy for the $21^{\text {st }}$ century. The Phi Delta Kappan, 77(3), 238-245.

Stiggins, R. J. (2010). Essential formative assessment competencies for teachers and school leaders. In H. L. Andrade \& G. J. Cizek (Eds.), Handbook of Formative Assessment (pp. 233-250). New York: Routledge.

Stobart, G. (2008). Testing times: The uses and abuses of assessment. Abingdon, UK: Routledge.

Strauf, R. (2016). Mixed methods: Interviews, surveys and cross cultural comparisons. Cambridge, UK: Cambridge University Press.

Tabachnick, B. G., \& Fidell, L. S. (2007). Using multivariate statistics (5 $5^{\text {th }}$ ed.). New York: Allyn \& Bacon.

Taras, M. (2010). Assessment for learning: Assessing the theory and evidence. Social and Behavioral Sciences, 2, 3015-3022. doi.org/10.1016/j.sbspro.2010.03.457

Tashakkori, A., \& Teddlie, C. (2003). The past and future of mixed methods research: From data triangulation to mixed model designs. In A. Tashakkori \& C. Teddlie (Eds.), Handbook of mixed methods in social and behavioural research (pp. 671-701). Thousand Oaks, CA: Sage.

Taylor, M., Kinsella, P., Yates, A., McKenzie, L. H., \& Meyer, L. (2007). Evaluation of the Senior Subject Adviser Pilot Initiative 2007. Wellington: Ministry of Education. 
Taylor, M., Yates, A., Meyer, L. H., \& Kinsella, P. (2011). Teacher professional leadership in support of teacher professional development. Teaching and Teacher Education, 27(1), 85-94. doi.org/10.1016/j.tate.2010.07.005

Teddlie, C., \& Tashakkori, A. (2009). Foundations of mixed methods research. Thousand Oaks, CA: Sage.

Teddlie, C., \& Tashakkori, A. (2010). Overview of contemporary issues in mixed methods research. In A. Tashakkori, \& C. Teddlie (Eds.), Handbook of mixed methods in social and behavioral research ( $2^{\text {nd }}$ ed.). Thousand Oaks, CA: Sage.

Thompson, A. G. (1992). Teachers' beliefs and conceptions: A synthesis of the research. In D. A. Grouws (Ed.), Handbook of research on mathematics teaching and learning (pp. 127-146). New York: Macmillan.

Thrupp, M. (2017). New Zealand's national standards policy: How should we view it a decade on? Teachers and Curriculum, 17(1), 11-15.

Thrupp, M., \& Alcorn, N. (2010). A little knowledge being a dangerous thing? Decile-based approaches to developing NCEA league tables. New Zealand Annual Review of Education, 20, 52-73.

Timperley, H. S., Wilson, A., Barrar, H., \& Fung, I. (2007). Teacher Professional Learning and Development Best Evidence Synthesis. Wellington: Ministry of Education.

Tong, S. Y. A., \& Adamson, B. (2015). Student voices in school-based assessment. Australian Journal of Teacher Education, 40(2), 15-28. doi.org/10.14221/ajte.2015v40n2.2

Torrance, H. (1995). Introduction. In H. Torrance (Ed.), Evaluating authentic assessment: Problems and possibilities in new approaches to assessment (pp. 1-8). Buckingham: Open University Press.

Torrance, H. (2007). Assessment as learning? How the use of explicit learning objectives, assessment criteria and feedback in post-secondary education and training can come to dominate learning. Assessment in Education: Principles, Policy \& Practice, 14(3), 281-294. doi.10.1080/09695940701591867

Turner, T. R., Irving, S. E., Li, M., \& Yuan, J. (2010). Availability of NCEA standards: Impact on success rate. Auckland: University of Auckland, Starpath Project.

Vygotsky, L. (1978). Mind and society. Cambridge, MA: Harvard Univesity Press. 
Walkey, F., \& Welch, G. (2010). Demystifying factor analysis: How it works and how to use it. USA: Xlibris.

Walliman, N. (2005). Your research project ( $2^{\text {nd }}$ ed.). London: Sage.

Weiner, B (1985). Spontaneous causal thinking. Psychological Bulletin, 97(1), 7484. doi:10.1037/0033-2909.97.1.74

Westheimer, J. (2008). Learning among colleagues: Teacher community and the shared enterprise of education. In M. Cochran-Smith, S. Feiman-Nemser, \& D. J. McIntyre (Eds.), Handbook of research on teacher education: Enduring questions in changing contexts (pp. 756-783). New York, NY: Routledge.

Wiliam, D. (1994). Towards a philosophy for educational assessment. Update on a paper given at the British Educational Research Association's $20^{\text {th }}$ annual conference, Oxford. Retrieved from https://pdfs.semanticscholar.org/8025/955a8c637001fa4d467869a5695214036e 78.pdf

Wiliam, D. (2008). Quality in assessment. In S. Swaffield (Ed.), Unlocking assessment: Understanding for reflection and application. Abingdon: Routledge.

Willig, C., \& Stainton-Rogers, W. (2008). Handbook of qualitative research in psychology. London: Sage.

Wolf, D., Bixby, J., Glenn, J., \& Gardner, H. (1991). To use their minds well: Investigating new forms of student assessment. Review of Research in Education, 17, 31-74.

Wyatt-Smith, C. M., Klenowski, V., \& Gunn, S. (2010). The centrality of teachers' judgement practice in assessment: A study of standards in moderation. Assessment in Education: Principles, Policy \& Practice, 17(1), 59-75. doi.org/10.1080/09695940903565610

Wylie, C. (1999). Ten years on: How schools view educational reform. Wellington, NZ: New Zealand Council of Educational Research.

Wylie, C. (2012). Vital connections: Why we need more than self-managing schools. Wellington, NZ: New Zealand Council of Educational Research.

Wylie, C., \& Bonne, L. (2016). Secondary schools in 2015: Findings from the NZCER national survey. Wellington, NZ: New Zealand Council for Educational Research. Retrieved from http://dx.doi.org/10.18296/rep.0001 
Wyse, D., \& Torrance, H. (2009). The development and consequences of national curriculum assessment for primary education in England. Educational Research, 51(2), 213-238. doi.org/10.1080/00131880902891479

Xu, Y., \& Brown, G. T. L. (2016). Teacher assessment literacy in practice: A reconceptualization. Teaching and Teacher Education, 58, 149-162. https://doi.org/10.1016/j.tate.2016.05.010

Yan, Z. (2014). Predicting teachers' intentions to implement school-based assessment using the theory of planned behaviour. Educational Research and Evaluation: An International Journal on Theory and Practice, 20(2), 83-97. doi.10.1080/13803611.2013.877394

Yates, A. (2012). Devolving professional learning to subject specialists: Towards embedding assessment reform in New Zealand. Professional Development in Education, 38(4), 613-629.

Yip, D.Y., \& Cheung, D. (2005). Teachers' concerns on school-based assessment practical work. Journal of Biological Education, 39(4), 156-162. doi.org/10.1080/00219266.2005.9655989

Yong, A. G., \& Pearce, S. (2013). A beginner's guide to factor analysis: Focusing on exploratory factor analysis. Tutorials in Quantitative Methods for Psychology, 9(2), 79-94. doi.org/10.20982/tqmp.09.2.p079

Yung, B. H. W. (2000). Teachers' beliefs and their teaching of practical work in a school-based assessment scheme (Doctoral diss.). University of Hong Kong, Hong Kong.

Yung, B. H. W. (2012). Issues and challenges in school-based assessment of science practical work. In K. C. D. Tan \& M. Kim (Eds.), Issues and challenges in science education research: Moving forward (pp. 125-140). Netherlands: Springer.

Zhang, Y., \& Wildemuth, B. M. (2009). Qualitative analysis of content. In B. Wildemuth (Ed.), Applications of social research methods to questions in information and library science (pp. 318-329). Santa Barbara, CA: Libraries Unlimited.

Zhao, Y., \& Cziko, G. A. (2001). Teacher adoption of technology: A perceptual control theory perspective. Journal of Technology and Teacher Education, 9(1), 5-30. 
Zohrabi, M. (2013). Mixed method research: Instruments, validity, reliability and reporting findings. Theory and Practice in Language Studies, 3(2), 254-262.

Zwick, W. R. \& Velicer, W. F. (1986). Comparison of five rules for determining the number of components to retain. Psychological Bulletin, 99(3), 432-442. 


\section{Appendix 1: The survey}

\section{Conceptions of assessment}

Thank you for completing this questionnaire. The questionnaire is in three parts and should take no longer than 20 minutes to complete.

Part $\mathrm{A}$ is designed to find out about your beliefs and understandings about ASSESSMENT, whatever that term means to you. Please answer the questions using your own understanding of assessment. There are no right or wrong answers; I am interested only in your frank opinions. Please give your initial response to the questions, rather than deliberating over them

Part B is designed to find out your knowledge in relation to NCEA internal assessment. Again there are no right or wrong answers.

Part $\mathrm{C}$ is designed to collect demographic data relating to you.

Thank you very much for answering these questions.

Anne Yates, PhD student, Victoria University of Wellington. 

Please tick one box for each statement

\section{Part A: Conceptions of Assessment}

1. Assessment provides information on how well schools are doing

2. Assessment places students into categories

3. Assessment is a way to determine how much students have learned from teaching

4. Assessment provides feedback to students about their performance

5. Assessment is integrated with teaching practice

6. Assessment results are trustworthy

7. Assessment forces teachers to teach in a way against their beliefs

8. Teachers conduct assessments but make little use of the results

9. Assessment results should be treated cautiously because of measurement error

10. Assessment is an accurate indicator of a school's quality

11. Assessment is assigning a grade or level to student work

12. Assessment establishes what students have learned

13. Assessment feeds back to students their learning needs

14. Assessment information modifies ongoing teaching of students

$\begin{array}{cccccc}\text { Strongly } & \text { Mostly } & \text { Slightly } & \text { Moderately } & \text { Mostly } & \text { Strongly } \\ \text { Disagree } & \text { Disagree } & \text { Agree } & \text { Agree } & \text { Agree } & \text { Agree }\end{array}$

$\square$

$\square \square$

$\square$

$\square$

$\square$

$\square$

$\square$

$\square$

$\square$

$\square$

$\square \square$

$\square$

$\square$

$\square$

$\square$

$\square$

$\square \square$

$\square$

$\square$

$\square \square$

$\square \quad \square$

$\square$

$\square \square$

$\square$

$\square$

$\square$

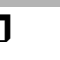

$\square$

$\square$

$\square$

$\square$

$\square$

$\square$

$\square$

$\square$

$\square$

$\square$

$\square$

$\begin{array}{ll}\square & \square \\ \square & \square\end{array}$

$\square$

$\begin{array}{lll}\square & \square & \square \\ \square & \square & \square\end{array}$




\section{Part A (cont): Conceptions of Assessment}

15. Assessment results are consistent

16. Assessment is unfair to students

17. Assessment results are filed \& ignored

18. Teachers should take into account the error and imprecision in all assessment

19. Assessment is a good way to evaluate a school

20. Assessment determines if students meet qualifications standards

21. Assessment measures students' higher order thinking skills

22. Assessment helps students improve their learning

23. Assessment allows different students to get different instruction

\section{Assessment results can be depended on}

25. Assessment interferes with teaching

26. Assessment has little impact on teaching

27. Assessment is an imprecise process

CoA-III Abridged (C2002, Dr. Gavin Brown, University of Auckland

$\begin{array}{cccccc}\text { Strongly } & \text { Mostly } & \text { Slightly } & \text { Moderately } & \text { Mostly } & \text { Strongly } \\ \text { Disagree } & \text { Disagree } & \text { Agree } & \text { Agree } & \text { Agree } & \text { Agree }\end{array}$

$\square$ $\square \square$

$\square$

$\square$

$\square$

$\square$

$\square$

$\square$

$\square$

$\square$

$\square$

$\square$

$\square$

$\square \square$

$\square \square$

$\square \square$

$\square \square$

$\square \square$

$\square$

$\square$

$\square$

$\square$

$\square$

$\square$

$\square$

$\square$

$\begin{array}{ll}\square & \square \\ \square & \square\end{array}$

$\square$

$\square$

$\square \square$

$\square$

$\square$

$\square$

$\square$

$\square$

$\square \square$

$\square$

$\square$

$\square$

$\square$

$\square$

$\square \square$

$\square$

$\begin{array}{lll}\square & \square & \square \\ \square & \square & \square\end{array}$

Please continue ... 


\begin{tabular}{|c|c|c|c|c|c|c|c|}
\hline & Part B: Knowledge of NCEA internal assessment & $\begin{array}{l}\text { Strongly } \\
\text { Disagree }\end{array}$ & $\begin{array}{l}\text { Mostly } \\
\text { Disagree }\end{array}$ & $\begin{array}{l}\text { Slightly } \\
\text { Agree }\end{array}$ & $\begin{array}{l}\text { Moderately } \\
\text { Agree }\end{array}$ & $\begin{array}{l}\text { Mostly } \\
\text { Agree }\end{array}$ & $\begin{array}{l}\text { Strongly } \\
\text { Agree }\end{array}$ \\
\hline 1 & $\begin{array}{l}\text { I am knowledgeable in motivating all senior students to do their best (not just high } \\
\text { achievers) }\end{array}$ & $\square$ & $\square$ & $\square$ & $\square$ & $\square$ & $\square$ \\
\hline 2 & I am knowledgeable generating student interest in my senior subject & $\square$ & $\square$ & $\square$ & $\square$ & $\square$ & $\square$ \\
\hline 3 & $\begin{array}{l}\text { I am knowledgeable making appropriate judgment decisions against NCEA } \\
\text { standards, especially around the grade margins }\end{array}$ & $\square$ & $\square$ & $\square$ & $\square$ & $\square$ & $\square$ \\
\hline 4 & $\begin{array}{l}\text { I am knowledgeable adapting web material tasks to meet the requirements of an } \\
\text { internally assessed standard }\end{array}$ & $\square$ & $\square$ & $\square$ & $\square$ & $\square$ & $\square$ \\
\hline 5 & $\begin{array}{l}\text { I am knowledgeable writing NCEA internal assessment tasks and assessment } \\
\text { schedules }\end{array}$ & $\square$ & $\square$ & $\square$ & $\square$ & $\square$ & $\square$ \\
\hline 6 & $\begin{array}{l}\text { I am knowledgeable making judgment decisions for NCEA assessment, especially } \\
\text { around the grade margins }\end{array}$ & $\square$ & $\square$ & $\square$ & $\square$ & $\square$ & $\square$ \\
\hline 7 & $\begin{array}{l}\text { I am knowledgeable in creating a Level } 2 \text { accounting and/or economics course that } \\
\text { meets the needs of my particular students. }\end{array}$ & $\square$ & $\square$ & $\square$ & $\square$ & $\square$ & $\square$ \\
\hline
\end{tabular}


Part C - Would you also provide the following information?

1) What is your role? (Tick one only)

$\square$ Teacher

$\square$ MU holder

Head of Department

$\square$ Assistant or Deputy Principal

$\square$ Principal

Other:

2) What is your highest degree? (Tick one only)

Bachelor

$\square$ Postgraduate Certificate

$\square$ Postgraduate Diploma

Master

$\square$ Doctor

3) What is your specialist teaching subject?

$\square$ Economics

$\square$ Accounting

$\square$ Both 
4) For how many years have you taught in New Zealand? (Tick one only)

$\square$ Less than 2

$\square$ Between 2 and 5

$\square$ Between 6 and 10

$\square$ Between 11 and 20

More than 20

5) Are you an overseas trained teacher?

$\square$ Yes

$\square$ No

6) What training in educational assessment have you had? (Tick all that apply)

$\square$ None

$\square$ Some hours as part of pre-service training

$\square$ Workshops or Seminars

$\square$ Completed an undergraduate paper

$\square$ Completed a postgraduate paper

$\square$ Other: (give details)

7) In accounting, which internally assessed achievement standards do your students complete? (Tick all that apply)

$\square \operatorname{AS} 91481(2.5)$

$\square \operatorname{AS} 91179(2.6)$

$\square \operatorname{AS} 91386(2.7)$

For each standard that the students complete please identify the tasks used to assess the standards, i.e. Own, Commercial, TKI exemplars, modified TKI exemplar, other (give details).

Please explain why you use these tasks. 
8) In economics, which internally assessed achievement standards do your students complete? (Tick all that apply)

$\square \operatorname{AS} 91225(2.4)$

$\square \operatorname{AS} 91226(2.5)$

AS91227 (2.6)

AS91228 (2.7)

For each standard that the students complete please identify the tasks used to assess the standards, i.e. Own, Commercial, TKI exemplars, modified TKI exemplar, other (give details).

Please explain why you use these tasks.

9) Please provide the range of grades your students achieved in 2012 for each of the internally assessed standards.

Accounting

AS91481 (2.5): N $\square, A \square, M \square, E \square$

$\operatorname{AS91179~(2.6):~N~} \square, A \square, M \square, E \square$

AS91386 (2.7) N $\square$, A $\square, \mathrm{M} \square, \mathrm{E} \square$

\section{Economics}

AS91225 (2.4): N $\square, A \square, M \square, E \square$

AS91226 (2.5): N $\square, \mathrm{A} \square, \mathrm{M} \square, \mathrm{E} \square$

AS91227 (2.6): $\mathrm{N} \square, \mathrm{A} \square, \mathrm{M} \square, \mathrm{E} \square$

AS91228 (2.7): N $\square, A \square, M \square$, E $\square$

10) What is your gender? (Tick one only)

$\square$ Female

$\square$ Male 
11) Which ethnic group do you belong to? (Tick one only)

$\square$ NZ European / Pākehā

$\square$ NZ Māori

$\square$ Pacific Nation

Asian: (give details)

$\checkmark$ Other: (give details)

12) At which type of school do you teach? (Tick one only)

State co-educational secondary school

State single sex secondary school

$\square$ Integrated secondary school

$\square$ Private secondary school

13) The decile rating of my school is

14) The researcher would really like to hear your thoughts about NCEA internal assessment and would appreciate your participation in an interview. Please indicate whether you are willing to volunteer to be interviewed as part of this study

$\square$ Yes

$\square$ No

If the answer to $\mathrm{Q} 15$ is yes, please provide the following

14) What is your school's name?

16) What is your name?

17) What is your email address 


\section{Appendix 2: the generic interview schedule}

1. What do you think is the purpose of assessment in schools?

2. Do you think the purpose varies between junior and senior secondary school?

3. What do you think is the main purpose of formative assessmesnt?

4. What do you think is the main purpose of summative assessment?

5. Do you think it is possible to use NCEA in a formative way? Please explain.

6. Do you use the TKI exemplars to assess the internally assessed standards? Why? Why not?

7. Are there any other approaches you would be willing to use for assessing these standards?

8. NZQA information about NCEA internal assessment states that the internal assessment component of NCEA allows schools to assess in authentic ways and provides students with the opportunity to show what they can achieve, to work in familiar surroundings and to have ample time to show what they can achieve.

a. Are you able to achieve this?

b. If answer is yes - please provide me with an example

c. What makes this assessment authentic?

9. NZQA also claims the ability to internally assess and improved flexibility in programme design gives schools opportunities to develop specific programmes and assessment regimes that suit their students. Do you do this?

a. If answer is yes - Please provide me with an example.

b. If answer is no - Why don't you think you are able to achieve this? 


\section{Appendix 3 Ethics approval}

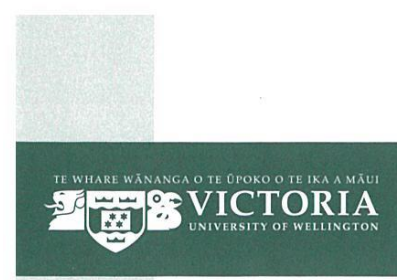

FACULTY OF EDUCATION

PO Box 17-310 Wellington 6012, New Zealand

Website www.victoria.ac.nz

26 March 2012

Anne Yates

Lecturer

Victoria University of Wellington Faculty of Education

$\mathrm{C} /$ - School of Educational Psychology and Pedagogy

Donald Street

Wellington

\section{Dear Anne}

\section{RE: Ethics application SEPI/2013/10 RM RM 19669}

I am pleased to advise you that your ethics application 'An investigation of the relationships between teachers' beliefs and practices about assessment and students' achievement in NCEA.', with the required changes, has been approved by the Victoria University of Wellington Faculty of Education Ethics Committee. Please note that the approval for your research to commence is from the date of this letter.

Best wishes for your research.

Yours Sincerely

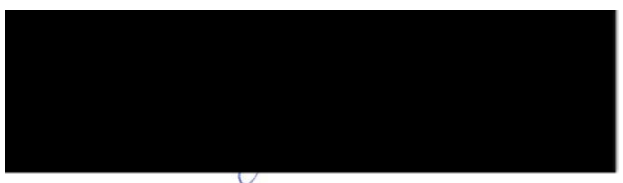

Dr Sue Cornforth

Co-Convener

Victoria University of Wellington Faculty of Education Ethics Committee 


\section{Appendix 4 Ethics amendment}

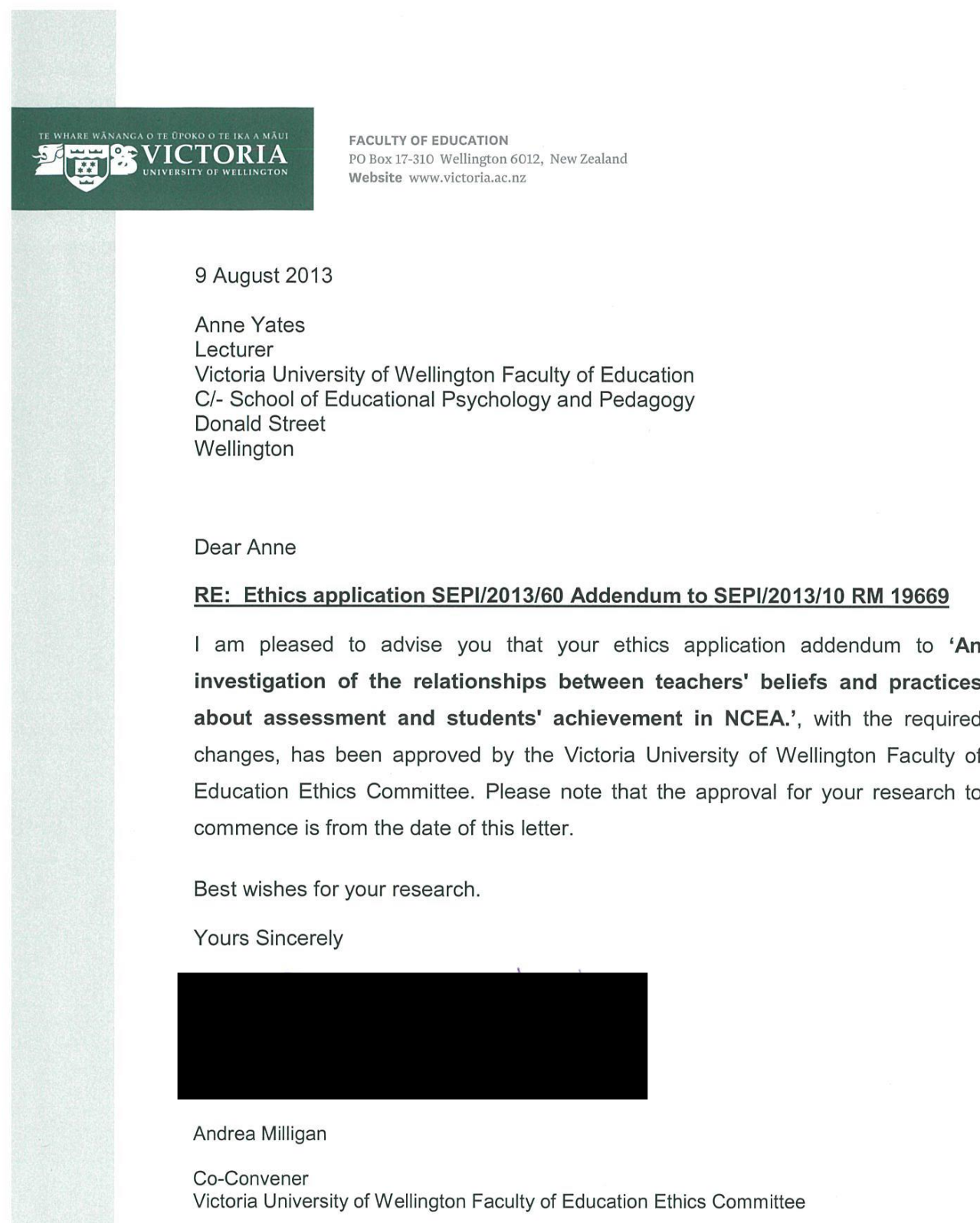




\section{Appendix 5: Factor matrix for 4 factor solution}

\section{Factor Matrix ${ }^{\mathrm{a}}$}

\begin{tabular}{|c|c|c|c|c|}
\hline & \multicolumn{4}{|c|}{ Factor } \\
\hline & 1 & 2 & 3 & 4 \\
\hline Assessment provides information on how well schools are doing & .586 & & & \\
\hline \multicolumn{5}{|l|}{ Assessment places students into categories } \\
\hline $\begin{array}{l}\text { Assessment is a way to determine how much students have learned from } \\
\text { teaching }\end{array}$ & .690 & & & \\
\hline Assessment provides feedback to students about their performance & .568 & & .302 & \\
\hline Assessment is integrated with teaching practice & .469 & & & \\
\hline Assessment results are trustworthy & .661 & & & \\
\hline Assessment forces teachers to teach in a way against their beliefs & -.369 & .309 & .513 & \\
\hline Teachers conduct assessments but make little use of the results & & .306 & & \\
\hline $\begin{array}{l}\text { Assessment results should be treated cautiously because of measurement } \\
\text { error }\end{array}$ & & .319 & .337 & .305 \\
\hline Assessment is an accurate indicator of a school's quality & .526 & .613 & & \\
\hline \multicolumn{5}{|l|}{ Assessment is assigning a grade or level to student work } \\
\hline Assessment establishes what students have learned & .696 & & & \\
\hline Assessment feeds back to students their learning needs & .467 & & & \\
\hline Assessment information modifies ongoing teaching of students & .466 & & .339 & -.515 \\
\hline Assessment results are consistent & .644 & & & \\
\hline Assessment is unfair to students & -.512 & .337 & & \\
\hline Assessment results are filed $\&$ ignored & -.398 & & & \\
\hline \multicolumn{5}{|l|}{$\begin{array}{l}\text { Teachers should take into account the error and imprecision in all } \\
\text { assessment }\end{array}$} \\
\hline Assessment is a good way to evaluate a school & .614 & 638 & & \\
\hline Assessment determines if students meet qualifications standards & .617 & & & \\
\hline Assessment measures students' higher order thinking skills & .713 & & & \\
\hline Assessment helps students improve their learning & .700 & & & \\
\hline Assessment allows different students to get different instruction & .327 & -.344 & & \\
\hline Assessment results can be depended on & .795 & & & \\
\hline Assessment interferes with teaching & -.474 & .378 & .435 & \\
\hline \multicolumn{5}{|l|}{ Assessment has little impact on teaching } \\
\hline Assessment is an imprecise process & -.348 & .328 & .461 & \\
\hline
\end{tabular}

Extraction Method: Maximum Likelihood.

a. 4 factors extracted. 5 iterations required. 


\section{Appendix 6: The anti-image correlation matrix for a four factor solution}

\begin{tabular}{|c|c|c|c|c|c|c|c|c|c|c|c|c|c|c|c|c|c|c|c|c|c|c|c|c|c|c|c|}
\hline $\begin{array}{l}\text { Assessment } \\
\text { provides } \\
\text { information } \\
\text { on how well } \\
\text { schools are } \\
\text { doing }\end{array}$ & $\begin{array}{r}1 \\
.853^{\mathrm{a}} \\
\end{array}$ & $\begin{array}{r}2 \\
-.239\end{array}$ & $\begin{array}{r}3 \\
-.112\end{array}$ & $\begin{array}{r}4 \\
-.029\end{array}$ & $\begin{array}{r}5 \\
-.192\end{array}$ & $\begin{array}{r}6 \\
-.079\end{array}$ & $\begin{array}{r}7 \\
.054\end{array}$ & $\begin{array}{r}8 \\
.023\end{array}$ & $\begin{array}{r}9 \\
-.084\end{array}$ & $\begin{array}{r}10 \\
-.161\end{array}$ & $\begin{array}{r}11 \\
.143\end{array}$ & $\begin{array}{r}12 \\
.072\end{array}$ & $\begin{array}{r}13 \\
.232\end{array}$ & $\begin{array}{r}14 \\
.046\end{array}$ & $\begin{array}{r}15 \\
-.101\end{array}$ & $\begin{array}{r}16 \\
-.066\end{array}$ & $\begin{array}{r}17 \\
-.071\end{array}$ & $\begin{array}{r}18 \\
.134\end{array}$ & $\begin{array}{r}19 \\
-.210\end{array}$ & $\begin{array}{r}20 \\
-.006\end{array}$ & $\begin{array}{r}21 \\
.056\end{array}$ & $\begin{array}{r}22 \\
-.207\end{array}$ & $\begin{array}{r}23 \\
.061\end{array}$ & $\begin{array}{r}24 \\
.017\end{array}$ & $\begin{array}{r}25 \\
.119\end{array}$ & $\begin{array}{r}26 \\
.050\end{array}$ & $\begin{array}{r}27 \\
-.012\end{array}$ \\
\hline $\begin{array}{l}\text { Assessment } \\
\text { places } \\
\text { students into } \\
\text { categories }\end{array}$ & -239 & $.598^{\mathrm{a}}$ & .048 & -.060 & -.118 & .096 & -.075 & -.006 & -.003 & $\begin{array}{l}.143 \\
\end{array}$ & -.095 & -.065 & -.136 & .047 & -.077 & -.026 & -.117 & .045 & -.160 & -.063 & .099 & .039 & -.041 & .041 & -.080 & $\begin{array}{l}.037 \\
\end{array}$ & .071 \\
\hline $\begin{array}{l}\text { Assessment } \\
\text { is a way to } \\
\text { determine } \\
\text { how much } \\
\text { students } \\
\text { have learned } \\
\text { from } \\
\text { teaching }\end{array}$ & -.112 & .048 & $.860^{\mathrm{a}}$ & -.195 & -.050 & $\begin{array}{l}.195 \\
\end{array}$ & -.128 & -.094 & -.110 & $\begin{array}{l}.203 \\
\end{array}$ & .057 & -.312 & .144 & $\begin{array}{l}.052 \\
\end{array}$ & -.134 & .152 & .191 & .106 & -.182 & .075 & -.302 & .013 & -.063 & .092 & -.092 & -.121 & .017 \\
\hline $\begin{array}{l}\text { Assessment } \\
\text { provides } \\
\text { feedback to } \\
\text { students } \\
\text { about their } \\
\text { performance }\end{array}$ & -.029 & -.060 & -.195 & $.896^{\mathrm{a}}$ & -.130 & -.040 & -.046 & -.007 & .112 & .065 & -.079 & .009 & -.213 & -.316 & \begin{tabular}{|l|}
.078 \\
\end{tabular} & -.054 & .030 & -.074 & .022 & -.134 & -.030 & .116 & -.051 & -.103 & .070 & -.033 & -.052 \\
\hline $\begin{array}{l}\text { Assessment } \\
\text { is integrated } \\
\text { with teaching } \\
\text { practice }\end{array}$ & -.192 & -.118 & -.050 & -.130 & $.827^{\mathrm{a}}$ & $\begin{array}{l}.232 \\
\end{array}$ & .186 & $\begin{array}{r}5.397 \mathrm{E} \\
-5\end{array}$ & -.030 & $\begin{array}{l}.093 \\
\end{array}$ & $\begin{array}{l}.087 \\
\end{array}$ & -.214 & -.046 & \begin{tabular}{|l|}
.143 \\
\end{tabular} & $\begin{array}{l}.022 \\
\end{array}$ & -.075 & .099 & -.223 & .033 & .038 & -.023 & .136 & -.116 & .023 & -.152 & $\begin{array}{l}.137 \\
\end{array}$ & .101 \\
\hline $\begin{array}{l}\text { Assessment } \\
\text { results are } \\
\text { trustworthy }\end{array}$ & $\begin{array}{l}-.079 \\
\end{array}$ & .096 & -195 & -.040 & -.232 & $.881^{\mathrm{a}}$ & -.041 & .138 & .203 & $\begin{array}{l}-047 \\
\end{array}$ & .026 & .004 & -.018 & .199 & -.090 & -.007 & -.043 & $\begin{array}{l}.187 \\
\end{array}$ & .061 & $\begin{array}{l}.127 \\
\end{array}$ & .084 & .002 & \begin{tabular}{|l|}
.098 \\
\end{tabular} & -.313 & .104 & .106 & $\begin{array}{l}.106 \\
\end{array}$ \\
\hline $\begin{array}{l}\text { Assessment } \\
\text { forces } \\
\text { teachers to } \\
\text { teach in a } \\
\text { way against } \\
\text { their beliefs }\end{array}$ & .054 & -.075 & -.128 & -.046 & .186 & -.041 & $.829^{\mathrm{a}}$ & -.085 & -.179 & .093 & -.045 & -.053 & .080 & -.108 & .106 & -.168 & .103 & -.007 & -.053 & -.014 & .058 & .130 & -.069 & -.073 & -.299 & .077 & -.136 \\
\hline $\begin{array}{l}\text { Teachers } \\
\text { conduct } \\
\text { assessments } \\
\text { but make } \\
\text { little use of } \\
\text { the results }\end{array}$ & .023 & -.006 & -.094 & -.007 & $\begin{array}{r}5.397 \mathrm{E} \\
-5\end{array}$ & .138 & -.085 & $.692^{\mathrm{a}}$ & .036 & -.124 & -.017 & -.030 & .081 & .060 & \begin{tabular}{|c|}
.039 \\
\end{tabular} & -.054 & -.449 & .220 & .131 & -.193 & .175 & .085 & -.074 & -.144 & .018 & -.004 & -.287 \\
\hline $\begin{array}{l}\text { Assessment } \\
\text { results } \\
\text { should be } \\
\text { treated } \\
\text { cautiously } \\
\text { because of } \\
\text { measuremen } \\
\text { t error }\end{array}$ & -.084 & -.003 & -.110 & .112 & -.030 & .203 & $\begin{array}{l}.179 \\
\end{array}$ & .036 & $.684^{\mathrm{a}}$ & -.187 & $\begin{array}{l}.101 \\
\end{array}$ & -.016 & .040 & .165 & $\begin{array}{l}.204 \\
\end{array}$ & .025 & .045 & -.176 & $\begin{array}{l}.181 \\
\end{array}$ & -.116 & .053 & .010 & $\begin{array}{l}.049 \\
\end{array}$ & -.214 & -.061 & .119 & -.287 \\
\hline $\begin{array}{l}\text { Assessment } \\
\text { is an } \\
\text { accurate } \\
\text { indicator of a } \\
\text { school's } \\
\text { quality }\end{array}$ & -.161 & .143 & .203 & .065 & .093 & $\begin{array}{l}.047 \\
\end{array}$ & .093 & -.124 & -.187 & $.659^{\mathrm{a}}$ & .024 & -.254 & -.169 & $\begin{array}{l}.030 \\
\end{array}$ & -.109 & -.061 & .161 & .150 & -.666 & .164 & -.178 & .085 & $\begin{array}{l}.009 \\
\end{array}$ & .072 & -.136 & -.088 & .089 \\
\hline $\begin{array}{l}\text { Assessment } \\
\text { is assigning } \\
\text { a grade or } \\
\text { level to } \\
\text { student work }\end{array}$ & .143 & -.095 & .057 & -.079 & .087 & .026 & -.045 & -.017 & -.101 & .024 & $.521^{\mathrm{a}}$ & -.131 & .052 & -.159 & -.021 & .034 & -.017 & -.021 & -.083 & .043 & -203 & -.073 & .195 & .056 & -.184 & -.071 & .210 \\
\hline $\begin{array}{l}\text { Assessment } \\
\text { establishes } \\
\text { what } \\
\text { students } \\
\text { have learned }\end{array}$ & .072 & -.065 & -.312 & .009 & -.214 & .004 & -.053 & -.030 & -.016 & -.254 & -.131 & $.894^{\mathrm{a}}$ & -.042 & \begin{tabular}{|c|}
.034 \\
\end{tabular} & $\begin{array}{l}.124 \\
\end{array}$ & $\begin{array}{l}.113 \\
\end{array}$ & -.091 & .065 & .056 & $\begin{array}{l}.174 \\
\end{array}$ & -.094 & -.202 & .009 & .009 & .102 & -.116 & -.030 \\
\hline
\end{tabular}




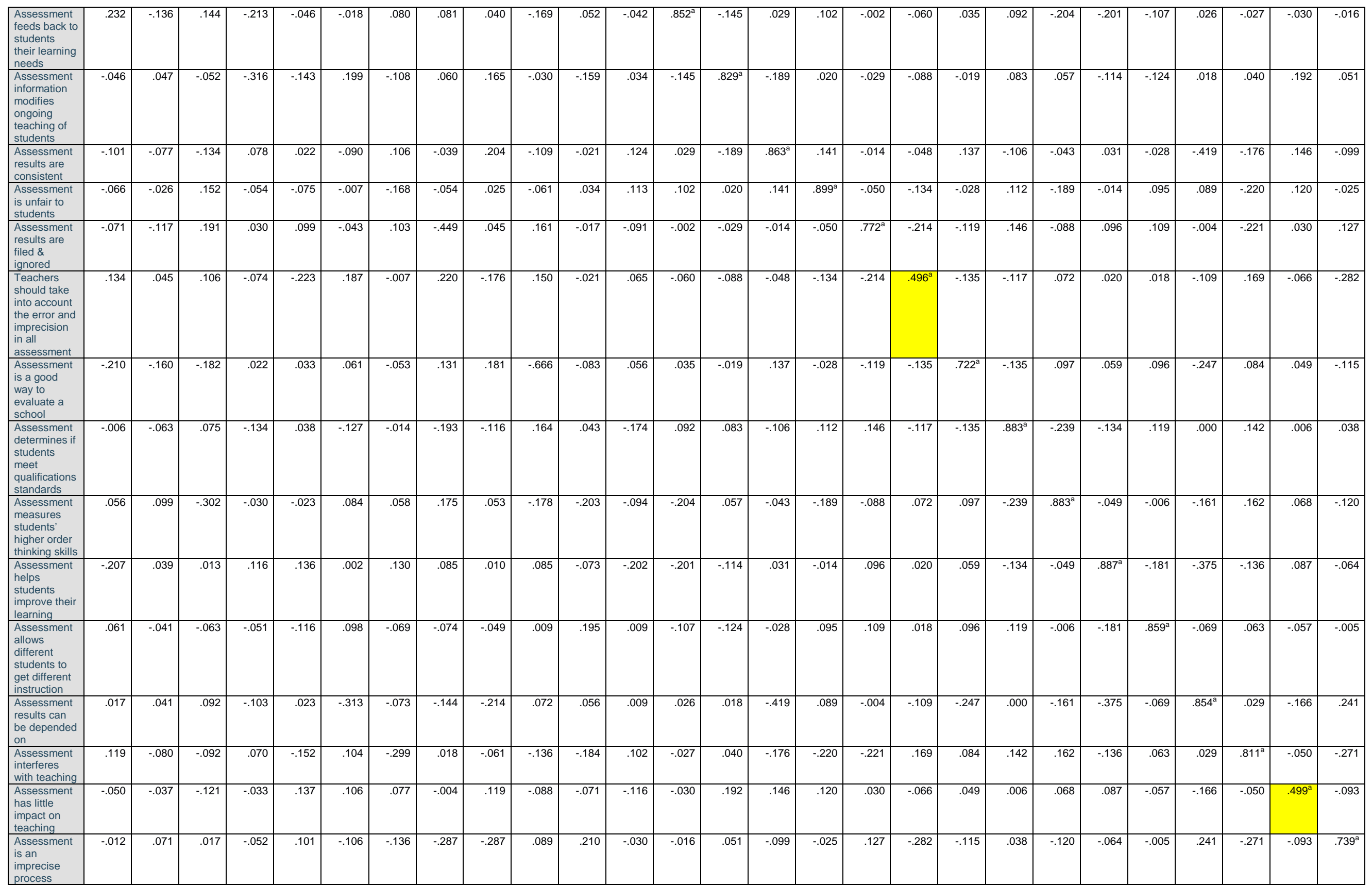


